


THE ORIGIN OF SPECIES

VOL. II 



\section{THE ORIGIN OF SPECIES}

\section{BY MEANS OF NATURAL SELECTION}

OR THE PRESERVATION OF FAVORED

RACES IN THE STRUGGLE FOR LIFE

\section{BY CHARLES DARWIN}

M. A., LL. D., F. R.S.

WITH ADDITIONS AND CORRECTIONS

FROM SIXTH AND LAST ENGLISH EDITION

IN TWO VOLUMES

VOL. II

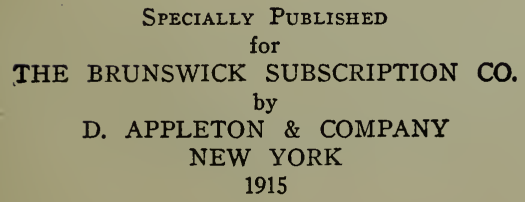


Authorized Edition. 


\section{CONTENTS OF VOL. II.}

\section{CHAPTER IX.}

\section{HYBRIDISM.}

Distinction between the sterility of first crosses and of hybridsSterility various in degree, not universal, affected by close interbreeding, removed by domestication-Laws governing the sterility of hybrids-Sterility not a special endowment, but incidental on other differences, not accumulated by natural selection-Causes of the sterility of first crosses and of hybrids -Parallelism between the effects of changed conditions of life and of crossing-Dimorphism and trimorphism-Fertility of varieties when crossed and of their mongrel offspring not universal-Hybrids and mongrels compared independently of their fertility-Summary . . . . . . . Page 1

\section{CHAPTER $X$.}

ON THE IMPERFECTION OF THE GEOLOGICAL RECORD.

On the absence of intermediate varieties at the present day-On the nature of extinct intermediate varieties; on their numberOn the lapse of time, as inferred from the rate of denudation and of deposition-On the lapse of time as estimated by years - On the poorness of our palæontological collections-On the intermittence of geological formations-On the denudation of granitic areas- $0 \mathrm{n}$ the absence of intermediate varieties in any one formation-On the sudden appearance of groups of species -On their sudden appearance in the lowest known fossiliferous strata-Antiquity of the habitable earth . . . . 48 
CHAPTER XI.

ON THE GEOLOGICAL SUCCESSION OF ORGANIC BEINGS.

On the slow and successive appearance of new species-On their different rates of change-Species once lost do not reappearGroups of species follow the same general rules in their appearance and disappearance as do single species-On extinction -On simultaneous changes in the forms of life throughout the world-On the affinities of extinct species to each other and to living species-On the state of development of ancient formsOn the succession of the same types within the same areasSummary of preceding and present chapter . Page 89

\section{CHAPTER XII.}

GEOGRAPHICAL DISTRIBUTION.

Present distribution cannot be accounted for by differences is physical conditions-Importance of barriers-Affinity of the productions of the same continent-Centres of creation-Means of dispersal by changes of climate and of the level of the land. and by occasional means-Dispersal during the Glacial period -Alternate Glacial periods in the North and South . . 129

\section{CHAPTER XIII.}

GEOGRAPHICAL DISTRIBUTION-continued.

Distribution of fresh-water productions-On the inhabitants of oceanic islands-Absence of Batrachians and of terrestrial Mammals - On the relation of the inhabitants of islands to those of the nearest mainland-On colonisation from the nearest source with subsequent modification-Summary of the last and present chapter 


\section{CHAPTER XIV.}

MUTUAL AFFINITIES OF ORGANIC BEINGS: MORPHOLOGY :

EMBRYOLOGY : RUDIMENTARY ORGANS.

Chassification, groups subordinate to groups-Natural systemRules and difficulties in classification, explained on the theory of descent with modification-Classification of varieties-Descent always used in classification-Analogical or adaptive characters-Affinities, general, complex, and radiating-Extinction separates and defines groups-MORPHоLOGY, between members of the same class, between parts of the same individualEmbryology, laws of, explained by variations not supervening at an early age, and being inherited at a corresponding age-RUDIMENTARY ORGANS: their origin explained-Summary . . . . . . . . . .Page 202

\section{CHAPTER XV.}

RECAPITULATION AND CONCLUSION.

Reeapitulation of the objections to the theory of Natural Selection -Recapitulation of the general and special circumstances in its favour-Causes of the general belief in the immutability of species-How far the theory of Natural Selection may be extended-Effects of its adoption on the study of Natural History -Concluding remarks

.267

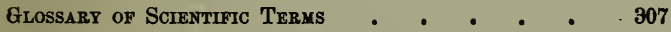

INDEX • • • • • • • • • • • • 323 



\section{ORIGIN OF SPECIES.}

\section{CHAPTER IX.}

HYBRIDISM.

Distinction between the sterility of first crosses and of hybridsSterility various in degree, not universal, affected by close interbreeding, removed by domestication-Laws governing the sterility of hybrids-Sterility not a special endowment, but incidental on other differences, not accumulated by natural selection-Causes of the sterility of first crosses and of hybrids -Parallelism between the effects of changed conditions of life and of crossing-Dimorphism and trimorphism-Fertility of varieties when crossed and of their mongrel offspring not universal-Hybrids and mongrels compared independently of their fertility-Summary.

THE view commonly entertained by naturalists is that species, when intercrossed, have been specially endowed with sterility, in order to prevent their confusion. This view certainly seems at first highly probable, for species living together could hardly have been kept distinct had they been capable of freely crossing. The subject is in many ways important for us, more especially as the sterility of species when first crossed, and that of their hybrid offspring, cannot have been acquired, as I shall show, by the preservation of successive profitable 
degrees of sterility. It is an incidental result of differences in the reproductive systems of the parentspecies.

In treating this subject, two classes of facts, to a large extent fundamentally different, have generally been confounded; namely, the sterility of species when first crossed, and the sterility of the hybrids produced from them.

Pure species have of course their organs of reproduction in a perfect condition, yet when intercrossed they produce either few or no offspring. Hybrids, on the other hand, have their reproductive organs functionally impotent, as may be clearly seen in the state of the male element in both plants and animals; though the formative organs themselves are perfect in structure, as far as the microscope reveals. In the first case the two sexual elements which go to form the embryo are perfect; in the second case they are either not at all developed, or are imperfectly developed. This distinction is important, when the cause of the sterility, which is common to the two cases, has to be considered. The distinction probably has been slurred over, owing to the sterility in both cases being looked on as a special endowment, beyond the province of our reasoning powers.

The fertility of varieties, that is of the forms known or believed to be descended from common parents, when crossed, and likewise the fertility of their mongrel offspring, is, with reference to my theory, of equal importance with the sterility of species; for it seems to make a broad and clear distinction between varieties and species.

Degrees of Sterility.-First, for the sterility of spe- 
cies when crossed and of their hybrid offspring. It is impossible to study the several memoirs and works of those two conscientious and admirable observers, Kölreuter and Gärtner, who almost devoted their lives to this subject, without being deeply impressed with the high generality of some degree of sterility. Kölreuter makes the rule universal; but then he cuts the knot, for in ten cases in which he found two forms, considered by most authors as distinct species, quite fertile together, he unhesitatingly ranks them as varieties. Gärtner, also, makes the rule equally universal; and he disputes the entire fertility of Kölreuter's ten cases. But in these and in many other cases, Gärtner is obliged carefully to count the seeds, in order to show that there is any degree of sterility. He always compares the maximum number of seeds produced by two species when first crossed, and the maximum produced by their hybrid offspring, with the average number produced by both pure parent-species in a state of nature. But causes of serious error here intervene: a plant, to be hybridised, must be castrated, and, what is often more important, must be secluded in order to prevent pollen being brought to it by insects from other plants. Nearly all the plants experimented on by Gärtner were potted, and were kept in a chamber in his house. That these processes are often injurious to the fertility of a plant cannot be doubted; for Gärtner gives in his table about a score of cases of plants which he castrated, and artificially fertilised with their own pollen, and (excluding all cases such as the Leguminosæ, in which there is an acknowledged difficulty in the manipulation) half of these twenty plants had their fertility in some degree impaired. Moreover, as Gärtner repeatedly 26 
crossed some forms, such as the common red and blue pimpernels (Anagallis arvensis and cœrulea), which the best botanists rank as varieties, and found them absolutely sterile, we may doubt whether many species are really so sterile, when intercrossed, as he believed.

It is certain, on the one hand, that the sterility of various species when crossed is so different in degree and graduates away so insensibly, and, on the other hand, that the fertility of pure species is so easily affected by various circumstances, that for all practical purposes it is most difficult to say where perfect fertility ends and sterility begins. I think no better evidence of this can be required than that the two most experienced observers who have ever lived, namely Kölreuter and Gärtner, arrived at diametrically opposite conclusions in regard to some of the very same forms. It is also most instructive to compare-but I have not space here to enter on details-the evidence advanced by our best botanists on the question whether certain doubtful forms should be ranked as species or varieties, with the evidence from fertility adduced by different hybridisers, or by the same observer from experiments made during different years. It can thus be shown that neither sterility nor fertility affords any certain distinction between species and varieties. The evidence from this source graduates away, and is doubtful in the same degree as is the evidence derived from other constitutional and structural differences.

In regard to the sterility of hybrids in successive generations; though Gärtner was enabled to rear some hybrids, carefully guarding them from a cross with either pure parent, for six or seven, and in one case for 
ten generations, yet he asserts positively that their fertility never increases, but generally decreases greatlyand suddenly. With respect to this decrease, it may first be noticed that when any deviation in structure or constitution is common to both parents, this is often transmitted in an augmented degree to the offspring; and both sexual elements in hybrid plants are already affected in some degree. But I believe that their fertility has been diminished in nearly all these cases by an independent eause, namely, by too close interbreeding. I have made so many experiments and collected so many facts, showing on the one hand that an occasional cross with a distinct individual or variety increases the vigour and fertility of the offspring, and on the other hand that very close interbreeding lessens their vigour and fertility, that I cannot doubt the correctness of this conclusion. Hybrids are seldom raised by experimentalists in great numbers; and as the parent-species, or other allied hybrids, generally grow in the same garden, the visits of insects must be carefully prevented during the flowering season: hence hybrids, if left to themselves, will generally be fertilised during each generation by pollen from the same flower; and this would probably be injurious to their fertility, already lessened by their hybrid origin. I am strengthened in this conviction by a remarkable statement repeatedly made by Gärtner, namely, that if even the less fertile hybrids be artificially fertilised with hybrid pollen of the same kind, their fertility, notwithstanding the frequent ill effects from manipulation, sometimes decidedly increases, and goes on increasing. Now, in the process of artificial fertilisation, pollen is as often taken by chance (as I know from my own experience) from the anthers of another flower, 
as from the anthers of the flower itself which is to be fertilised; so that a cross between two flowers, though probably often on the same plant, would be thus effected. Moreover, whenever complicated experiments are in progress, so careful an observer as Gärtner would have castrated his hybrids, and this would have ensured in each generation a cross with pollen from a distinct flower, either from the same plant or from another plant of the same hybrid nature. And thus, the strange fact of an increase of fertility in the successive generations of artificially fertilised hybrids, in contrast with those spontaneously self-fertilised, may, as I believe, be accounted for by too close interbreeding having been avoided.

Now let us turn to the results arrived at by a third most experienced hybridiser, namely, the Hon. and Rev. W. Herbert. He is as emphatic in his conclusion that some hybrids are perfectly fertile-as fertile as the pure parent-species-as are Kölreuter and Gärtner that some degree of sterility between distinct species is a universal law of nature. He experimented on some of the very same species as did Gärtner. The difference in their results may, I think, be in part accounted for by Herbert's great horticultural skill, and by his having hot-houses at his command. Of his many important statements I will here give only a single one as an example, namely, that " every ovule in a pod of Crinum capense fertilised by C. revolutum produced a plant, which I never saw to occur in a case of its natural fecundation." So that here we have perfect or even more than commonly perfect fertility, in a first cross between two distinct species.

This case of the Crinum leads me to refer to a 
singular fact, namely, that individual plants of certain species of Lobelia, Verbascum and Passiflora, can easily be fertilised by pollen from a distinct species, but not by pollen from the same plant, though this pollen can be proved to be perfectly sound by fertilising other plants or species. In the genus Hippeastrum, in Corydalis as shown by Professor Hildebrand, in various orchids as shown by Mr. Scott and Fritz Müller, all the individuals are in this peculiar condition. So that with some species, certain abnormal individuals, and in other species all the individuals, can actually be hybridised much more readily than they can be fertilised by pollen from the same individual plant! To give one instance, a bulb of Hippeastrum aulicum produced four flowers; three were fertilised by Herbert with their own pollen, and the fourth was subsequently fertilised by the pollen of a compound hybrid descended from three distinct species: the result was that "the ovaries of the three first flowers soon ceased to grow, and after a few days perished entirely, whereas the pod impregnated by the pollen of the hybrid made vigorous growth and rapid progress to maturity, and bore good seed, which vegetated freely." Mr. Herbert tried similar experiments during many years, and always with the same result. These cases serve to show on what slight and mysterious causes the lesser or greater fertility of a species sometimes depends.

The practical experiments of horticulturists, though not made with scientific precision, deserve some notice. It is notorious in how complicated a manner the species of Pelargonium, Fuchsia, Calceolaria, Petunia, Rhododendron, \&c., have been crossed, yet many of these hybrids seed freely. For instance, Herbert asserts that 
a hybrid from Calceolaria integrifolia and plantaginea, species most widely dissimilar in general habit, "reproduces itself as perfectly as if it had been a natural species from the mountains of Chili." I have taken some pains to ascertain the degree of fertility of some of the complex crosses of Rhododendrons, and I am assured that many of them are perfectly fertile. Mr. C. Noble, for instance, informs me that he raises stocks for grafting from a hybrid between Rhod. ponticum and catawbiense, and that this hybrid "seeds as freely as it is possible to imagine." Had hybrids when fairly treated, always gone on decreasing in fertility in each successive generation, as Gärtner believed to be the case, the fact would have been notorious to nurserymen. Horticulturists raise large beds of the same hybrid, and such alone are fairly treated, for by insect agency the several individuals are allowed to cross freely with each other, and the injurious influence of close interbreeding is thus prevented. Any one may readily convince himself of the efficiency of insect-agency by examining the flowers of the more sterile kinds of hybrid Rhododendrons, which produce no pollen, for he will find on their stigmas plenty of pollen brought from other flowers.

In regard to animals, much fewer experiments have been carefully tried than with plants. If our systematic arrangements can be trusted, that is, if the genera of animals are as distinct from each other as are the geners of plants, then we may infer that animals more widely distinct in the scale of nature can be crossed more easily than in the case of plants; but the hybrids themselves are, I think, more sterile. It should, however, be borne in mind that, owing to few animals breeding freely under 
confinement, few experiments have been fairly tried: for instance, the canary-bird has been crossed with nine distinct species of finches, but, as not one of these breeds freely in confinement, we have no right to expect that the first crosses between them and the canary, or that their hybrids, should be perfectly fertile. Again, with respect to the fertility in successive generations of the more fertile hybrid animals, I hardly know of an instance in which two families of the same hybrid have been raised at the same time from different parents, so as to avoid the ill effects of close interbreeding. On the contrary, brothers and sisters have usually been crossed in each successive generation, in opposition to the constantly repeated admonition of every breeder. And in this case, it is not at all surprising that the inherent sterility in the hybrids should have gone on increasing.

Although I know of hardly any thoroughly wellauthenticated cases of perfectly fertile hybrid animals, I have reason to believe that the hybrids from Cervulus vaginalis and Reevesii, and from Phasianus colchicus with P. torquatus, are perfectly fertile. M. Quatrefages states that the hybrids from two moths (Bombyx cynthia and arrindia) were proved in Paris to be fertile inter se for eight generations. It has lately been asserted that two such distinct species as the hare and rabbit, when they can be got to breed together, produce offspring, which are highly fertile when crossed with one of the parent-species. The hybrids from the common and Chinese geese (A. cygnoides), species which are so different that they are generally ranked in distinct genera, have often bred in this country with either pure parent, and in one single instance they have bred inter 
se. This was effected by Mr. Eyton, who raised two hybrids from the same parents, but from different hatches; and from these two birds he raised no less than eight hybrids (grandchildren of the pure geese) from one nest. In India, however, these cross-bred geese must be far more fertile; for I am assured by two eminently capable judges, namely Mr. Blyth and Capt. Hutton, that whole flocks of these crossed geese are kept in various parts of the country; and as they are kept for profit, where neither pure parent-species, exists, they must certainly be highly or perfectly fertile.

With our domesticated animals, the various races when crossed together are quite fertile; yet in many cases they are descended from two or more wild species. From this fact we must conclude either that the aboriginal parent-species at first produced perfectly fertile hybrids, or that the hybrids subsequently reared under domestication became quite fertile. This latter alternative, which was first propounded by Pallas, seems by far the most probable, and can, indeed, hardly be doubted. It is, for instance, almost certain that our dogs are descended from several wild stocks; yet, with perhaps the exception of certain indigenous domestic dogs of South America, all are quite fertile together; but analogy makes me greatly doubt, whether the several aboriginal species would at first have freely bred together and have produced quite fertile hybrids. So again I have lately acquired decisive evidence that the crossed offspring from the Indian humped and common cattle are inter se perfectly fertile; and from the observations by Rütimeyer on their important osteological differences, as well as from those by Mr. Blyth on their differences in habits, voice, constitution, \&c., these two 
forms must be regarded as good and distinct species. The same remarks may be extended to the two chief races of the pig. We must, therefore, either give up the belief of the universal sterility of species when crossed; or we must look at this sterility in animals, not as an indelible characteristic, but as one capable of being remored by domestication.

Finally, considering all the ascertained facts on the intercrossing of plants and animals, it may be concluded that some degree of sterility, both in first crosses and in hybrids, is an extremely general result; but that it cannot, under our present state of knowledge, be con sidered as absolutely universal.

Laws governing the Sterility of first Crosses and of Hybrids.

We will now consider a little more in detail the laws governing the sterility of first crosses and of hybrids. Our chief object will be to see whether or not these laws indicate that species have been specially endowed with this quality, in order to prevent their crossing and blending together in utter confusion. The following conclusions are drawn up chiefly from Gärtner's admirable work on the hybridisation of plants. I have taken much pains to ascertain how far they apply to animals, and, considering how scanty our knowledge is in regard to hybrid animals, I have been surprised to find how generally the same rules apply to both kingdoms.

It has been already remarked, that the degree of fertility, both of first crosses and of hybrids, graduates from zero to perfect fertility. It is surprising in how 
many curious ways this gradation can be shown; but only the barest outline of the facts can here be given. When pollen from a plant of one family is placed on the stigma of a plant of a distinct family, it exerts no more influence than so much inorganic dust. From this absolute zero of fertility, the pollen of different species applied to the stigma of some one species of the same genus, yields a perfect gradation in the number of seeds produced, up to nearly complete or even quite complete fertility; and, as we have seen, in certain abnormal cases, even to an excess of fertility, beyond that which the plant's own pollen produces. So in hybrids themselves, there are some which never have produced, and probably never would produce, even with the pollen of the pure parents, a single fertile seed: but in some of these cases a first trace of fertility may be detected, by the pollen of one of the pure parent-species causing the flower of the hybrid to wither earlier than it otherwise would have done; and the early withering of the flower is well known to be a sign of incipient fertilisation. From this extreme degree of sterility we have self-fertilised hybrids producing a greater and greater number of seeds up to perfect fertility.

The hybrids raised from two species which are very difficult to cross, and which rarely produce any offspring, are generally very sterile; but the parallelism between the difficulty of making a first cross, and the sterility of the hybrids thus produced-two classes of facts which are generally confounded together-is by no means strict. There are many cases, in which two pure species, as in the genus Verbascum, can be united with unusual facility, and produce numerous hybrid. 
offspring, yet these hybrids are remarkably sterile. On the other hand, there are species which can be crossed very rarely, or with extreme difficulty, but the hybrids, when at last produced, are very fertile. Even within the limits of the same genus, for instance in Dianthus, these two opposite cases occur.

The fertility, both of first crosses and of hybrids, is more easily affected by unfavourable conditions, than is that of pure species. But the fertility of first crosses is likewise innately variable; for it is not always the same in degree when the same two species are crossed under the same circumstances; it depends in part upon the constitution of the individuals which happen to have been chosen for the experiment. So it is with hybrids, for their degree of fertility is often found to differ greatly in the several individuals raised from seed out of the same capsule and exposed to the same conditions.

By the term systematic affinity is meant, the general resemblance between species in structure and constitution. Now the fertility of first crosses, and of the hybrids produced from them, is largely governed by their systematic affinity. This is clearly shown by hybrids never having been raised between species ranked by systematists in distinct families; and on the other hand, by very closely allied species generally uniting with facility. But the correspondence between systematic affinity and the facility of crossing is by no means strict. A multitude of cases could be given of very closely allied species which will not unite, or only with extreme difficulty; and on the other hand of very distinct species which unite with the utmost facility. In the same family there may be a genus, as Dianthus, in 
which very many species can most readily be crossed; and another genus, as Silene, in which the most persevering efforts have failed to produce between extremely close species a single hybrid. Even within the limits of the same genus, we meet with this same difference; for instance, the many species of Nicotiana have been more largely crossed than the species of almost any other genus; but Gärtner found that $\mathrm{N}$. acuminata, which is not a particularly distinct species, obstinately failed to fertilise, or to be fertilised by no less than eight other species of Nicotiana. Many analogous facts could be given.

No one has been able to point out what kind or what amount of difference, in any recognisable character, is sufficient to prevent two species crossing. It can be shown that plants most widely different in habit and general appearance, and having strongly marked differences in every part of the flower, even in the pollen, in the fruit, and in the cotyledons, can be crossed. Annual and perennial plants, deciduous and evergreen trees, plants inhabiting different stations and fitted for extremely different climates, can often be crossed with ease.

By a reciprocal cross between two species, I mean the case, for instance, of a female-ass being first crossed by a stallion, and then a mare by a male-ass; these two species may then be said to have been reciprocally crossed. There is often the widest possible difference in the facility of making reciprocal crosses. Such cases are highly important, for they prove that the capacity in any two species to cross is often completely independent of their systematic affinity, that is of any difference in their structure or constitution, excepting in 
their reproductive systems. The diversity of the result in reciprocal crosses between the same two species was long ago observed by Kölreuter. To give an instance: Mirabilis jalapa can easily be fertilised by the pollen of M. longiflora, and the hybrids thus produced are sufficiently fertile; but Kölreuter tried more than two hundred times, during eight following years, to fertilise reciprocally M. longiflora with the pollen of M. jalapa, and utterly failed. Several other equally striking cases could be given. Thuret has observed the same fact with certain sea-weeds or Fuci. Gärtner, moreover, found that this difference of facility in making reciprocal crosses is extremely common in a lesser degree. He has observed it even between closely related forms (as Matthiola annua and gilabra) which many botanists rank only as varieties. It is also a remarkable fact, that hybrids raised from reciprocal crosses, though of course compounded of the very same two species, the one species having first been used as the father and then as the mother, though they rarely differ in external characters, yet generally differ in fertility in a small, and occasionally in a high degree.

Several other singular rules could be given from Gärtner: for instance, some species have a remarkable power of crossing with other species; other species of the same genus have a remarkable power of impressing their likeness on their hybrid offspring; but these two powers do not at all necessarily go together. There are certain hybrids which, instead of having, as is usual, an intermediate character between their two parents, always closely resemble one of them; and such hybrids, though externally so like one of their pure parentspecies, are with are exceptinns axtremely sterile. So 
again amongst hybrids which are usually intermediate in structure between their parents, exceptional and abnormal individuals sometimes are born, which closely resemble one of their pure parents; and these hybrids are almost always utterly sterile, even when the other hybrids raised from seed from the same capsule have a considerable degree of fertility. These facts show how completely the fertility of a hybrid may be independent of its external resemblance to either pure parent.

Considering the several rules now given, which govern the fertility of first crosses and of hybrids, we see that when forms, which must be considered as good and distinct species, are united, their fertility graduates from zero to perfect fertility, or even to fertility under certain conditions in excess; that their fertility, besides being eminently susceptible to favourable and unfavourable conditions, is innately variable; that it is by no means always the same in degree in the first cross and in the hybrids produced from this cross; that the fertility of hybrids is not related to the degree in which they resemble in external appearance either parent; and lastly, that the facility of making a first cross between any two species is not always governed by their systematic affinity or degree of resemblance to each other. This latter statement is clearly proved by the difference in the result of reciprocal crosses between the same two species, for, according as the one species or the other is used as the father or the mother, there is generally some difference, and occasionally the widest possible difference, in the facility of effecting an union. The hybrids, moreover, produced from reciprocal crosses often differ in fertility.

Now do these complex and singular rules indicate 
that species have been endorved with sterility simply to prevent their becoming confounded in nature? I think not. For why should the sterility be so extremely different in degree, when various species are crossed, all of which we must suppose it would be equally important to keep from blending together? Why should the degree of sterility be innately variable in the individuals of the same species? Why should some species cross with facility, and yet produce very sterile hybrids; and other species cross with extreme difficulty, and yet produce fairly fertile hybrids? Why should there often be so great a difference in the result of a reciprocal cross between the same two species? Why, it may even be asked, has the production of hybrids been permitted? To grant to species the special power of producing hybrids, and then to stop their further propagation by different degrees of sterility, not strictly related to the facility of the first union between their parents, seems a strange arrangement.

The foregoing rules and facts, on the other hand, appear to me clearly to indicate that the sterility both of first crosses and of hybrids is simply incidental or dependent on unknown differences in their reproductive systems; the differences being of so peculiar and limited a nature, that, in reciprocal crosses between the same two species, the male sexual element of the one will often freely act on the female sexual element of the other, but not in a reversed direction. It will be advisable to explain a little more fully by an example what I mean by sterility being incidental on other differences, and not a specially endowed quality. As the capacity of one plant to be grafted or budded on another is unimportant for their welfare in a state of nature, I pre- 
sume that no one will suppose that this capacity is a specially endowed quality, but will admit that it is incidental on differences in the laws of growth of the two plants. We can sometimes see the reason why one tree will not take on another, from differences in their rate of growth, in the hardness of their wood, in the period of the flow or nature of their sap, \&c.; but in a multitudo of cases we can assign no reason whatever. Great diversity in the size of two plants, one being woody and the other herbaceous, one being evergreen and the other deciduous, and adaptation to widely different climates, do not always prevent the two grafting together. As in hybridisation, so with grafting, the capacity is limited by systematic affinity, for no one has been able to graft together trees belonging to quite distinct families; and, on the other hand, closely allied species, and varieties of the same species, can usually, but not invariably, be grafted with ease. But this capacity, as in hybridisation, is by no means absolutely governed by systematic affinity. Although many distinct genera within the same family have been grafted together, in other cases species of the same genus will not take on each other. The pear can be grafted far more readily on the quince, which is ranked as a distinct genus, than on the apple, which is a member of the same genus. Even different varieties of the pear take with different degrees of facility on the quince; so do different varieties of the apricot and peach on certain varieties of the plum.

As Gärtner found that there was sometimes an innate difference in different individuals of the same two species in crossing; so Sageret believes this to be the case with different individuals of the same two spe- 
cies in being grafted together. As in reciprocal crosses, the facility of effecting an union is often very far from equal, so it sometimes is in grafting; the common gooseberry, for instance, cannot be grafted on the currant, whereas the currant will take, though with difficulty, on the gooseberry.

We have seen that the sterility of hybrids, which have their reproductive organs in an imperfect condition, is a different case from the difficulty of uniting two pure species, which have their reproductive organs perfect; yet these two distinct classes of cases run to a large extent parallel. Something analogous occurs in grafting; for Thouin found that three species of Robinia, which seeded freely on their own roots, and which could be grafted with no great difficulty on a fourth species, when thus grafted were rendered barren. On the other hand, certain species of Sorbus, when grafted on other species yielded twice as much fruit as when on their own roots. We are reminded by this latter fact of the extraordinary cases of Hippeastrum, Passiflora, \&c., which seed much more freely when fertilised with the pollen of a distinct species, than when fertilised with pollen from the same plant.

We thus see, that, although there is a clear and great difference between the mere adhesion of grafted stocks, and the union of the male and female elements in the act of reproduction, yet that there is a rude degree of parallelism in the results of grafting and of crossing distinct species. And as we must look at the curious and complex laws governing the facility with which trees can be grafted on each other as incidental on unknown differences in their vegetative systems, so I beliere that the still more complex laws governing the facility of first 
crosses are incidental on unknown differences in their reproductive systems. These differences in both cases, follow to a certain extent, as might have been expected, systematic affinity, by which term every kind of resemblance and dissimilarity between organic beings is attempted to be expressed. The facts by no means seem to indicate that the greater or lesser difficulty of either grafting or crossing various species has been a special endowment; although in the case of crossing, the difficulty is as important for the endurance and stability of specific forms, as in the case of grafting it is unimportant for their welfare.

\section{Origin and Causes of the Sterility of first Crosses and of Hybrids.}

At one time it appeared to me probable, as it has to others, that the sterility of first crosses and of hybrids might have been slowly acquired through the natural selection of slightly lessened degrees of fertility, which, like any other variation, spontaneously appeared in certain individuals of one variety when crossed with those of another variety. For it would clearly be advantageous to two varieties or incipient species, if they could be kept from blending, on the same principle that, when man is selecting at the same time two varieties, it is necessary that he should keep them separate. In the first place, it may be remarked that species inhabiting distinct regions are often sterile when crossed; now it could clearly have been of no advantage to such separated species to have been rendered mutually sterile, and consequently this could not have been effected through natural selection; but it may perhaps be argued, 
that, if a species was rendered sterile with some one compatriot, sterility with other species would follow as a necessary contingency. In the second place, it is almost as much opposed to the theory of natural selection as to that of special creation, that in reciprocal crosses the male element of one form should have been rendered utterly impotent on a second form, whilst at the same time the male element of this second form is enabled freely to fertilise the first form; for this peculiar state of the reproductive system could hardly have been advantageous to either species.

In considering the probability of natural selection having come into action, in rendering species mutually sterile, the greatest difficulty will be found to lie in the existence of many graduated steps from slightly lessened fertility to absolute sterility. It may be admitted that it would profit an incipient species, if it were rendered in some slight degree sterile when crossed with its parent form or with some other variety; for thus fewer bastardised and deteriorated offspring would be produced to commingle their blood with the new species in process of formation. But he who will take the trouble to reflect on the steps by which this first degree of sterility could be increased through natural selection to that high degree which is common with so many species, and which is universal with species which have been differentiated to a generic or family rank, will find the subject extraordinarily complex. After mature reflection it seems to me that this could not have been effected through natural selection. Take the case of any two species which, when crossed, produced few and sterile offspring; now, what is there which could favour the survival of those individuals which happened to 
be endowed in a slightly higher degree with mutual infertility, and which thus approacbed by one small step towards absolute sterility? Yet an advance of this kind, if the theory of natural selection be brought to bear, must have incessantly occurred with many species, for a multitude are mutually quite barren. With sterile neuter insects we have reason to believe that modifications in their structure and fertility have been slowly accumulated by natural selection, from an advantage having been thus indirectly given to the community to which they belonged over other communities of the same species; but an individual animal not belonging to a 80cial community, if rendered slightly sterile when crossed with some other variety, would not thus itself gain any advantage or indirectly give any advantage to the other individuals of the same variety, thus leading to their preservation.

But it would be superfluous to discuss this question in detail; for with plants we have conclusive evidence that the sterility of crossed species must be due to some principle, quite independent of natural selection. Both Gärtner and Kölreuter have proved that in genera including numerous species, a series can be formed from species which when crossed yield fewer and fewer seeds, to species which never produce a single seed, but yet are affected by the pollen of certain other species, for the germen swells. It is here manifestly impossible to select the more sterile individuals, which have already ceased to yield seeds; so that this acme of sterility, when the germen alone is affected, cannot have been gained through selection; and from the laws governing the various grades of sterility being so uniform throughout the animal and regetable kingdoms, we may infer 
that the cause, whatever it may be, is the same or nearly the same in all cases.

We will now look a little closer at the probable nature of the differences between species which induce sterility in first crosses and in hybrids. In the case of first crosses, the greater or less difficulty in effecting an union and in obtaining offspring apparently depends on several distinct causes. There must sometimes be a physical impossibility in the male element reaching the ovule, as would be the case with a plant having a pistil too long for the pollen-tubes to reach the ovarium. It has also been observed that when the pollen of one species is placed on the stigma of a distantly allied species, though the pollen-tubes protrude, they do not penetrate the stigmatic surface. Again, the male element may reach the female element but be incapable of causing an embryo to be developed, as seems to have been the case with some of Thuret's experiments on Fuci. No explanation can be given of these facts, any more than why certain trees cannot be grafted on others. Lastly, an embryo may be developed, and then perish at an early period. This latter alternative has not been sufficiently attended to; but I believe, from observations communicated to me by Mr. Hewitt, who has had great experience in hybridising pheasants and fowls, that the early death of the embryo is a very frequent cause of sterility in first crosses. Mr. Salter has recently given the results of an examination of about 500 eggs produced from various crosses between three species of Gallus and their hybrids; the majority of these eggs had been fertilised; and in the majority of the fertilised eggs, the embryos had either been partially developed and had then per- 
ished, or had become nearly mature, but the young chickens had been unable to break through the shell. Of the chickens which were born, more than four-fifths died within the first few days, or at latest weeks, "without any obvious cause, apparently from mere inability to live;" so that from the 500 eggs only twelve chickens were reared. With plants, hybridised embryos probably often perish in a like manner; at least it is known that hybrids raised from very distinct species are sometimes weak and dwarfed, and perish at an early age; of which fact Max Wichura has recently given some striking cases with hybrid willows. It may be here worth noticing that in some cases of parthenogenesis, the embryos within the eggs of silk moths which had not been fertilised, pass through their early stages of development and then perish like the embryos produced by a cross between distinct species. Until becoming acquainted with these facts, I was unwilling to believe in the frequent early death of hybrid embryos; for hybrids, when once born, are generally healthy and longlived, as we see in the case of the common mule. Hybrids, however, are differently circumstanced before and after birth: when born and living in a country where their two parents live, they are generally placed under suitable conditions of life. But a hybrid partakes of only half of the nature and constitution of its mother; it may therefore before birth, as long as it is nourished within its mother's womb, or within the egg or seed produced by the mother, be exposed to conditions in some degree unsuitable, and consequently be liable to perish at an early period; more especially as all very young beings are eminently sensitive to injurious or unnatural conditions of life. But after all, the cause 
more probably lies in some imperfection in the original act of impregnation, causing the embryo to be imperfectly developed, rather than in the conditions to which it is subsequently exposed.

In regard to the sterility of hybrids, in which the sexual elements are imperfectly developed, the case is somewhat different. I have more than once alluded to a large body of facts showing that, when animals and plants are removed from their natural conditions, they are extremely liable to have their reproductive systems seriously affected. This, in fact, is the great bar to the domestication of animals. Between the sterility thus superinduced and that of hybrids, there are many points of similarity. In both cases the sterility is independent of general health, and is often accompanied by excess of size or great luxuriance. In both cases the sterility occurs in various degrees; in both, the male element is the most liable to be affected; but sometimes the female more than the male. In both, the tendency goes to a certain extent with systematic affinity, for whole groups of animals and plants are rendered impotent by the same unnatural conditions; and whole groups of species tend to produce sterile hybrids. On the other hand, one species in a group will sometimes resist great changes of conditions with unimpaired fertility; and certain species in a group will produce unusually fertile hybrids. No one can tell, till he tries, whether any particular animal will breed under confinement, or any exotic plant seed freely under culture; nor can he tell till he tries, whether any two species of a genus will produce more or less sterile hybrids. Lastly, when organic beings are placed during several generations under conditions not natural to them, 
they are extremely liable to vary, which seems to be partly due to their reproductive systems having been specially affected, though in a lesser degree than when sterility ensues. So it is with hybrids, for their offspring in successive generations are eminently liable to vary, as every experimentalist has observed.

Thus we see that when organic beings are placed under new and unnatural conditions, and when hybrids are produced by the unnatural crossing of two species, the reproductive system, independently of the general state of health, is affected in a very similar manner. In the one case, the conditions of life have been disturbed, though often in so slight a degree as to be inappreciable by us; in the other case, or that of hybrids, the external conditions have remained the same, but the organisation has been disturbed by two distinct structures and constitutions, including of course the reproductive systems, having been blended into one. For it is scarcely possible that two organisations should be compounded into one, without some disturbance occurring in the development, or periodical action, or mutual relations of the different parts and organs one to another or to the conditions of life. When hybrids are able to breed inter se, they transmit to their offspring from generation to generation the same compounded organisation, and hence we need not be surprised that their sterility, though in some degree variable, does not diminish; it is even apt to increase, this being generally the result, as before explained, of too close interbreeding. The above view of the sterility of hybrids being caused by two constitutions being compounded into one has been strongly maintained by Max Wichura. 
It must, however, be owned that we cannot understand, on the above or any other view, several facts with respect to the sterility of hybrids; for instance, the unequal fertility of hybrids produced from reciprocal crosses; or the increased sterility in those hybrids which occasionally and exceptionally resemble closely either pure parent. Nor do I pretend that the foregoing remarks go to the root of the matter; no explanation is offered why an organism, when placed under unnatural conditions, is rendered sterile. All that I have attempted to show is, that in two cases, in some respects allied, sterility is the common result,-in the one case from the conditions of life having been disturbed, in the other case from the organisation having been disturbed by two organisations being compounded into one.

A similar parallelism holds good with an allied yet very different class of facts. It is an old and almost universal belief founded on a considerable body of evidence, which I have elsewhere given, that slight changes in the conditions of life are beneficial to all living things. We see this acted on by farmers and gardeners in their frequent exchanges of seed, tubers, \&c., from one soil or climate to another, and back again. During the convalescence of animals, great benefit is derived from almost any change in their habits of life. Again, both with plants and animals, there is the clearest evidence that a cross between individuals of the same species, which differ to a certain extent, gives vigour and fertility to the offspring; and that close interbreeding continued during several generations between the nearest relations, if these be kept under the same conditions of life, almost always leads to decreased size, weakness, or sterility. 
Hence it seems that, on the one hand, slight changes in the conditions of life benefit all organic beings, and on the other hand, that slight crosses, that is crosses between the males and females of the same species, which have been subjected to slightly different conditions, or which have slightly varied, give vigour and fertility to the offspring. But, as we have seen, organic beings long habituated to certain uniform conditions under a state of nature, when subjected, as under confinement, to a considerable change in their conditions, very frequently are rendered more or less sterile; and we know that a cross between two forms, that have become widely or specifically different, produce hybrids which are almost always in some degree sterile. I am fully persuaded that this double parallelism is by no means an accident or an illusion. He who is able to explain why the elephant and a multitude of other animals are incapable of breeding when kept under only partial confinement in their native country, will be able to explain the primary cause of hybrids being so generally sterile. He will at the same time be able to explain how it is that the races of some of our domesticated animals, which have often been subjected to new and not uniform conditions, are quite fertile together, although they are descended from distinct species, which would probably have been sterile if aboriginally crossed. The above two parallel series of facts seem to be connected together by some common but unknown bond, which is essentially related to the principle of life; this principle, according to Mr. Herbert Spencer, being that life depends on, or consists in, the incessant action and reaction of various forces, which, as throughout nature, are always tending towards an equilibrium; and when 
this tendency is slightly disturbed by any change, the vital forces gain in power.

\section{Reciprocal Dimorphism and Trimorphism.}

This subject may be here briefly discussed, and will be found to throw some light on hybridism. Several plants belonging to distinct orders present two forms, which exist in about equal numbers and which differ in no respect except in their reproductive organs; one form having a long pistil with short stamens, the other a short pistil with long stamens; the two having differently sized pollen-grains. With trimorphic plants there are three forms likewise differing in the lengths of their pistils and stamens, in the size and colour of the pollen-grains, and in some other respects; and as in each of the three forms there are two sets of stamens, the three forms possess altogether six sets of stamens and three kinds of pistils. These organs are so proportioned in length to each other, that half the stamens in two of the forms stand on a level with the stigma of the third form. Now I have shown, and the result has been confirmed by other observers, that, in order to obtain full fertility with these plants, it is necessary that the stigma of the one form should be fertilised by pollen taken from the stamens of corresponding height in another form. So that with dimorphic species two unions, which may be called legitimate, are fully fertile; and two, which may be called illegitimate, are more or less infertile. With trimorphic species six unions are legitimate, or fully fertile,-and twelve are illegitimate, or more or less infertile. 
The infertility which may be observed in various dimorphic and trimorphic plants, when they are illegitimately fertilised, that is by pollen taken from stamens not corresponding in height with the pistil, differs much in degree, up to absolute and utter sterility; just in the same manner as occurs in crossing distinct species. As the degree of sterility in the latter case depends in an eminent degree on the conditions of life being more or less favourable, so I have found it with illegitimate unions. It is well known that if pollen of a distinct species be placed on the stigma of a flower, and its own pollen be afterwards, even after a considerable interval of time, placed on the same stigma, its action is so strongly prepotent that it generally annihilates the effect of the foreign pollen; so it is with the pollen of the several forms of the same species, for legitimate pollen is strongly prepotent over illegitimate pollen, when both are placed on the same stigma. I ascertained this by fertilising several flowers, first illegitimately, and twenty-four hours afterwards legitimately with the pollen taken from a peculiarly coloured variety, and all the seedlings were similarly coloured; this shows that the legitimate pollen, though applied twenty-four hours subsequently, had wholly destroyed or prevented the action of the previously applied illegitimate pollen. Again, as in making reciprocal crosses between the same two species, there is occasionally a great difference in the result, so the same thing occurs with trimorphic plants; for instance, the midstyled form of Lythrum salicaria was illegitimately fertilised with the greatest ease by pollen from the longer stamens of the short-styled form, and yielded many seeds; but the latter form did not yield a single seed 
when fertilised by the longer stamens of the mid-styled form.

In all these respects, and in others which might be added, the forms of the same undoubted species when illegitimately united behave in exactly the same manner as do two distinct species when crossed. This led me carefully to observe during four years many seedlings, raised from several illegitimate unions. The chief result is that these illegitimate plants, as they may be called, are not fully fertile. It is possible to raise from dimorphic species, both long-styled and short-styled illegitimate plants, and from trimorphic plants all three. illegitimate forms. These can then be properly united in a legitimate manner. When this is done, there is no apparent reason why they should not yield as many seeds as did their parents when legitimately fertilised. But such is not the case. They are all infertile, in various degrees; some being so utterly and incurably sterile that they did not yield during four seasons a single seed or even seed-capsule. The sterility of these illegitimate plants, when united with each other in 8 legitimate manner, may be strictly compared with that of hybrids when crossed inter se. If, on the other hand, a hybrid is crossed with either pure parent-species, the sterility is usually much lessened: and so it is when an illegitimate plant is fertilised by a legitimate plant. In the same manner as the sterility of hybrids does not always run parallel with the difficulty of making the first cross between the two parent-species, so the sterility of certain illegitimate plants was unusually great, whilst the sterility of the union from which they were derived was by no means great. With hybrids raised from the same seed-capsule the degree of sterility is innately 
variable, so it is in a marked manner with illegitimate plants. Lastly, many hybrids are profuse and persistent flowerers, whilst other and more sterile hybrids produce few flowers, and are weak, miserable dwarfs; exactly similar cases occur with the illegitimate offspring of various dimorphic and trimorphic plants.

Altogether there is the closest identity in character and behaviour between illegitimate plants and hybrids. It is hardly an exaggeration to maintain that illegitimate plants are hybrids, produced within the limits of the same species by the improper union of certain forms, whilst ordinary hybrids are produced from an improper union between so-called distinct species. We have also already seen that there is the closest similarity in all respects between first illegitimate unions and first crosses between distinct species. This will perhaps be made more fully apparent by an illustration; we may suppose that a botanist found two well-marked varieties (and such occur) of the long-styled form of the trimorphic Lythrum salicaria, and that he determined to try by crossing whether they were specifically distinct. He would find that they yielded only about one-fifth of the proper number of seeds, and that they behaved in all the other above specified respects as if they had been two distinct species. But to make the case sure, he would raise plants from his supposed hybridised seed, and he would find that the seedlings were miserably dwarfed and utterly sterile, and that they behaved in all other respects like ordinary hybrids. He might then maintain that he had actually proved, in accordance with the common view, that his two varieties were as good and as distinct species as any in the world; but he would be completely mistaken. 
The facts now given on dimorphic and trimorphic plants are important, because they show us, first, that the physiological test of lessened fertility, both in first crosses and in hybrids, is no safe criterion of specific distinction; secondly, because we may conclude that there is some unknown bond which connects the infertility of illegitimate unions with that of their illegitimate offspring, and we are led to extend the same view to first crosses and hybrids; thirdly, because we find, and this seems to me of especial importance, that two or three forms of the same species may exist and may differ in no respect whatever, either in structure or in constitution, relatively to external conditions, and yet be sterile when united in certain ways. For we must remember that it is the union of the sexual elements of individuals of the same form, for instance, of two longstyled forms, which results in sterility; whilst it is the union of the sexual elements proper to two distinct forms which is fertile. Hence the case appears at first sight exactly the reverse of what occurs, in the ordinary unions of the individuals of the same species and with crosses between distinct species. It is, however, doubtful whether this is really so; but I will not enlarge on this obscure subject.

We may, however, infer as probable from the consideration of dimorphic and trimorphic plants, that the sterility of distinct species when crossed and of their hybrid progeny, depends exclusively on the nature of their sexual elements, and not on any difference in their structure or general constitution. We are also led to this same conclusion by considering reciprocal crosses, in which the male of one species cannot be united, or can be united with great difficulty, with the female of 
a second species, whilst the converse cross can be effected with perfect facility. That excellent observer, Gärtner, likewise concluded that species when crossed are sterile owing to differences confined to their reproductive systems.

\section{Fertility of Varieties when Crossed, and of their Mongrel Offspring, not universal.}

It may be urged, as an overwhelming argument, that there must be some essential distinction between species and varieties, inasmuch as the latter, however much they may differ from each other in external appearance, cross with perfect facility, and yield perfectly fertile offspring. With some exceptions, presently to be given, I fully admit that this is the rule. But the subject is surrounded by difficulties, for, looking to varieties produced under nature, if two forms hitherto reputed to be varieties be found in any degree sterile together, they are at once ranked by most naturalists as species. For instance, the blue and red pimpernel, which are considered by most botanists as varieties, are said by Gärtner to be quite sterile when crossed, and he subsequently ranks them as undoubted species. If we thus argue in a circle, the fertility of all varieties produced under nature will assuredly have to be granted.

If we turn to varieties, produced, or supposed to have been produced, under domestication, we are still involved in some doubt. For when it is stated, for instance, that certain South American indigenous domestic dogs do not readily unite with European dogs, the explanation which will occur to every one, and probably 
the true one, is that they are descended from aboriginally distinct species. Nevertheless the perfect fertility of so many domestic races, differing widely from each other in appearance, for instance those of the pigeon, or of the cabbage, is a remarkable fact; more especially when we reflect how many species there are, which, though resembling each other most closely, are utterly sterile when intercrossed. Several considerations, however, render the fertility of domestic varieties less remarkable. In the first place, it may be observed that the amount of external difference between two species is no sure guide to their degree of mutual sterility, so that similar differences in the case of varieties would be no sure guide. It is certain that with species the cause lies exclusively in differences in their sexual constitution. Now the varying conditions to which domesticated animals and cultivated plants have been subjected, have had so little tendency towards modifying the reproductive system in a manner leading to mutual sterility, that we have good grounds for admitting the directly opposite doctrine of Pallas, namely, that such conditions generally eliminate this tendency; so that the domesticated descendants of species, which in their natural state probably would have been in some degree sterile when crossed, become perfectly fertile together. With plants, so far is cultivation from giving a tendency towards sterility between distinct species, that in several well-authenticated cases already alluded to, certain plants have been affected in an opposite manner, for they have become self-impotent whilst still retaining the capacity of fertilising, and being fertilised by, other species. If the Pallasian doctrine of the elimination of sterility through long-con- 
tinued domestication be admitted, and it can hardly be rejected, it becomes in the highest degree improbable that similar conditions long-continued should likewise induce this tendency; though in certain cases, with species having a peculiar constitution, sterility might occasionally be thus caused. Thus, as I believe, we can understand why with domesticated animals varieties have not been produced which are mutually sterile; and why with plants only a few such cases, immediately to be given, have been observed.

The real difficulty in our present subject is not, as it appears to me, why domestic varieties have not become mutually infertile when crossed, but why this has so generally occurred with natural varieties, as soon as they have been permanently modified in a sufficient degree to take rank as species. We are far from precisely knowing the cause; nor is this surprising, seeing how profoundly ignorant we are in regard to the normal and abnormal action of the reproductive system. But we can see that species, owing to their struggle for existence with numerous competitors, will have been exposed during long periods of time to more uniform conditions, than have domestic varieties; and this may well make a wide difference in the result. For we know how commonly wild animals and plants, when taken from their natural conditions and subjected to captivity, are rendered sterile; and the reproductive functions of organic beings which have always lived under natural conditions would probably in like manner be eminently sensitive to the influence of an unnatural cross. Domesticated productions, on the other hand, which, as shown by the mere fact of their domestication, were not originally highly sensitive to changes 
in their conditions of life, and which can now generally resist with undiminished fertility repeated changes of conditions, might be expected to produce varieties, which would be little liable to have their reproductive powers injuriously affected by the act of crossing with other varieties which had originated in a like manner.

I have as yet spoken as if the varieties of the same species were invariably fertile when intercrossed. But it is impossible to resist the evidence of the existence of a certain amount of sterility in the few following cases, which I will briefly abstract. The evidence is at least as good as that from which we believe in the sterility of a multitude of species. The evidence is, also, derived from hostile witnesses, who in all other cases consider fertility and sterility as safe criterions of specific distinction. Gärtner kept during several years a dwarf kind of maize with yellow seeds, and a tall variety with red seeds growing near each other in his garden; and although these plants have separated sexes, they never naturally crossed. He then fertilised thirteen flowers of the one kind with pollen of the other; but only a single head produced any seed, and this one head produced only five grains. Manipulation in this case could not have been injurious, as the plants have separated sexes. No one, I believe, has suspected that these varieties of maize are distinct species; and it is important to notice that the hybrid plants thus raised were themselves perfectly fertile; so that even Gärtner did not venture to consider the two varieties as specifically distinct.

Girou de Buzareingues crossed three varieties of gourd, which like the maize has separated sexes, and he asserts that their mutual fertilisation is by so much the 
less easy as their differences are greater. How far these experiments may be trusted, I know not; but the forms experimented on are ranked by Sageret, who mainly founds his classification by the test of infertility, as varieties, and Naudin has come to the same conclusion.

The following case is far more remarkable, and seems at first incredible; but it is the result of an astonishing number of experiments made during many years on nine species of Verbascum, by so good an observer and so hostile a witness as Gärtner: namely that the yellow and white varieties when crossed produce less seed than the similarly coloured varieties of the same species. Moreover, he asserts that, when yellow and white varieties of one species are crossed with yellow and white varieties of a distinct species, more seed is produced by the crosses between the similarly coloured flowers, than between those which are differently coloured. Mr. Scott also has experimented on the species and varieties of Verbascum; and although unable to confirm Gärtner's results on the crossing of the distinct species, he finds that the dissimilarly coloured varieties of the same species yield fewer seeds, in the proportion of 86 to 100 , than the similarly coloured varieties. Yet these varieties differ in no respect except in the colour of their flowers; and one variety can sometimes be raised from the seed of another.

Kölreuter, whose accuracy has been confirmed by every subsequent observer, has proved the remarkable fact, that one particular variety of the common tobacco was more fertile than the other varieties, when crossed with a widely distinct species. He experimented on five forms which are commonly reputed to be varieties, and which he tested by the severest trial, namely, by 
reciprocal crosses, and he found their mongrel offspring perfectly fertile. But one of these five varieties, when used either as the father or mother, and crossed with the Nicotiana glutinosa, always yielded hybrids not so sterile as those which were produced from the four other varieties when crossed with $\mathrm{N}$. glutinosa. Hence the reproductive system of this one variety must have been in some manner and in some degree modified.

From these facts it can no longer be maintained that varieties when crossed are invariably quite fertile. From the great difficulty of ascertaining the infertility of varieties in a state of nature, for a supposed variety, if proved to be infertile in any degree, would almost universally be ranked as a species;-from man attending only to external characters in his domestic varieties, and from such varieties not having been exposed for very long periods to uniform conditions of life;-from these several considerations we may conclude that fertility does not constitute a fundamental distinction between varieties and species when crossed. The general sterility of crossed species may safely be looked at, not as a special acquirement or endowment, but as incidental on changes of an unknown nature in their sexual elements.

Hybrids and Mongrels compared, independently of their fertility.

Independently of the question of fertility, the offspring of species and of varieties when crossed may be compared in several other respects. Gärtner, whose strong wish it was to draw a distinct line between species and varieties, could find very few, and, as it seems 
to me, quite unimportant differences between the socalled hybrid offspring of species, and the so-called mongrel offspring of varieties. And, on the other hand, they agree most closely in many important respects.

I shall here discuss this subject with extreme brevity. The most important distinction is, that in the first generation mongrels are more variable than hybrids; but Gärtner admits that hybrids from species which have long been cultivated are often variable in the first generation; and I have myself seen striking instances of this fact. Gärtner further admits that hybrids between very closely allied species are more variable than those from very distinct species; and this shows that the difference in the degree of variability graduates away. When mongrels and the more fertile hybrids are propagated for several generations, an extreme amount of variability in the offspring in both cases is notorious; but some few instances of both hybrids and mongrels long retaining a uniform character could be given. The variability, however, in the successive generations of mongrels is, perhaps, greater than in hybrids.

This greater variability in mongrels than in hybrids does not seem at all surprising. For the parents of mongrels are varieties, and mostly domestic varieties (very few experiments having been tried on natural varieties), and this implies that there has been recent variability, which would often continue and would augment that arising from the act of crossing. The slight variability of hybrids in the first generation, in contrast with that in the succeeding generations, is a curious fact and deserves attention. For it bears on the view which I have taken of one of the causes of 
ordinary variability; namely, that the reproductive system from being eminently sensitive to changed conditions of life, fails under these circumstances to perform its proper function of producing offspring closely similar in all respects to the parent-form. Now hybrids in the first generation are descended from species (excluding those long-cultivated) which have not had their reproductive systems in any way affected, and they are not variable; but hybrids themselves have their reproductive systems seriously affected, and their descendants are highly variable.

But to return to our comparison of mongrels and hybrids: Gärtner states that mongrels are more liable than hybrids to revert to either parent-form; but this, if it be true, is certainly only a difference in degree. Moreover, Gärtner expressly states that hybrids from long cultivated plants are more subject to reversion than hybrids from species in their natural state; and this probably explains the singular difference in the results arrived at by different observers: thus Max Wichura doubts whether hybrids ever revert to their parent-forms, and he experimented on uncultivated species of willows; whilst Naudin, on the other hand, insists in the strongest terms on the almost universal tendency to reversion in hybrids, and he experimented chiefly on cultivated plants. Gärtner further states that when any two species, although most closely allied to each other, are crossed with a third species, the hybrids are widely different from each other; whereas if two very distinct varieties of one species are crossed with another species, the hybrids do not differ much. But this conclusion, as far as I can make out, is founded on a single experiment; and seems directly 
opposed to the results of several experiments made by Kölreuter.

Such alone are the unimportant differences which Gärtner is able to point out between hybrid and mongrel plants. On the other hand, the degrees and kinds of resemblance in mongrels and in hybrids to their respective parents, more especially in hybrids produced from nearly related species, follow according to Gärtner the same laws. When two species are crossed, one has sometimes a prepotent power of impressing its likeness on the hybrid. So I believe it to be with varieties of plants; and with animals one variety certainly often has this prepotent power over another variety. Hybrid plants produced from a reciprocal cross, generally resemble each other closely; and so it is with mongrel plants from a reciprocal cross. Both hybrids and mongrels can be reduced to either pure parentform, by repeated crosses in successive generations with either parent.

These several remarks are apparently applicable to animals; but the subject is here much complicated, partly owing to the existence of secondary sexual characters; but more especially owing to prepotency in transmitting likeness running more strongly in one sex than in the other, both when one species is crossed with another, and when one variety is crossed with another variety. For instance, I think those authors are right who maintain that the ass has a prepotent power over the horse, so that both the mule and the hinny resemble more closely the ass than the horse; but that the prepotency runs more strongly in the male than in the female ass, so that the mule, which is the offspring of the male ass and mare, is more like an ass, than is 
the hinny, which is the offspring of the female ass and stallion.

Much stress has been laid by some authors on the supposed fact, that it is only with mongrels that the offspring are not intermediate in character, but closely resemble one of their parents; but this does sometimes occur with hybrids, yet I grant much less frequently than with mongrels. Looking to the cases which I have collected of cross-bred animals closely resembling one parent, the resemblances seem chiefly confined to characters almost monstrous in their nature, and which have suddenly appeared-such as albinism, melanism, deficiency of tail or horns, or additional fingers and toes; and do not relate to characters which have been slowly acquired through selection. A tendency to sudden reversions to the perfect character of either parent would, also, be much more likely to occur with mongrels, which are descended from varieties often suddenly produced and semi-monstrous in character, than with hybrids, which are descended from species slowly and naturally produced. On the whole, I entirely agree with Dr. Prosper Lucas, who, after arranging an enormous body of facts with respect to animals, comes to the conclusion that the laws of resemblance of the child to its parents are the same, whether the two parents differ little or much from each other, namely, in the union of individuals of the same variety, or of different varieties, or of distinct species.

Independently of the question of fertility and sterility, in all other respects there seems to be a general and close similarity in the offspring of crossed species, and of crossed varieties. If we look at species as having been specially created, and at varieties as having been 
produced by secondary laws, this similarity would be an astonishing fact. But it harmonises perfectly with the view that there is no essential distinction between species and varieties.

\section{Summary of Chapter.}

First crosses between forms, sufficiently distinct to be ranked as species, and their hybrids, are very gen. erally, but not universally, sterile. The sterility is of all degrees, and is often so slight that the most careful experimentalists have arrived at diametrically opposite conclusions in ranking forms by this test. The sterility is innately variable in individuals of the same species, and is eminently susceptible to the action of favourable and unfavourable conditions. The degree of sterility does not strictly follow systematic affinity, but is governed by several curious and complex laws. It is generally different, and sometimes widely different in reciprocal crosses between the same two species. It is not always equal in degree in a first cross and in the hybrids produced from this cross.

In the same manner as in grafting trees, the capacity in one species or variety to take on another, is incidental on differences, generally of an unknown nature, in their vegetative systems, so in crossing, the greater or less facility of one species to unite with another is in. eidental on unknown differences in their reproductive systems. There is no more reason to think that species have been specially endowed with various degrees of sterility to prevent their crossing and blending in na. ture, than to think that trees have been specially endowed with various and somewhat analogous degrees of 
difficulty in being grafted together in order to prevent their inarching in our forests.

The sterility of first crosses and of their hybrid progeny has not been acquired through natural selection. In the case of first crosses it seems to depend on several circumstances; in some instances in chief part on the early death of the embryo. In the case of hybrids, it apparently depends on their whole organisation having been disturbed by being compounded from two distinct forms; the sterility being closely allied to that which so frequently affects pure species, when exposed to new and unnatural conditions of life. He who will explain these latter cases will be able to explain the sterility of hybrids. This view is strongly supported by a parallelism of another kind: namely, that, firstly, slight changes in the conditions of life add to the vigour and fertility of all organic beings; and secondly, that the crossing of forms, which have been exposed to slightly different conditions of life or which have varied, favours the size, vigour, and fertility of their offspring. The facts given on the sterility of the illegitimate unions of dimorphic and trimorphic plants and of their illegitimate progeny, perhaps render it probable that some unknown bond in all cases connects the degree of fertility of first unions with that of their offspring. The consideration of these facts on dimorphism, as well as of the results of reciprocal crosses, clearly leads to the conclusion that the primary cause of the sterility of crossed species is confined to differences in their sexual elements. But why, in the case of distinct species, the sexual elements should so generally have become more or less modified, leading to their mutual infertility, we do not know; but it 
seems to stand in some close relation to species having been exposed for long periods of time to nearly uniform conditions of life.

It is not surprising that the difficulty in crossing any two species, and the sterility of their hybrid offspring, should in most cases correspond, even if due to distinct causes: for both depend on the amount of difference between the species which are crossed. Nor is it surprising that the facility of effecting a first cross, and the fertility of the hybrids thus produced, and the capacity of being grafted together-though this latter capacity evidently depends on widely different circumstances-should all run, to a certain extent, parallel with the systematic affinity of the forms subjected to experiment; for systematic affinity includes resemblances of all kinds.

First crosses between forms known to be varieties, or sufficiently alike to be considered as varieties, and their mongrel offspring, are very generally, but not, as is so often stated, invariably fertile. Nor is this almost universal and perfect fertility surprising, when it is remembered how liable we are to argue in a circle with respect to varieties in a state of nature; and when we remember that the greater number of varieties have been produced under domestication by the selection of mere external differences, and that they have not been long exposed to uniform conditions of life. It should also be especially kept in mind, that long-continued domestication tends to eliminate sterility, and is therefore little likely to induce this same quality. Independently of the question of fertility, in all other respects there is the closest general resemblance between hybrids and mongrels,-in their variability, in their 
power of absorbing each other by repeated crosses, and in their inheritance of characters from both parentforms. Finally, then, although we are as ignorant of the precise cause of the sterility of first crosses and of hybrids as we are why animals and plants removed from their natural conditions become sterile, yet the facts given in this chapter do not seem to me opposed to the belief that species aboriginally existed as varieties. 


\section{CHAPTER X.}

ON THE IMPERFECTION OF THE GEOLOGICAL RECORD.

On the absence of intermediate varieties at the present day-On the nature of extinct intermediate varieties; on their numberOn the lapse of time, as inferred from the rate of denudation and of deposition-On the lapse of time as estimated by years -On the poorness of our palæontological collections-On the intermittence of geological formations-On the denudation of granitic areas-On the absence of intermediate varieties in any one formation-On the sudden appearance of groups of species -On their sudden appearance in the lowest known fossiliferous strata-Antiquity of the habitable earth.

IN the sixth chapter I enumerated the chief objections which might be justly urged against the views maintained in this volume. Most of them have now been discussed. One, namely the distinctness of specific forms, and their not being blended together by innumerable transitional links, is a very obvious difficulty. I assigned reasons why such links do not commonly occur at the present day under the circumstances apparently most favourable for their presence, namely, on an extensive and continuous area with graduated physical conditions. I endeavoured to show, that the life of each species depends in a more important manner on the presence of other already defined organic forms, than on climate, and, therefore, that the really governing conditions of life do not graduate away quite insensibly like heat or moisture. I endeavoured, also, to 
show that intermediate varieties, from existing in lesser numbers than the forms which they connect, will generally be beaten out and exterminated during the course of further modification and improvement. The main cause, however, of innumerable intermediate links not now occurring everywhere throughout nature, depends on the very process of natural selection, through which new varieties continually take the places of and supplant their parent-forms. But just in proportion as this process of extermination has acted on an enormous scale, so must the number of intermediate varieties, which have formerly existed, be truly enormous. Why then is not every geological formation and every stratum full of such intermediate links? Geology assuredly does not reveal any such finely-graduated organic chain; and this, perhaps, is the most obvious and serious objection which can be urged against the theory. The explanation lies, as I believe, in the extreme imperfection of the geological record.

In the first place, it should always be borne in mind what sort of intermediate forms must, on the theory, have formerly existed. I have found it difficult, when looking at any two species, to avoid picturing to myself forms directly intermediate between them. But this is a wholly false view; we should always look for forms intermediate between each species and a common but unknown progenitor; and the progenitor will generally have differed in some respects from all its modified descendants. To give a simple illustration: the fantail and pouter pigeons are both descended from the rock-pigeon; if we possessed all the intermediate varieties which have ever existed, we should have an extremely close series between both and the rock- 
pigeon; but we should have no varieties directly intermediate between the fantail and pouter; none, for instance, combining a tail somewhat expanded with a crop somewhat enlarged, the characteristic features of these two breeds. These two breeds, moreover, have become so much modified, that, if we had no historical or indirect evidence regarding their origin, it would not have been possible to have determined, from a mere comparison of their structure with that of the rockpigeon, C. livia, whether they had descended from this species or from some other allied form, such as C. œnas.

So, with natural species, if we look to forms very distinct, for instance to the horse and tapir, we have no reason to suppose that links directly intermediate between them ever existed, but between each and an unknown common parent. The common parent will have had in its whole organisation much general resemblance to the tapir and to the horse; but in some points of structure may have differed considerably from both, even perhaps more than they differ from each other. Hence, in all such cases, we should be unable to recognise the parent-form of any two or more species, even if we closely compared the structure of the parent with that of its modified descendants, unless at the same time we had a nearly perfect chain of the intermediate links.

It is just possible by the theory, that one of two living forms might have descended from the other; for instance, a horse from a tapir; and in this case direct intermediate links will have existed between them. But such a case would imply that one form had remained for a very long period unaltered, whilst its descendants had undergone a rast amount of change; 
and the principle of competition between organism and organism, between child and parent, will render this a very rare event; for in all cases the new and improved forms of life tend to supplant the old and unimproved forms.

By the theory of natural selection all living species have been connected with the parent-species of each genus, by differences not greater than we see between the natural and domestic varieties of the same species at the present day; and these parent-species, now generally extinct, have in their turn been similarly connected with more ancient forms; and so on backwards, always converging to the common ancestor of each great class. So that the number of intermediate and transitional links, between all living and extinct species, must have been inconceivably great. But assuredly, if this theory be true, such have lived upon the earth.

On the Lapse of Time, as inferred from the rate of Deposition and extent of Denudation.

Independently of our not finding fossil remains of such infinitely numerous connecting links, it may be objected that time cannot have sufficed for so great an amount of organic change, all changes having been effected slowly. It is hardly possible for me to recall to the reader who is not a practical geologist, the facts leading the mind feebly to comprehend the lapse of time. He who can read Sir Charles Lyell's grand work on the Principles of Geology, which the future historian will recognise as having produced a revolution in natural science, and yet does not admit how vast have 
been the past periods of time, may at once cluse this volume. Not that it suffices to study the Principles of Geology, or to read special treatises by different observers on separate formations, and to mark how each author attempts to give an inadequate idea of the duration of each formation, or even of each stratum. We can best gain some idea of past time by knowing the agencies at work, and learning how deeply the surface of the land has been denuded, and how much sediment has been deposited. As Lyell has well remarked, the extent and thickness of our sedimentary formations are the result and the measure of the denudation which the earth's crust has elsewhere undergone. Therefore a man should examine for himself the great piles of superimposed strata, and watch the rivulets bringing down mud, and the waves wearing away the sea-cliffs, in order to comprehend something about the duration of past time, the monuments of which we see all around us.

It is good to wander along the coast, when formed of moderately hard rocks, and mark the process of degradation. The tides in most cases reach the cliffs only for a short time twice a day, and the waves eat into them only when they are charged with sand or pebbles; for there is good evidence that pure water effects nothing in wearing away rock. At last the base of the cliff is undermined, huge fragments fall down, and these, remaining fixed, have to be worn away atom by atom, until after being reduced in size they can be rolled about by the waves, and then they are more quickly ground into pebbles, sand, or mud. But how often do we see along the bases of retreating cliffs rounded boulders, all thickly clothed by marine productions, 
showing how little they are abraded and how seldom they are rolled about! Moreover, if we follow for a few miles any line of rocky cliff, which is undergoing degradation, we find that it is only here and there, along a short length or round a promontory, that the cliffs are at the present time suffering. The appearance of the surface and the regetation show that elsewhere years have elapsed since the waters washed their base.

We have, however, recently learnt from the observations of Ramsay, in the van of many excellent observers-of Jukes, Geikie, Croll, and others, that subaerial degradation is a much more important agency than coast-action, or the power of the waves. The whole surface of the land is exposed to the chemical action of the air and of the rain-water with its dissolved carbonic acid, and in colder countries to frost; the disintegrated matter is carried down even gentle slopes during heavy rain, and to a greater extent than might be supposed, especially in arid districts, by the wind; it is then transported by the streams and rivers, which when rapid deepen their channels, and triturate the fragments. On a rainy day, even in a gently undulating country, we see the effects of subaerial degradation in the muddy rills which flow down every slope. Messrs. Ramsay and Whitaker have shown, and the observation is a most striking one, that the great lines of escarpment in the Wealden district and those ranging across England, which formerly were looked at as ancient seacoasts, cannot have been thus formed, for each line is composed of one and the same formation, whilst our sea-cliffs are everywhere formed by the intersection of various formations. This being the case, we are compelled to admit that the escarpments owe their 
origin in chief part to the rocks of which they are composed having resisted subaerial denudation better than the surrounding surface; this surface consequently has been gradually lowered, with the lines of harder rock left projecting. Nothing impresses the mind with the vast duration of time, according to our ideas of time, more forcibly than the conviction thus gained that subaerial agencies which apparently have so little power, and which seem to work so slowly, have produced great results.

When thus impressed with the slow rate at which the land is worn away through subaerial and littoral action, it is good, in order to appreciate the past duration of time, to consider, on the one hand, the masses of rock which have been removed over many extensive areas, and on the other hand the thickness of our sedimentary formations. I remember having been much struck when viewing volcanic islands, which have been worn by the waves and pared all round into perpendicular cliffs of one or two thousand feet in height; for the gentle slope of the lava-streams, due to their formerly liquid state, showed at a glance how far the hard, rocky beds had once extended into the open ocean. The same story is told still more plainly by faults,those great cracks along which the strata have been upheaved on one side, or thrown down on the other, to the height or depth of thousands of feet; for since the crust cracked, and it makes no great difference whether the upheaval was sudden, or, as most geologists now beliere, was slow and effected by many starts, the surface of the land has been so completely planed down that no trace of these vast dislocations is externally visible. The Craven fault, for instance, extends for 
upwards of 30 miles, and along this line the vertical displacement of the strata raries from 600 to 3000 feet. Professor Ramsay has published an account of a downthrow in Anglesea of 2300 feet; and he informs me that he fully believes that there is one in Merionethshire of 12,000 feet; yet in these cases there is nothing on the surface of the land to show such prodigious movements; the pile of rocks on either side of the crack having been smoothly swept away.

On the other hand, in all parts of the world the piles of sedimentary strata are of wonderful thickness. In the Cordillera I estimated one mass of conglomerate at ten thousand feet; and although conglomerates have probably been accumulated at a quicker rate than finer sediments, yet from being formed of worn and rounded pebbles, each of which bears the stamp of time, they are good to show how slowly the mass must have been heaped together. Professor Ramsay has given me the maximum thickness, from actual measurement in most cases, of the successive formations in different parts of Great Britain; and this is the result:-

$$
\text { Palozic }
$$

Palæozoic strata (not including igneous beds)...... 57,154

Secondary strata ........................... 13,190

Tertiary strata.......................... 2,240

-making altogether 72,584 feet; that is, very nearly thirteen and three-quarters British miles. Some of the formations, which are represented in England by thin beds, are thousands of feet in thickness on the Continent. Moreover, between each successive formation, we have, in the opinion of most geologists, blank periods of enormous length. So that the lofty pile of sedimentary rocks in Britain gives but an inadequato 
idea of the time which has elapsed during their accumulation. The consideration of these various facts impresses the mind almost in the same manner as does the vain endeavour to grapple with the idea of eternity.

Nevertheless this impression is partly false. Mr. Croll, in an interesting paper, remarks that we do not err " in forming too great a conception of the length of "geological periods," but in estimating them by years. When geologists look at large and complicated phenomena, and then at the figures representing several million years, the two produce a totally different effect on the mind, and the figures are at once pronounced too small. In regard to subaerial denudation, Mr. Croll shows, by calculating the known amount of sediment annually brought down by certain rivers, relatively to their areas of drainage, that 1000 feet of solid rock, as it became gradually disintegrated, would thus be removed from the mean level of the whole area in the course of six million years. This seems an astonishing result, and some considerations lead to the suspicion that it may be too large, but even if halved or quartered it is still very surprising. Few of us, however, know what a million really means: Mr. Croll gires the following illustration: take a narrow strip of paper, 83 feet 4 inches in length, and stretch it along the wall of a large hall; then mark off at one end the tenth of an inch. This tenth of an inch will represent one hundred years, and the entire strip a million years. But let it be borne in mind, in relation to the subject of this work, wnat a hundred years implies, represented as it is by a measure utterly insignificant in a hall of the above dimensions. Several eminent breeders, during a single lifetime, have so largely modified some of the higher 
animals which propagate their kind much more slowly than most of the lower animals, that they have formed what well deserves to be called a new sub-breed. Few men have attended with due care to any one strain for more than half a century, so that a hundred years represents the work of two breeders in succession. It is not to be supposed that species in a state of nature ever change so quickly as domestic animals under the guidance of methodical selection. The comparison would be in every way fairer with the effects which follow from unconscious selection, that is the preservation of the most useful or beautiful animals, with no intention of modifying the breed; but by this process of unconscious selection, various breeds have been sensibly changed in the course of two or three centuries.

Species, however, probably change much more slowly, and within the same country only a few change at the same time. This slowness follows from all the inhabitants of the same country being already so well adapted to each other, that new places in the polity of nature do not occur until after long intervals, due to the occurrence of physical changes of some kind, or through the immigration of new forms. Moreover variations or individual differences of the right nature, by which some of the inhabitants might be better fitted to their new places under the altered circumstances, would not always occur at once. Unfortunately we have no means of determining, according to the standard of years, how long a period it takes to modify a species; but to the subject of time we must return. 


\section{On the Poorness of Palcoontological Collections.}

Now let us turn to our richest geological museums, and what a paltry display we behold! That our collections are imperfect is admitted by every one. The remark of that admirable palæontologist, Edward Forbes, should never be forgotten, namely, that very many fossil species are known and named from single and often broken specimens, or from a few specimens collected on some one spot. Only a small portion of the surface of the earth has been geologically explored, and no part with sufficient care, as the important dis. coveries made every year in Europe prove. No organ ism wholly soft can be preserved. Shells and bones de. cay and disappear when left on the bottom of the sea, where sediment is not accumulating. We probably take a quite erroneous view, when we assume that sediment is being deposited over nearly the whole bed of the sea, at a rate sufficiently quick to embed and preserve fossil remains. Throughout an enormously large proportion of the ocean, the bright blue tint of the water bespeaks its purity. The many cases on record of a formation conformably covered, after an immense interval of time, by another and later formation, without the underlying bed having suffered in the interval any wear and tear, seem explicable only on the view of the bottom of the sea not rarely lying for ages in an unaltered condition. The remains which do become embedded, if in sand or gravel, will, when the beds are upraised, generally be dissolved by the percolation of rain-water charged with carbonic acid. Some of the many kinds of animals which live on the beach between high and low water mark seem to be rarely preserved. For instance, the 
several species of the Chthamalinæ (a sub-family of sessile cirripedes) coat the rocks all over the world in infinite numbers: they are all strictly littoral, with the exception of a single Mediterranean species, which inhabits deep water, and this has been found fossil in Sicily, whereas not one other species has hitherto been found in any tertiary formation: yet it is known that the genus Chthamalus existed during the Chalk period. Lastly, many great deposits requiring a vast length of time for their accumulation, are entirely destitute of organic remains, without our being able to assign any reason: one of the most striking instances is that of the Flysch formation, which consists of shale and sandstone, several thousand, occasionally even six thousand feet in thickness, and extending for at least 300 miles from Vienna to Switzerland; and although this great mass has been most carefully searched, no fossils, except a few vegetable remains, have been found.

With respect to the terrestrial productions which lived during the Secondary and Palæozoic periods, it is superfluous to state that our evidence is fragmentary in an extreme degree. For instance, until recently not a land-shell was known belonging to either of these vast periods, with the exception of one species discovered by Sir C. Lyell and Dr. Dawson in the carboniferous strata of North America; but now land-shells have been found in the lias. In regard to mammiferous remains, a glance at the historical table published in Lyell's Manual will bring home the truth, how accidental and rare is their preservation, far better than pages of detail. Nor is their rarity surprising, when we remember how large a proportion of the bones of tertiary mammals have been discovered either in caves or in lacustrine 
deposits; and that not a cave or true lacustrine bed is known belonging to the age of our secondary or palæozoic formations.

But the imperfection in the geological record largely results from another and more important cause than any of the foregoing; namely, from the several formations being separated from each other by wide intervals of time. This doctrine has been emphatically admitted by many geologists and palæontologists, who, like E. Forbes, entirely disbelieve in the change of species. When we see the formations tabulated in written works, or when we follow them in nature, it is difficult to aroid believing that they are closely consecutive. But we know, for instance, from Sir R. Murchison's great work on Russia, what wide gaps there are in that country between the superimposed formations; so it is in North America, and in many other parts of the world. The most skilful geologist, if his attention had been confined exclusively to these large territories, would never have suspected that, during the periods which were blank and barren in his own country, great piles of sediment, charged with new and peculiar forms of life, had elsewhere been accumulated. And if, in each separate territory, hardly any idea can be formed of the length of time which has elapsed between the consecutive formations, we may infer that this could nowhere be ascertained. The frequent and great changes in the mineralogical composition of consecutive formations, generally implying great changes in the geography of the surrounding lands, whence the sediment was derived, accord with the belief of vast intervals of time having elapsed between each formation.

We can, I think, see why the geological formations 
of each region are almost invariably intermittent; that is, have not followed each other in close sequence. Scarcely any fact struck me more when examining many hundred miles of the South American coasts, which have been upraised several hundred feet within the recent period, than the absence of any recent deposits sufficiently extensive to last for even a short geological period. Along the whole west coast, which is inhabited by a peculiar marine fauna, tertiary beds are so poorly developed, that no record of several successive and peculiar marine faunas will probably be preserved to a distant age. A little reflection will explain why, along the rising coast of the western side of South America, no extensive formations with recent or tertiary remains can anywhere be found, though the supply of sediment must for ages have been great, from the enormous degradation of the coast-rocks and from muddy streams entering the sea. The explanation, no doubt, is, that the littoral and sub-littoral deposits are continually worn away, as soon as they are brought up by the slow and gradual rising of the land within the grinding action of the coast-waves.

We may, I think, conclude that sediment must be accumulated in extremely thick, solid, or extensive masses, in order to withstand the incessant action of the waves, when first upraised and during successive oscillations of level as well as the subsequent subaerial degradation. Such thick and extensive accumulations of sediment may be formed in two ways; either in profound depths of the sea, in which case the bottom will not be inhabited by so many and such varied forms of life, as the more shallow seas; and the mass when upraised will give an imperfect record of the organisms 
which existed in the neighbourhood during the period of its accumulation. Or, sediment may be deposited to any thickness and extent over a shallow bottom, if it continue slowly to subside. In this latter case, as long as the rate of subsidence and the supply of sediment nearly balance each other, the sea will remain shallow and favourable for many and varied forms, and thus a rich fossiliferous formation, thick enough, when upraised, to resist a large amount of denudation, may be formed.

I am convinced that nearly all our ancient formations, which are throughout the greater part of their thickness rich in fossils, have thus been formed during subsidence. Since publishing my views on this subject in 1845 , I have watched the progress of Geology, and have been surprised to note how author after author, in treating of this or that great formation, has come to the conclusion that it was accumulated during subsidence. I may add, that the only ancient tertiary formation on the west coast of South America, which has been bulky enough to resist such degradation as it has as yet suffered, but which will hardly last to a distant geological age, was deposited during a downward oscillation of level, and thus gained considerable thickness.

All geological facts tell us plainly that each area has undergone numerous slow oscillations of level, and apparently these oscillations have affected wide spaces. Consequently, formations rich in fossils and sufficiently thick and extensive to resist subsequent degradation, will have been formed over wide spaces during periods of subsidence, but only where the supply of sediment was sufficient to keep the sea shallow and to embed 
and preserve the remains before they had time to decay. On the other hand, as long as the bed of the sea remains stationary, thick deposits cannot have been accumulated in the shallow parts, which are the most favourable to life. Still less can this have happened during the alternate periods of elevation; or, to speak. more accurately, the beds which were then accumulated will generally have been destroyed by being upraised and brought within the limits of the coastaction.

These remarks apply chiefly to littoral and sub-littoral deposits. In the case of an extensive and shallow sea, such as that within a large part of the Malay Archipelago, where the depth varies from 30 or 40 to 60 fathoms, a widely extended formation might be formed during a period of elevation, and yet not suffer excessively from denudation during its slow upheaval; but the thickness of the formation could not be great, for owing to the elevatory movement it would be less than the depth in which it was formed; nor would the deposit be much consolidated, nor be capped by overlying formations, so that it would run a good chance of being worn away by atmospheric degradation and by the action of the sea during subsequent oscillations of level. It has, however, been suggested by Mr. Hopkins, that if one part of the area, after rising and before being denuded, subsided, the deposit formed during the rising movement, though not thick, might afterwards become protected by fresh accumulations, and thus be preserved for a long period.

Mr. Hopkins also expresses his belief that sedimentary beds of considerable horizontal extent have rarely been completely destroyed. But all geologists, except- 
ing the few who believe that our present metamorphic schists and plutonic rocks once formed the primordial nucleus of the globe, will admit that these latter rocks have been stript of their covering to an enormous extent. For it is scarcely possible that such rocks could have been solidified and crystallized whilst uncovered; but if the metamorphic action occurred at profound depths of the ocean, the former protecting mantle of rock may not have been very thick. Admitting then that gneiss, mica-schist, granite, diorite, \&c., were once necessarily covered up, how can we account for the naked and extensive areas of such rocks in many parts of the world, except on the belief that they have subsequently been completely denuded of all overlying strata? That such extensive areas do exist cannot be doubted: the granitic region of Parime is described by Humboldt as being at least nineteen times as large as Switzerland. South of the Amazon, Boué colours an area composed of rocks of this nature as equal to that of Spain, France, Italy, part of Germany, and the British Islands, all conjoined. This region has not been carefully explored, but from the concurrent testimony of travellers, the granitic area is very large: thus, Von Eschwege gives a detailed section of these rocks, stretching from Rio de Janeiro for 260 geographical miles inland in a straight line; and I travelled for 150 miles in another direction, and saw nothing but granitic rocks. Numerous specimens, collected along the whole coast from near Rio Janeiro to the mouth of the Plata, a distance of 1100 geographical miles, were examined by me, and they all belonged to this class. Inland, along the whole northern bank of the Plata I saw, besides modern tertiary beds, only one small patch 
of slightly metamorphosed rock, which alone could have formed a part of the original capping of the granitic series. Turning to a well-known region, namely, to the United States and Canada, as shown in Professor H. D. Rogers's beautiful map, I have estimated the areas by cutting out and weighing the paper, and I find that the metamorphic (excluding "the semi-meta"morphic") and granitic rocks exceed, in the proportion of 19 to 12.5, the whole of the newer Palæozoic formations. In many regions the metamorphic and granitic rocks would be found much more widely extended than they appear to be, if all the sedimentary beds were removed which rest unconformably on them, and which could not have formed part of the original mantle under which they were crystallized. Hence it is probable that in some parts of the world whole formations have been completely denuded, with not a wreck left behind.

One remark is here worth a passing notice. During periods of elevation the area of the land and of the adjoining shoal parts of the sea will be increased, and new stationswill often be formed:-all circumstances favourable, as previously explained, for the formation of new varieties and species; but during such periods there will generally be a blank in the geological record. On the other hand, during subsidence, the inhabited area and number of inhabitants will decrease (excepting on the shores of a continent when first broken up into an archipelago), and consequently during subsidence, though there will be much extinction, few new varieties or species will be formed; and it is during these very periods of subsidence, that the deposits which are richest in fossils have been accumulated. 
On the Absence of Numerous Intermediate Varieties in any Single Formation.

From these several considerations, it cannot be doubted that the geological record, viewed as a whole, is extremely imperfect; but if we confine our attention to any one formation, it becomes much more difficult to understand why we do not therein find closely graduated varieties between the allied species which lived at its conmencement and at its close. Several cases are on record of the same species presenting varieties in the upper and lower parts of the same formation; thus, Trautschold gives a number of instances with Ammonites; and Hilgendorf has described a most curious case of ten graduated forms of Planorbis multiformis in the successive beds of a fresh-water formation in Switzerland. Although each formation has indisputably required a vast number of years for its deposition, several reasons can be given why each should not commonly include a graduated series of links between the species which lived at its commencement and close; but I cannot assign due proportional weight to the following considerations.

Although each formation may mark a very long lapse of years, each probably is short compared with the period requisite to change one species into another. I am aware that two palæontologists, whose opinions are worthy of much deference, namely Bronn and Woodward, have concluded that the average duration of each formation is twice or thrice as long as the average duration of specific forms. But insuperable difficulties, as it seems to me, prevent us from coming to any just conclusion on this head. When we see a species first 
appearing in the middle of any formation, it would be rash in the extreme to infer that it had not elsewhere previously existed. So again when we find a species disappearing before the last layers have been deposited, it would be equally rash to suppose that it then became extinct. We forget how small the area of Europe is compared with the rest of the world; nor have the several stages of the same formation throughout Europe been correlated with perfect accuracy.

We may safely infer that with marine animals of all kinds there has been a large amount of migration due to climatal and other changes; and when we see a species first appearing in any formation, the probability is that it only then first immigrated into that area. It is well-known, for instance, that several species appear somewhat earlier in the palæozoic beds of North America than in those of Europe; time having apparently been required for their migration from the American to the European seas. In examining the latest deposits in various quarters of the world, it has everywhere been noted, that some few still existing species are common in the deposit, but have become extinct in the immediately surrounding sea; or, conversely, that some are now abundant in the neighbouring sea, but are rare or absent in this particular deposit. It is an excellent lesson to reflect on the ascertained amount of migration of the inhabitants of Europe during the glacial epoch, which forms only a part of one whole geological period; and likewise to reflect on the changes of level, on the extreme change of climate, and on the great lapse of time, all included within this same glacial period. Yet it may be doubted whether, in any quarter of the world, sedimentary deposits, in30 


\section{ABSENCE OF INTERMEDIATE VARIETIES ¡CHAP. $\mathrm{X}$.}

including fossil remains, have gone on accumulating within the same area during the whole of this period. It is not, for instance, probable that sediment was deposited during the whole of the glacial period near the mouth of the Mississippi, within that limit of depth at which marine animals can best flourish: for we know that great geographical changes occurred in other parts of America during this space of time. When such beds as were deposited in shallow water near the mouth of the Mississippi during some part of the glacial period shall have been upraised, organic remains will probably first appear and disappear at different levels, owing to the migrations of species and to geographical changes. And in the distant future, a geologist, examining these beds, would be tempted to conclude that the average duration of life of the embedded fossils had been less than that of the glacial period, instead of having been really far greater, that is, extending from before the glacial epoch to the present day.

In order to get a perfect gradation between two forms in the upper and lower parts of the same formation, the deposit must have gone on continuously accumulating during a long period, sufficient for the slow process of modification; hence the deposit must be a very thick one; and the species undergoing change must have lived in the same district throughout the whole time. But we have seen that a thick formation, fossiliferous throughout its entire thickness, can accumulate only during a period of subsidence; and to keep the depth approximately the same, which is necessary that the same marine species may live on the same space, the supply of sediment must nearly counterbalance the amount of subsidence. But this same move- 
ment of subsidence will tend to submerge the area whence the sediment is derived, and thus diminish the supply, whilst the downward movement continues. In fact, this nearly exact balancing between the supply of sediment and the amount of subsidence is probably a rare contingency; for it has been observed by more than one palæontologist, that very thick deposits are usually barren of organic remains, except near their upper or lower limits.

It would seem that each separate formation, like the whole pile of formations in any country, has generally been intermittent in its accumulation. When we see, as is so often the case, a formation composed of beds of widely different mineralogical composition, we may reasonably suspect that the process of deposition has been more or less interrupted. Nor will the closest inspection of a formation give us any idea of the length of time which its deposition may have consumed. Many instances could be given of beds only a few feet in thickness, representing formations, which are elsewhere thousands of feet in thickness, and which must have required an enormous period for their accumulation; yet no one ignorant of this fact would have even suspected the vast lapse of time represented by the thinner formation. Many cases could be given of the lower beds of a formation having been upraised, denuded, submerged, and then re-covered by the upper beds of the same formation,-facts, showing what wide, yet easily overlooked, intervals have occurred in its accumulation. In other cases we have the plainest evidence in great fossilised trees, still standing upright as they grew, of many long intervals of time and changes of level during the process of deposition, which would 


\section{ABSENCE OF INTERMEDIATE VARIETIES [ChAp. X.}

not have been suspected, had not the trees been preserved: thus Sir C. Lyell and Dr. Dawson found carboniferous beds 1400 feet thick in Nova Scotia, with ancient root-bearing strata, one above the other at no less than sixty-eight different levels. Hence, when the same species occurs at the bottom, middle, and top of a formation, the probability is that it has not lived on the same spot during the whole period of deposition, but. has disappeared and reappeared, perhaps many times, during the same geological period. Consequently if it were to undergo a considerable amount of modification during the deposition of any one geological formation, a section would not include all the fine intermediate gradations which must on our theory have existed, but abrupt, though perhaps slight, changes of form.

It is all-important to remember that naturalists have no golden rule by which to distinguish species and varieties; they grant some little variability to each species, but when they meet with a somewhat greater amount of difference between any two forms, they rank both as species, unless they are enabled to connect them together by the closest intermediate gradations; and this, from the reasons just assigned, we can seldom hope to effect in any one geological section. Supposing $\mathrm{B}$ and $\mathrm{C}$ to be two species, and a third, $\mathrm{A}$, to be found in an older and underlying bed; even if A were strictly intermediate between $\mathrm{B}$ and $\mathrm{C}$, it would simply be ranked as a third and distinct species, unless at the same time it could be closely connected by intermediate varieties with either one or both forms. Nor should it be forgotten, as before explained, that $\mathrm{A}$ might be the actual progenitor of $B$ and $C$, and yet would not necessarily be strictly intermediate between 
them in all respects. So that we might obtain the parent-species and its several modified descendants from the lower and upper beds of the same formation, and unless we obtained numerous transitional gradations, we should not recognise their blooc-relationship, and should consequently rank them as distinct species.

It is notorious on what excessively slight differences many palæontologists have founded their species; and they do this the more readily if the specimens come from different sub-stages of the same formation. Some experienced conchologists are now sinking many of the very fine species of D'Orbigny and others into the rank of varieties; and on this view we do find the kind of evidence of change which on the theory we ought to find. Look again at the later tertiary deposits, which include many shells believed by the majority of naturalists to be identical with existing species; but some excellent naturalists, as Agassiz and Pictet, maintain that all these tertiary species are specifically distinct, though the distinction is admitted to be very slight; so that here, unless we believe that these eminent naturalists have been misled by their imaginations, and that these late tertiary species really present no difference whatever from their living representatives, or unless we admit, in opposition to the judgment of most naturalists, that these tertiary species are all truly distinct from the recent, we have evidence of the frequent occurrence of slight modifications of the kind required. If we look to rather wider intervals of time, namely, to distinct but consecutive stages of the same great formation, we find that the embedded fossils, though universally ranked as specifically different, yet are far more closely related to each other than are the species 


\section{ABSENCE OF INTERMEDIATE VARIÉ'ILI' [CaAp. >}

found in more widely separated formations; so that here again we have undoubted evidence of change in the direction required by the theory; but to this latter subject I shall return in the following chapter.

With animals and plants that propagate rapidly and do not wander much, there is reason to suspect, as we have formerly seen, that their varieties are generally at first local; and that such local varieties do not spread widely and supplant their parent-forms until they have been modified and perfected in some considerable degree. According to this view, the chance of discovering in a formation in any one country all the early stages of transition between any two forms, is small, for the successive changes are supposed to have been local or confined to some one spot. Most marine animals have a wide range; and we have seen that with plants it is those which have the widest range, that oftenest present varieties; so that, with shells and other marine animals, it is probable that those which had the widest range, far exceeding the limits of the known geological formations in Europe, have oftenest given rise, first to local varieties and ultimately to new species; and this again would greatly lessen the chance of our being able to trace the stages of transition in any one geological formation.

It is a more important consideration, leading to the same result, as lately insisted on by Dr. Falconer, namely, that the period during which each species underwent modification, though long as measured by years, was probably short in comparison with that during which it remained without undergoing any change.

It should not be forgotten, that at the present day, with perfect specimens for examination, two forms can 
seldom be connected by intermediate varieties, and thus proved to be the same species, until many specimens are collected from many places; and with fossil species this can rarely be done. We shall, perhaps, best perceive the improbability of our being enabled to connect species by numerous, fine, intermediate, fossil links, by asking ourselves whether, for instance, geologists at some future period will be able to prove that our different breeds of cattle, sheep, horses, and dogs are descended from a single stock or from several aboriginal stocks; or, again, whether certain sea-shells inhabiting the shores of North America, which are ranked by some conchologists as distinct species from their European representatives, and by other conchologists as only varieties, are really varieties, or are, as it is called, specifically distinct. This could be effected by the future geologist only by his discovering in a fossil state numerous intermediate gradations; and such success is improbable in the highest degree.

It has been asserted over and over again, by writers who believe in the immutability of species, that geology yields no linking forms. This assertion, as we shall see in the next chapter, is certainly erroneous. As Sir J. Lubbock has remarked, "Every species is a link " between other allied forms." If we take a genus having a score of species, recent and extinct, and destroy four-fifths of them, no one doubts that the remainder will stand much more distinct from each other. If the extreme forms in the genus happen to have been thus destroyed, the genus itself will stand more distinct from other allied genera. What geological research has not revealed, is the former existence of infinitely 


\section{ABSENCE OF INTERMEDIATE VARIETIES [Chap. X.}

numerous gradations, as fine as existing varieties, connecting together nearly all existing and extinct species. But this ought not to be expected; yet this has been repeatedly advanced as a most serious objection against my views.

It may be worth while to sum up the foregoing remarks on the causes of the imperfection of the geological record under an imaginary illustration. The Malay Archipelago is about the size of Europe from the North Cape to the Mediterranean, and from Britain to Russia; and therefore equals all the geological formations which have been examined with any accuracy, excepting those of the United States of America. I fully agree with Mr. Godwin-Austen, that the present condition of the Malay Archipelago, with its numerous large islands separated by wide and shallow seas, probably represents the former state of Europe, whilst most of our formations were accumulating. The Malay Archipelago is one of the richest regions in organic beings; yet if all the species were to be collected which have ever lived there, how imperfectly would they represent the natural history of the world!

But we have every reason to believe that the terrestrial productions of the archipelago would be preserved in an extremely imperfect manner in the formations which we suppose to be there accumulating. Not many of the strictly littoral animals, or of those which lived on naked submarine rocks, would be embedded; and those embedded in gravel or sand would not endure to a distant epoch. Wherever sediment did not accumulate on the bed of the sea, or where it did not accumulate at a sufficient rate to protect organic bodies from decay, no remains could be preserved. 
Formations rich in fossils of many kinds, and of thickness sufficient to last to an age as distant in futurity as the secondary formations lie in the past, would generally be formed in the archipelago only during periods of subsidence. These periods of subsidence would be separated from each other by immense intervals of time, during which the area would be either stationary or rising; whilst rising, the fossiliferous formations on the steeper shores would be destroyed, almost as soon as accumulated, by the incessant coastaction, as we now see on the shores of South America. Even throughout the extensive and shallow seas within the archipelago, sedimentary beds could hardly be accumulated of great thickness during the periods of elevation, or become capped and protected by subsequent deposits, so as to have a good chance of enduring to a very distant future. During the periods of subsidence, there would probably be much extinction of life; during the periods of elevation, there would be much variation, but the geological record would then be less perfect.

It may be doubted whether the duration of any one great period of subsidence over the whole or part of the archipelago, together with a contemporaneous accumulation of sediment, would exceed the average duration of the same specific forms; and these contingencies are indispensable for the preservation of all the transitional gradations between any two or more species. If such gradations were not all fully preserved, transitional varieties would merely appear as so many new, though closely allied species. It is also probable that each great period of subsidence would be interrupted by oscillations of level, and that slight climatal changes 


\section{ABSENCE OF INTERMEDIATE VARIETIES [CBAP. X.}

would intervene during such lengthy periods; and in these cases the inhabitants of the archipelago would migrate, and no closely consecutive record of their modifications could be preserved in any one formation.

Very many of the marine inhabitants of the archipelago now range thousands of miles beyond its confines; and analogy plainly leads to the belief that it would be chiefly these far-ranging species, though only some of them, which would oftenest produce new rarieties; and the varieties would at first be local or confined to one place, but if possessed of any decided advantage, or when further modified and improved, they would slowly spread and supplant their parent-forms. When such varieties returned to their ancient homes, as they would differ from their former state in a nearly uniform, though perhaps extremely slight degree, and as they would be found embedded in slightly different sub-stages of the same formation, they would, according to the principles followed by many palæontologists, be ranked as new and distinct species.

If then there be some degree of truth in these remarks, we have no right to expect to find, in our geological formations, an infinite number of those fine transitional forms which, on our theory, have connected all the past and present species of the same group into one long and branching chain of life. We ought only to look for a few links, and such assuredly we do findsome more distantly, some more closely, related to each other; and these links, let them be ever so close, if found in different stages of the same formation, would, by many palæontologists, be ranked as distinct species. But I do not pretend that I should ever have suspected how poor was the record in the best preserved 
geological sections, had not the absence of innumerable transitional links between the species which lived at the commencement and close of each formation, pressed so hardly on my theory.

On the sudden Appearance of whole Groups of allied Species.

The abrupt manner in which whole groups of species suddenly appear in certain formatious, has been urged by several palæontologists-for instance, by Agassiz, Pictet, and Sedgwick-as a fatal objection to the belief in the transmutation of species. If numerous species, belonging to the same genera or families, have really started into life at once, the fact would be fatal to the theory of evolution through natural selection. For the development by this means of a group of forms, all of which are descended from some one progenitor, must have been an extremely slow process; and the progenitors must have lived long before their modified descendants. But we continually overrate the perfection of the geological record, and falsely infer, because certain genera or families have not been found beneath a certain stage, that they did not exist before that stage. In all cases positive palæontological evidence may be implicitly trusted; negative evidence is worthless, as experience has so often shown. We continually forget how large the world is, compared with the area over which our geological formations have been carefully examined; we forget that groups of species may elsewhere have long existed, and have slowly multiplied, before they invaded the ancient archipelagoes of Europe and the United States. We do not make due allowance 
for the intervals of time which have elapsed between our consecutive formations,-longer perhaps in many cases than the time required for the accumulation of each formation. These intervals will have given time for the multiplication of species from some one parentform: and in the succeeding formation, such groups or species will appear as if suddenly created.

I may here recall a remark formerly made, namely, that it might require a long succession of ages to adapt an organism to some new and peculiar line of life, for instance, to fly through the air; and consequently that the transitional forms would often long remain confined to some one region; but that, when this adaptation had once been effected, and a few species had thus acquired a great advantage over other organisms, a comparatively short time would be necessary to produce many divergent forms, which would spread rapidly and widely, throughout the world. Professor Pictet, in his excellent Review of this work, in commenting on early transitional forms, and taking birds as an illustration, cannot see how the successive modifications of the anterior limbs of a supposed prototype could possibly have been of any advantage. But look at the penguins of the Southern Ocean; have not these birds their front limbs in this precise intermediate state of "neither true "arms nor true wings"? Yet these birds hold their place victoriously in the battle for life; for they exist in infinite numbers and of many kinds. I do not suppose that we here see the real transitional grades through which the wings of birds have passed; but what special difficulty is there in believing that it might profit the modified descendants of the penguin, first to become enabled to flap along the surface of the 
sea like the logger-headed duck, and ultimately to rise from its surface and glide through the air?

I will now give a few examples to illustrate the foregoing remarks, and to show how liable we are to error in supposing that whole groups of species have suddenly been produced. Even in so short an interval as that between the first and second editions of Pictet's great work on Palæontology, published in 1844-46 and in $1853-5 \%$, the conclusions on the first appearance and disappearance of several groups of animals have been considerably modified; and a third edition would require still further changes. I may recall the wellknown fact that in geological treatises, published not many years ago, mammals were always spoken of as having abruptly come in at the commencement of the tertiary series. And now one of the richest known accumulations of fossil mammals belongs to the middle of the secondary series; and true mammals have been discovered in the new red sandstone at nearly the commencement of this great series. Cuvier used to urge that no monkey occurred in any tertiary stratum; but now extinct species have been discovered in India, South America and in Europe, as far back as the miocene stage. Had it not been for the rare accident of the preservation of footsteps in the new red sandstone of the United States, who would have ventured to suppose that no less than at least thirty different bird-like animals, some of gigantic size, existed during that period? Not a fragment of bone has been discovered in these beds. Not long ago, palæontologists maintained that the whole class of birds came suddenly into existence during the eocene period; but now we know, on the authority of Professor Owen, that a bird certainly lived during 
the deposition of the upper greensand; and still more recently, that strange bird, the Archeopteryx, with a long lizard-like tail, bearing a pair of feathers on each joint, and with its wings furnished with two free claws, has been discovered in the oolitic slates of Solenhofen. Hardly any recent discovery shows more forcibly than this, how little we as yet know of the former inhabitants of the world.

I may give another instance, which, from having passed under my own eyes, has much struck me. In a memoir on Fossil Sessile Cirripedes, I stated that, from the large number of existing and extinct tertiary species; from the extraordinary abundance of the individuals of many species all over the world, from the Arctic regions to the equator, inhabiting various zones of depths from the upper tidal limits to 50 fathoms; from the perfect manner in which specimens are preserved in the oldest tertiary beds; from the ease with which even a fragment of a valve can be recognised; from all these circumstances, I inferred that, had sessile cirripedes existed during the secondary periods, they would certainly have been preserved and discovered; and as not one species had then been discovered in beds of this age, I concluded that this great group had been suddenly developed at the commencement of the tertiary series. This was a sore trouble to me, adding as I then thought one more instance of the abrupt appearance of a great group of species. But my work had hardly been published, when a skilful palæontologist, M. Bosquet, sent me a drawing of a perfect specimen of an unmistakable sessile cirripede, which he had himself extracted from the chalk of Belgium. And, as if to make the case as striking as possible, this cirripede 
was - Chthamalus, a very common, large, and ubiquitous genus, of which not one species has as yet been found even in any tertiary stratum. Still more recently, a Pyrgoma, a member of a distinct sub-family of sessile cirripedes, has been discovered by Mr. Woodward in the upper chalk; so that we now have abundant evidence of the existence of this group of animals during the secondary period.

The case most frequently insisted on by palæontologists of the apparently sudden appearance of a whole group of species, is that of the teleostean fishes, low down, according to Agassiz, in the Chalk period. This group includes the large majority of existing species. But certain Jurassic and Triassic forms are now commonly admitted to be teleostean; and even some palæozoic forms have thus been classed by one high authority. If the teleosteans had really appeared suddenly in the northern hemisphere at the commencement of the chalk formation the fact would have been highly remarkable; but it would not have formed an insuperable difficulty, unless it could likewise have been shown that at the same period the species were suddenly and simultaneously developed in other quarters of the world. It is almost superfluous to remark that hardly any fossilfish are known from south of the equator; and by running through Pictet's Palæontology it will be seen that very few species are known from several formations in Europe. Some few families of fish now have a confined range; the teleostean fishes might formerly have had a similarly confined range, and after having been largely developed in some one sea, have spread widely. Nor have we any right to suppose that the seas of the world have always been so freely open from south to 
north as they are at present. Even at this day, if the Malay Archipelago were converted into land, the tropical parts of the Indian Ocean would form a large and perfectly enclosed basin, in which any great group of marine animals might be multiplied; and here they would remain confined, until some of the species became adapted to a cooler climate, and were enable to double the Southern capes of Africa or Australia, and thus reach other and distant seas.

From these considerations, from our ignorance of the geology of other countries beyond the confines of Europe and the United States, and from the revolution in our palæontological knowledge effected by the discoveries of the last dozen years, it seems to me to be about as rash to dogmatize on the succession of organic forms throughout the world, as it would be for a naturalist to land for five minutes on a barren point in Australia, and then to discuss the number and range of its productions.

\section{On the sudden Appearance of Groups of allied Species} in the lowest known Fossiliferous Strata.

There is another and allied difficulty, which is much more serious. I allude to the manner in which species belonging to several of the main divisions of the animal kingdom suddenly appear in the lowest known fossiliferous rocks. Most of the arguments which have convinced me that all the existing species of the same group are descended from a single progenitor, apply with equal force to the earliest known species. For instance, it cannot be doubted that all the Cambrian and 
Silurian trilobites are descended from some one crustacean, which must have lived long before the Cambrian age, and which probably differed greatly from any known animal. Some of the most ancient animals, as the Nautilus, Lingula, \&c., do not differ much from living species; and it cannot on our theory be supposed, that these old species were the progenitors of all the species belonging to the same groups which have subsequently appeared, for they are not in any degree intermediate in character.

Consequently, if the theory be true, it is indisputable that before the lowest Cambrian stratum was deposited long periods elapsed, as long as, or probably far longer than, the whole interval from the Cambrian age to the present day; and that during these vast periods the world swarmed with living creatures. Here we encounter a formidable objection; for it seems doubtful whether the earth, in a fit state for the habitation of living creatures, has lasted long enough. Sir W. Thompson concludes that the consolidation of the crust can hardly have occurred less than 20 or more than 400 million years ago, but probably not less than 98 or more than 200 million years. These very wide limits show how doubtful the data are; and other elements may have hereafter to be introduced into the problem. Mr. Croll estimates that about 60 million years have elapsed since the Cambrian period, but this, judging from the small amount of organic change since the commencement of the Glacial epoch, appears a very short time for the many and great mutations of life, which have certainly occurred since the Cambrian formation; and the previous 140 million years can hardly be considered as sufficient for the development of the 31 
varied forms of life which already existed during the Cambrian period. It is, however, probable, as Sir William Thompson insists, that the world at a very early period was subjected to more rapid and violent changes in its physical conditions than those now occurring; and such changes would have tended to induce changes at a corresponding rate in the organisms which then existed.

To the question why we do not find rich fossiliferous deposits belonging to these assumed earliest periods prior to the Cambrian system, I can give no satisfactory answer. Several eminent geologists, with Sir R. Murchison at their head, were until recently convinced that we beheld in the organic remains of the lowest Silurian stratum the first dawn of life. Other highly competent judges, as Lyell and E. Forbes, have disputed this conclusion. We should not forget that only a small portion of the world is known with accuracy. Not very long ago M. Barrande added another and lower stage, abounding with new and peculiar species, beneath the then known Silurian system; and now, still lower down in the Lower Cambrian formation, Mr. Hicks has found in South Wales beds rich in trilobites, and containing various molluses and annelids. The presence of phosphatic nodules and bituminous matter, even in some of the lowest azoic rocks, probably indicates life at these periods; and the existence of the Eozoon in the Laurentian formation of Canada is generally admitted. There are three great series of strata beneath the Silurian system in Canada, in the lowest of which the Eozoon is found. Sir W. Logan states that their " united thickness may possibly far surpass that " of all the succeeding rocks, from the base of the palæo- 
"zoic series to the present time. We are thus carried " back to a period so remote, that the appearance of the "so-called Primordial fauna (of Barrande) may by some "be considered as a comparatively modern event." The Eozoon belongs to the most lowly organised of all classes of animals, but is highly organised for its class; it existed in countless numbers, and, as Dr. Dawson has remarked, certainly preyed on other minute organic beings, which must have lived in great numbers. Thus the words, which I wrote in 1859 , about the existence of living beings long before the Cambrian period, and which are almost the same with those since used by Sir W. Logan, have proved true. Nevertheless, the difficulty of assigning any good reason for the absence of vast piles of strata rich in fossils beneath the Cambrian system is very great. It does not seem probable that the most ancient beds have been quite worn away by denudation, or that their fossils have been wholly obliterated by metamorphic action, for if this had heen the case we should have found only small remnants of the formations next succeeding them in age, and these would always have existed in a partially metamorphosed condition. But the descriptions which we possess of the Silurian deposits over immense territories in Russia and in North America, do not support the view, that the older a formation is, the more invariably it has suffered extreme denudation and metamorphism.

The case at present must remain inexplicable; and may be truly urged as a valid argument against the views here entertained. To show that it may hereafter receive some explanation, I will give the following hypothesis. From the nature of the organic remains which do not appear to have inhabited profound depths, 
in the several formations of Europe and of the United States; and from the amount of sediment, miles in thickness, of which the formations are composed, we may infer that from first to last large islands or tracts of land, whence the sediment was derived, occurred in the neighbourhood of the now existing continents of Europe and North America. This same view has since been maintained by Agassiz and others. But we do not know what was the state of things in the intervals between the several successive formations; whether Europe and the United States during these intervals existed as dry land, or as a submarine surface near land, on which sediment was not deposited, or as the bed of an open and unfathomable sea.

Looking to the existing oceans, which are thrice as extensive as the land, we see them studded with many islands; but hardly one truly oceanic island (with the exception of New Zealand, if this can be called a truly oceanic island) is as yet known to afford even a remnant of any palæozoic or secondary formation. Hence we may perhaps infer, that during the palæozoic and secondary periods, neither continents nor continental islands existed where our oceans now extend; for had they existed, palæozoic and secondary formations would in all probability have been accumulated from sediment derived from their wear and tear; and these would have been at least partially upheaved by the oscillations of level, which must have intervened during these enormously long periods. If then we may infer anything from these facts, we may infer that, where our oceans now extend, oceans have extended from the remotest period of which we have any record; and on the other hand, that where continents now exist, large tracts of 
land have existed, subjected no doubt to great oscillations of level, since the Cambrian period. The coloured map appended to my volume on Coral Reefs, led me to conclude that the great oceans are still mainly areas of subsidence, the great archipelagoes still areas of oscillations of level, and the continents areas of elevation. But we have no reason to assume that things have thus remained from the beginning of the world. Our continents seem to have been formed by a preponderance, during many oscillations of level, of the force of elevation; but may not the areas of preponderant movement have changed in the lapse of ages? At a period long antecedent to the Cambrian epoch, continents may have existed where oceans are now spread out; and clear and open oceans may have existed where our continents now stand. Nor should we be justified in assuming that if, for instance, the bed of the Pacific Ocean were now converted into a continent we should there find sedimentary formations in a recognisable condition older than the Cambrian strata, supposing such to have been formerly deposited; for it might well happen that strata which had subsided some milesnearer to the centre of the earth, and which had been pressed on by an enormous weight of superincumbent water, might have undergone far more metamorphic action than strata which have always remained nearer to the surface. The immense areas in some parts of the world, for instance in South America, of naked metamorphic rocks, which must have been heated under great pressure, have always seemed to me to require some special explanation; and we may perhaps believe that we see in these large areas, the many formations long anterior to the Cambrian epoch in a completely metamorphosed and denuded condition. 
The several difficulties here discussed, namely-that, though we find in our geological formations many links between the species which now exist and which formerly existed, we do not find infinitely numerous fine transitional forms closely joining them all together;-the sudden manner in which several groups of species first appear in our European formations; - the almost entire absence, as at present known, of formations rich in fossils beneath the Cambrian strata,-are all undoubtedly of the most serious nature. We see this in the fact that the most eminent palæontologists, namely, Cuvier, Agassiz, Barrande, Pictet, Falconer, E. Forbes, \&c., and all our greatest geologists, as Lyell,Murchison, Sedgwick, \&c., have unanimously, often vehemently, maintained the immutability of species. But Sir Charles Lyell now gives the sup port of his high authority to the opposite side; and most geologists and palæontologists are much shaken in their former belief. Those who believe that the geological record is in any degree perfect, will undoubtedly at once reject the theory. For my part, following out Lyell's metaphor, I look at the geological record as a history of the world imperfectly kept, and written in a changing dialect; of this history we possess the last volume alone, relating only to two or three countries. Of this volume, only here and there a short chapter has been preserved; and of each page, only here and there a few lines. Each word of the slowly-changing language, more or less different in the successive chapters, may represent the forms of life, which are entombed in our consecutive formations, and which falsely appear to have been abruptly introduced. On this view, the difficulties above discussed are greatly dimin. ished, or even disappear. 


\section{CHAPTER XI.}

ON THE GEOLOGICAL SUCCESSION OF ORGANIC BEINGS.

On the slow and successive appearance of new species-On their different rates of change-Species once lost do not reappearGroups of species follow the same general rules in their appearance and disappearance as do single species-On extinction -On simultaneous changes in the forms of life throughout the world-On the affinities of extinct species to each other and to living species-On the state of development of ancient formsOn the succession of the same types within the same areasSummary of preceding and present chapter.

LET us now see whether the several facts and laws relating to the geological succession of organic beings accord best with the common view of the immutability of species, or with that of their slow and gradual modification, through variation and natural selection.

New species have appeared very slowly, one after another, both on the land and in the waters. Lyell has shown that it is hardly possible to resist the evidence on this head in the case of the several tertiary stages; and every year tends to fill up the blanks between the stages, and to make the proportion between the lost and existing forms more gradual. In some of the most recent beds, though undoubtedly of high antiquity if measured by years, only one or two species are extinct, and only one or two are new, having appeared there for the first time, either locally, or, as far as we know, on the face of the earth. The secondary formations are more broken; 
but, as Bronn has remarked, neither the appearance nor disappearance of the many species embedded in each formation has been simultaneous.

Species belonging to different genera and classes have not changed at the same rate, or in the same degree. In the older tertiary beds a few living shells may still be found in the midst of a multitude of extinct forms. Falconer has given a striking instance of a similar fact, for an existing crocodile is associated with many lost mammals and reptiles in the sub-Himalayan deposits. The Silurian Lingula differs but little from the living species of this genus; whereas most of the other Silurian Molluses and all the Crustaceans have changed greatly. The productions of the land seem to have changed at a quicker rate than those of the sea, of which a striking instance has been observed in Switzerland. There is some reason to believe that organisms high in the scale, change more quickly than those that are low: though there are exceptions to this rule. The amount of organic change, as Pictet has remarked, is not the same in each successive so-called formation. Yet if we compare any but the most closely related formations, all the species will be found to have undergone some change. When a species has once disappeared from the face of the earth, we have no reason to believe that the same identical form ever reappears. The strongest apparent exception to this latter rule is that of the so-called " colonies" of M. Barrande, which intrude for a period in the midst of an older formation, and then allow the pre-existing fauna to reappear; but Lyell's explanation, namely, that it is a case of temporary migration from a distinct geographical province, seems satisfactory.

These several facts accord well with our theory, 
which includes no fixed law of development, causing all the inhabitants of an area to change abruptly, or simultaneously, or to an equal degree. The process of modification must be slow, and will generally effect only a few species at the same time; for the variability of each species is independent of that of all others. Whether such variations or individual differences as may arise will be accumulated through natural selection in a greater or less degree, thus causing a greater or less amount of permanent modification, will depend on many complex contingencies-on the variations being of a beneficial nature, on the freedom of intercrossing, on the slowly changing physical conditions of the country, on the immigration of new colonists, and on the nature of the other inhabitants with which the varying species come into competition. Hence it is by no means surprising that one species should retain the same identieal form much longer than others; or, if changing, should change in a less degree. We find similar relations between the existing inhabitants of distinct countries; for instance, the land-shells and coleopterous insects of Madeira have come to differ considerably from their nearest allies on the continent of Europe, whereas the marine shells and birds have remained unaltered. We can perhaps understand the apparently quicker rate of change in terrestrial and in more highly organised productions compared with marine and lower productions, by the more complex relations of the higher beings to their organic and inorganic conditions of life, as explained in a former chapter. When many of the inhabitants of any area have become modified and improved, we can understand, on the principle of competition, and from the all-important relations of organ- 
ism to organism in the struggle for life, that any form which did not become in some degree modified and improved, would be liable to extermination. Hence we see why all the species in the same region do at last, if we look to long enough intervals of time, become modified, for otherwise they would become extinct.

In members of the same class the average amount of change, during long and equal periods of time, may, perhaps, be nearly the same; but as the accumulation of enduring formations, rich in fossils, depends on great masses of sediment being deposited on subsiding areas, our formations have been almost necessarily accumulated at wide and irregularly intermittent intervals of time; consequently the amount of organic change exhibited by the fossils embedded in consecutive formations is not equal. Each formation, on this view, does not mark a new and complete act of creation, but only an occasional scene, taken almost at hazard, in an ever slowly changing drama.

We can clearly understand why a species when once lost should never reappear, even if the very same conditions of life, organic and inorganic, should recur. For though the offspring of one species might be adapted (and no doubt this has occurred in innumerable instances) to fill the place of another species in the economy of nature, and thus supplant it; yet the two forms - the old and the new-would not be identically the same; for both would almost certainly inherit different characters from their distinct progenitors; and organisms already differing would vary in a different manner. For instance, it is possible, if all our fantail pigeons were destroyed, that fanciers might make a new breed hardly distinguishable from the present breed; but if 
the parent rock-pigeon were likewise destroyed, and under nature we have every reason to believe that parent-forms are generally supplanted and exterminated by their improved offspring, it is incredible that a fantail, identical with the existing breed, could be raised from any other species of pigeon, or even from any other wellestablished race of the domestic pigeon, for thesuccessive variations would almost certainly be in some degree different, and the newly-formed variety would probably inherit from its progenitor some characteristic differences.

Groups of species, that is, genera and families, follow the same general rules in their appearance and disappearance as do single species, changing more or less quickly, and in a greater or lesser degree. A group, when it has once disappeared, never reappears; that is, its existence, as long as it lasts, is continuous. I am aware that there are some apparent exceptions to this rule, but the exceptions are surprisingly few, so few that E. Forbes, Pictet, and Woodward (though all strongly opposed to such views as I maintain) admit its truth; and the rule strictly accords with the theory. For all the species of the same group, however long it may have lasted, are the modified descendants one from the other, and all from a common progenitor. In the genus Lingula, for instance, the species which have successively appeared at all ages must have been connected by an unbroken series of generations, from the lowest Silurian stratum to the present day.

We have seen in the last chapter that whole groups of species sometimes falsely appear to have been abruptly developed; and I have attempted to give an explanation of this fact, which if true would be fatal to my views. But such cases are certainly exceptional; the 
general rule being a gradual increase in number, until the group reaches its maximum, and then, sooner or later, a gradual decrease. If the number of the species included within a genus, or the number of the genera within a family, be represented by a vertical line of varying thickness, ascending through the successive geological formations, in which the species are found, the line will sometimes falsely appear to begin at its lower end, not in a sharp point, but abruptly; it then gradually thickens upwards, often keeping of equal thickness for a space, and ultimately thins out in the upper beds, marking the decrease and final extinction of the species. This gradual increase in number of the species of a group is strictly conformable with the theory, for the species of the same genus, and the genera of the same family, can increase only slowly and progressively; the process of modification and the production of a number of allied forms necessarily being a slow and gradual process, - one species first giving rise to two or three varieties, these being slowly converted into species, which in their turn produce by equally slow steps other varieties and species, and so on, like the branching of a great tree from a single stem, till the group becomes large.

\section{On Extinction.}

We have as yet only spoken incidentally of the disappearance of species and of groups of species. On the theory of natural selection, the extinction of old forms and the production of new and improved forms are intimately connected together. The old notion of all the inhabitants of the earth having been swept away by catastrophes at successive periods is very generally given up, even by those geologists, as Elie de Beaumont, Mur- 
chison, Barrande, \&c., whose general views would naturally lead them to this conclusion. On the contrary, we have every reason to believe, from the study of the tertiary formations, that species and groups of species gradually disappear, one after another, first from one spot, then from another, and finally from the world. In some few cases however, as by the breaking of an isthmus and the consequent irruption of a multitude of new inhabitants into an adjoining sea, or by the final subsidence of an island, the process of extinction may have been rapid. Both single species and whole groups of species last for very unequal periods; some groups, as we have seen, have endured from the earliest known dawn of life to the present day; some have disappeared before the close of the palæozoic period. No fixed law seems to determine the length of time during which any single species or any single genus endures. There is reason to believe that the extinction of a whole group of species is generally a slower process than their production: if their appearance and disappearance be represented, as before, by a vertical line of varying thickness the line is found to taper more gradually at its upper end, which marks the progress of extermination, than at its lower end, which marks the first appearance and the early increase in number of the species. In some cases, however, the extermination of whole groups, as of ammonites, towards the close of the secondary period, has been wonderfully sudden.

The extinction of species has been involved in the most gratuitous mystery. Some authors have even supposed that, as the individual has a definite length of life, so have species a definite duration. No one can have marvelled more than I have done at the extinction 
of species. When I found in La Plata the tooth of a horse embedded with the remains of Mastodon, Megatherium, Toxodon, and other extinct monsters, which all co-existed with still living shells at a very late geological period, I was filled with astonishment; for, seeing that the horse, since its introduction by the Spaniards into South America, has run wild over the whole country and has increased in numbers at an unparalleled rate, I asked myself what could so recently have exterminated the former horse under conditions of life apparently so favourable. But my astonishment was groundless. Professor Owen soon perceived that the tooth, though so like that of the existing horse, belonged to an extinct species. Had this horse been still living, but in some degree rare, no naturalist would have felt the least surprise at its rarity; for rarity is the attribute of a vast number of species of all classes, in all countries. If we ask ourselves why this or that species is rare, we answer that something is unfavourable in its conditions of life; but what that something is we can hardly ever tell. On the supposition of the fossil horse still existing as a rare species, we might have felt certain, from the analogy of all other mammals, even of the slow-breeding elephant, and from the history of the naturalisation of the domestic horse in South America, that under more favourable conditions it would in a very few years have stocked the whole continent. But we could not have told what the unfavourable conditions were which checked its increase, whether some one or several contingencies, and at what period of the horse's life, and in what degree they severally acted. If the conditions had gone on, however slowly, becoming less and less favourable, we assuredly should not have 
perceived the fact, yet the fossil horse would certainly have become rarer and rarer, and finally extinct;-its place being seized on by some more successful competitor.

It is most difficult always to remember that the increase of every creature is constantly being checked by unperceived hostile agencies; and that these same unperceived agencies are amplysufficient to cause rarity, and finally extinction. So little is this subject understood, that I have heard surprise repeatedly expressed at such great monsters as the Mastodon and the more ancient Dinosaurians having become extinct; as if mere bodily strength gave victory in the battle of life. Mere size, on the contrary, would in some cases determine, as has been remarked by Owen, quicker extermination from the greater amount of requisite food. Before man inhabited India or Africa, some cause must have checked the continued increase of the existing elephant. A highly capable judge, Dr. Falconer, believes that it is chiefly insects which, from incessantly harassing and weakening the elephant in India, check its increase; and this was Bruce's conclusion with respect to the African elephant in Abyssinia. It is certain that insects and blood-sucking bats determine the existence of the larger naturalised quadrupeds in several parts of S. America.

We see in many cases in the more recent tertiary formations, that rarity precedes extinction; and we know that this has been the progress of events with those animals which have been exterminated, either locally or wholly, through man's agency. I may repeat what I published in 1845, namely, that to admit that species generally become rare before they become extinct-to feel no surprise at the rarity of a species, and yet to marvel greatly when the species ceases to exist, is much the 
same as to admit that sickness in the individual is the forerunner of death-to feel no surprise at sickness, but, when the sick man dies, to wonder and to suspect that he died by some deed of violence.

The theory of natural selection is grounded on the belief that each new variety and ultimately each new species, is produced and maintained by having some advantage over those with which it comes into competition; and the consequent extinction of the less-favoured forms almost inevitably follows. It is the same with our domestic productions; when a new and slightly improved variety has been raised, it at first supplants the less improved varieties in the same neighbourhood; when much improved it is transported far and near, like our short-horn cattle, and takes the place of other breeds in other countries. Thus the appearance of new forms and the disappearance of old forms, both those naturally and those artificially produced, are bound together. In flourishing groups, the number of new specific forms which have been produced within a given time has at some periods probably been greater than the number of the old specific forms which have been exterminated; but we know that species have not gone on indefinitely increasing, at least during the later geological epochs, so that, looking to later times, we may believe that the production of new forms has caused the extinction of about the same number of old forms.

The competition will generally be most severe, as formerly explained and illustrated by examples, between the forms which are most like each other in all respects. Hence the improved and modified descendants of a species will generally cause the extermination of the parentspecies; and if many new forms have been developed 
from any one species, the nearest allies of that species, i.e. the species of the same genus, will be the most liable to extermination. Thus, as I believe, a number of new species descended from one species, that is a new genus, comes to supplant an old genus, belonging to the same family. But it must often have happened that a new species belonging to some one group has seized on the place occupied by a species belonging to a distinct group, and thus have caused its extermination. If many allied forms be developed from the successful intruder, many will have to yield their places; and it will generally be the allied forms, which will suffer from some inherited inferiority in common. But whether it be species belonging to the same or to a distinct class, which have yielded their places to other modified and improved species, a few of the sufferers may often be preserved for a long time, from being fitted to some peculiar line of life, or from inhabiting some distant and isolated station, where they will have escaped serere competition. For instance, some species of Trigonia, a great genus of shells in the secondary formations, survive in the Australian seas; and a few members of the great and almost extinct group of Ganoid fishes still inhabit our fresh waters. Therefore the utter extinction of a group is generally, as we have seen, a slower process than its production.

With respect to the apparently sudden extermination of whole families or orders, as of Trilobites at tine close of the palæozoic period and of Ammonites at the close of the secondary period, we must remember what has been already said on the probable wide interrals of time between our consecutive formations; and in these intervals there mar have been much slow extermination. Moreover, when, by sudden immigration or by unusu- 
ally rapid development, many species of a new group have taken possession of an area, many of the older species will have been exterminated in a correspondingly rapid manner; and the forms which thus yield their places will commonly be allied, for they will partake of the same inferiority in common.

Thus, as it seems to me, the manner in which single species and whole groups of species become extinct accords well with the theory of natural selection. We need not marvel at extinction; if we must marvel, let it be at our own presumption in imagining for a moment that we understand the many complex contingencies on which the existence of each species depends. If we forget for an instant that each species tends to increase inordinately, and that some check is always in action, yet seldom perceived by us, the whole economy of nature will be utterly obscured. Whenever we can precisely say why this species is more abundant in individuals than that; why this species and not another can be naturalised in a given country; then, and not until then, we may justly feel surprise why we cannot account for the extinction of any particular species or group of species.

\section{On the Forms of Life changing almost simultaneously throughout the World.}

Scarcely any palæontological discovery is more striking than the fact that the forms of life change almost simultaneously throughout the world. Thus our European Chalk formation can be recognised in many distant regions, under the most different climates, where not a fragment of the mineral chalk itself can be found; namely in North America, in equatorial South America, 
in Tierra del Fuego, at the Cape of Good Hope, and in the peninsula of India. For at these distant points, the organic remains in certain beds present an unmistakeable resemblance to those of the Chalk. It is not that the same species are met with; for in some cases not one species is identically the same, but they belong to the same families, genera, and sections of genera, and sometimes are similarly characterised in such trifling points as mere superficial sculpture. Moreover, other forms, which are not found in the Chalk of Europe, but which occur in the formations either above or below, occur in the same order at these distant points of the world. In the several successive palæozoic formations of Russia, Western Europe, and North America, a similar parallelism in the forms of life has been observed by several authors; so it is, according to Lyell, with the European and North American tertiary deposits. Even if the few fossil species which are common to the Old and New Worlds were kept wholly out of view, the general parallelism in the successive forms of life, in the palæozoic and tertiary stages, would still be manifest, and the several formations could be easily correlated.

These observations, however, relate to the marine inhabitants of the world: we have not sufficient data to judge whether the productions of the land and of fresh water at distant points change in the same parallel manner. We may doubt whether they have thus changed: if the Megatherium, Mylodon, Macrauchenia, and Toxodon had been brought to Europe from La Plata, without any information in regard to their geological position, no one would have suspected that they had coexisted with sea-shells all still living; but as these 
anomalous monsters co-existed with the Mastodon and Horse, it might at least have been inferred that they had lived during one of the later tertiary stages.

When the marine forms of life are spoken of as having changed simultaneously throughout the world, it must not be supposed that this expression relates to the same year, or to the same century, or even that it has a very strict geological sense; for if all the marine animals now living in Europe, and all those that lived in Europe during the pleistocene period (a very remote period as measured by years, including the whole glacial epoch) were compared with those now existing in South America or in Australia, the most skilful naturalist would hardly be able to say whether the present or the pleistocene inhabitants of Europe resembled most closely those of the southern hemisphere. So, again, several highly competent observers maintain that the existing productions of the United States are more closely related to those which lived in Europe during certain late tertiary stages, than to the present inhabitants of Europe; and if this be so, it is evident that fossiliferous beds now deposited on the shores of North America would hereafter be liable to be classed with somewhat older European beds. Nevertheless, looking to a remotely future epoch, there can be little doubt that all the more modern marine formations, namely, the upper pliocene, the pleistocene and strictly modern beds of Europe, North and South America, and Australia, from containing fossil remains in some degree allied, and from not including those forms which are found only in the older underlying deposits, would be correctly ranked as simultaneous in a geological sense.

The fact of the forms of life changing simultaneous- 
ly, in the above large sense, at distant parts of the world, has greatly struck these admirable observers, MM. de Verneuil and d'Archiac. After referring to the parallelism of the palæozoic forms of life in various parts of Europe, they add, "If, struck by this strange sequence, we turn our attention to North America, and there discover a series of analogous phenomena, it will appear certain that all these modifications of species, their extinction, and the introduction of new ones, cannot be owing to mere changes in marine currents or other causes more or less local and temporary, but depend on general laws which govern the whole animal kingdom." M. Barrande has made forcible remarks to precisely the same effect. It is, indeed, quite futile to look to changes of currents, climate, or other physical conditions, as the cause of these greai mutations in the forms of life throughout the world, under the most different climates. We must, as Barrande has remarked, look to some special law. We shall see this more clearly when we treat of the present distribution of organic beings, and find how slight is the relation between the physical conditions of various countries and the nature of their inhabitants.

This great fact of the parallel succession of the forms of life throughout the world, is explicable on the theory of natural selection. New species are formed by having some advantage over older forms; and the forms, which are already dominant, or have some advantage over the other forms in their own country, give birth to the greatest number of new varieties or incipient species. We have distinct evidence on this head, in the plants which are dominant, that is, which are commonest and most widely diffused, producing the greatest number of 
new varieties. It is also natural that the dominant, varying, and far-spreading species, which have already invaded to a certain extent the territories of other species, should be those which would have the best chance of spreading still further, and of giving rise in new countries to other new varieties and species. The process of diffusion would often be very slow, depending on climatal and geographical changes, on strange accidents, and on the gradual acclimatisation of new species to the various climates through which they might have to pass, but in the course of time the dominant forms would generally succeed in spreading and would ultimately prevail. The diffusion would, it is probable, be slower with the terrestrial inhabitants of distinct continents than with the marine inhabitants of the continuous sea. We might therefore expect to find, as we do find, a less strict degree of parallelism in the succesion of the productions of the land than with those of the sea.

Thus, as it seems to me, the parallel, and, taken in a large sense, simultaneous, succession of the same forms of life throughout the world, accords well with the principle of new species having been formed by dominant species spreading widely and varying; the new species thus produced being themselves dominant, owing to their having had some advantage over their already dominant parents, as well as over other species, and again spreading, varying, and producing new forms. The old forms which are beaten and which yield their places to the new and victorious forms, will generally be allied in groups, from inheriting some inferiority in common; and therefore, as new and improved groups spread throughout the world, old groups disappear from the world; and the succession of forms everywhere 
tends to correspond both in their first appearance and final disappearance.

There is one other remark connected with this subject worth making. I have given my reasons for believing that most of our great formations, rich in fossils, were deposited during periods of subsidence; and that blank intervals of vast duration, as far as fossils are concerned, occurred during the periods when the bed of the sea was either stationary or rising, and likewise when sediment was not thrown down quickly enough to embed and preserve organic remains. During these long and blank intervals I suppose that the inhabitants of each region underwent a considerable amount of modification and extinction, and that there was much migration from other parts of the world. As we have reason to believe that large areas are affected by the same movement, it is probable that strictly contemporaneous formations have often been accumulated over very wide spaces in the same quarter of the world; but we are very far from having any right to conclude that this has invariably been the case, and that large areas have invariably been affected by the same movements. When two formations have been deposited in two regions during nearly, but not exactly, the same period, we should find in both, from the causes explained in the foregoing paragraphs, the same general succession in the forms of life; but the species would not exactly correspond; for there will have been a little more time in the one region than in the other for modification, extinction, and immigration.

I suspect that cases of this nature occur in Europe. Mr. Prestwich, in his admirable Memoirs on the eocene deposits of England and France, is able to draw a close 
general parallelism between the successive stages in the two countries; but when he compares certain stages in England with those in France, although he finds in both a curious accordance in the numbers of the species belonging to the same genera, yet the species themselves differ in a manner very difficult to account for, considering the proximity of the two areas,-unless, indeed, it be assumed that an isthmus separated two seas inhabited by distinct, but contemporaneous, faunas. Lyell has made similar observations on some of the later tertiary formations. Barrande, also, shows that there is a striking general parallelism in the successive Silurian deposits of Bohemia and Scandinavia; nevertheless he finds a surprising amount of difference in the species. If the several formations in these regions have not been deposited during the same exact periods, -a formation in one region often corresponding with a blank interval in the other,-and if in both regions the species have gone on slowly changing during the accumulation of the several formations and during the long intervals of time between them; in this case the several formations in the two regions could be arranged in the same order, in accordance with the general succession of the forms of life, and the order would falsely appear to be strictly parallel; nevertheless the species would not be all the same in the apparently corresponding stages in the two regions.

\section{On the Affinities of Extinct Species to each other, and to Living Forms.}

Let us now look to the mutual affinities of extinct and living species. All fall into a few grand classes; and this fact is at once explained on the principle of 
descent. The more ancient any form is, the more, as a general rule, it differs from living forms. But, as Buckland long ago remarked, extinct species can all be classed either in still existing groups, or between them. That the extinct forms of life help to fill up the intervals between existing genera, families, and orders, is certainly true; but as this statement has often been ignored or even denied, it may be well to make some remarks on this subject, and to give some instances. If we confine our attention either to the living or to the extinct species of the same class, the series is far less perfect than if we combine both into one general system. In the writings of Professor Owen we continually meet with the expression of generalised forms, as applied to extinct animals; and in the writings of Agassiz, of prophetic or synthetic types; and these terms imply that such forms are in fact intermediate or connecting links. Another distinguished palæontologist, M. Gaudry, has shown in the most striking manner that many of the fossil mammals discovered by him in Attica serve to break down the intervals between existing genera. Cuvier ranked the Ruminants and Pachyderms as two of the most distinct orders of mammals: but so many fossil links have been disentombed that Owen has had to alter the whole classification, and has placed certain pachyderms in the same sub-order with ruminants; for example, he dissolves by gradations the apparently wide interval between the pig and the camel. The Ungulata or hoofed quadrupeds are now divided into the even-toed or odd-toed divisions; but the Macrauchenia of S. America connects to a certain extent these two grand divisions. No one will deny that the Hipparion is intermediate between the existing horse 
and certain older ungulate forms. What a wonderful connecting link in the chain of mammals is the Typotherium from S. America, as the name given to it by Professor Gervais expresses, and which cannot be placed in any existing order. The Sirenia form a very distinct group of mammals, and one of the most remarkable peculiarities in the existing dugong and lamentin is the entire absence of hind limbs without even a rudiment being left; but the extinct Halitherium had, according to Professor Flower, an ossified thigh-bone " articulated to a well-defined acetabulum in the pelvis," and it thus makes some approach to ordinary hoofed quadrupeds, to which the Sirenia are in other respects allied. The cetaceans or whales are widely different from all other mammals, but the tertiary Zeuglodon and Squalodon, which have been placed by some naturalists in an order by themselves, are considered by Professor Huxley to be undoubtedly cetaceans, "and to constitute connecting links with the aquatic carnivora."

Even the wide interval between birds and reptiles has been shown by the naturalist just quoted to be partially bridged over in the most unexpected manner, on the one hand, by the ostrich and extinct Archeopteryx, and on the other hand, by the Compsognathus, one of the Dinosaurians-that group which includes the most gigantic of all terrestrial reptiles. Turning to the Invertebrata, Barrande asserts, and a higher authority could not be named, that he is every day taught that, although palæozoic animals can certainly be classed under existing groups, yet that at this ancient period the groups were not so distinctly separated from each other as they now are.

Some writers have objected to any extinct species, 
or group of species, being considered as intermediate between any two living species, or groups of species. If by this term it is meant that an extinct form is directly intermediate in all its characters between two living forms or groups, the objection is probably valid. But in a natural classification many fossil species certainly stand between living species, and some extinct genera between living genera, even between genera belonging to distinct families. The most common case, especially with respect to very distinct groups, such as fish and reptiles, seems to be, that, supposing them to be distinguished at the present day by a score of characters, the ancient members are separated by a somewhat lesser number of characters; so that the two groups formerly made a somewhat nearer approach to each other than they now do.

It is a common belief that the more ancient a form is, by so much the more it tends to connect by some of its characters groups now widely separated fro- ${ }^{-}$each other. This remark no doubt must be restrivied to those groups which have undergone much change in the course of geological ages; and it would be difficult to prove the truth of the proposition, for every now and then even a living animal, as the Lepidosiren, is discovered having affinities directed towards very distinct groups. Yet if we compare the older Reptiles and Batrachians, the older Fish, the older Cephalopods, and the eocene Mammals, with the more recent members of the same classes, we must admit that there is truth in the remark.

Let us see how far these several facts and inferences accord with the theory of descent with modification. As the subject is somewhat complex, I must request 
the reader to turn to the diagram in the fourth chapter. We may suppose that the numbered letters in italics represent genera; and the dotted lines diverging from them the species in each genus. The diagram is much too simple, too few genera and too few species being given, but this is unimportant for us. The horizontal lines may represent successive geological formations, and all the forms beneath the uppermost line may be considered as extinct. The three existing genera $a^{14}$, $q^{14}, p^{14}$, will form a small family; $b^{14}$ and $f^{14}$ a closely allied family or sub-family; and $o^{14}, e^{14}, m^{14}$, a third family. These three families, together with the many extinct genera on the several lines of descent diverging from the parent-form (A) will form an order, for all will have inherited something in common from their ancient progenitor. On the principle of the continued tendency to divergence of character, which was formerly illustrated by this diagram, the more recent any form is, the more it will generally differ from its ancient progenitor. Hence we can understand the rule that the most ancient fossils differ most from existing forms. We must not, however, assume that divergence of character is a necessary contingency; it depends solely on the descendants from a species being thus enabled to seize on many and different places in the economy of nature. Therefore it is quite possible, as we have seen in the case of some Silurian forms, that a species might go on being slightly modified in relation to its slightly altered conditions of life, and yet retain throughout a vast period the same general characteristics. This is represented in the diagram by the letter $\mathrm{F}^{\mathbf{1 4}}$.

All the many forms, extinct and recent, descended from (A), make, as before remarked, one order; and 
this order, from the continued effects of extinction and divergence of character, has become divided into several sub-families and families, some of which are supposed to have perished at different periods, and some to have endured to the present day.

By looking at the diagram we can see that if many of the extinct forms supposed to be imbedded in the successive formations, were discovered at several points low down in the series, the three existing families on the uppermost line would be rendered less distinct from each other. If, for instance, the genera $a^{1}, a^{5}, a^{10}$, $f^{8}, m^{3}, m^{6}, m^{9}$, were disinterred, these three families would be so closely linked together that they probably would have to be united into one great family, in nearly the same manner as has occurred with ruminants and certain pachyderms. Yet he who objected to consider as intermediate the extinct genera, which thus link together the living genera of three families, would be partly justified, for they are intermediate, not directly, but only by a long and circuitous course through many widely different forms. If many extinct forms were to be discovered above one of the middle horizontal lines or geological formations-for instance, above No. VI.-but none from beneath this line, then only two of the families (those on the left hand, $a^{\mathbf{1 4}}$, \&c., and $b^{14}$, \&c.) would have to be united into one; and there would remain two families, which would be less distinct from each other than they were before the discovery of the fossils. So again if the three families formed of eight genera ( $a^{14}$ to $m^{14}$ ), on the uppermost line, be supposed to differ from each other by half-a-dozen important characters, then the families which existed at the period marked VI. would certainly have differed from 
each other by a less number of characters; for they would at this early stage of descent have diverged in a less degree from their common progenitor. Thus it comes that ancient and extinct genera are often in a greater or less degree intermediate in character between their modified descendants, or between their collateral relations.

Under nature the process will be far more complicated than is represented in the diagram; for the groups will have been more numerous; they will have endured for extremely unequal lengths of time, and will have been modified in various degrees. As we possess only the last volume of the geological record, and that in a very broken condition, we have no right to expect, except in rare cases, to fill up the wide intervals in the natural system, and thus to unite distinct families or orders. All that we have a right to expect is, that those groups which have, within known geological periods, undergone much modification, should in the older formations make some slight approach to each other; so that the older members should differ less from each other in some of their characters than do the existing members of the same groups; and this by the concurrent evidence of our best palæontologists is frequently the case.

Thus, on the theory of descent with modification, the main facts with respect to the mutual affinities of the extinct forms of life to each other and to living forms, are explained in a satisfactory manner. And they are wholly inexplicable on any other view.

On this same theory, it is evident that the fauna during any one great period in the earth's history will be intermediate in general character between that which preceded and that which succeeded it. Thus the spe- 
cies which lived at the sixth great stage of descent in the diagram are the modified offspring of those which lived at the fifth stage, and are the parents of those which became still more modified at the seventh stage; hence they could hardly fail to be nearly intermediate in character between the forms of life above and below. We must, however, allow for the entire extinction of some preceding forms, and in any one region for the immigration of new forms from other regions, and for a large amount of modification during the long and blank intervals between the successive formations. Subject to these allowances, the fauna of each geological period undoubtedly is intermediate in character, between the preceding and succeeding faunas. I need give only one instance, namely, the manner in which the fossils of the Devonian system, when this system was first discovered, were at once recognised by palæontologists as intermediate in character between those of the overlying carboniferous, and underlying Silurian systems. But each fauna is not necessarily exactly intermediate, as unequal intervals of time have elapsed between consecutive formations.

It is no real objection to the truth of the statement that the fauna of each period as a whole is nearly intermediate in character between the preceding and succeeding faunas, that certain genera offer exceptions to the rule. For instance, the species of mastodons and elephants, when arranged by Dr. Falconer in two series, -in the first place according to their mutual affinities, and in the second place according to their periods of existence,-do not accord in arrangement. The species extreme in character are not the oldest or the most recent; nor are those which are intermediate in charac- 
ter, intermediate in age. But supposing for an instant, in this and other such cases, that the record of the first appearance and disappearance of the species was complete, which is far from the case, we have no reason to believe that forms successively produced necessarily endure for corresponding lengths of time. A very ancient form may occasionally have lasted much longer than a form elsewhere subsequently produced, especially in the case of terrestrial productions inhabiting separated districts. To compare small things with great; if the principal living and extinct races of the domestic pigeon were arranged in serial affinity, this arrangement would not closely accord with the order in time of their production, and even less with the order of their disappearance; for the parent rock-pigeon still lives; and many varieties between the rock-pigeon and the carrier have become extinct; and carriers which are extreme in the important character of length of beak originated earlier than short-beaked tumblers, which are at the opposite end of the series in this respect.

Closely connected with the statement, that the organic remains from an intermediate formation are in some degree intermediate in character, is the fact, insisted on by all palæontologists, that fossils from two consecutive formations are far more closely related to each other, than are the fossils from two remote formations. Pictet gives as a well-known instance, the general resemblance of the organic remains from the several stages of the Chalk formation, though the species are distinct in each stage. This fact alone, from its generality, seems to have shaken Professor Pictet in his belief in the immutability of species. He who is acquainted with the distribution of existing species over 
the globe, will not attempt to account for the close resemblance of distinct species in closely consecutive formations, by the physical conditions of the ancient areas having remained nearly the same. Let it be remembered that the forms of life, at least those inhabiting the sea, have changed almost simultaneously throughout the world, and therefore under the most different climates and conditions. Consider the prodigious vicissitudes of climate during the pleistocene period, which includes the whole glacial epoch, and note how little the specific forms of the inhabitants of the sea have been affected.

On the theory of descent, the full meaning of the fossil remains from closely consecutive formations being closely related, though ranked as distinct species, is obvious. As the accumulation of each formation has often been interrupted, and as long blank intervals have intervened between successive formations, we ouglit not to expect to find, as I attempted to show in the last chapter, in any one or in any two formations, all the intermediate varieties between the species which appeared at the commencement and close of these periods: but we ought to find after intervals, very long as measured by years, but only moderately long as measured geologically, closely allied forms, or, as they have been called by some authors, representative species; and these assuredly we do find. We find, in short, such evidence of the slow and scarcely sensible mutations of specific forms, as we have the right to expect. 
On the State of Development of Ancient compared with Living Forms.

We have seen in the fourth chapter that the degree of differentiation and specialisation of the parts in organic beings, when arrived at maturity, is the best standard, as yet suggested, of their degree of perfection or highness. We have also seen that, as the specialisation of parts is an advantage to each being, so natural selection will tend to render the organisation of each being more specialised and perfect, and in this sense higher; not but that it may leave many creatures with simple and unimproved structures fitted for simple conditions of life, and in some cases will even degrade or simplify the organisation, yet leaving such degraded beings better fitted for their new walks of life. In another and more general manner, new species become superior to their predecessors; for they have to beat in the struggle for life all the older forms, with which they come into close competition. We may therefore conclude that if under a nearly similar climate the eocene inhabitants of the world could be put into competition with the existing inhabitants, the former would be beaten and exterminated by the latter, as would the secondary by the eocene, and the palæozoic by the secondary forms. So that by this fundamental test of victory in the battle for life, as well as by the standard of the specialisation of organs, modern forms ought, on the theory of natural selection, to stand higher than ancient forms. Is this the case? A large majority of palæontologists would answer in the affirmative; and it seems that this answer must be admitted as true, though difficult of proof. 
It is no valid objection to this conclusion, that certain Brachiopods have been but slightly modified from an extremely remote geological epoch; and that certain land and fresh-water shells have remained nearly the same, from the time when, as far as is known, they irst appeared. It is not an insuperable difficulty that Foraminifera have not, as insisted on by Dr. Carpenter, progressed in organisation since even the Laurentian epoch; for some organisms would have to remain fitted for simple conditions of life, and what could be better fitted for this end than these lowly organised Protozoa? Such objections as the above would be fatal to my view, if it included advance in organisation as a necessary contingent. They would likewise be fatal, if the above Foraminifera, for instance, could be proved to have first come into existence during the Laurentian epoch, or the above Brachiopods during the Cambrian formation; for in this case, there would not have been time sufficient for the development of these organisms up to the standard which they had then reached. When advanced up to any given point, there is no necessity, on the theory of natural selection, for their further continued progress; though they will, during each successive age, have to be slightly modified, so as to hold their places in relation to slight changes in their conditions. The foregoing objections hinge on the question whether we really know how old the world is, and at what period the various forms of life first appeared; and this may well be disputed.

The problem whether organisation on the whole has advanced is in many ways excessively intricate. The geological record, at all times imperfect, does not extend far enough back, to shew with unmistakeable clear- 
ness that within the known history of the world organisation has largely advanced. Even at the present day, looking to members of the same class, naturalists are not unanimous which forms ought to be ranked as highest: thus, some look at the selaceans or sharks, from their approach in some important points of structure to reptiles, as the highest fish; others look at the teleosteans as the highest. The ganoids stand intermediate between the selaceans and teleosteans; the latter at the present day are largely preponderant in number; but formerly selaceans and ganoids alone existed; and in this case, according to the standard of highness chosen, so will it be said that fishes have advanced or retrograded in organisation. To attempt to compare members of distinct types in the scale of highness seems hopeless; who will decide whether a cuttle-fish be higher than a bee-that insect which the great Von Baer believed to be "in fact more highly organised than a fish, although upon another type"? In the complex struggle for life it is quite credible that crustaceans, not very high in their own class, might beat cephalopods, the highest molluses; and such crustaceans, though not highly developed, would stand very high in the scale of invertebrate animals, if judged by the most decisive of all trials-the law of battle. Besides these inherent difficulties in deciding which forms are the most advanced in organisation, we ought not solely to compare the highest members of a class at any two periodsthough undoubtedly this is one and perhaps the most important element in striking a balance-but we ought to compare all the members, high and low, at the two periods. At an ancient epoch the highest and lowest molluscoidal animals, namely, cephalopods and brachio- 
pods, swarmed in numbers; at the present time both groups are greatly reduced, whilst others, intermediate in organisation, have largely increased; consequently some naturalists maintain that molluscs were formerly more highly developed than at present; but a stronger case can be made out on the opposite side, by considering the vast reduction of brachiopods, and the fact that our existing cephalopods, though few in number, are more highly organised than their ancient representatives. We ought also to compare the relative proportional numbers at any two periods of the high and low classes throughout the world: if, for instance, at the present day fifty thousand kinds of vertebrate animals exist, and if we knew that at some former period only ten thousand kinds existed, we ought to look at this increase in number in the highest class, which implies a great displacement of lower forms, as a decided advance in the organisation of the world. We thus see how hopelessly difficult it is to compare with perfect fairness under such extremely ccmplex relations, the standard of organisation of the imperfectly-known faunas of successive periods.

We shall appreciate this difficulty more clearly, by looking to certain existing faunas and floras. From the extraordinary manner in which European productions have recently spread over New Zealand, and have seized on places which must have been previously occupied by the indigenes, we must believe, that if all the animals and plants of Great Britain were set free in New Zealand, a multitude of British forms would in the course of time become thoroughly naturalised there, and would exterminate many of the natives. On the other hand, from the fact that hardly a single inhabitant of the 
southern hemisphere has become wild in any part of Europe, we may well doubt whether, if all the productions of New Zealand were set free in Great Britain, any considerable number would be enabled to seize on places now occupied by our native plants and animals. Under this point of view, the productions of Great Britain stand much higher in the scale than those of New Zealand. Yet the most skilful naturalist, from an examination of the species of the two countries, could not have foreseen this result.

Agassiz and several other highly competent judges insist that ancient animals resemble to a certain extent the embryos of recent animals belonging to the same classes; and that the geological succession of extinct forms is nearly parallel with the embryological development of existing forms. This view accords admirably well with our theory. In a future chapter I shall attempt to show that the adult differs from its embryo, owing to variations having supervened at a not early age, and having been inherited at a corresponding age. This process, whilst it leaves the embryo almost unaltered, continually adds, in the course of successive generations, more and more difference to the adult. Thus the embryo comes to be left as a sort of picture, preserved by nature, of the former and less modified condition of the species. This view may be true, and yet may never be capable of proof. Seeing, for instance, that the oldest known mammals, reptiles, and fishes strictly belong to their proper classes, though some of these old forms are in a slight degree less distinct from each other than are the typical members of the same groups at the present day, it would be vain to look for animals having the common embryological character of 
the Vertebrata, until beds rich in fossils are discovered far beneath the lowest Cambrian strata-a discovery of which the chance is small.

On the Succession of the same Types within the same Areas, during the later Tertiary periods.

Mr. Clift many years ago showed that the fossil mammals from the Australian caves were closely allied to the living marsupials of that continent. In South America a similar relationship is manifest, even to an uneducated eye, in the gigantic pieces of armour, like those of the armadillo, found in several parts of La Plata; and Professor Owen has shown in the most striking manner that most of the fossil mammals, buried there in such numbers, are related to South American types. This relationship is even more clearly seen in the wonderful collection of fossil bones made by MM. Lund and Clausen in the caves of Brazil. I was so much impressed with these facts that I strongly insisted, in 1839 and 1845, on this "law of the succession of types," - on "this wonderful relationship in the same continent between the dead and the living." Professor Owen has subsequently extended the same generalisation to the mammals of the old World. We see the same law in this author's restorations of the extinct and gigantic birds of New Zealand. We see it also in the birds of the caves of Brazil. Mr. Woodward has shown that the same law holds good with sea-shells, but, from the wide distribution of most molluscs, it is not well displayed by them. Other cases could be added, as the relation between the extinct and living land-shells of Madeira; and between the extinct and living brackish water-shells of the Aralo-Caspian Sea. 
Now what does this remarkable law of the succession of the same types within the same areas mean? He would be a bold man who, after comparing the present climate of Australia and of parts of South America, under the same latitude, would attempt to account, on the one hand through dissimilar physical conditions, for the dissimilarity of the inhabitants of these two continents; and, on the other hand through similarity of conditions, for the uniformity of the same types in each continent during the later tertiary periods. Nor can it be pretended that it is an immutable law that marsupials should have been chiefly or solely produced in Australia; or that Edentata and other American types should have been solely produced in South America. For we know that Europe in ancient times was peopled by numerous marsupials; and I have shown in the publications above alluded to, that in America the law of distribution of terrestrial mammals was formerly different from what it now is. North America formerly partook strongly of the present character of the southern half of the continent; and the southern half was formerly more closely allied, than it is at present, to the northern half. In a similar manner we know, from Falconer and Cautley's discoveries, that Northern India was formerly more closely related in its mammals to Africa than it is at the present time. Analogous facts could be given in relation to the distribution of marine animals.

On the theory of descent with modification, the great law of the long enduring, but not immutable, succession of the same types within the same areas, is at once explained; for the inhabitants of each quarter of the world will obviously tend to leave in that quarter, during the next succeeding period of time, closely allied 
CHAP. XI.] SAME TYPES IN THE SAME AREAS.

though in some degree modified descendants. If the inhabitants of one continent formerly differed greatly from those of another continent, so will their modified descendants still differ in nearly the same manner and degree. But after very long intervals of time, and after great geographical changes, permitting much intermigration, the feebler will yield to the more dominant forms, and there will be nothing immutable in the distribution of organic beings.

It may be asked in ridicule, whether I suppose that the megatherium and other allied huge monsters, which formerly lived in South America, have left behind them the sloth, armadillo, and anteater, as their degenerate descendants. This cannot for an instant be admitted. These huge animals have become wholly extinct, and have left no progeny. But in the caves of Brazil, there are many extinct species which are closely allied in size and in all other characters to the species still living in South America; and some of these fossils may have been the actual progenitors of the living species. It must not be forgotten that, on our theory, all the species of the same genus are the descendants of some one species; so that, if six genera, each having eight species, be found in one geological formation, and in a succeeding formation there be six other allied or representative genera each with the same number of species, then we may conclude that generally only one species of each of the older genera has left modified descendants, which constitute the new genera containing the several species; the other seven species of each old genus having died out and left no progeny. Or, and this will be a far commoner case, two or three species in two or three alone of the six older genera will be the parents of the new genera: the 
other species and the other old genera having become utterly extinct. In failing orders, with the genera and species decreasing in numbers as is the case with the Edentata of South America, still fewer genera and species will leave modified blood-descendants.

\section{Summary of the preceding and present Chapters.}

I have attempted to show that the geological record is extremely imperfect; that only a small portion of the globe has been geologically explored with care; that only certain classes of organic beings have been largely preserved in a fossil state; that the number both of specimens and of species, preserved in our museums, is absolutely as nothing compared with the number of generations which must have passed away even during a single formation; that, owing to subsidence being almost necessary for the accumulation of deposits rich in fossil species of many kinds, and thick enough to outlast future degradation, great intervals of time must have elapsed between most of our successive formations; that there has probably been more extinction during the periods of subsidence, and more variation during the periods of elevation, and during the latter the record will have been less perfectly kept; that each single formation has not been continuously deposited; that the duration of each formation is probably short compared with the average duration of specific forms; that migration has played an important part in the first appearance of new forms in any one area and formation; that widely ranging species are those which have varied most frequently, and have oftenest given rise to new species; that varieties have at first been local; and lastly, 
although each species must have passed through numerous transitional stages, it is probable that the periods, during which each underwent modification, though many and long as measured by years, have been short in comparison with the periods during which each remained in an unchanged condition. These causes, taken conjointly, will to a large extent explain whythough we do find many links-we do not find interminable varieties, connecting together all extinct and existing forms by the finest graduated steps. It should also be constantly borne in mind that any linking variety between two forms, which might be found, would be ranked, unless the whole chain could be perfectly restored, as a new and distinct species; for it is not pretended that we have any sure criterion by which species and varieties can be discriminated.

He who rejects this view of the imperfection of the geological record, will rightly reject the whole theory. For he may ask in vain where are the numberless transitional links which must formerly have connected the closely allied or representative species, found in the successive stages of the same great formation? He may disbelieve in the immense intervals of time which must have elapsed between our consecutive formations; he may overlook how important a part migration has played, when the formations of any one great region, as those of Europe, are considered; he may urge the apparent, but often falsely apparent, sudden coming in of whole groups of species. He may ask where are the remains of those infinitely numerous organisms which must have existed long before the Cambrian system was deposited? We now know that at least one animal did then exist; but I can answer this last question only 
by supposing that where our oceans now extend they have extended for an enormous period, and where our oscillating continents now stand they have stood since the commencement of the Cambrian system; but that, long before that epoch, the world presented a widely different aspect; and that the older continents formed of formations older than any known to us, exist now only as remnants in a metamorphosed condition, or lie still buried under the ocean.

Passing from these difficulties, the other great leading facts in palæontology agree admirably with the theory of descent with modification through variation and natural selection. We can thus understand how it is that new species come in slowly and successively; how species of different classes do not necessarily change together, or at the same rate, or in the same degree; yet in the long run that all undergo modification to some extent. The extinction of old forms is the almost inevitable consequence of the production of new forms. We can understand why, when a species has once disappeared, it never reappears. Groups of species increase in numbers slowly, and endure for unequal periods of time; for the process of modification is necessarily slow, and depends on many complex contingencies. The dominant species belonging to large and dominant groups tend to leave many modified descendants, which form new sub-groups and groups. As these are formed, the species of the less vigorous groups, from their inferiority inherited from a common progenitor, tend to become extinct together, and to leave no modified offspring on the face of the earth. But the utter extinction of a whole group of species has sometimes been a slow process, from the survival of a few descend- 
ants, lingering in protected and isolated situations. When a group has once wholly disappeared, it does not reappear; for the link of generation has been broken.

We can understand how it is that dominant forms which spread widely and yield the greatest number of varieties tend to people the world with allied, but modified, descendants; and these will generally succeed in displacing the groups which are their inferiors in the struggle for existence. Hence, after long intervals of time, the productions of the world appear to have changed simultaneously.

We can understand how it is that all the forms of life, ancient and recent, make together a few grand classes. We can understand, from the continued tenJency to divergence of character, why the more ancient a form is, the more it generally differs from those now living; why ancient and extinct forms often tend to fill up gaps between existing forms, sometimes blending two groups, previously classed as distinct, into one; but more commonly bringing them only a little closer together. The more ancient a form is, the more often it stands in some degree intermediate between groups now distinct; for the more ancient a form is, the more nearly it will be related to, and consequently resemble, the common progenitor of groups, since become widely divergent. Extinct forms are seldom directly intermediate between existing forms; but are intermediate only by a long and circuitous course through other extinct and different forms. We can clearly see why the organic remains of closely consecutive formations are closely allied; for they are closely linked together by generation. We can clearly see why the remains of an intermediate formation are intermediate in character. 
The inhabitants of the world at each successive period in its history have beaten their predecessors in the race for life, and are, in so far, higher in the scale, and their structure has generally become more specialised; and this may account for the common belief held by so many palæontologists, that organisation on the whole has progressed. Extinct and ancient animals resemble to a certain extent the embryos of the more recent animals belonging to the same classes, and this wonderful fact receives a simple explanation according to our views. The succession of the same types of structure within the same areas during the later geological periods ceases to be mysterious, and is intelligible on the principle of inheritance.

If then the geological record be as imperfect as many believe, and it may at least be asserted that the record cannot be proved to be much more perfect, the main objections to the theory of natural selection are greatly diminished or disappear. On the other hand, all the chief laws of palæontology plainly proclaim, as it seems to me, that species have been produced by ordinary generation: old forms having been supplanted by new and improved forms of life, the products of Variation and the Survival of the Fittest. 
Cgap. Xĩi.] GEOGRAPHICAL DISTRIBUtion.

\section{CHAPTER XII.}

GEOGRAPHICAL DISTRIBUTION.

Present distribution cannot be accounted for by differences in physical conditions-Importance of barriers-Affinity of the productions of the same continent-Centres of creation-Means of dispersal by changes of climate and of the level of the land, and by occasional means-Dispersal during the Glacial period -Alternate Glacial periods in the North and South.

IN considering the distribution of organic beings over the face of the globe, the first great fact which strikes us is, that neither the similarity nor the dissimilarity of the inhabitants of various regions can be wholly accounted for by climatal and other physical conditions. Of late, almost every author who has studied the subject has come to this conclusion. The case of America alone would almost suffice to prove its truth; for if we exclude the arctic and northern temperate parts, all authors agree that one of the most fundamental divisions in geographical distribution is that between the New and Old Worlds; yet if we travel over the vast American continent, from the central parts of the United States to its extreme southern point, we meet with the most diversified conditions; humid districts, arid deserts, lofty mountains, grassy plains, forests, marshes, lakes, and great rivers, under almost every temperature. There is hardly a climate or condition in the Old World which cannot be paralleled in the New 
-at least as closely as the same species generally require. No doubt small areas can be pointed out in the Old World hotter than any in the New World; but these are not inhabited by a fauna different from that of the surrounding districts; for it is rare to find a group of organisms confined to a small area, of which the conditions are peculiar in only a slight degree. Notwithstanding this general parallelism in the conditions of the Old and New Worlds, how widely different are their living productions!

In the southern hemisphere, if we compare large tracts of land in Australia, South Africa, and western South America, between latitudes $25^{\circ}$ and $35^{\circ}$, we shall find parts extremely similar in all their conditions, yet it would not be possible to point out three faunas and floras more utterly dissimiler. Or, again, we may compare the productions of South America south of lat. $35^{\circ}$ with those north of $25^{\circ}$, which consequently are separated by a space of ten degrees of latitude, and are exposed to considerably different conditions; yet they are incomparably more closely related to each other than they are to the productions of Australia or Africa under nearly the same climate. Analogous facts could be given with respect to the inhabitants of the sea.

A second great fact which strikes us in our general review is, that barriers of any kind, or obstacles to free migration, are related in a close and important manner to the differences between the productions of various regions. We see this in the great difference in nearly all the terrestrial productions of the New and old Worlds, excepting in the northern parts, where the land almost joins, and where, under a slightly different climate, there might have been free migration for the 
northern temperate forms, as there now is for the strictly arctic productions. We see the same fact in the great difference between the inhabitants of Australia, Africa, and South America under the same latitude; for these countries are almost as much isolated from each other as is possible. On each continent, also, we see the same fact; for on the opposite sides of lofty and continuous mountain-ranges, of great deserts and even of large rivers, we find different productions; though as mountain-chains, deserts, \&c., are not as impassable, or likely to have endured so long, as the oceans separating continents, the differences are very inferior in degree to those characteristic of distinct continents.

Turning to the sea, we find the same law. The marine inhabitants of the eastern and western shores of South America are very distinct, with extremely few shells, crustacea, or echinodermata in common; but Dr. Günther has recently shown that about thirty per cent. of the fishes are the same on the opposite sides of the isthmus of Panama; and this fact has led naturalists to believe that the isthmus was formerly open. Westward of the shores of America, a wide space of open ocean extends, with not an island as a halting-place for emigrants; here we have a barrier of another kind, and as soon as this is passed we meet in the eastern islands of the Pacific with another and totally distinct fauna. So that three marine faunas range far northward and southward in parallel lines not far from each other, under corresponding climates; but from being separated from each other by impassable barriers, either of land or open sea, they are almost wholly distinct. On the other hand, proceeding still farther westward from 
the eastern islands of the tropical parts of the Pacific, we encounter no impassable barriers, and we have innumerable islands as halting-places, or continuous coasts, until, after travelling over a hemisphere, we come to the shores of Africa; and over this vast space we meet with no well-defined and distinct marine faunas. Although so few marine animals are common to the above-named three approximate faunas of Eastern and Western America and the Eastern Pacific islands, yet many fishes range from the Pacific into the Indian Ocean, and many shells are common to the eastern islands of the Pacific and the eastern shores of Africa on almost exactly opposite meridians of longitude.

A third great fact, partly included in the foregoing statement, is the affinity of the productions of the same continent or of the same sea, though the species themselves are distinct at different points and stations. It is a law of the widest generality, and every continent offers innumerable instances. Nevertheless the naturalist, in travelling, for instance, from north to south, never fails to be struck by the manner in which successive groups of beings, specifically distinct, though nearly related, replace each other. He hears from closely allied, yet distinct kinds of birds, notes nearly similar, and sees their nests similarly constructed, but not quite alike, with eggs coloured in nearly the same manner. The plains near the Straits of Magellan are inhabited by one species of Rhea (American ostrich) and northward the plains of La Plata by another species of the same genus; and not by a true ostrich or emu, like those inhabiting Africa and Australia under the same latitude. On these same plains of La Plata we see the 
agouti and bizcacha, animals having nearly the same habits as our hares and rabbits, and belonging to the same order of Rodents, but they plainly display an American type of structure. We ascend the lofty peaks of the Cordillera, and we find an alpine species of bizcacha; we look to the waters, and we do not find the beaver or musk-rat, but the coypu and capybara, rodents of the S. American type. Innumerable other instances could be given. If we look to the islands off the American shore, however much they may differ in geological structure, the inhabitants are essentially American, though they may be all peculiar species. We may look back to past ages, as shown in the last chapter, and we find American types then prevailing on the American continent and in the American seas. We see in these facts some deep organic bond, throughout space and time, over the same areas of land and water, independently of physical conditions. The naturalist must be dull who is not led to enquire what this bond is.

The bond is simply inheritance, that cause which alone, as far as we positively know, produces organisms quite like each other, or, as we see in the case of varieties, nearly alike. The dissimilarity of the inhabitants of different regions may be attributed to modification through variation and natural selection, and probably in a subordinate degree to the definite influence of different physical conditions. The degrees of dissimilarity will depend on the migration of the more dominant forms of life from one region into another having been more or less effectually prevented, at periods more or less remote;-on the nature and number of the former immigrants; - and on the action of the inhabitants on 
each other in leading to the preservation of different modifications; the relation of organism to organism in the struggle for life being, as I have already often remarked, the most important of all relations. Thus the high importance of barriers comes into play by checking migration; as does time for the slow process of modification through natural selection. Widely-ranging species, abounding in individuals, which have already triumphed over many competitors in their own widely-extended homes, will have the best chance of seizing on new places, when they spread into new countries. In their new homes they will be exposed to new conditions, and will frequently undergo further modification and improvement; and thus they will become still further victorious, and will produce groups of modified descendants. On this principle of inheritance with modification we can understand how it is that sections of genera, whole genera, and even families, are confined to the same areas, as is so commonly and notoriously the case.

There is no evidence, as was remarked in the last chapter, of the existence of any law of necessary development. As the variability of each species is an independent property, and will be taken advantage of by natural selection, only so far as it profits each individual in its complex struggle for life, so the amount of modification in different species will be no uniform quantity. If a number of species, after having long competed with each other in their old home, were to migrate in a body into a new and afterwards isolated country, they would be little liable to modification; for neither migration nor isolation in themselves effect anything. These principles come into play only by bring- 
ing organisms into new relations with each other and in a lesser degree with the surrounding physical conditions. As we have seen in the last chapter that some forms have retained nearly the same character from an enormously remote geological period, so certain species have migrated over vast spaces, and have not become greatly or at all modified.

According to these views, it is obvious that the several species of the same genus, though inhabiting the most distant quarters of the world, must originally have proceeded from the same source, as they are descended from the same progenitor. In the case of those species which have undergone during whole geological periods little modification, there is not much difficulty in believing that they have migrated from the same region; for during the vast geographical and climatal changes which have supervened since ancient times, almost any amount of migration is possible. But in many other cases, in which we have reason to believe that the species of a genus have been produced within comparatively recent times, there is great difficulty on this head. It is also obvious that the individuals of the same species, though now inhabiting distant and isolated regions, must have proceeded from one spot, where their parents were first produced: for, as has been explained, it is incredible that individuals identically the same should have been produced from parents specifically distinct.

Single Centres of supposed Creation.-We are thus brought to the question which has been largely discussed by naturalists, namely, whether species have been created at one or more points of the earth's surface. Undoubtedly there are many cases of extreme 
difficulty in understanding how the same species could possibly have migrated from some one point to the seviral distant and isolated points, where now found. Nevertheless the simplicity of the view that each species was first produced within a single region captivates the mind. He who rejects it, rejects the vera causa of ordinary generation with subsequent migration, and calls in the agency of a miracle. It is universally admitted, that in most cases the area inhabited by a species is continuous; and that when a plant or animal inhabits two points so distant from each other, or with an interval of such a nature, that the space could not have been easily passed over by migration, the fact is given as something remarkable and exceptional. The incapacity of migrating across a wide sea is more clear in the case of terrestrial mammals than perhaps with any other organic beings; and, accordingly, we find no inexplicable instances of the same mammals inhabiting distant points of the world. No geologist feels any difficulty in Great Britain possessing the same quadrupeds with the rest of Europe, for they were no doubt once united. But if the same species can be produced at two separate points, why do we not find a single mammal common to Europe and Australia or South America? The conditions of life are nearly the same, so that a multitude of European animals and plants have become naturalised in America and Australia; and some of the aboriginal plants are identically the same at these distant points of the northern and southern hemispheres? The answer, as I believe, is, that mammals have not been able to migrate, whereas some plants, from their varied means of dispersal, have migrated across the wide and broken interspaces. The great 
and striking influence of barriers of all kinds, is intelligible only on the view that the great majority of species have been produced on one side, and have not been able to migrate to the opposite side. Some few families, many sub-families, very many genera, and a still greater number of sections of genera, are confined to a single region; and it has been observed by several naturalists that the most natural genera, or those genera in which the species are most closely related to each other, are generally confined to the same country, or if they have a wide range that their range is continuous. What a strange anomaly it would be, if a directly opposite rule were to prevail, when we go down one step lower in the series, namely, to the individuals of the same species, and these had not been, at least at first, confined to some one region!

Hence it seems to me, as it has to many other naturalists, that the view of each species having been produced in one area alone, and having subsequently migrated from that area as far as its powers of migration and subsistence under past and present conditions permitted, is the most probable. Undoubtedly many cases occur, in which we cannot explain how the same species could have passed from one point to the other. But the geographical and climatal changes which have certainly occurred within recent geological times, must. have rendered discontinuous the formerly continuous range of many species. So that we are reduced to consider whether the exceptions to continuity of range are so numerous and of so grave a nature, that we ought to give up the belief, rendered probable by general considerations, that each species has been produced within one area and has migrated thence as far as it could. 
It would be hopelessly tedious to discuss all the exceptional cases of the same species, now living at distant and separated points, nor do I for a moment pretend that any explanation could be offered of many instances. But, after some preliminary remarks, I will discuss a few of the most striking classes of facts; namely, the existence of the same species on the summits of distant mountain ranges, and at distant points in the aretic and antarctic regions; and secondly (in the following chapter), the wide distribution of freshwater productions; and thirdly, the occurrence of the same terrestrial species on islands and on the nearest mainland, though separated by hundreds of miles of open sea. If the existence of the same species at distant and isolated points of the earth's surface, can in manyinstances be explained on the view of each species having migrated from a single birthplace; then, considering our ignorance with respect to former climatal and geographical changes and to the various occasional means of transport, the belief that a single birthplace is the law, seems to me incomparably the safest.

In discussing this subject, we shall be enabled at the same time to consider a point equally important for us, namely, whether the several species of a genus which must on our theory all be descended from a common progenitor, can have migrated, undergoing modification during their migration, from some one area. If, when most of the species inhabiting one region are different from those of another region, though closely allied to them, it can be shown that migration from the one region to the other has probably occurred at some former period, our general view will be much strengthened; for the explanation is obvious on the principle of 
descent with modification. A volcanic island, for instance, upheaved and formed at the distance of a few hundreds of miles from a continent, would probably receive from it in the course of time a few colonists, and their descendants, though modified, would still be related by inheritance to the inhabitants of that continent. Cases of this nature are common, and are, as we shall hereafter see, inexplicable on the theory of independent creation. This view of the relation of the species of one region to those of another, does not differ much from that advanced by Mr. Wallace, who concludes that " every species has come into existence coincident both in space and time with a pre-existing closely allied species." And it is now well known that he attributes this coincidence to descent with modification.

The question of single or multiple centres of creation differs from another though allied question,namely, whether all the individuals of the same species are descended from a single pair, or single hermaphrodite, or whether, as some authors suppose, from many individuals simultaneously created. With organic beings which never intercross, if such exist, each species must be descended from a succession of modified varieties, that have supplanted each other, but have never blended with other individuals or varieties of the same species; so that, at each successive stage of modification, all the individuals of the same form will be descended from a single parent. But in the great majority of cases, namely, with all organisms which habitually unite for each birth, or which occasionally intercross, the individuals of the same species inhabiting the same area will be kept nearly uniform by intercrossing; so that many individuals will go on simultaneously changing, and the whole 
amount of modification at each stage will not be due to descent from a single parent. To illustrate what I mean: our English race-horses differ from the horses of every other breed; but they do not owe their difference and superiority to descent from any single pair, but to continued care in the selecting and training of many individuals during each generation.

Before discussing the three classes of facts, which I have selected as presenting the greatest amount of difficulty on the theory of "single centres of creation," I must say a few words on the means of dispersal.

\section{Means of Dispersal.}

Sir C. Lyell and other authors have ably treated this subject. I can give here only the briefest abstract of the more important facts. Change of climate must have had a powerful influence on migration. A region now impassable to certain organisms from the nature of its climate, might have been a high road for migration, when the climate was different. I shall, however, presently have to discuss this branch of the subject in some detail. Changes of level in the land must also have been highly influential: a narrow isthmus now separates two marine faunas; submerge it, or let it formerly have been submerged, and the two faunas will now blend together, or may formerly have blended. Where the sea now extends, land may at a former period have connected islands or possibly even continents together, and thus have allowed terrestrial productions to pass from one to the other. No geologist disputes that great mutations of level have occurred within the period of existing organisms. Edward Forbes insisted that all the islands in the Atlantic must have been recently 
connected with Europe or Africa, and Europe likewise with America. Other authors have thus hypothetically bridged over every ocean, and united almost every island with some mainland. If indeed the arguments used by Forbes are to be trusted, it must be admitted that scarcely a single island exists which has not recently been united to some continent. This view cuts the Gordian knot of the dispersal of the same species to the more distant points, and removes many a difficulty; but to the best of my judgment we are not authorised in admitting such enormous geographical changes within the period of existing species. It seems to me that we have abundant evidence of great oscillations in the level of the land or sea; but not of such vast changes in the position and extension of our continents, as to have united them within the recent period to each other and to the several intervening oceanic islands. I freely admit the former existence of many islands, now buried beneath the sea, which may have served as halting-places for plants and for many animals during their migration. In the coral-producing oceans such sunken islands are now marked by rings of coral or atolls standing over them. Whenever it is fully admitted, as it will some day be, that each species has proceeded from a single birthplace, and when in the course of time we know something definite about the means of distribution, we shall be enabled to speculate with security on the former extension of the land. But I do not believe that it will ever be proved that within the recent period most of our continents which now stand quite separate have been continuously, or almost continuously united with each other, and with the many existing oceanic islands. Several facts in distribution,--such as the great difference 
in the marine faunas on the opposite sides of almost every continent,- - the close relation of the tertiary inhabitants of several lands and even seas to their present inhabitants,- - the degree of affinity between the mammals inhabiting islands with those of the nearest continent, being in part determined (as we shall hereafter see) by the depth of the intervening ocean,- -these and other such facts are opposed to the admission of such prodigious geographical revolutions within the recent period, as are necessary on the view advanced by Forbes and admitted by his followers. The nature and relative proportions of the inhabitants of oceanic islands are likewise opposed to the belief of their former continuity with continents. Nor does the almost universally volcanic composition of such islands favour the admission that they are the wrecks of sunken continents;-if they had originally existed as continental mountain ranges, some at least of the islands would have been formed, like other mountain summits, of granite, metamorphic schists, old fossiliferous and other rocks, instead of consisting of mere piles of volcanic matter.

I must now say a few words on what are called accidental means, but which more properly should be called occasional means of distribution. I shall here confine myself to plants. In botanical works, this or that plant is often stated to be ill adapted for wide dissemination; but the greater or less facilities for transport across the sea may be said to be almost wholly unknown. Until I tried, with Mr. Berkeley's aid, a few experiments, it was not even known how far seeds could resist the injurious action of sea-water. To my surprise I found that out of 87 kinds, 64 germinated after an immersion of 28 days, and a few survived an immer- 
sion of 137 days. It deserves notice that certain orders were far more injured than others: nine Leguminosæ were tried, and, with one exception, they resisted the salt-water badly; seven species of the allied orders, $\mathrm{Hy}$ drophyllaceæ and Polemoniaceæ, were all killed by a month's immersion. For convenience' sake I chiefly tried small seeds without the capsule or fruit; and as all of these sank in a few days they could not have been floated across wide spaces of the sea, whether or not they were injured by the salt-water. Afterwards I tried some larger fruits, capsules, \&c., and some of these floated for a long time. It is well known what a difference there is in the buoyancy of green and seasoned timber; and it occurred to me that floods would often wash into the sea dried plants or branches with seed-capsules or fruit attached to them. Hence I was led to dry the stems and branches of 94 plants with ripe fruit, and to place them on sea-water. The majority sank rapidly, but some which, whilst green, floated for a short time, when dried floated much longer; for instance, ripe hazelnuts sank immediately, but when dried they floated for 90 days, and afterwards when planted germinated; an asparagus-plant with ripe berries floated for 23 days, when dried it floated for 85 days, and the seeds afterwards germinated; the ripe seeds of Helosciadium sank in two days, when dried they floated for above 90 days, and afterwards germinated. Altogether, out of the 94 dried plants, 18 floated for above 28 days; and some of the 18 floated for a very much longer period. So that as $\frac{64}{87}$ kinds of seeds germinated after an immersion of 28 days; and as $\frac{18}{94}$ distinct species with ripe fruit (but not all the same species as in the foregoing experiment) floated, after being dried, for above 28 days, we may 
conclude, as far as anything can be inferred from these scanty facts, that the seeds of $\frac{14}{100}$ kinds of plants of any country might oe floated by sea-currents during 28 days, and would retain their power of germination. In Johnston's Physical Atlas, the average rate of the several Atlantic currents is 33 miles per diem (some currents running at the rate of 60 miles per diem); on this average, the seeds of $\frac{14}{100}$ plants belonging to one country might be floated across 924 miles of sea to another country, and when stranded, if blown by an inland gale to a favourable spot, would germinate.

Subsequently to my experiments, M. Martens tried similar ones, but in a much better manner, for he placed the seeds in a box in the actual sea, so that they were alternately wet and exposed to the air like really floating plants. He tried 98 seeds, mostly different from mine; but he chose many large fruits and likewise seeds from plants which live near the sea; and this would have favoured both the average length of their flotation and their resistance to the injurious action of the salt-water. On the other hand, he did not previously dry the plants or branches with the fruit; and this, as we have seen, would have caused some of them to have floated much longer. The result was that $\frac{1}{9} \frac{8}{8}$ of his seeds of different kinds floated for 42 days, and were then capable of germination. But I do not doubt that plants exposed to the waves would float for a less time than those protected from violent movement as in our experiments. Therefore it would perhaps be safer to assume that the seeds of about $\frac{10}{100}$ plants of a flora, after having been dried, could be floated across a space of sea 900 miles in width, and would then germinate. The fact of the larger fruits often floating longer than 
the small, is interesting; as plants with large seeds or fruit which, as Alph. de Candolle has shown, generally have restricted ranges, could hardly be transported by any other means.

Seeds may be occasionally transported in another manner. Drift timber is thrown up on most islands, even on those in the midst of the widest oceans; and the natives of the coral-islands in the Pacific procure stones for their tools, solely from the roots of drifted trees, these stones being a valuable royal tax. I find that when irregularly shaped stones are embedded in the roots of trees, small parcels of earth are frequently enclosed in their interstices and behind them,--so perfectly that not a particle could be washed away during the longest transport: out of one small portion of earth thus completely enclosed by the roots of an oak about 50 years old, three dicotyledonous plants germinated: I am certain of the accuracy of this observation. Again, I can show that the carcases of birds, when floating on the sea, sometimes escape being immediately devoured: and many kinds of seeds in the crops of floating birds long retain their vitality: peas and vetches, for instance, are killed by even a few days' immersion in sea-water; but some taken out of the crop of a pigeon, which had floated on artificial sea-water for 30 days, to my surprise nearly all germinated.

Living birds can hardly fail to be highly effective agents in the transportation of seeds. I could give many facts showing how frequently birds of many kinds are blown by gales to vast distances across the ocean. We may safely assume that under such circumstances their rate of flight would often be 35 miles an hour; and some authors have given a far higher estimate. I 
have never seen an instance of nutritious seeds passing through the intestines of a bird; but hard seeds of fruit pass uninjured through even the digestive organs of a turkey. In the course of two months, I picked up in my garden 12 kinds of seeds, out of the excrement of small birds, and these seemed perfect, and some of them, which were tried, germinated. But the following fact is more important: the crops of birds do not secrete gastric juice, and do not, as I know by trial, injure in the least the germination of seeds; now, after a bird has found and devoured a large supply of food, it is positively asserted that all the grains do not pass into the gizzard for twelve or even eighteen hours. A bird in this interval might easily be blown to the distance of 500 miles, and hawks are known to look out for tired birds, and the contents of their torn crops might thus readily get scattered. Some hawks and owls bolt their prey whole, and, after an interval of from twelve to twenty hours, disgorge pellets, which, as I know from experiments made in the Zoological Gardens, include seeds capable of germination. Some seeds of the oat, wheat, millet, canary, hemp, clover, and beet germinated after having been from twelve to twenty-one hours in the stomachs of different birds of prey; and two seeds of beet grew after having been thus retained for two days and fourteen hours. Fresh-water fish, I find, eat seeds of many land and water plants; fish are frequently devoured by birds, and thus the seeds might be transported from place to place. I forced many kinds of seeds into the stomachs of dead fish, and then gave their bodies to fishing-eagles, storks, and pelicans; these birds, after an interval of many hours, either rejected the seeds in pellets or passed them in their excre. 
ment; and several of these seeds retained the power of germination. Certain seeds, however, were always killed by this process.

Locusts are sometimes blown to great distances from the land; I myself caught one $3 \% 0$ miles from the coast of Africa, and have heard of others caught at greater distances. The Rev. R. T. Lowe informed Sir C. Lyell that in November 1844 swarms of locusts visited the island of Madeira. They were in countless numbers, as thick as the flakes of snow in the heaviest snowstorm. and extended upwards as far as could be seen with a telescope. During two or three days they slowly careered round and round in an immense ellipse, at least five or six miles in diameter, and at night alighted on the taller trees, which were completely coated with them. They then disappeared over the sea, as suddenly as they had appeared, and have not since visited the island. Now, in parts of Natal it is believed by some farmers, though on insufficient evidence, that injurious seeds are introduced into their grass-land in the dung left by the great flights of locusts which often visit that country. In consequence of this belief Mr. Weale sent me in a letter a small packet of the dried pellets, out of which I extracted under the microscope several seeds, and raised from them seven grass plants, belonging to two species, of two genera. Hence a swarm of locusts, such as that which visited Madeira, might readily be the means of introducing several kinds of plants into an island lying far from the mainland.

Although the beaks and feet of birds are generally clean, earth sometimes adheres to them: in one case I removed sixty-one grains, and in another case twentytwo grains of dry argillaceous earth from the foot of a 
partridge, and in the earth there was a pebble as large as the seed of a vetch. Here is a better case: the leg of a woodcock was sent to me by a friend, with a little cake of dry earth attached to the shank, weighing only nine grains; and this contained a seed of the toad-rush (Juncus bufonius) which germinated and flowered. Mr. Swaysland, of Brighton, who during the last forty years has paid close attention to our migratory birds, informs me that he has often shot wagtails (Motacillæ), wheatears, and whinchats (Saxicolæ), on their first arrival on our shores, before they had alighted; and he has several times noticed little cakes of earth attached to their feet. Many facts could be given showing how generally soil is charged with seeds. For instance, Prof. Newton sent me the leg of a red-legged partridge (Caccabis rufa) which had been wounded and could not fly, with a ball of hard earth adhering to it, and weighing six and a half ounces. The earth had been kept for three years, but when broken, watered and placed under a bell glass, no less than 82 plants sprung from it: these consisted of 12 monocotyledons, including the common oat, and at least one kind of grass, and of 70 dicotyledons, which consisted, judging from the young leaves, of at least three distinct species. With such facts before us, can we doubt that the many birds which are annually blown by gales across great spaces of ocean, and which annually migrate - for instance, the millions of quails across the Mediterranean-must occasionally transport a few seeds embedded in dirt adhering to their feet or beaks? But I shall have to recur to this subject.

As icebergs are known to be sometimes loaded with earth and stones, and have even carried brushwood, 
bones, and the nest of a land-bird, it can hardly be doubted that they must occasionally, as suggested by Lyell, have transported seeds from one part to another of the arctic and antarctic regions; and during the Glacial period from one part of the now temperate regions to another. In the Azores, from the large number of plants common to Europe, in comparison with the species on the other islands of the Atlantic, which stand nearer to the mainland, and (as remarked by Mr. H. C. Watson) from their somewhat northern character in comparison with the latitude, I suspected that these islands had been partly stocked by ice-borne seeds, during the Glacial epoch. At my request Sir C. Lyell wrote to M. Hartung to inquire whether he had observed erratic boulders on these islands, and he answered that he had found large fragments of granite and other rocks, which do not occur in the archipelago. Hence we may safely infer that icebergs formerly landed their rocky burthens on the shores of these mid-ocean islands, and it is at least possible that they may have brought thither some few seeds of northern plants.

Considering that these several means of transport, and that other means, which without doubt remain to be discovered, have been in action year after year for tens of thousands of years, it would, I think, be a marvellous fact if many plants had not thus become widely transported. These means of transport are sometimes called accidental, but this is not strictly correct: the currents of the sea are not accidental, nor is the direction of prevalent gales of wind. It should be observed that scarcely any means of transport would carry seeds for very great distances: for seeds do not retain their 
vitality when exposed for a great length of time to the action of sea-water; nor could they be long carried in the crops or intestines of birds. These means, however, would suffice for occasional transport across tracts of sea some hundred miles in breadth, or from island to island, or from a continent to a neighbouring island, but not from one distant continent to another. The floras of distant continents would not by such means become mingled; but would remain as distinct as they now are. The currents, from their course, would never bring seeds from North America to Britain, though they might and do bring seeds from the West Indies to our western shores, where, if not killed by their very long immersion in salt water, they could not endure our climate. Almost every year, one or two land-birds are blown across the whole Atlantic Ocean, from North America to the western shores of Ireland and England; but seeds could be transported by these rare wanderers only by one means, namely, by dirt adhering to their feet or beaks, which is in itself a rare accident. Even in this case, how small would be the chance of a seed falling on favourable soil, and coming to maturity! But it would be a great error to argue that because a wellstocked island, like Great Britain, has not, as far as is known (and it would be very difficult to prove this), received within the last few centuries, through occasional means of transport, immigrants from Europe or any other continent, that a poorly-stocked island, though standing more remote from the mainland, would not receive colonists by similar means. Out of a hundred kinds of seeds or animals transported to an island, even if far less well-stocked than Britain, perhaps not more than one would be so well fitted to its new home, 
as to become naturalised. But this is no valid argument against what would be effected by occasional means of transport, during the long lapse of geological time, whilst the island was being upheaved, and before it had become fully stocked with inhabitants. On almost bare land, with few or no destructive insects or birds living there, nearly every seed which chanced to arrive, if fitted for the climate, would germinate and survive.

\section{Dispersal during the Glacial Period.}

The identity of many plants and animals, on mountain-summits, separated from each other by hundreds of miles of lowlands, where Alpine species could not possibly exist, is one of the most striking cases known of the same species living at distant points, without the apparent possibility of their having migrated from one point to the other. It is indeed a remarkable fact to see so many plants of the same species living on the snowy regions of the Alps or Pyrenees, and in the extreme northern parts of Europe; but it is far more remarkable, that the plants on the White Mountains, in the United States of America, are all the same with those of Labrador, and nearly all the same, as we hear from Asa Gray, with those on the loftiest mountains of Europe. Even as long ago as 1747, such facts led Gmelin to conclude that the same species must have been independently created at many distinct points; and we might have remained in this same belief, had not Agassiz and others called vivid attention to the Glacial period, which, as we shall immediately see, affords a simple explanation of these facts. We have evidence of almost every conceivable kind, organic and 
inorganic, that, within a very recent geological period, central Europe and North America suffered under an arctic climate. The ruins of a house burnt by fire do not tell their tale more plainly than do the mountains of Scotland and Wales, with their scored flanks, polished surfaces, and perched boulders, of the icy streams with which their valleys were lately filled. So greatly has the climate of Europe changed, that in Northern Italy, gigantic moraines, left by old glaciers, are now clothed by the vine and maize. Throughout a large part of the United States, erratic boulders and scored rocks plainly reveal a former cold period.

The former influence of the glacial climate on the distribution of the inhabitants of Europe, as explained by Edward Forbes, is substantially as follows. But we shall follow the changes more readily, by supposing a new glacial period slowly to come on, and then pass away, as formerly occurred. As the cold came on, and as each more southern zone became fitted for the inhabitants of the north, these would take the places of the former inhabitants of the temperate regions. The latter, at the same time, would travel further and further southward, unless they were stopped by barriers, in which case they would perish. The mountains would become covered with snow and ice, and their former Alpine inhabitants would descend to the plains. By the time that the cold had reached its maximum, we should have an arctic fauna and flora, covering the central parts of Europe, as far south as the Alps and Pyrenees, and even stretching into Spain. The now temperate regions of the United States would likewise be covered by arctic plants and animals and these would be nearly the same with those of Europe; for the 
present circumpolar inhabitants, which we suppose to have everywhere travelled southward, are remarkably uniform round the world.

As the warmth returned, the arctic forms would retreat northward, closely followed up in their retreat by the productions of the more temperate regions. And as the snow melted from the bases of the mountains, the arctic forms would seize on the cleared and thawed ground, always ascending, as the warmth increased and the snow still further disappeared, higher and higher, whilst their brethren were pursuing their northern journey. Hence, when the warmth had fully returned, the same species, which had lately lived together on the European and North American lowlands, would again be found in the arctic regions of the Old and New Worlds, and on many isolated mountain-summits far distant from each other.

Thus we can understand the identity of many plants at points so immensely remote as the mountains of the United States and those of Europe. We can thus also understand the fact that the Alpine plants of each mountain-range are more especially related to the arctic forms living due north or nearly due north of them: for the first migration when the cold came on, and the re-migration on the returning warmth, would generally have been due south and north. The Alpine plants, for example, of Scotland, as remarked by Mr. H. C. Watson, and those of the Pyrenees, as remarked by Ramond, are more especially allied to the plants of northern Scandinavia; those of the United States to Labrador; those of the mountains of Siberia to the arctic regions of that country. These views, grounded as they are on the perfectly well-ascertained occurrence 
of a former Glacial period, seem to me to explain in so satisfactory a manner the present distribution of the Alpine and Arctic productions of Europe and America, that when in other regions we find the same species on distant mountain-summits, we may almost conclude, without other evidence, that a colder climate formerly permitted their migration across the intervening lowlands, now become too warm for their existence.

As the arctic forms moved first southward and afterwards backwards to the north, in unison with the changing climate, they will not have been exposed during their long migrations to any great diversity of temperature; and as they all migrated in a body together, their mutual relations will not have been much disturbed. Hence, in accordance with the principles inculcated in this volume, these forms will not have been liable to much modification. But with the Alpine productions, left isolated from the moment of the returning warmth, first at the bases and ultimately on the summits of the mountains, the case will have been somewhat different; for it is not likely that all the same arctic species will have been left on mountain-ranges far distant from each other, and have survived there ever since; they will also in all probability, have become mingled with ancient Alpine species, which must have existed on the mountains before the commencement of the Glacial epoch, and which during the coldest period will have been temporarily driven down to the plains; they will, also, have been subsequently exposed to somewhat different climatal influences. Their mutual relations will thus have been in some degree disturbed; consequently they will have been liable to modification; and they have been modified; for if we compare the present 
Alpine plants and animals of the several great European mountain-ranges one with another, though many of the species remain identically the same, some exist as varieties, somt as doubtful forms or sub-species, and some as distinct yet closely allied species representing each other on the several ranges.

In the foregoing illustration I have assumed that at the commencement of our imaginary Glacial period, the arctic productions were as uniform round the polar regions as they are at the present day. But it is also necessary to assume that many sub-arctic and some few temperate forms were the same round the world, for some of the species which now exist on the lower mountain-slopes and on the plains of North America and Europe are the same; and it may be asked how I account for this degree of uniformity in the sub-arctic and temperate forms round the world, at the commencement of the real Glacial period. At the present day, the sub-arctic and northern temperate productions of the Old and New Worlds are separated from each other by the whole Atlantic Ocean and by the northern part of the Pacific. During the Glacial period, when the inhabitants of the Old and New Worlds lived farther southwards than they do at present, they must have been still more completely separated from each other by wider spaces of ocean; so that it may well be asked how the same species could then or previously have entered the two continents. The explanation, I believe, lies in the nature of the climate before the commencement of the Glacial period. At this, the newer Pliocene period, the majority of the inhabitants of the world were specifically the same as now, and we have good reason to believe that the climate was warmer than at the present 
day. Hence we may suppose that the organisms which now live under latitude $60^{\circ}$, lived during the Pliocene period farther north under the Polar Circle, in latitude $66^{\circ}-67^{\circ}$; and that the present arctic productions then lived on the broken land still nearer to the pole. Now, if we look at a terrestrial globe, we see under the Polar Circle that there is almost continuous land from western Europe, through Siberia, to eastern America. And this continuity of the circumpolar land, with the consequent freedom under a more favourable climate for intermigration, will account for the supposed uniformity of the sub-arctic and temperate productions of the Old and New Worlds, at a period anterior to the Glacial epoch.

Believing, from reasons before alluded to, that our continents have longremained in nearly the same relative position, though subjected to great oscillations of level, I am strongly inclined to extend the above view, and to infer that during some still earlier and still warmer period, such as the older Pliocene period, a large number of the same plants and animals inhabited the almost continuous circumpolar land; and that these plants and animals, both in the Old and New Worlds, began slowly to migrate southwards as the climate became less warm, long before the commencement of the Glacial period. We now see, as I believe, their descendants, mostly in a modified condition, in the central parts of Europe and the United States. On this view we can understand the relationship with very little identity, between the productions of North America and Europe, -a relationship which is highly remarkable, considering the distance of the two areas, and their separation by the whole Atlantic Ocean. We can further understand the singular fact remarked on by several observers 
that the productions of Europe and America during the later tertiary stages were more closely related to each other than they are at the present time; for during these warmer periods the northern parts of the old and New Worlds will have been almost continuously united by land, serving as a bridge, since rendered impassable by cold, for the intermigration of their inhabitants.

During the slowly decreasing warmth of the Pliocene period, as soon as the species in common, which inhabited the New and old Worlds, migrated south of the Polar Circle, they will have been completely cut off from each other. This separation, as far as the more temperate productions are concerned, must have taken place long ages ago. As the plants and animals migrated southward, they will have become mingled in the one great region with the native American productions, and would have had to compete with them; and in the other great region, with those of the Old World. Consequently we have here everything favourable for much modification,-for far more modification than with the Alpine productions, left isolated, within a much more recent period, on the several mountain-ranges and on the arctic lands of Europe and N. America. Hence it has come, that when we compare the now living productions of the temperate regions of the New and Old Worlds, we find very few identical species (though Asa Gray has lately shown that more plants are identical than was formerly supposed), but we find in every great class many forms, which some naturalists rank as geographical races, and others as distinct species; and a host of closely allied or representative forms which are ranked by all naturalists as specifically distinct. 
As on the land, so in the waters of the sea, a slow southern migration of a marine fauna, which, during the Pliocene or even a somewhat earlier period, was nearly uniform along the continuous shores of the Polar Circle, will account, on the theory of modification, for many closely allied forms now living in marine areas completely sundered. Thus, I think, we can understand the presence of some closely allied, still existing and extinct tertiary forms, on the eastern and western shores of temperate North America; and the still more striking fact of many closely allied crustaceans (as described in Dana's admirable work), some fish and other marine animals, inhabiting the Mediterranean and the seas of Japan,- -these two areas being now completely separated by the breadth of a whole continent and by wide spaces of ocean.

These cases of close relationship in species either now or formerly inhabiting the seas on the eastern and western shores of North America, the Mediterranean and Japan, and the temperate lands of North America and Europe, are inexplicable on the theory of creation. We cannot maintain that such species have been created alike, in correspondence with the nearly similar physical conditions of the areas; for if we compare, for instance, certain parts of South America with parts of South Africa or Australia, we see countries closely similar in all their physical conditions, with their inhabitants utterly dissimilar.

Alternate Glacial Periods in the North and South.

But we must return to our more immediate subject. I am convinced that Forbes's view may be largely ex- 
tended. In Europe we meet with the plainest evidence of the Glacial period, from the western shores of Britain to the Oural range, and southward to the Pyrenees. We may infer from the frozen mammals and nature of the mountain vegetation, that Siberia was similarly affected. In the Lebanon, according to Dr. Hooker, perpetual snow formerly covered the central axis, and fed glaciers which rolled 400 feet down the ralleys. The same observer has recently found great moraines at a low level on the Atlas range in N. Africa. Along the Himalaya, at points 900 miles apart, glaciers have left the marks of their former low descent; and in Sikkim, Dr. Hooker saw maize growing on ancient and gigantic moraines. Southward of the Asiatic continent, on the opposite side of the equator, we know, from the excellent researches of Dr. J. Haast and Dr. Hector, that in New Zealand immense glaciers formerly descended to a low level; and the same plants found by Dr. Hooker on widely separated mountains in this island tell the same story of a former cold period. From facts communicated to me by the Rev. W. B. Clarke, it appears also that there are traces of former glacial action on the mountains of the south-eastern corner of Australia.

Looking to America; in the northern half, ice-borne fragments of rock have been observed on the eastern side of the continent, as far south as lat. $36^{\circ}-37^{\circ}$, and on the shores of the Pacific, where the climate is now so different, as far south as lat. $46^{\circ}$. Erratic boulders have, also, been noticed on the Rocky Mountains. In the Cordillera of South America, nearly under the equator, glaciers once extended far below their present level. In Central Chile I examined a vast mound of 
detritus with great boulders, crossing the Portillo valley, which there can hardly be a doubt once formed a huge moraine; and Mr. D. Forbes informs me that he found in various parts of the Cordillera, from lat. $13^{\circ}$ to $30^{\circ} \mathrm{S}$., at about the height of 12,000 feet, deeply-furrowed rocks, resembling those with which he was familiar in Norway, and likewise great masses of detritus, including grooved pebbles. Along this whole space of the Cordillera true glaciers do not now exist even at much more considerable heights. Farther south on both sides of the continent, from lat. $41^{\circ}$ to the southernmost extremity, we have the clearest evidence of former glacial action, in numerous immense boulders transported far from their parent source.

From these several facts, namely from the glacial action having extended all round the northern and southern hemispheres-from the period having been in a geological sense recent in both hemispheres-from its having lasted in both during a great length of time, as may be inferred from the amount of work effectedand lastly from glaciers having recently descended to a low level along the whole line of the Cordillera, it at one time appeared to me that we could not avoid the conclusion that the temperature of the whole world had been simultaneously lowered during the Glacial period. But now Mr. Croll, in a series of admirable memoirs, has attempted to show that a glacial condition of climate is the result of various physical causes, brought into operation by an increase in the eccentricity of the earth's orbit. All these causes tend towards the same end; but the most powerful appears to be the indirect influence of the eccentricity of the orbit upon oceanic currents. According to Mr. Croll, cold periods 
regularly recur every ten or fifteen thousand years; and these at long intervals are extremely severe, owing to certain contingencies, of which the most important, as Sir C. Lyell has shown, is the relative position of the land and water. Mr. Croll believes that the last great Glacial period occurred about 240,000 years ago, and endured with slight alterations of climate for about 160,000 years. With respect to more ancient Glacial periods, several geclogists are convinced from direct evidence that such occurred during the Miocene and Eocene formations, not to mention still more ancient formations. But the most important result for us, arrived at by Mr. Croll, is that whenever the northern hemisphere passes through a cold period the temperature of the southern hemisphere is actually raised, with the winters rendered much milder, chiefly through changes in the direction of the ocean-currents. So conversely it will be with the northern hemisphere, whilst the southern passes through a Glacial period. This conclusion throws so much light on geographical distribution that I am strongly inclined to trust in it; but I will first give the facts, which demand an explanation.

In South America, Dr. Hooker has shown that besides many closely allied species, between forty and fifty of the flowering plants of Tierra del Fuego, forming no inconsiderable part of its scanty flora, are common to North America and Europe, enormously remote as these areas in opposite hemispheres are from each other. On the lofty mountains of equatorial America a host of peculiar species belonging to European genera occur. On the Organ mountains of Brazil, some few temperate European, some Antarctic, and some Andean genera were found by Gardner, which do not exist 
in the low intervening hot countries. On the Silla of Caraccas, the illustrious Humboldt long ago found species belonging to genera characteristic of the Cordillera.

In Africa, several forms characteristic of Europe and some few representatives of the flora of the Cape of Good Hope occur on the mountains of Abyssinia. At the Cape of Good Hope a very few European species, believed not to have been introduced by man, and on the mountains several representative European forms are found, which have not been discovered in the intertropical parts of Africa. Dr. Hooker has also lately shown that several of the plants living on the upper parts of the lofty island of Fernando Po and on the neighbouring Cameroon mountains, in the Gulf of Guinea, are closely related to those on the mountains of Abyssinia, and likewise to those of temperate Europe. It now also appears, as I hear from Dr. Hooker, that some of these same temperate plants have been discovered by the Rev. R. T. Lowe on the mountains of the Cape Verde islands. This extension of the same temperate forms, almost under the equator, across the whole continent of Africa and to the mountains of the Cape Verde archipelago, is one of the most astonishing facts ever recorded in the distribution of plants.

On the Himalaya, and on the isolated mountainranges of the peninsula of India, on the heights of Ceylon, and on the volcanic cones of Java, many plants occur, either identically the same or representing each other, and at the same time representing plants of Europe, not found in the intervening hot lowlands. A list of the genera of plants collected on the loftier peaks of Java, raises a picture of a collection made on 
a hillock in Europe! Still more striking is the fact that peculiar Australian forms are represented by certain plants growing on the summits of the mountains of Borneo. Some of these Australian forms, as I hear from Dr. Hooker, extend along the heights of the peninsula of Malacca, and are thinly scattered on the one hand over India, and on the other hand as far north as Japan.

On the southern mountains of Australia, Dr. F. Müller has discovered several European species; other species, not introduced by man, occur on the lowlands; and a long list can be given, as I am informed by Dr. Hooker, of European genera, found in Australia, but not in the intermediate torrid regions. In the admirable 'Introduction to the Flora of New Zealand,' by Dr. Hooker, analogous and striking facts are given in regard to the plants of that large island. Hence we see that certain plants growing on the more lofty mountains of the tropics in all parts of the world, and on the temperate plains of the north and south, are either the same species or varieties of the same species. It should, however, be observed that these plants are not strictly arctic forms; for, as Mr. H. C. Watson has remarked, "in receding from polar towards equatorial latitudes, the Alpine or mountain floras really become less and less Arctic." Besides these identical and closely allied forms, many species inhabiting the same widely sundered areas, belong to genera not now found in the intermediate tropical lowlands.

These brief remarks apply to plants alone; but some few analogous facts could be given in regard to terrestrial animals. In marine productions, similar cases likewise occur; as an example, I may quote a statement 
by the highest authority, Prof. Dana, that "it is certainly a wonderful fact that New Zealand should have a closer resemblance in its crustacea to Great Britain, its antipode, than to any other part of the world." Sir J. Richardson, also, speaks of the reappearance on the shores of New Zealand, Tasmania, \&c., of northern forms of fish. Dr. Hooker informs me that twenty-five species of Algæ are common to New Zealand and to Europe, but have not been found in the intermediate tropical seas.

From the foregoing facts, namely, the presence of temperate forms on the highlands across the whole of equatorial Africa, and along the Peninsula of India, to Ceylon and the Malay Archipelago, and in a less wellmarked manner across the wide expanse of tropical South America, it appears almost certain that at some former period, no doubt during the most severe part of a Glacial period, the lowlands of these great continents were everywhere tenanted under the equator by a considerable number of temperate forms. At this period the equatorial climate at the level of the sea was probably about the same with that now experienced at the height of from five to six thousand feet under the same latitude, or perhaps even rather cooler. During this, the coldest period, the lowlands under the equator must have been clothed with a mingled tropical and temperate vegetation, like that described by Hooker as growing luxuriantly at the height of from four to five thousand feet on the lower slopes of the Himalaya, but with perhaps a still greater preponderance of temperate forms. So again in the mountainous island of Fernando Po, in the Gulf of Guinea, Mr. Mann found temperate European forms beginning to appear at the height 
of about five thousand feet. On the mountains of Panama, at the height of only two thousand feet, Dr. Seemann found the vegetation like that of Mexico, "with forms of the torrid zone harmoniously blended with those of the temperate."

Now let us see whether Mr. Croll's conclusion that when the northern hemisphere suffered from the extreme cold of the great Glacial period, the southern hemisphere was actually warmer, throws any clear light on the present apparently inexplicable distribution of various organisms in the temperate parts of both hemispheres, and on the mountains of the tropics. The Glacial period, as measured by years, must have been very long; and when we remember over what vast spaces some naturalised plants and animals have spread within a few centuries, this period will have been ample for any amount of migration. As the cold became more and more intense, we know that Arctic forms invaded the temperate regions; and, from the facts just given, there can hardly be a doubt that some of the more vigorous, dominant, and widest-spreading temperate forms invaded the equatorial lowlands. The inhabitants of these hot lowlands would at the same time have migrated to the tropical and subtropical regions of the south, for the southern hemisphere was at this period warmer. On the decline of the Glacial period, as both hemispheres gradually recovered their former temperatures, the northern temperate forms living on the lowlands under the equator, would have been driven to their former homes or have been destroyed, being replaced by the equatorial forms returning from the south. Some, however, of the northern temperate forms would almost certainly have ascended any adjoining high land, 
where, if sufficiently lofty, they would have long survived like the Arctic forms on the mountains of Europe. They might have survived, even if the climate was not perfectly fitted for them, for the change of temperature must have been very slow, and plants undoubtedly possess a certain capacity for acclimatisation, as shown by their transmitting to their offspring different constitutional powers of resisting heat and cold.

In the regular course of events the southern hemisphere would in its turn be subjected to a severe Glacial period, with the northern hemisphere rendered warmer; and then the southern temperate forms would invade the equatorial lowlands. The northern forms which had before been left on the mountains would now descend and mingle with the southern forms. These latter, when the warmth returned, would return to their former homes, leaving some few species on the mountains, and carrying southward with them some of the northern temperate forms which had descended from their mountain fastnesses. Thus, we should have some few species identically the same in the northern and southern temperate zones and on the mountains of the intermediate tropical regions. But the species left during a long time on these mountains, or in opposite hemispheres, would have to compete with many new forms and would be exposed to somewhat different physical conditions; hence they would be eminently liable to modification, and would generally now exist as varieties or as representative species; and this is the case. We must, also, bear in mind the occurrence in both hemispheres of former Glacial periods; for these will account, in accordance with the same principles, for the many quite distinct species inhabiting the same 
widely separated areas, and belonging to genera not now found in the intermediate torrid zones.

It is a remarkable fact strongly insisted on by Hooker in regard to America, and by Alph. de Candolle in regard to Australia, that many more identical or slightly modified species have migrated from the north to the south, than in a reversed direction. We see, however, a few southern forms on the mountains of Borneo and Abyssinia. I suspect that this preponderant migration from the north to the south is due to the greater extent of land in the north, and to the northern forms having existed in their own homes in greater numbers, and having consequently been advanced through natural selection and competition to a higher stage of perfection, or dominating power, than the southern forms. And thus, when the two sets became commingled in the equatorial regions, during the alternations of the Glacial periods, the northern forms were the more powerful and were able to hold their places on the mountains, and afterwards to migrate southward with the southern forms; but not so the southern in regard to the northern forms. In the same manner at the present day, we see that very many European productions cover the ground in La Plata, New Zealand, and to a lesser degree in Australia, and have beaten the natives; whereas extremely few southern forms have become naturalised in any part of the northern hemisphere, though hides, wool, and other objects likely to carry seeds have been largely imported into Europe during the last two or three centuries from La Plata and during the last forty or fifty years from Australia. The Neilgherrie mountains in India, however, offer a partial exception; for here, as I hear from Dr. Hooker, 
Australian forms are rapidly sowing themselves and becoming naturalised. Before the last great Glacial period, no doubt the intertropical mountains were stocked with endemic Alpine forms; but these have almost everywhere yielded to the more dominant forms generated in the larger areas and more efficient workshops of the north. In many islands the native productions are nearly equalled, or even outnumbered, by those which have become naturalised; and this is the first stage towards their extinction. Mountains are islands on the land, and their inhabitants have yielded to those produced within the larger areas of the north, just in the same way as the inhabitants of real islands have everywhere yielded and are still yielding to continental forms naturalised through man's agency.

The same principles apply to the distribution of terrestrial animals and of marine productions, in the northern and southern temperate zones, and on the intertropical mountains. When, during the height of the Glacial period, the ocean-currents were widely different to what they now are, some of the inhabitants of the temperate seas might have reached the equator; of these a few would perhaps at once be able to migrate southward, by keeping to the cooler currents, whilst others might remain and survive in the colder depths until the southern hemisphere was in its turn subjected to a glacial climate and permitted their further progress; in nearly the same manner as, according to Forbes, isolated spaces inhabited by Arctic productions exist to the present day in the deeper parts of the northern temperate seas.

I am far from supposing that all the difficulties in regard to the distribution and affinities of the identical 
and allied species, which now live so widely separated in the north and south, and sometimes on the intermediate mountain-ranges, are remored on the views above given. The exact lines of migration cannot be indicated. We cannot say why certain species and not others have migrated; why certain species have been modified and have given rise to new forms, whilst others have remained unaltered. We cannot hope to explain such facts, until we can say why one species and not another becomes naturalised by man's agency in a foreign land; why one species ranges twice or thrice as far, and is twice or thrice as common, as another species within their own homes.

Various special difficulties also remain to be solved; for instance, the occurrence, as shown by Dr. Hooker, of the same plants at points so enormously remote as Kerguelen Land, New Zealand, and Fuegia; but icebergs, as suggested by Lyell, may have been concerned in their dispersal. The existence at these and other distant points of the southern hemisphere, of species, which, though distinct, belong to genera exclusively confined to the south, is a more remarkable case. Some of these species are so distinct, that we cannot suppose that there has been time since the commencement of the last Glacial period for their migration and subsequent modification to the necessary degree. The facts seem to indicate that distinct species belonging to the same genera have migrated in radiating lines from a common centre; and I am inclined to look in the southern, as in the northern hemisphere, to a former and warmer period, before the commencement of the last Glacial period, when the Antarctic lands, now covered with ice, supported a highly peculiar and isolated flora. It may 
be suspected that before this flora was exterminated during the last Glacial epoch, a few forms had been already widely dispersed to various points of the southern hemisphere by occasional means of transport, and by the aid as halting-places, of now sunken islands. Thus the southern shores of America, Australia, and New Zealand may have become slightly tinted by the same peculiar forms of life.

Sir C. Lyell in a striking passage has speculated, in language almost identical with mine, on the effects of great alterations of climate throughout the world on geographical distribution. And we have now seen that Mr. Croll's conclusion that successive Glacial periods in the one hemisphere coincide with warmer periods in the opposite hemisphere, together with the admission of the slow modification of species, explains a multitude of facts in the distribution of the same and of the allied forms of life in all parts of the globe. The living waters have flowed during one period from the north and during another from the south, and in both cases have reached the equator; but the stream of life has flowed with greater force from the north than in the opposite direction, and has consequently more freely inundated the south. As the tide leaves its drift in horizontal lines, rising higher on the shores where the tide rises highest, so have the living waters left their living drift on our mountain summits, in a line gently rising from the Arctic lowlands to a great altitude under the equator. The various beings thus left stranded may be compared with savage races of man, driven up and surviving in the mountain fastnesses of almost every land, which serve as a record, full of interest to us, of the former inhabitants of the surrounding lowlands. 


\section{CHAPTER XIII.}

\section{GEOGRAPHICAL DISTRIBUTION-continued.}

Distribution of fresh-water productions-On the inhabitants of oceanic islands-Absence of Batrachians and of terrestrial Mammals-On the relation of the inhabitants of islands to those of the nearest mainland-On colonisation from the nearest source with subsequent modification-Summary of the last and present chapter.

\section{Fresh-water Productions.}

As lakes and river-systems are separated from each other by barriers of land, it might have been thought that fresh-water productions would not have ranged widely within the same country, and as the sea is apparently a still more formidable barrier, that they would never have extended to distant countries. But the case is exactly the reverse. Not only have many freshwater species, belonging to different classes, an enormous range, but allied species prevail in a remarkable manner throughout the world. When first collecting in the fresh waters of Brazil, I well remember feeling much surprise at the similarity of the fresh-water insects, shells, \&c., and at the dissimilarity of the surrounding terrestrial beings, compared with those of Britain.

But the wide ranging power of fresh-water productions can, I think, in most cases be explained by their having become fitted, in a manner highly useful to 
them, for short and frequent migrations from pond to pond, or from stream to stream, within their own countries; and liability to wide dispersal would follow from this capacity as an almost necessary consequence. We can here consider only a few cases; of these, some of the most difficult to explain are presented by fish. It was formerly believed that the same fresh-water species never existed on two continents distant from each other. But Dr. Günther has lately shown that the Galaxias attenuatus inhabits Tasmania, New Zealand, the Falkland Islands, and the mainland of South America. This is a wonderful case, and probably indicates dispersal from an Antarctic centre during a former warm period. This case, however, is rendered in some degree less surprising by the species of this genus having the power of crossing by some unknown means considerable spaces of open ocean: thus there is one species common to New Zealand and to the Auckland Islands, though separated by a distance of about 230 miles. On the same continent fresh-water fish often range widely, and as if capriciously; for in two adjoining river-systems some of the species may be the same, and some wholly different.

It is probable that they are occasionally transported by what may be called accidental means. Thus fishes still alive are not very rarely dropped at distant points by whirlwinds; and it is known that the ova retain their vitality for a considerable time after removal from the water. Their dispersal may, however, be mainly attributed to changes in the level of the land within the recent period, causing rivers to flow into each other. Instances, also, could be given of this having occurred during floods, without any change of level. The wide difference of the fish on the opposite sides of most 
mountain-ranges, which are continuous, and which consequently must from an early period have completely prevented the inosculation of the river-systems on the two sides, leads to the same conclusion. Some freshwater fish belong to very ancient forms, and in such cases there will have been ample time for great geographical changes, and consequently time and means for much migration. Moreover, Dr. Günther has recently been led by several considerations to infer that with fishes the same forms have a long endurance. Saltwater fish can with care be slowly accustomed to live in fresh water; and, according to Valenciennes, there is hardly a single group of which all the members are confined to fresh water, so that a marine species belonging to a fresh-water group might travel far along the shores of the sea, and could, it is probable, become adapted without much difficulty to the fresh waters of a distant land.

Some species of fresh-water shells have very wide ranges, and allied species which, on our theory, are descended from a common parent, and must have proceeded from a single source, prevail throughout the world. Their distribution at first perplexed me much, as their ova are not likely to be transported by birds; and the ova, as well as the adults, are immediately killed by sea-water. I could not even understand how some naturalised species have spread rapidly throughout the same country. But two facts, which I have observed-and many others no doubt will be discoveredthrow some light on this subject. When ducks suddenly emerge from a pond covered with duck-weed, I have twice seen these little plants adhering to their backs; and it has happened to me, in removing a little duck- 
weed from one aquarium to another, that I have unintentionally stocked the one with fresh-water shells from the other. But another agency is perhaps more effectual: I suspended the feet of a duck in an aquarium, where many ova of fresh-water shells were hatching; and $I$ found that numbers of the extremely minute and just-hatched shells crawled on the feet, and clung to them so firmly that when taken out of the water they could not be jarred off, though at a somewhat more advanced age they would voluntarily drop off. These just-hatched molluses, though aquatic in their nature, survived on the duck's feet, in damp air, from twelve to twenty hours; and in this length of time a duck or heron might fly at least six or seven hundred miles, and if blown across the sea to an oceanic island, or to any other distant point, would be sure to alight on a pool or rivulet. Sir Charles Lyell informs me that a Dytiscus has been caught with an Ancylus (a fresh-water shell like a limpet) firmly adhering to it; and a waterbeetle of the same family, a Colymbetes, once flew on board the 'Beagle,' when forty-five miles distant from the nearest land: how much farther it might have been blown by a favouring gale no one can tell.

With respect to plants, it has long been known what enormous ranges many fresh-water, and even marsh species, have, both orer continents and to the most remote oceanic islands. This is strikingly illustrated, according to Alph. de Candolle, in those large groups of terrestrial plants, which have very few aquatic members; for the latter seem immediately to acquire. as if in consequence, a wide range. I think favourable means of dispersal explain this fact. I have before mentioned that earth occasionally adheres in some quantity to the 
feet and beaks of birds. Wading birds, which frequent the muddy edges of ponds, if suddenly flushed, would be the most likely to have muddy feet. Birds of this order wander more than those of any other; and they are occasionally found on the most remote and barren islands of the open ocean; they would not be likely to alight on the surface of the sea, so that any dirt on their feet would not be washed off; and when gaining the land, they would be sure to fly to their natural freshwater haunts. I do not believe that botanists are aware how charged the mud of ponds is with seeds; I have tried several little experiments, but will here give only the most striking case: I took in February three tablespoonfuls of mud from three different points, beneath water, on the edge of a little pond: this mud when dried weighed only $6 \frac{3}{4}$ ounces; I kept it covered up in my study for six months, pulling up and counting each plant as it grew; the plants were of many kinds, and were altogether 537 in number; and yet the viscid mud was all contained in a breakfast cup! Considering these facts, I think it would be an inexplicable circumstance if water-birds did not transport the seeds of fresh-water plants to unstocked ponds and streams, situated at very distant points. The same agency may have come into play with the eggs of some of the smaller fresh-water animals.

Other and unknown agencies probably have also played a part. I have stated that fresh-water fish eat some kinds of seeds, though they reject many other kinds after having swallowed them; even small fish swallow seeds of moderate size, as of the yellow waterlily and Potamogeton. Herons and other birds, century after century, have gone on daily devouring fish; 
they then take flight and go to other waters, or are blown across the sea; and we have seen that seeds retain their power of germination, when rejected many hours afterwards in pellets or in the excrement. When I saw the great size of the seeds of that fine water-lily, the Nelumbium, and remembered Alph. de Candolle's remarks on the distribution of this plant, I thought that themeans of its dispersal must remain inexplicable; but Audubon states that he found the seeds of the great southern water-lily (probably, according to Dr. Hooker, the Nelumbium luteum) in a heron's stomach. Now this bird must often have flown with its stomach thus well stocked to distant ponds, and then getting a hearty meal of fish, analogy makes me believe that it would have rejected the seeds in a pellet in a fit state for germination.

In considering these several means of distribution, it should be remembered that when a pond or stream is first formed, for instance, on a rising islet, it will be unoccupied; and a single seed or egg will have a good chance of succeeding. Although there will always be a struggle for life between the inhabitants of the same pond, however few in kind, yet as the number even in a well-stocked pond is small in comparison with the number of species inhabiting an equal area of land, the competition between them will probably be less severe than between terrestrial species; consequently an intruder from the waters of a foreign country would have a better chance of seizing on a new place, than in the case of terrestrial colonists. We should also remember that many fresh-water productions are low in the scale of nature, and we have reason to believe that such beings become modified more slowly than the high; and 
this will give time for the migration of aquatic species. We should not forget the probability of many freshwater forms having formerly ranged continuously over immense areas, and then having become extinct at intermediate points. But the wide distribution of freshwater plants and of the lower animals, whether retaining the same identical form or in some degree modified, apparently depends in main part on the wide dispersal of their seeds and eggs by animals, more especially by fresh-water birds, which have great powers of flight, and naturally travel from one piece of water to another.

\section{On the Inhabitants of Oceanic Islands.}

We now come to the last of the three classes of facts, which I have selected as presenting the greatest amount of difficulty with respect to distribution, on the view that not only all the individuals of the same species have migrated from some one area, but that allied species, although now inhabiting the most distant points, have proceeded from a single area,-the birthplace of their early progenitors. I have already given my reasons for disbelieving in continental extensions within the period of existing species, on so enormous a scale that all the many islands of the several oceans were thus stocked with their present terrestrial inhabitants. This view removes many difficulties, but it does not accord with all the facts in regard to the productions of islands. In the following remarks I shall not confine myself to the mere question of dispersal, but shall consider some other cases bearing on the truth of the two theories of independent creation and of descent with modification. 


\section{INHABITANTS OF OCEANIC ISLANDS. [CHAP. XIIL.}

The species of all kinds which inhabit oceanic islands are few in number compared with those on equal continental areas: Alph. de Candolle admits this for plants, and Wollaston for insects. New Zealand, for instance, with its lofty mountains and diversified stations, extending over 780 miles of latitude, together with the outlying islands of Auckland, Campbell and Chatham, contain altogether only 960 kinds of flowering plants; if we compare this moderate number with the species which swarm over equal areas in SouthWestern Australia or at the Cape of Good Hope, we must admit that some cause, independently of different physical conditions, has given rise to so great a difference in number. Even the uniform county of Cambridge has 847 plants, and the little island of Anglesea 764, but a few ferns and a few introduced plants are included in these numbers, and the comparison in some other respects is not quite fair. We have evidence that the barren island of Ascension aboriginally possessed less than half-a-dozen flowering plants; yet many species have now become naturalised on it, as they have in New Zealand and on every other oceanic island which can be named. In St. Helena there is reason to believe that the naturalised plants and animals have nearly or quite exterminated many native productions. He who admits the doctrine of the creation of each separate species, will have to admit that a sufficient number of the best adapted plants and animals were not created for oceanic islands; for man has unintentionally stocked them far more fully and perfectly than did nature.

Although in oceanic islands the species are few in number, the proportion of endemic kinds (i. e. those 
found nowhere else in the world) is often extremely large. If we compare, for instance, the number of endemic land-shells in Madeira, or of endemic birds in the Galapagos Archipelago, with the number found on any continent, and then compare the area of the island with that of the continent, we shall see that this is true. This fact might have been theoretically expected, for, as already explained, species occasionally arriving after long intervals of time in the new and isolated district, and having to compete with new associates, would be eminently liable to modification, and would often produce groups of modified descendants. But it by no means follows that, because in an island nearly all the species of one class are peculiar, those of another class, or of another section of the same class, are peculiar; and this difference seems to depend partly on the species which are not modified having immigrated in a body, so that their mutual relations have not been much disturbed; and partly on the frequent arrival of unmodified immigrants from the mother-country, with which the insular forms have intercrossed. It should be borne in mind that the offspring of such crosses would certainlygain in vigour; so that even an occasional cross would produce more effect than might have been anticipated. I will give a few illustrations of the foregoing remarks: in the Galapagos Islands there are 26 land-birds; of these 21 (or perhaps 23) are peculiar, whereas of the 11 marine birds only 2 are peculiar; and it is obvious that marine birds could arrive at these islands much more easily and frequently than land-birds. Bermuda, on the other hand, which lies at about the same distance from North America as the Galapagos Islands do from South America, and which has a very 37 
peculiar soil, does not possess a single endemic landbird; and we know from Mr. J. M. Jones's admirable account of Bermuda, that very many North American birds occasionally or even frequently visit this island. Almost every year, as I am informed by Mr. E. V. Harcourt, many European and African birds are blown to Madeira; this island is inhabited by 99 kinds of which one alone is peculiar, though very closely related to a European form; and three or four other species are confined to this island and to the Canaries. So that the islands of Bermuda and Madeira have been stocked from the neighbouring continents with birds, which for long ages have there struggled together, and have become mutually co-adapted. Hence when settled in their new homes, each kind will have been kept by the others to its proper place and habits, and will consequently have been but little liable to modification. Any tendency to modification will also have been checked by intercrossing with the unmodified immigrants, often arriving from the mothercountry. Madeira again is inhabited by a wonderful number of peculiar land-shells, whereas not one species of sea-shell is peculiar to its shores: now, though we do not know how sea-shells are dispersed, yet we can see that their eggs or larvæ, perhaps attached to seaweed or floating timber, or to the feet of wadingbirds, might be transported across three or four hundred miles of open sea far more easily than land-shells. The different orders of insects inhabiting Madeira present nearly parallel cases.

Oceanic islands are sometimes deficient in animals of certain whole classes, and their places are occupied by other classes; thus in the Galapagos Islands reptiles, 
Chap. XIII.] INHABITANTS OF OCEANIC ISLANDS. 181

and in New Zealand gigantic wingless birds, take, or recently took, the place of mammals. Although New Zealand is here spoken of as an oceanic island, it is in some degree doubtful whether it should be so ranked; it is of large size, and is not separated from Australia by a profoundly deep sea; from its geological character and the direction of its mountain-ranges, the Rev. W. B. Clarke has lately maintained that this island, as well as New Caledonia, should be considered as appurtenances of Australia. Turning to plants, Dr. Hooker has shown that in the Galapagos Islands the proportional numbers of the different orders are very different from what they are elsewhere. All such differences in number, and the absence of certain whole groups of animals and plants, are generally accounted for by supposed differences in the physical conditions of the islands; but this explanation is not a little doubtful. Facility of immigration seems to have been fully as important as the nature of the conditions.

Many remarkable little facts could be given with respect to the inhabitants of oceanic islands. For instance, in certain islands not tenanted by a single mammal, some of the endemic plants have beautifully hooked seeds; yet few relations are more manifest than that hooks serve for the transportal of seeds in the wool or fur of quadrupeds. But a hooked seed might be carried to an island by other means; and the plant then becoming modified would form an endemic species, still retaining its hooks, which would form a useless appendage like the shrivelled wings under the soldered wingcovers of many insular beetles. Again, islands often possess trees or bushes belonging to orders which else- 
where include only herbaceous species; now trees, as Alph. de Candolle has shown, generally have, whatever the cause may be, confined ranges. Hence trees would be little likely to reach distant oceanic islands; and an herbaceous plant, which had no chance of successfully competing with the many fully developed trees growing on a continent, might, when established on an island, gain an advantage over other herbaceous plants by growing taller and taller and overtopping them. In this case, natural selection would tend to add to the stature of the plant, to whatever order it belonged, and thus first convert it into a bush and then into a tree.

\section{Absence of Batrachians and Terrestrial Mammals on} Oceanic Islands.

With respect to the absence of whole orders of animals on oceanic islands, Bory St. Vincent long ago remarked that Batrachians (frogs, toads, newts) are never found on any of the many islands with which the great oceans are studded. I have taken pains to verify this assertion, and have found it true, with the exception of New Zealand, New Caledonia, the Andaman Islands, and perhaps the Salomon Islands and the Seychelles. But $I$ have already remarked that it is doubtful whether New Zealand and New Caledonia ought to be classed as oceanic islands; and this is still more doubtful with respect to the Andaman and Salomon groups and the Seychelles. This general absence of frogs, toads, and newts on so many true oceanic islands cannot be accounted for by their physical conditions: indeed it seems that islands are peculiarly fitted for these animals; for frogs have been introduced into Ma- 
deira, the Azores, and Mauritius, and have multiplied so as to become a nuisance. But as these animals and their spawn are immediately killed (with the exception, as far as known, of one Indian species) by seawater, there would be great difficulty in their transportal across the sea, and therefore we can see why they do not exist on strictly oceanic islands. But why, on the theory of creation, they should not have been created there, it would be very difficult to explain.

Mammals offer another and similar case. I have carefully searched the oldest voyages, and have not found a single instance, free from doubt, of a terrestrial mammal (excluding domesticated animals kept by the natives) inhabiting an island situated above 300 miles from a continent or great continental island; and many islands situated at a much less distance are equally barren. The Falkland Islands, which are inhabited by a wolf-like fox, come nearest to an exception; but this group cannot be considered as oceanic, as it lies on a bank in connection with the mainland at the distance of about 280 miles; moreover, icebergs formerly brought boulders to its western shores, and they may have formerly transported foxes, as now frequently happens in the arctic regions. Yet it cannot be said that small islands will not support at least small mammals, for they occur in many parts of the world on very small islands, when lying close to a continent; and hardly an island can be named on which our smaller quadrupeds have not become naturalised and greatly multiplied. It cannot be said, on the ordinary view of creation, that there has not been time for the creation of mammals; many volcanic islands are sufficiently ancient, as shown 
by the stupendous degradation which they have suffered, and by their tertiary strata: there has also been time for the production of endemic species belonging to other classes; and on continents it is known that new species of mammals appear and disappear at a quicker rate than other and lower animals. Although terrestrial mammals do not occur on oceanic islands, aerial mammals do occur on almost every island. New Zealand possesses two bats found nowhere else in the world: Norfolk Island, the Viti Archipelago, the Bonin Islands, the Caroline and Marianne Archipelagoes, and Mauritius, all possess their peculiar bats. Why, it may be asked, has the supposed creative force produced bats and no other mammals on remote islands? On my view this question can easily be answered; for no terrestrial mammal can be transported across a wide space of sea, but bats can fly across. Bats have been seen wandering by day far over the Atlantic Ocean; and two North American species either regularly or occasionally visit Bermuda, at the distance of 600 miles from the mainland. I hear from Mr. Tomes, who has specially studied this family, that many species have enormous ranges, and are found on continents and on far distant iolands. Hence we have only to suppose that such wandering species have been modified in their new homes in relation to their new position, and we can understand the presence of endemic bats on oceanic islands, with the absence of all other terrestrial mammals.

Another interesting relation exists, namely between the depth of the sea separating islands from each other or from the nearest continent, and the degree of affinity 
of their mammalian inhabitants. Mr. Windsor Earl has made some striking observations on this head, since greatly extended by Mr. Wallace's admirable researches, in regard to the great Malay Archipelago, which is traversed near Celebes by a space of deep ocean, and this separates two widely distinct mammalian faunas. On either side the islands stand on a moderately shallow submarine bank, and these islands are inhabited by the same or by closely allied quadrupeds. I have not as yet had time to follow up this subject in all quarters of the world; but as far as I have gone, the relation holds good. For instance, Britain is separated by a shallow channel from Europe, and the mammals are the same on both sides; and so it is with all the islands near the shores of Australia. The West Indian Islands, on the other hand, stand on a deeply submerged bank, nearly 1000 fathoms in depth, and here we find American forms, but the species and even the genera are quite distinct. As the amount of modification which animals of all kinds undergo partly depends on the lapse of time, and as the islands which are separated from each other or from the mainland by shallow channels, are more likely to have been continuously united within a recent period than the islands separated by deeper channels, we can understand how it is that a relation exists between the depth of the sea separating two mammalian faunas, and the degree of their affinity, -a relation which is quite inexplicable on the theory of independent acts of creation.

The foregoing statements in regard to the inhabitants of oceanic islands,-namely, the fewness of the species, with a large proportion consisting of endemic forms-the members of certain groups, but not those of 
other groups in the same class, having been modifiedthe absence of certain whole orders, as of batrachians and of terrestrial mammals, notwithstanding the presence of aerial bats, - the singular proportions of certain orders of plants,-herbaceous forms having been developed into trees, \&c.,--seem to me to accord better with the belief in the efficiency of occasional means of transport, carried on during a long course of time, than with the belief in the former connection of all oceanic islands with the nearest continent; for on this latter view it is probable that the various classes would have immigrated more uniformly, and from the species having entered in a body their mutual relations would not have been much disturbed, and consequently they would either have not been modified, or all the species in a more equable manner.

I do not deny that there are many and serious difficulties in understanding how many of the inhabitants of the more remote islands, whether still retaining the same specific form or subsequently modified, have reached their present homes. But the probability of other islands having once existed as halting-places, of which not a wreck now remains, must not be overlooked. I will specify one difficult case. Almost all oceanic islands, even the most isolated and smallest, are inhabited by land-shells, generally by endemic species, but sometimes by species found elsewhere,-striking instances of which have been given by Dr. A. A. Gould in relation to the Pacific. Now it is notorious that land-shells are easily killed by sea-water; their eggs, at least such as I have tried, sink in it and are killed. Yet there must be some unknown, but occasionally efficient means for their transportal. Would the just- 
hatched young sometimes adhere to the feet of birds roosting on the ground, and thus get transported? It occurred to me that land-shells, when hybernating and having a membranous diaphragm over the mouth of the shell, might be floated in chinks of drifted timber across moderately wide arms of the sea. And I find that several species in this state withstand uninjured an immersion in sea-water during seven days: one shell, the Helix pomatia, after having been thus treated and again hybernating was put into sea-water for twenty days, and perfectly recovered. During this length of time the shell might have been carried by a marine current of average swiftness, to a distance of 660 geographical miles. As this Helix has a thick calcareous operculum, I removed it, and when it had formed a new membranous one, I again immersed it for fourteen days in sea-water, and again it recovered and crawled away. Baron Aucapitaine has since tried similar experiments: he placed 100 land-shells, belonging to ten species, in a box pierced with holes, and immersed it for a fortnight in the sea. Out of the hundred shells, twenty-seven recovered. The presence of an operculum seems to have been of importance, as out of twelve specimens of Cyclostoma elegans, which is thus furnished, eleven revived. It is remarkable, seeing how well the Helix pomatia resisted with me the salt-water, that not one of fifty-four specimens belonging to four other species of Helix tried by Aucapitaine, recovered. It is, however, not at all probable that land-shells have often been thus transported; the feet of birds offer a more probable method. 
On the Relations of the Inhabitants of Islands to those of the nearest Mainland.

The most striking and important fact for us is the affinity of the species which inhabit islands to those of the nearest mainland, without being actually the same. Numerous instances could be given. The Galapagos Archipelago, situated under the equator, lies at the distance of between 500 and 600 miles from the shores of South America. Here almost every product of the land and of the water bears the unmistakable stamp of the American continent. There are twenty-six landbirds; of these, twenty-one, or perhaps twenty-three are ranked as distinct species, and would commonly be assumed to have been here created; yet the close affinity of most of these birds to American species is manifest in every character, in their habits, gestures, and tones of voice. So it is with the other animals, and with a large proportion of the plants, as shown by Dr. Hooker in his admirable Flora of this archipelago. The naturalist, looking at the inhabitants of these volcanic islands in the Pacific, distant several hundred miles from the continent, feels that he is standing on American land. Why should this be so? why should the species which are supposed to have been created in the Galapagos Archipelago, and nowhere else, bear so plainly the stamp of affinity to those created in America? There is nothing in the conditions of life, in the geological nature of the islands, in their height or climate, or in the proportions in which the several classes are associated together, which closely resembles the conditions of the South American coast: in fact, there is a considerable dissimilarity in all these respects. On the 
other hand, there is a considerable degree of resemblance in the volcanic nature of the soil, in the climate, height, and size of the islands, between the Galapagos and Cape Verde Archipelagoes: but what an entire and absolute difference in their inhabitants! The inhabitants of the Cape Verde Islands are related to those of Africa, like those of the Galapagos to America. Facts such as these, admit of no sort of explanation on the ordinary view of independent creation; whereas on the view here maintained, it is obvious that the Galapagos Islands would be likely to receive colonists from America, whether by occasional means of transport or (though I do not believe in this doctrine) by formerly continuous land, and the Cape Verde Islands from Africa; such colonists would be liable to modification,-the principle of inheritance still betraying their original birthplace.

Many analogous facts could be given: indeed it is an almost universal rule that the endemic productions of islands are related to those of the nearest continent, or of the nearest large island. The exceptions are few, and most of them can be explained. Thus although Kerguelen Land stands nearer to Africa than to America, the plants are related, and that very closely, as we know from Dr. Hooker's account, to those of America: but on the view that this island has been mainly stocked by seeds brought with earth and stones on icebergs, drifted by the prevailing currents, this anomaly disappears. New Zealand in its endemic planes is much more closely related to Australia, the nearest mainland, than to any other region: and this is what might have been expected; but it is also plainly related to South America, which, although the next nearest continent, is 
so enormously remote, that the fact becomes an anomaly. But this difficulty partially disappears on the view that New Zealand, South America, and the other southern lands have been stocked in part from a nearly intermediate though distant point, namely from the antarctic islands, when they were clothed with regetation, during a warmer tertiary period, before the commencement of the last Glacial period. The affinity, which though feeble, I am assured by Dr. Hooker is real, between the flora of the south-western corner of Australia and of the Cape of Good Hope, is a far more remarkable case; but this affinity is confined to the plants, and will, no doubt, some day be explained.

The same law which has determined the relationship between the inhabitants of islands and the nearest mainland, is sometimes displayed on a small scale, but in a most interesting manner, within the limits of the same archipelago. Thus each separate island of the Galapagos Archipelago is tenanted, and the fact is a marvellous one, by many distinct species; but these species are related to each other in a very much closer manner than to the inhabitants of the American continent, or of any other quarter of the world. This is what might have been expected, for islands situated so near to each other would almost necessarily receive immigrants from the same original source, and from each other. But how is it that many of the immigrants have been differently modified, though only in a small degree, in islands situated within sight of each other, having the same geological nature, the same height, climate, \&c.? This long appeared to me a great difficulty: but it arises in chief part from the deeply-seated error of considering the physical conditions of a country 
as the most important; whereas it cannot be disputed that the nature of the other species with which each has to compete, is at least as important, and generally a far more important element of success. Now if we look to the species which inhabit the Galapagos Archipelago, and are likewise found in other parts of the world, we find that they differ considerably in the several islands. This difference might indeed have been expected if the islands had been stocked by occasional means of transport-a seed, for instance, of one plant having been brought to one island, and that of another plant to another island, though all proceeding from the same general source. Hence, when in former times an immigrant first settled on one of the islands, or when it subsequently spread from one to another, it would undoubtedly be exposed to different conditions in the different islands, for it would have to compete with a different set of organisms; a plant, for instance, would find the ground best fitted for it occupied by somewhat different species in the different islands, and would be exposed to the attacks of somewhat different enemies. If then it varied, natural selection would probably favour different varieties in the different islands. Some species, however, might spread and yet retain the same character throughout the group, just as we see some species spreading widely throughout a continent and remaining the same.

The really surprising fact in this case of the Galapagos Archipelago, and in a lesser degree in some analogous cases, is that each new species after being formed in any one island, did not spread quickly to the other islands. But the islands, though in sight of each other, are separated by deep arms of the sea, in most cases 
wider than the British Channel, and there is no reason to suppose that they have at any former period been continuously united. The currents of the sea are rapid and sweep between the islands, and gales of wind are extraordinarily rare; so that the islands are far more effectually separated from each other than they appear on a map. Nevertheless some of the species, both of those found in other parts of the world and of those confined to the archipelago, are common to the several islands; and we may infer from their present manner of distribution, that they have spread from one island to the others. But we often take, I think, an erroneous view of the probability of closely-allied species invading each other's territory, when put into free intercommunication. Undoubtedly, if one species has any advantage over another, it will in a very brief time wholly or in part supplant it; but if both are equally well fitted for their own places, both will probably hold their separate places for almost any length of time. Being familiar with the fact that many species, naturalised through man's agency, have spread with astonishing rapidity over wide areas, we are apt to infer that most species would thus spread; but we should remember that the species which become naturalised in new countries are not generally closely allied to the aboriginal inhahitants, but are very distinct forms, belonging in a large proportion of cases, as shown by Alph. de Candolle, to distinct genera. In the Galapagos Archipelago, many even of the birds, though so well adapted for flying from island to island, differ on the different islands; thus there are three closely-allied species of mockingthrush, each confined to its own island. Now let us suppose the mocking-thrush of Chatham Island to be 
blown to Charles Island, which has its own mockingthrush; why should it succeed in establishing itself there? We may safely infer that Charles Island is well stocked with its own species, for annually more eggs are laid and young birds hatched, than can possibly be reared; and we may infer that the mocking-thrush peculiar to Charles's Island is at least as well fitted for its home as is the species peculiar to Chatham Island. Sir C. Lyell and Mr. Wollaston have communicated to me a remarkable fact bearing on this subject; namely, that Madeira and the adjoining islet of Porto Santo possess many distinct but representative species of landshells, some of which live in crevices of stone; and although large quantities of stone are annually transported from Porto Santo to Madeira, yet this latter island has not become colonised by the Porto Santo species; nevertheless both islands have been colonised by European land-shells, which no doubt had some advantage over the indigenous species. From these considerations I think we need not greatly marvel at the endemic species which inhabit the several islands of the Galapagos Archipelago, not having all spread from island to island. On the same continent, also, preoccupation has probably played an important part in checking the commingling of the species which inhabit different districts with nearly the same physical conditions. Thus, the south-east and south-west corners of Australia have nearly the same physical conditions, and are united by continuous land, yet they are inhabited by a vast number of distinct mammals, birds, and plants; so it is, according to Mr. Bates, with the butterflies and other animals inhabiting the great, open, and continuous valley of the Amazons. 
The same principle which governs the general character of the inhabitants of oceanic islands, namely, the relation to the source whence colonists could have been most easily derived, together with their subsequent modification, is of the widest application throughout nature. We see this on every mountain-summit, in every lake and marsh. For Alpine species, excepting in as far as the same species have become widely spread during the Glacial epoch, are related to those of the surrounding lowlands; thus we have in South America, Alpine humming-birds, Alpine rodents, Alpine plants, \&c., all strictly belonging to American forms; and it is obvious that a nountain, as it became slowly upheaved, would be colonised from the surrounding lowlands. So it is with the inhabitants of lakes and marshes, excepting in so far as great facility of transport has allowed the same forms to prevail throughout large portions of the world. We see this same principle in the character of most of the blind animals inhabiting the caves of America and of Europe. Other analogous facts could be given. It will, I believe, be found universally true, that wherever in two regions, let them be ever so distant, many closely allied or representative species occur, there will likewise be found some identical species; and wherever many closely-allied species occur, there will be found many forms which some naturalists rank as distinct species, and others as mere varieties; these doubtful forms showing us the steps in the progress of modification.

The relation between the power and extent of migration in certain species, either at the present or at some former period, and the existence at remote points of the world of closely-allied species, is shown in an- 
other and more general way. Mr. Gould remarked to me long ago, that in those genera of birds which range over the world, many of the species have very wide ranges. I can hardly doubt that this rule is generally true, though difficult of proof. Amongst mammals, we see it strikingly displayed in Bats, and in a lesser degree in the Felidæ and Canidæ. We see the same rule in the distribution of butterflies and beetles. So it is with most of the inhabitants of fresh water, for many of the genera in the most distinct classes range over the world, and many of the species have enormous ranges. It is not meant that all, but that some of the species have very wide ranges in the genera which range very widely. Nor is it meant that the species in such genera have on an average a very wide range; for this will largely depend on how far the process of modification has gone; for instance, two varieties of the same species inhabit America and Europe, and thus the species has an immense range; but, if variation were to be carried a little further, the two varieties would be ranked as distinct species, and their range would be greatly reduced. Still less is it meant, that species which have the capacity of crossing barriers and ranging widely, as in the case of certain powerfullywinged birds, will necessarily range widely; for we should never forget that to range widely implies not only the power of crossing barriers. but the more important power of being victorious in distant lands in the struggle for life with foreign associates. But according to the view that all the species of a genus, though distributed to the most remote points of the world, are descended from a single progenitor, we ought to find, and I believe as a general rule we 38 
do find, that some at least of the species range very widely.

We should bear in mind that many genera in all classes are of ancient origin, and the species in this case will have had ample time for dispersal and subsequent modification. There is also reason to believe from geological evidence, that within each great class the lower organisms change at a slower rate than the higher; consequently they will have had a better chance of ranging widely and of still retaining the same specific character. This fact, together with that of the reeds and eggs of most lowly organised forms being very minute and better fitted for distant transportal, probably accounts for a law which has long been observed, and which has lately been discussed by Alph. de Candolle in regard to plants, namely, that the lower any group of organisms stands the more widely it ranges.

The relations just discussed,-namely, lower organisms ranging more widely than the higher,-some of the species of widely-ranging genera themselves ranging widely, - such facts, as alpine, lacustrine, and marsh productions being generally related to those which live on the surrounding low lands and dry lands, - the striking relationship between the inhabitants of islands and those of the nearest mainland-the still closer relationship of the distinct inhabitants of the islands in the same archipelago-are inexplicable on the ordinary view of the independent creation of each species, but are explicable if we admit colonisation from the nearest or readiest source, together with the subsequent adaptation of the colonists to their new homes. 
Summary of the last and present Chapters.

In these chapters I have endeavoured to show, that if we make due allowance for our ignorance of the full effects of changes of climate and of the level of the land, which have certainly occurred within the recent period, and of other changes which have probably occurred,-if we remember how ignorant we are with respect to the many curious means of occasional transport,-if we bear in mind, and this is a very important consideration, how often a species may have ranged continuously over a wide area, and then have become extinct in the intermediate tracts, - the difficulty is not insuperable in believing that all the individuals of the same species, wherever found, are descended from common parents. And we are led to this conclusion, which has been arrived at by many naturalists under the designation of single centres of creation, by various general considerations, more especially from the importance of barriers of all kinds, and from the analogical distribution of sub-genera, genera, and families.

With respect to distinct species belonging to the same genus, which on our theory have spread from one parent-source; if we make the same allowances as before for our ignorance, and remember that some forms of life have changed very slowly, enormous periods of time having been thus granted for their migration; the difficulties are far from insuperable; though in this case, as in that of the individuals of the same species, they are often great.

As exemplifying the effects of climatal changes on distribution, I have attempted to show how important a part the last Glacial period has played, which affected 
even the equatorial regions, and which, during the alternations of the cold in the north and south, allowed the productions of opposite hemispheres to mingle, and left some of them stranded on the mountain-summits in all parts of the world. As showing how diversified are the means of occasional transport, I have discussed at some little length the means of dispersal of freshwater productions.

If the difficulties be not insuperable in admitting that in the long course of time all the individuals of the same species, and likewise of the several species belonging to the same genus, have proceeded from some one source; then all the grand leading facts of geographical distribution are explicable on the theory of migration, together with subsequent modification and the multiplication of new forms. We can thus understand the high importance of barriers, whether of land or water, in not only separating, but in apparently form. ing the several zoological and botanical provinces. We can thus understand the concentration of related species within the same areas; and how it is that under different latitudes, for instance in South America, the inhabitants of the plains and mountains, of the forests, marshes, and deserts, are linked together in so mysterious a manner, and are likewise linked to the extinct beings which formerly inhabited the same continent. Bearing in mind that the mutual relation of organism to organism is of the highest importance, we can see why two areas having nearly the same physical conditions should often be inhabited by very different forms of life; for according to the length of time which has elapsed since the colonists entered one of the regions, or both; according to the nature of the communication which 
allowed certain forms and not others to enter, either in greater or lesser numbers; according or not, as those which entered happened to come into more or less direct competition with each other and with the aborigines; and according as the immigrants were capable of varying more or less rapidly, there would ensue in the two or more regions, independently of their physical conditions, infinitely diversified conditions of life,-there would be an almost endless amount of organic action and reaction,-and we should find some groups of beings greatly, and some only slightly modified,- -some developed in great force, some existing in scanty numbers-and this we do find in the several great geographical provinces of the world.

On these same principles we can understand, as I have endeavoured to show, why oceanic islands should have few inhabitants, but that of these, a large proportion should be endemic or peculiar; and why, in relation to the means of migration, one group of beings should have all its species peculiar, and another group, even within the same class, should have all its species the same with those in an adjoining quarter of the world. We can see why whole groups of organisms, as batrachians and terrestrial mammals, should be absent from oceanic islands, whilst the most isolated islands should possess their own peculiar species of aerial mammals or bats. We can see why, in islands, there should be some relation between the presence of mammals, in a more or less modified condition, and the depth of the sea between such islands and the mainland. We can clearly see why all the inhabitants of an archipelago, though specifically distinct on the several islets, should be closely related to each other; and should likewise 
be related, but less closely, to those of the nearest continent, or other source whence immigrants might have been derived. We can see why, if there exist very closely allied or representative species in two areas, however distant from each other, some identical species will almost always there be found.

As the late Edward Forbes often insisted, there is a striking parallelism in the laws of life throughout time and space; the laws governing the succession of forms in past times being nearly the same with those governing at the present time the differences in different areas. We see this in many facts. The endurance of each species and group of species is continuous in time; for the apparent exceptions to the rule are so few, that they may fairly be attributed to our not having as yet discovered in an intermediate deposit certain forms which are absent in it, but which occur both above and below: so in space, it certainly is the general rule that the area inhabited by a single species, or by a group of species, is continuous, and the exceptions, which are not rare, may, as I have attempted to show, be accounted for by former migrations under different circumstances, or through occasional means of transport, or by the species having become extinct in the intermediate tracts. Both in time and space species and groups of species have their points of maximum development. Groups of species, living during the same period of time, or living within the same area, are often characterised by triffing features in common, as of sculpture or colour. In looking to the long succession of past ages, as in looking to distant provinces throughout the world, we find that species in certain classes differ little from each other, whilst those in another class, or only in a different 
section of the same order, differ greatly from each other. In both time and space the lowly organised members of each class generally change less than the highly organised; but there are in both cases marked exceptions to the rule. According to our theory, these several relations throughout time and space are intelligible; for whether we look to the allied forms of life which have changed during successive ages, or to those which have changed after having migrated into distant quarters, in both cases they are connected by the same bond of ordinary generation; in both cases the laws of variation have been the same, and modifications have been accumulated by the same means of natural selection. 


\section{CHAPTER XIV.}

MUTUAL AFFINITIES OF ORGANIC BEINGS: MORPHOLOGY: EMBRYOLOGY: RUDIMENTARY ORGANS.

Classification, groups subordinate to groups-Natural systemRules and difficulties in classification, explained on the theory of descent with modification-Classification of varieties-Descent always used in classification-Analogical or adaptive characters-Affinities, general, complex, and radiating-Extinction separates and defines groups-MoRPHOLOGY, between members of the same class, between parts of the same individual-EMBRYOLOGY, laws of, explained by variations not superrening at an early age, and being inherited at a corresponding ageRUDIMENTARY ORGAXS: their origin explained-Summary.

\section{Classification.}

Frou the most remote period in the history of the world organic beings have been found to resemble each other in descending degrees, so that they can be classed in groups under groups. This classification is not arbitrary like the grouping of the stars in constellations. The existence of groups would have been of simple significance, if one group had been exclusively fitted to inhabit the land and another the water; one to feed on flesh, another on regetable matter, and so on; but the case is widely different, for it is notorious how commonly members of even the same sub-group have different habits. In the second and fourth chapters, on Variation and on Natural Selection, I have attempted 
to show that within each country it is the widely ranging, the much diffused and common, that is the dominant species, belonging to the larger genera in each class, which vary most. The varieties, or incipient species, thus produced, ultimately become converted into new and distinct species; and these, on the principle of inheritance, tend to produce other new and dominant species. Consequently the groups which are now large, and which generally include many dominant species, tend to go on increasing in size. I further attempted to show that from the varying descendants of each species trying to occupy as many and as different places as possible in the economy of nature, they constantly tend to diverge in character. This latter conclusion is supported by observing the great diversity of forms which, in any small area, come into the closest competition, and by certain facts in naturalisation.

I attempted also to show that there is a steady tendency in the forms which are increasing in number and diverging in character, to supplant and exterminate the preceding, less divergent and less improved forms. I request the reader to turn to the diagram illustrating the action, as formerly explained, of these several principles; and he will see that the inevitable result is, that the modified descendants proceeding from one progenitor become broken up into groups subordinate to groups. In the diagram each letter on the uppermost line may represent a genus including several species, and the whole of the genera along this upper line form together one class, for all are descended from one ancient parent, and, consequently, have inherited something in common. But the three genera on the left hand have, on this same principle, much in common, and form a 
sub-family, distinct from that containing the next two genera on the right hand, which diverged from a common parent at the fifth stage of descent. These five genera have also much in common, though less than when grouped in sub-families; and they form a family distinct from that containing the three genera still farther to the right hand, which diverged at an earlier period. And all these genera, descended from (A), form an order distinct from the genera descended from (I). So that we here have many species descended from a single progenitor grouped into genera; and the genera into sub-families, families, and orders, all under one great class. The grand fact of the natural subordination of organic beings in groups under groups, which, from its familiarity, does not always sufficiently strike us, is in my judgment thus explained. No doubt organic beings, like all other objects, can be classed in many ways, either artificially by single characters, or more naturally by a number of characters. We know, for instance, that minerals and the elemental substances can be thus arranged. In this case there is of course no relation to genealogical succession, and no cause can at present be assigned for their falling into groups. But with organic beings the case is different, and the view above given accords with their natural arrangement in group under group; and no other explanation has ever been attempted.

Naturalists, as we have seen, try to arrange the species, genera, and families in each class, on what is called the Natural System. But what is meant by this system? Some authors look at it merely as a scheme for arranging together those living objects which are most alike, and for separating those which are most unlike; 
or as an artificial method of enunciating, as briefly as possible, general propositions, - that is, by one sentence to give the characters common, for instance, to all mammals, by another those common to all carnivora, by another those common to the dog-genus, and then, by adding a single sentence, a full description is given of each kind of dog. The ingenuity and utility of this system are indisputable. But many naturalists think that something more is meant by the Natural System; they believe that it reveals the plan of the Creator; but unless it be specified whether order in time or space, or both, or what else is meant by the plan of the Creator, it seems to me that nothing is thus added to our knowledge. Expressions such as that famous one by Linnæus, which we often meet with in a more or less concealed form, namely, that the characters do not make the genus, but that the genus gives the characters, seem to imply that some deeper bond is included in our classifications than mere resemblance. I believe that this is the case, and that community of descent-the one known cause of close similarity in organic beings-is the bond, which though observed by various degrees of modification, is partially revealed to us by our classifications.

Let us now consider the rules followed in classification, and the difficulties which are encountered on the view that classification either gives some unknown plan of creation, or is simply a scheme for enunciating general propositions and of placing together the forms most like each other. It might have been thought (and was in ancient times thought) that those parts of the structure which determined the habits of life, and the general place of each being in the economy of nature, 
would be of very high importance in classification. Nothing can be more false. No one regards the external similarity of a mouse to a shrew, of a dugong to a whale, of a whale to a fish, as of any importance. These resemblances, though so intimately connected with the whole life of the being, are ranked as merely "adaptive or analogical characters;" but to the consideration of these resemblances we shall recur. It may even be given as a general rule, that the less any part of the organisation is concerned with special habits, the more important it becomes for classification. As an instance: Owen, in speaking of the dugong, says, "The generative organs, being those which are most remotely related to the habits and food of an animal, I have always regarded as affording very clear indications of its true affinities. We are least likely in the modifications of these organs to mistake a merely adaptive for an essential character.' With plants how remarkable it is that the organs of vegetation, on which their nutrition and life depend, are of little signification; whereas the organs of reproduction, with their product the seed and embryo, are of paramount importance! So again in formerly discussing certain morphological characters which are not functionally important, we have seen that they are often of the highest service in classification. This depends on their constancy throughout many allied groups; and their constancy chiefly depends on any slight deviations not having been preserved and accumulated by natural selection, which acts only on serviceable characters.

That the mere physiological importance of an organ does not determine its classificatory value, is almost proved by the fact that in allied groups, in which the 
same organ, as we have every reason to suppose, has nearly the same physiological value, its classificatory value is widely different. No naturalist can have worked long at any group without being struck with this fact; and it has been fully acknowledged in the writings of almost every author. It will suffice to quote the highest authority, Robert Brown, who, in speaking of certain organs in the Proteaceæ, says their generic importance, "like that of all their parts, not only in this, but, as I apprehend, in every natural family, is very unequal, and in some cases seems to be entirely lost." Again, in another work he says, the genera of the Connaraceæ " differ in having one or more ovaria, in the existence or absence of albumen, in the imbricate or valvular æstivation. Any one of these characters singly is frequently of more than generic importance, though here even when all taken together they appear insufficient to separate Cnestis from Connarus." To give an example amongst insects: in one great division of the Hymenoptera, the antennæ, as Westwood has remarked, are most constant in structure; in another division they differ much, and the differences are of quite subordinate value in classification; yet no one will say that the antennæ in these two divisions of the same order are of unequal physiological importance. Any number of instances could be given of the varying importance for classification of the same important organ within the same group of beings.

Again, no one will say that rudimentary or atrophied organs are of high physiological or vital importance; yet, undoubtedly, organs in this condition are often of much value in classification. No one will dispute that the rudimentary teeth in the upper jaws of young rumi- 
nants, and certain rudimentary bones of the leg, are highly serviceable in exhibiting the close affinity between ruminants and pachyderms. Robert Brown has strongly insisted on the fact that the position of the rudimentary florets is of the highest importance in the classification of the grasses.

Numerous instances could be given of characters derived from parts which must be considered of very trifling physiological importance, but which are universally admitted as highly serviceable in the definition of whole groups. For instance, whether or not there is an open passage from the nostrils to the mouth, the only character, according to Owen, which absolutely distinguishes fishes and reptiles-the inflection of the angle of the lower jaw in Marsupials - the manner in which the wings of insects are folded-mere colour in certain Algæ-mere pubescence on parts of the flower in grasses - the nature of the dermal covering, as hair or feathers, in the Vertebrata. If the Ornithorhynchus had been covered with feathers instead of hair, this external and trifling character would have been considered by naturalists as an important aid in determining the degree of affinity of this strange creature to birds.

The importance, for classification, of trifling characters, mainly depends on their being correlated with many other characters of more or less importance. The value indeed of an aggregate of characters is very evident in natural history. Hence, as has often been remarked, a species may depart from its allies in several characters, both of high physiological importance, and of almost universal prevalence, and yet leave us in no doubt where it should be ranked. Hence, also, it has been found 
that a classification founded on any single character, however important that may be, has always failed; for no part of the organisation is invariably constant. The importance of an aggregate of characters, even when none are important, alone explains the aphorism enunciated by Linnæus, namely, that the characters do not give the genus, but the genus gives the characters; for this seems founded on the appreciation of many trifling points of resemblance, too slight to be defined. Certain plants, belonging to the Malpighiaceæ, bear perfect and degraded flowers; in the latter, as A. de Jussieu has remarked, "the greater number of the characters proper to the species, to the genus, to the family, to the class, disappear, and thus laugh at our classification." When Aspicarpa produced in France, during several years, only these degraded flowers, departing so wonderfully in a number of the most important points of structure from the proper type of the order, yet M. Richard sagaciously saw, as Jussieu observes, that this genus should still be retained amongst the Malpighiaceæ. This case well illustrates the spirit of our classifications.

Practically, when naturalists are at work, they do not trouble themselves about the physiological value of the characters which they use in defining a group or in allocating any particular species. If they find a character nearly uniform, and common to a great number of forms, and not common to others, they use it as one of high value; if common to some lesser number, they use it as of subordinate value. This principle has been broadly confessed by some naturalists to be the true one; and by none more clearly than by that excellent botanist, Aug. St. Hilaire. If several trifling 
characters are always found in combination, though no apparent bond of connection can be discovered between them, especial value is set on them. As in most groups of animals, important organs, such as those for propelling the blood, or for aerating it, or those for propagating the race, are found nearly uniform, they are considered as highly serviceable in classification; but in some groups all these, the most important vital organs, are found to offer characters of quite subordinate value. Thus, as Fritz Müller has lately remarked, in the same group of crustaceans, Cypridina is furnished with a heart, whilst in two closely allied genera, namely Cypris and Cytherea, there is no such organ; one species of Cypridina has well-developed branchiæ, whilst another species is destitute of them.

We can see why characters derived from the embryo should be of equal importance with those derived from the adult, for a natural classification of course includes all ages. But it is by no means obrious, on the ordinary view, why the structure of the embryo should be more important for this purpose than that of the adult, which alone plays its full part in the economy of nature. Yet it has been strongly urged by those great naturalists, Milne Edwards and Agassiz, that embryological characters are the most important of all; and this doctrine has very generally been admitted as true. Nevertheless, their importance has sometimes been exaggerated, owing to the adaptive characters of larvæ not having been excluded; in order to show this, Fritz Miuller arranged by the aid of such characters alone the great class of crustaceans. and the arrangement did not prove a natural one. But there can be no doubt that embryonic, excluding larval characters, are of the high- 
est value for classification, not only with animals but with plants. Thus the main divisions of flowering plants are founded on differences in the embryo,-on the number and position of the cotyledons, and on the mode of development of the plumule and radicle. We shall immediately see why these characters possess so high a value in classification, namely, from the natural system being genealogical in its arrangement.

Our classifications are often plainly influenced by chains of affinities. Nothing can be easier than to define a number of characters common to all birds; but with crustaceans, any such definition has hitherto been found impossible. There are crustaceans at the opposite ends of the series, which have hardly a character in common; yet the species at both ends, from being plainly allied to others, and these to others, and so onwards, can be recognised as unequivocally belonging to this, and to no other class of the Articulata.

Geographical distribution has often been used, though perhaps not quite logically, in classification, more especially in very large groups of closely allied forms. Temminck insists on the utility or even necessity of this practice in certain groups of birds; and it has been followed byseveral entomologists and botanists.

Finally, with respect to the comparative value of the various groups of species, such as orders, sub-orders, families, sub-families, and genera, they seem to be, at least at present, almost arbitrary. Several of the best botanists, such as Mr. Bentham and others, have strongly insisted on their arbitrary value. Instances could be given amongst plants and insects, of a group first ranked by practised naturalists as only a genus, and then raised to the rank of a sub-family or family; and this has 
been done, not because further research has detected important structural differences, at first overlooked, but because numerous allied species with slightly different grades of difference, have been subsequently discovered.

All the foregoing rules and aids and difficulties in classification may be explained, if I do not greatly deceive myself, on the view that the Natural System is founded on descent with modification;-that the characters which naturalists consider as showing true affinity between any two or more species, are those which have been inherited from a common parent, all true classification being genealogical; - that community of descent is the hidden bond which naturalists have been unconsciously seeking, and not some unknown plan of creation, or the enunciation of general propositions, and the mere putting together and separating objects more or less alike.

But I must explain my meaning more fully. I believe that the arrangement of the groups within each class, in due subordination and relation to each other, must be strictly genealogical in order to be natural; but that the amount of difference in the several branches or groups, though allied in the same degree in blood to their common progenitor, may differ greatly, being due to the different degrees of modification which they have undergone; and this is expressed by the forms being ranked under different genera, families, sections, or orders. The reader will best understand what is meant, if he will take the trouble to refer to the diagram in the fourth chapter. We will suppose the letters $A$ to $L$ to represent allied genera existing during the Silurian epoch, and descended from some still earlier form. In 
three of these genera (A, F, and I), a species has transmitted modified descendants to the present day, represented by the fifteen genera $\left(a^{14}\right.$ to $\left.z^{14}\right)$ on the uppermost horizontal line. Now all these modified descendants from a single species, are related in blood or descent in the same degree; they may metaphorically be called cousins to the same millionth degree; yet they differ widely and in different degrees from each other. The forms descended from A, now broken up into two or three families, constitute a distinct order from those descended from I, also broken up into two families. Nor can the existing species, descended from $A$, be ranked in the same genus with the parent A; or those from I, with the parent $I$. But the existing genus $F^{14}$ may be supposed to have been but slightly modified; and it will then rank with the parent-genus $\mathrm{F}$; just as some few still living organisms belong to Silurian genera. So that the comparative value of the differences between these organic beings, which are all related to each other in the same degree in blood, has come to be widely different. Nevertheless their genealogical arrangement remains strictly true, not only at the present time, but at each successive period of descent. All the modified descendants from $A$ will have inherited something in common from their common parent, as will all the descendants from I; so will it be with each subordinate branch of descendants, at each successive stage. If, however, we suppose any descendant of $\mathbf{A}$, or of I, to have become so much modified as to have lost all traces of its parentage, in this case, its place in the natural system will be lost, as seems to have occurred with some few existing organisms. All the descendants of the genus F, along its whole line of descent, are 
supposed to have been but little modified, and they form a single genus. But this genus, though much isolated, will still occupy its proper intermediate position. The representation of the groups, as here given in the diagram on a flat surface, is much too simple. The branches ought to have diverged in all directions. If the names of the groups had been simply written down in a linear series, the representation would have been still less natural; and it is notoriously not possible to represent in a series, on a flat surface, the affinities which we discover in nature amongst the beings of the same group. Thus, the natural system is genealogical in its arrangement, like a pedigree: but the amount of modification which the different groups have undergone has to be expressed by ranking them under different so-called genera, sub-families, families, sections, orders, and classes.

It may be worth while to illustrate this view of classification, by taking the case of languages. If we possessed a perfect pedigree of mankind, a genealogical arrangement of the races of man would afford the best classification of the various languages now spoken throughout the world; and if all extinct languages, and all intermediate and slowly changing dialects, were to be included, such an arrangement would be the only possible one. Yet it might be that some ancient languages had altered very little and had given rise to few new languages, whilst others had altered much owing to the spreading, isolation, and state of civilisation of the several co-descended races, and had thus given rise to many new dialects and languages. The various degrees of difference between the languages of the same stock, would have to be expressed by groups subordinate to 
groups; but the proper or even the only possible arrangement would still be genealogical; and this would be strictly natural, as it would connect together all languages, extinct and recent, by the closest affinities, and would give the filiation and origin of each tongue.

In confirmation of this view, let us glance at the classification of varieties, which are known or believed to be descended from a single species. These are grouped under the species, with the sub-varieties under the varieties; and in some cases, as with the domestic pigeon, with several other grades of difference. Nearly the same rules are followed as in classifying species. Authors have insisted on the necessity of arranging varieties on a natural instead of an artificial system; we are cautioned, for instance, not to class two varieties of the pine-apple together, merely because their fruit, though the most important part, happens to be nearly identical; no one puts the Swedish and common turnip together, though the esculent and thickened stems are so similar. Whatever part is found to be most constant, is used in classing varieties: thus the great agriculturist Marshall says the horns are very useful for this purpose with cattle, because they are less variable than the shape or colour of the body, \&c.; whereas with sheep the horns are much less serviceable, because less constant. In classing varieties, I apprehend that if we had a real pedigree, a genealogical classification would be universally preferred; and it has been attempted in some cases. For we might feel sure, whether there had been more or less modification, that the principle of inheritance would keep the forms together which were allied in the greatest number of points. In tumbler pigeons, though some of the sub-varieties differ in the 
important character of the length of the beak, yet all are kept together from having the common habit of tumbling; but the short-faced breed has nearly or quite lost his habit: nevertheless, without any thought on the subject, these tumblers are kept in the same group, because allied in blood and alike in some other respects.

With species in a state of nature, every naturalist has in fact brought descent into his classification; for he includes in his lowest grade, that of species, the two sexes; and how enormously these sometimes differ in the most important characters, is known to every naturalist: scarcely a single fact can be predicated in common of the adult males and hermaphrodites of certain cirripedes, and yet no one dreams of separating them. As soon as the three Orchidean forms, Monachanthus, Myanthus, and Catasetum, which had previously been ranked as three distinct genera, were known to be sometimes produced on the same plant, they were immediately considered as varieties; and now I have been able to show that they are the male, female, and hermaphrodite forms of the same species. The naturalist includes as one species the various larval stages of the same individual, however much they may differ from each other and from the adult, as well as the so-called alternate generations of Steenstrup, which can only in a technical sense be considered as the same individual. He includes monsters and varieties, not from their partial resemblance to the parent-form, but because they are descended from it.

As descent has universally been used in classing together the individuals of the same species, though the males and females and larvæ are sometimes extremely different; and as it has been used in classing varieties 
which have undergone a certain, and sometimes a considerable amount of modification, may not this same element of descent have been unconsciously used in grouping species under genera, and genera under higher groups, all under the so-called natural system? I believe it has been unconsciously used; and thus only can I understand the several rules and guides which have been followed by our best systematists. As we have no written pedigrees, we are forced to trace community of descent by resemblances of any kind. Therefore we chose those characters which are the least likely to have been modified, in relation to the conditions of life to which each species has been recently exposed. Rudimentary structures on this view are as good as, or even sometimes better than, other parts of the organisation. We care not how trifling a character may be-let it be the mere inflection of the angle of the jaw, the manner in which an insect's wing is folded, whether the skin be covered by hair or feathers-if it prevail throughout many and different species, especially those having very different habits of life, it assumes high value; for we can account for its presence in so many forms with such different habits, only by inheritance from a common parent. We may err in this respect in regard to single points of structure, but when several characters, let them be ever so trifling, concur throughout a large group of beings having different habits, we may feel almost sure, on the theory of descent, that these characters have been inherited from a common ancestor; and we know that such aggregated characters have especial value in classification.

We can understand why a species or a group of species may depart from its allies, in several of its most 
important characteristics, and yet be safely classed with them. This may be safely done, and is often done, as long as a sufficient number of characters, let them be ever so unimportant, betrays the hidden bond of community of descent. Let two forms have not a single character in common, yet, if these extreme forms are connected together by a chain of intermediate groups, we may at once infer their community of descent, and we put them all into the same class. As we find organs of high physiological importance-those which serve to preserve life under the most diverse conditions of existence-are generally the most constant, we attach especial value to them; but if these same organs, in another group or section of a group, are found to differ mucl, we at once value them less in our classification. We shall presently see why embryological characters are of such high classificatory importance. Gengraphical distribution may sometimes be brought usefully into play in classing large genera, because all the species of the same genus, inhabiting any distinct and isolated region, are in all probability descended from the same parents.

Analogical Resemblances.-We can understand, on the above views, the very important distinction between real affinities and analogical or adaptive resemblances. Lamarck first called attention to this subject, and he has been ably followed by Macleay and others. The resemblance in the shape of the body and in the fin-like anterior limbs between dugongs and whales, and between these two orders of mammals and fishes, are analogical. So is the resemblance between a mouse and a shrew-mouse (Sorex), which belong to different orders; and the still closer resemblance, insisted on by Mr. Mivart, between the mouse and a small marsupial animal 
(Antechinus) of Australia. These latter resemblances may be accounted for, as it seems to me, by adaptation for similarly active movements through thickets and herbage, together with concealment from enemies.

Amongst insects there are innumerable similar instances; thus Linnæus, misled by external appearances, actually classed an homopterous insect as a moth. We see something of the same kind even with our domestic varieties, as in the strikingly similar shape of the body in the improved breeds of the Chinese and common pig, which are descended from distinct species; and in the similarly thickened stems of the common and specifically distinct Swedish turnip. The resemblance between the greyhound and the racehorse is hardly more fanciful than the analogies which have been drawn by some authors between widely different animals.

On the view of characters being of real importance for classification, only in so far as they reveal descent, we can clearly understand why analogical or adaptive characters, although of the utmost importance to the welfare of the being, are almost valueless to the systematist. For animals, belonging to two most distinct lines of descent, may have become adapted to similar conditions, and thus have assumed a close external resemblance; but such resemblances will not reveal-will rather tend to conceal their blood-relationship. We can thus also understand the apparent paradox, that the very same characters are analogical when one group is compared with another, but give true affinities when the members of the same group are compared together: thus, the shape of the body and fin-like limbs are only analogical when whales are compared with fishes, being adaptations in both classes for swimming through 
the water; but between the several members of the whale family, the shape of the body and the fin-like limbs offer characters exhibiting true affinity; for as these parts are so nearly similar throughout the whole family, we cannot doubt that they have been inherited from a common ancestor. So it is with fishes.

Numerous cases could be given of striking resemblances in quite distinct beings between single parts or organs, which have been adapted for the same functions. A good instance is afforded by the close resemblance of the jaws of the dog and Tasmanian wolf or Thylacinus, -animals which are widely sundered in the natural system. But this resemblance is confined to general appearance, as in the prominence of the canines, and in the cutting shape of the molar teeth. For the teeth really differ much: thus the dog has on each side of the upper jaw four pre-molars and only two molars; whilst the Thylacinus has three pre-molars and four molars. The molar3 also differ much in the two animals in relative size and structure. The adult dentition is preceded by a widely different milk dentition. Any one may of course deny that the teeth in either case have been adapted for tearing flesh, through the natural selection of successive variations; but if this be admitted in the one case, it is unintelligible to me that it should be denied in the other. I am glad to find that so high an authority as Professor Flower has come to this same conclusion.

The extraordinary cases given in a former chapter, of widely different fishes possessing electric organs, - of widely different insects possessing luminous organs.and of orchids and asclepiads having pollen-masses with 
viscid discs, come under this same head of analogical resemblances. But these cases are sowonderful that they were introduced as difficulties or objections to our theory. In all such cases some fundamental difference in the growth or development of the parts, and generally in their matured structure, can be detected. The end gained is the same, but the means, though appearing superficially to be the same, are essentially different. The principle formerly alluded to under the term of analogical variation has probably in these cases often come into play; that is, the members of the same class, although only distantly allied, have inherited so much in common in their constitution, that they are apt to vary under similar exciting causes in a similar manner; and this would obviously aid in the acquirement through natural selection of parts or organs, strikingly like each other, independently of their direct inheritance from a common progenitor.

As species belonging to distinct classes have often been adapted by successive slight modifications to live under nearly similar circumstances,-to inhabit, for instance, the three elements of land, air, and water,-we can perhaps understand how it is that a numerical parallelism has sometimes been observed between the subgroups of distinct classes. A naturalist, struck with a parallelism of this nature, by arbitrarily raising or sinking the value of the groups in several classes (and all our experience shows that their valuation is as yet arbitrary), could easily extend the parallelism over a wide range; and thus the septenary, quinary, quarternary and ternary classifications have probably arisen.

There is another and curious class of cases in which close external resemblance does not depend on adapta- 
tion to similar habits of life, but has been gained for the sake of protection. I allude to the wonderful manner in which certain butterflies imitate, as first described by Mr. Bates, other and quite distinct species. This excellent observer has shown that in some districts of S. America, where, for instance, an Ithomia abounds in gaudy swarms, another butterfly, namely, a Leptalis, is often found mingled in the same flock; and the latter so closely resembles the Ithomia in every shade and stripe of colour and even in the shape of its wings, that Mr. Bates, with his eyes sharpened by collecting during eleven years, was, though always on his guard, continually deceived. When the mockers and the mocked are caught and compared, they are found to be very different in essential structure, and to belong not only to distinct genera, but often to distinct families. Had this mimicry occurred in only one or two instances, it might have been passed over as a strange coincidence. But, if we proceed from a district where one Leptalis imitates an Ithomia, another mocking and mocked species belonging to the same two genera, equally close in their resemblance, may be found. Altogether no less than ten genera are enumerated, which include species that imitate other butterflies. The mockers and mocked always inhabit the same region; we never find an imitator living remote from the form which it imitates. The mockers are almost invariably rare insects; the mocked in almost every case abound in swarms. In the same district in which a species of Leptalis closely imitates an Ithomia, there are sometimes other Lepidoptera mimicking the same Ithomia: so that in the same place. species of three genera of butterflies and even a moth are found all closely resembling a butter- 
fly belonging to a fourth genus. It deserves especial notice that many of the mimicking forms of the Leptalis, as well as of the mimicked forms, can be shown by a graduated series to be merely varieties of the same species; whilst others are undoubtedly distinct species. But why, it may be asked, are certain forms treated as the mimicked and others as the mimickers? Mr. Bates satisfactorily answers this question, by showing that the form which is imitated keeps the usual dress of the group to which it belongs, whilst the counterfeiters have changed their dress and do not resemble their nearest allies.

We are next led to inquire what reason can be assigned for certain butterflies and moths so often assuming the dress of another and quite distinct form; why, to the perplexity of naturalists, has nature condescended to the tricks of the stage? Mr. Bates has, no doubt, hit on the true explanation. The mocked forms, which always abound in numbers, must habitually escape destruction to a large extent, otherwise they could not exist in such swarms; and a large amount of evidence has now been collected, showing that they are distasteful to birds and other insect-devouring animals. The mocking forms, on the other hand, that inhabit the same district, are comparatively rare, and belong to rare groups; hence they must suffer habitually from some danger, for otherwise, from the number of eggs laid by all butterflies, they would in three or four generations swarm over the whole country. Now if a member of one of these persecuted and rare groups were to assume a dress so like that of a well-protected species that it continually deceived the practised eyes of an entomologist, it would often deceive predaceous birds 
and insects, and thus often escape destruction. Mr. Bates may almost be said to have actually witnessed the process by which the mimickers have come so closely to resemble the mimicked; for he found that sume of the forms of Leptalis which mimic so many other butterflies, varied in an extreme degree. In one district several varieties occurred, and of these one alone resembled to a certain extent, the common Ithomia of the same district. In another district there were two or three varieties, one of which was much commoner than the others, and this closely mocked another form of Ithomia. From facts of this nature, Mr. Bates concludes that the Leptalis first varies; and when a variety happens to resemble in some degree any common butterfly inhabiting the same district, this variety, from its resemblance to a flourishing and little-persecuted kind, has a better chance of escaping destruction from predaceous birds and insects, and is consequently oftener preserved;-“" the less perfect degrees of resemblance being generation after generation eliminated, and only the others left to propagate their kind." So that here we have an excellent illustration of natural selection.

Messrs. Wallace and Trimen have likewise described several equally striking cases of imitation in the Lepidoptera of the Malay Archipelago and Africa, and with some other insects. Mr. Wallace has also detected one such case with birds, but we have none with the larger quadrupeds. The much greater frequency of imitation with insects than with other animals, is probably the consequence of their small size; insects cannot defend themselves, excepting indeed the kinds furnished with a string, and I have never heard of an instance of 
such kinds mocking other insects, though they are mocked; insects cannot easily escape by flight from the larger animals which prey on them; therefore, speaking metaphorically, they are reduced, like most weak creatures, to trickery and dissimulation.

It should be observed that the process of imitation probably never commenced between forms widely dissimilar in colour. But starting with species already somewhat like each other, the closest resemblance, if beneficial, could readily be gained by the above means; and if the imitated form was subsequently and gradually modified through any agency, the imitating form would be led along the same track, and thus be altered to almost any extent, so that it might ultimately assume an appearance or colouring wholly unlike that of the other members of the family to which it belonged. There is, however, some difficulty on this head, for it is necessary to suppose in some cases that ancient members belonging to several distinct groups, before they had diverged to their present extent, accidentally resembled a member of another and protected group in a sufficient degree to afford some slight protection; this having given the basis for the subsequent acquisition of the most perfect resemblance.

On the Nature of the Affinities connecting Organic Beings.-As the modified descendants of dominant species, belonging to the larger genera, tend to inherit the advantages which made the groups to which they belong large and their parents dominant, they are almost sure to spread widely, and to seize on more and more places in the economy of nature. The larger and more dominant groups within each class thus tend to 
go on increasing in size; and they consequently supplant many smaller and feebler groups. Thus we can account for the fact that all organisms, recent and extinct, are included under a few great orders, and under still fewer classes. As showing how few the higher groups are in number, and how widely they are spread throughout the world, the fact is striking that the discovery of Australia has not added an insect belonging to a new class; and that in the vegetable kingdom, as I learn from Dr. Hooker, it has added only two or three families of small size.

In the chapter on Geological Succession I attempted to show, on the principle of each group having generally diverged much in character during the long-continued process of modification, how it is that the more ancient forms of life often present characters in some degree internediate between existing groups. As some few of the old and intermediate forms have transmitted to the present day descendants but little modified, these constitute our so-called osculant or aberrant species. The more aberrant any form is, the greater must be the number of connecting forms which have been exterminated and utterly lost. And we have some evidence of aberrant groups having suffered severely from extinction, for they are almost always represented by extremely few species; and such species as do occur are generally very distinct from each other, which again implies extinction. The genera Ornithorhynchus and Lepidosiren, for example, would not have been less aberrant had each been represented by a dozen species, instead of as at present by a single one, or by two or three. We can, I think, account for this fact only by looking at aberrant groups as forms which have been con. 
quered by more successful competitors, with a few members still preserved under unusually favourable conditions.

Mr. Waterhouse has remarked that, when a member belonging to one group of animals exhibits an affinity to a quite distinct group, this affinity in most cases is general and not special; thus, according to Mr. Waterhouse, of all Rodents, the bizcacha is most nearly related to Marsupials; but in the points in which it approaches this order, its relations are general, that is, not to any one marsupial species more than to another. As these points of affinity are believed to be real and not merely adaptive, they must be due in accordance with our view to inheritance from a common progenitor. Therefore we must suppose either that all Rodents, including the bizcacha, branched off from some ancient Marsupial, which will naturally have been more or less intermediate in character with respect to all existing Marsupials; or that both Rodents and Marsupials branched off from a common progenitor, and that both groups have since undergone much modification in divergent directions. On either view we must suppose that the bizcacha has retained, by inheritance, more of the characters of its ancient progenitor than have other Rodents; and therefore it will not be specially related to any one existing Marsupial, but indirectly to all or nearly all Marsupials, from having partially retained the character of their common progenitor, or of some early member of the group. On the other hand, of all Marsupials, as Mr. Waterhouse has remarked, the Phascolomys resembles most nearly, not any one species, but the general order of Rodents. In this case, however, it may be strongly suspected that the resemblance is only analogical, owing 40 
to the Phascolomys having become adapted to habits like those of a Rodent. The elder De Candolle has made nearly similar observations on the general nature of the affinities of distinct families of plants.

On the principle of the multiplication and gradual divergence in character of the species descended from a common progenitor, together with their retention by inheritance of some characters in common, we can understand the excessively complex and radiating affinities by which all the members of the same family or higher group are connected together. For the common progenitor of a whole family, now broken up by extinction into distinct groups and sub-groups, will have transmitted some of its characters, modified in various ways and degrees, to all the species; and they will consequently be related to each other by circuitous lines of affinity of various lengths (as may be seen in the diagram so often referred to), mounting up through many predecessors. As it is difficult to show the blood-relationship between the numerous kindred of any ancient and noble family even by the aid of a genealogical tree, and almost impossible to do so without this aid, we can understand the extraordinary difficulty which naturalists have experienced in describing, without the aid of a diagram, the various affinities which they perceive between the many living and extinct members of the same great natural class.

Extinction, as we have seen in the fourth chapter, has played an important part in defining and widening the intervals between the several groups in each class. We may thus account for the distinctness of whole classes from each other-for instance, of birds from all other vertebrate animals-by the belief that many ancient 
forms of life have been utterly lost, through which the early progenitors of birds were formerly connected with the early progenitors of the other and at that time less differentiated vertebrate classes. There has been much less extinction of the forms of life which once connected fishes with batrachians. There has been still less within some whole classes, for instance the Crustacea, for here the most wonderfully diverse forms are still linked together by a long and only partially broken chain of affinities. Extinction has only defined the groups: it has by no means made them; for if every form which has ever lived on this earth were suddenly to reappear, though it would be quite impossible to give definitions by which each group could be distinguished, still a natural classification, or at least a natural arrangement, would be possible. We shall see this by turning to the diagram; the letters, A to $\mathrm{L}$, may represent eleven Silurian genera, some of which have produced large groups of modified descendants, with every link in each branch and sub-branch still alive; and the links not greater than those between existing varieties. In this case it would be quite impossible to give definitions by which the several members of the several groups could be distinguished from their more immediate parents and descendants. Yet the arrangement in the diagram would still hold good and would be natural; for, on the principle of inheritance, all the forms descended, for instance, from A, would have something in common. In a tree we can distinguish this or that branch, though at the actual fork the two unite and blend together. We could not, as I have said, define the several groups; but we could pick out types, or forms, representing most of the characters of each group, whether large or small, 
and thus give a general idea of the value of the differences between them. This is what we should be driven to, if we were ever to succeed in collecting all the forms in any one class which have lived throughout all time and space. Assuredly we shall never succeed in making so perfect a collection: nevertheless, in certain classes, we are tending towards this end; and Milne Edwards has lately insisted, in an able paper, on the high importance of looking to types, whether or not we can separate and define the groups to which such types belong.

Finally, we have seen that natural selection, which follows from the struggle for existence, and which almost inevitably leads to extinction and divergence of character in the descendants from any one parent-species, explains that great and universal feature in the affinities of all organic beings, namely, their subordination in group under group. We use the element of descent in classing the individuals of both sexes and of all ages under one species, although they may have but few characters in common; we use descent in classing acknowledged varieties, however different they may be from their parents; and I believe that this element of descent is the hidden bond of connection which naturalists have sought under the term of the Natural System. On this idea of the natural system being, in so far as it has been perfected, genealogical in its arrangement, with the grades of difference expressed by the terms genera, families, orders, \&c., we can understand the rules which we are compelled to follow in our classification. We can understand why we value certain resemblances far more than others; why we use rudimentary and useless organs, or others of trifling physiological importance; 
why, in finding the relations between one group and another, we summarily reject analogical or adaptive characters, and yet use these same characters within the limits of the same group. We can clearly see how it is that all living and extinct forms can be grouped together within a few great classes; and how the several members of each class are connected together by the most complex and radiating lines of affinities. We shall never, probably, disentangle the inextricable web of the affinities between the members of any one class; but when we have a distinct object in view, and do not look to some unknown plan of creation, we may hope to make sure but slow progress.

Professor Häckel in his 'Generelle Morphologie' and in other works, has recently brought his great knowledge and abilities to bear on what he calls phylogeny, or the lines of descent of all organic beings. In drawing up the several series he trusts chiefly to embryological characters, but receives aid from homologous and rudimentary organs, as well as from the successive periods at which the various forms of life are believed to have first appeared in our geological formations. He has thus boldly made a great beginning, and shows us how classification will in the future be treated.

\section{Morphology.}

We have seen that the members of the same class, independently of their habits of life, resemble each other in the general plan of their organisation. This resemblance is often expressed by the term " unity of type;" or by saying that the several parts and organs in the different species of the class are homologous. The whole 
subject is included under the general term of Morphology. This is one of the most interesting departments of natural history, and may almost be said to be its very soul. What can be more curious than that the hand of a man, formed for grasping, that of a mole for digging, the leg of the horse, the paddle of the porpoise, and the wing of the bat, should all be constructed on the same pattern, and should include similar bones, in the same relative positions? How curious it is, to give a subordinate though striking instance, that the hind-feet of the kangaroo, which are so well fitted for bounding over the open plains,- those of the climbing, leaf-eating koala, equally well fitted for grasping the branches of trees,- those of the ground-dwelling, insect or root eating, bandicoots, -and those of some other Australian marsupials,-should all be constructed on the same extraordinary type, namely with the bones of the second and third digits extremely slender and enveloped within the same skin, so that they appear like a single toe furnished with two claws. Notwithstanding this similarity of pattern, it is obvious that the hind feet of these several animals are used for as widely different purposes as it is possible to conceive. The case is rendered all the more striking by the American opossums, which follow nearly the same habits of life as some of their Australian relatives, having feet constructed on the ordinary plan. Professor Flower, from whom these statements are taken, remarks in conclusion: "We may call this conformity to type, without getting much nearer to an explanation of the phenomenon;" and he then adds " but is it not powerfully suggestive of true relationship, of inheritance from a common an. cestor?" 
Geoffroy St. Hilaire has strongly insisted on the high importance of relative position or connexion in homologous parts; they may differ to almost any extent in form and size, and yet remain connected together in the same invariable order. We never find, for instance, the bones of the arm and fore-arm, or of the thigh and leg, transposed. Hence the same names can be given to the homologous bones in widely different animals. We see the same great law in the construction of the mouths of insects: what can be more different than the immensely long spiral proboscis of a sphinx-moth,the curious folded one of a bee or bug, and the great jaws of a beetle?yet all these organs, serving for such widely different purposes, are formed by infinitely numerous modifications of an upper lip, mandibles, and two pairs of maxillæ. The same law governs the construction of the mouths and limbs of crustaceans. So it is with the flowers of plants.

Nothing can be more hopeless than to attempt to explain this similarity of pattern in members of the same class, by utility or by the doctrine of final causes. The hopelessness of the attempt has been expressly admitted by Owen in his most interesting work on the 'Nature of Limbs.' On the ordinary view of the independent creation of each being, we can only say that so it is; - that it has pleased the Creator to construct all the animals and plants in each great class on a uniform plan; but this is not a scientific explanation.

The explanation is to a large extent simple on the theory of the selection of successive slight modifications, - each modification being profitable in some way to the modified form, but often affecting by correlation other parts of the organisation. In changes of this nature, 
there will be little or no tendency to alter the original pattern, or to transpose the parts. The bones of a limb might be shortened and flattened to any extent, becoming at the same time enveloped in thick membrane, so as to serve as a fin; or a webbed hand might have all its bones, or certain bones, lengthened to any extent, with the membrane connecting them increased, so as to serve as a wing; yet all these modifications would not tend to alter the framework of the bones or the relative connection of the parts. If we suppose that an early progenitor-the archetype as it may be calledof all mammals, birds, and reptiles, had its limbs constructed on the existing general pattern, for whatever purpose they served, we can at once perceive the plain signification of the homologous construction of the limbs throughout the class. So with the mouths of insects, we have only to suppose that their common progenitor had an upper lip, mandibles, and two pairs of maxillæ, these parts being perhaps very simple in form; and then natural selection will account for the infinite diversity in the structure and functions of the mouths of insects. Nevertheless, it is conceivable that the general pattern of an organ might become so much obscured as to be finally lost, by the reduction and ultimately by the complete abortion of certain parts, by the fusion of other parts, and by the doubling or multiplication of others,- -variations which we know to be within the limits of possibility. In the paddles of the gigantic extinct sea-lizards, and in the mouths of certain suctorial crustaceans, the general pattern seems thus to have become partially obscured.

There is another and equally curious branch of our subject; namely, serial homologies, or the comparison 
of the different parts or organs in the same individual, and not of the same parts or organs in different members of the same class. Most physiologists believe that the bones of the skull are homologous-that is, correspond in number and in relative connexion-with the elemental parts of a certain number of vertebræ. The anterior and posterior limbs in all the higher vertebrate classes are plainly homologous. So it is with the wonderfully complex jaws and legs of crustaceans. It is familiar to almost every one, that in a flower the relative position of the sepals, petals, stamens, and pistils, as well as their intimate structure, are intelligible on the view that they consist of metamorphosed leaves, arranged in a spire. In monstrous plants, we often get direct evidence of the possibility of one organ being transformed into another; and we can actually see, during the early or embryonic stages of development in flowers, as well as in crustaceans and many other animals, that organs, which when mature become extremely different are at first exactly alike.

How inexplicable are the cases of serial homologies on the ordinary view of creation! Why should the brain be enclosed in a box composed of such numerous and such extraordinarily shaped pieces of bone, apparently representing vertebræ? As Owen has remarked, the benefit derived from the yielding of the separate pieces in the act of parturition by mammals, will by no means explain the same construction in the skulls of birds and reptiles. Why should similar bones have been created to form the wing and the leg of a bat, used as they are for such totally different purposes, namely flying and walking? Why should one crustacean, which has an extremely complex mouth formed of many parts, 
consequently always have fewer legs; or conversely, those with many legs have simpler mouths? Why should the sepals, petals, stamens, and pistils, in each flower, though fitted for such distinct purposes, be all constructed on the same pattern?

On the theory of natural selection, we can, to a certain extent, answer these questions. We need not here consider how the bodies of some animals first became divided into a series of segments, or how they became divided into right and left sides, with corresponding organs, for such questions are almost beyond investigation. It is, however, probable that some serial structures are the result of cells multiplying by division, entailing the multiplication of the parts developed from such cells. It must suffice for our purpose to bear in mind that an indefinite repetition of the same part or organ is the common characteristic, as Owen has remarked, of all low or little specialised forms; therefore the unknown progenitor of the Vertebrata probably possessed many vertebræ; the unknown progenitor of the Articulata, many segments; and the unknown progenitor of flowering plants, many leaves arranged in one or more spires. We have also formerly seen that parts many times repeated are eminently liable to vary, not only in number, but in form. Consequently such parts, being already present in considerable numbers, and being highly variable, would naturally afford the materials for adaptation to the most different purposes; yet they would generally retain, through the force of inheritance, plain traces of their original or fundamental resemblance. They would retain this resemblance all the more, as the variations, which afforded the basis for their subsequent modification through natural selection, 
would tend from the first to be similar; the parts being at an early stage of growth alike, and being subjected to nearly the same conditions. Such parts, whether more or less modified, unless their common origin became wholly obscured, would be serially homologous.

In the great class of molluses, though the parts in distinct species can be shown to be homologous, only a few serial homologies, such as the ralves of Chitons, can be indicated; that is, we are seldom enabled to say that one part is homologous with another part in the same individual. And we can understand this fact; for in molluscs, even in the lowest members of the class, we do not find nearly so much indefinite repetition of any one part as we find in the other great classes of the animal and vegetable kingdoms.

But morphology is a much more complex subject than it at first appears, as has lately been well shown in a remarkable paper by Mr. E. Ray Lankester, who has drawn an important distinction between certain classes of cases which have all been equally ranked by naturalists as homologous. He proposes to call the structures which resemble each other in distinct animals. owing to their descent from a common progenitor with subsequent modification, homogenous; and the resemblances which cannot thus be accounted for, he proposes to call homoplastic. For instance, he believes that the hearts of birds and mammals are as a whole homogenous, - that is, have been derived from a common progenitor; but that the four cavities of the heart in the two classes are homoplastic, - that is, have been independently developed. Mr. Lankester also adduces the close resemblance of the parts on the right and left sides 
of the body, and in the successive segments of the same individual animal; and here we have parts commonly called homologous, which bear no relation to the descent of distinct species from a common progenitor. Homoplastic structures are the same with those which I have classed, though in a very imperfect manner, as analogous modifications or resemblances. Their formation may be attributed in part to distinct organisms, or to distinct parts of the same organism, having varied in an analogous manner; and in part to similar modifications, having been preserved for the same general purpose or function,- of which many instances have been given.

Naturalists frequently speak of the skull as formed of metamorphosed vertebræ; the jaws of crabs as metamorphosed legs; the stamens and pistils in flowers as metamorposed leaves; but it would in most cases be more correct, as Professor Huxley has remarked, to speak of both skull and vertebræ, jaws and legs, \&c., as having been metamorphosed, not one from the other, as they now exist, but from some common and simpler element. Most naturalists, however, use such language only in a metaphorical sense; they are far from meaning that during a long course of descent, primordial organs of any kind-vertebræ in the one case and legs in the otherhave actually been converted into skulls or jaws. Yet so strong is the appearance of this having occurred, that naturalists can hardly avoid employing language having this plain signification. According to the views here maintained, such language may be used literally; and the wonderful fact of the jaws, for instance, of a crab retaining numerous characters which they probably would have retained through inheritance, if they had 
really been metamorphosed from true through extremely simple legs, is in part explained.

\section{Development and Embryology.}

This is one of the most important subjects in the whole round of history. The metamorphoses of insects, with which every one is familiar, are generally effected abruptly by a few stages; but the transformations are in reality numerous and gradual, though concealed. A certain ephemerous insect (Chlöeon) during its development, moults, as shown by Sir J. Lubbock, above twenty times, and each time undergoes a certain amount of change; and in this case we see the act of metamorphosis performed in a primary and gradual manner. Many insects, and especially certain crustaceans, show us what wonderful changes of structure can be effected during development. Such changes, however, reach their acme in the so-called alternate generations of some of the lower animals. It is, for instance, an astonishing fact that a delicate branching coralline, studded with polypi and attached to a submarine rock, should produce, first by budding and then by transverse division, a host of huge floating jelly-fishes; and that these should produce eggs, from which are hatched swimming animalcules, which attach themselves to rocks and become developed into branching corallines; and so on in an endless cycle. The belief in the essential identity of the process of alternate generation and of ordinary metamorphosis has been greatly strengthened by Wagner's discovery of the larva or maggot of a fly, namely the Cecidomyia, producing asexually other larvæ, and these others, which finally are developed into ma- 
ture males and females, propagating their kind in the ordinary manner by eggs.

It may be worth notice that when Wagner's remarkable discovery was first announced, I was asked how was it possible to account for the larvæ of this fly having acquired the power of asexual reproduction. As long as the case remained unique no answer could be given. But already Grimm has shown that another fly, a Chironomus, reproduces itself in nearly the same manner, and he believes that this occurs frequently in the Order. It is the pupa, and not the larva, of the Chironomus which has this power; and Grimm further shows that this case, to a certain extent, "unites that of the Cecidomyia with the parthenogenesis of the Coccidæ;" -the term parthenogenesis implying that the mature females of the Coccidæ are capable of producing fertile eggs without the concourse of the males. Certain animals belonging to several classes are now known to have the power of ordinary reproduction at an unusually early age; and we have only to accelerate parthenogenetic production by gradual steps to an earlier and earlier age,-Chironomus showing us an almost exactly intermediate stage, viz., that of the pupa-and we can perhaps account for the marvellous case of the Cecidomyia.

It has already been stated that various parts in the same individual which are exactly alike during an early embryonic period, become widely different and serve for widely different purposes in the adult state. So again it has been shown that generally the embryos of the most distinct species belonging to the same class are closely similar, but become, when fully developed, widely dissimilar. A better proof of this latter fact 
cannot be given than the statement by Von Baer that " the embryos of mammalia, of birds, lizards, and "snakes, probably also of chelonia are in their earliest "states exceedingly like one another, both as a whole " and in the mode of development of their parts; so "much so, in fact, that we can often distinguish the "embryos only by their size. In my possession are two " little embryos in spirit, whose names I have omitted " to attach, and at present I am quite unable to say to "what class they belong. They may be lizards or small "birds, or very young mammalia, so complete is " the similarity in the mode of formation of the head " and trunk in these animals. The extremities, how" ever, are still absent in these embryos. But even " if they had existed in the earliest stage of their de"velopment we should learn nothing, for the feet of "lizards and mammals, the wings and feet of birds, "no less than the hands and feet of man, all arise from "the same fundamental form." The larvæ of most crustaceans, at corresponding stages of development, closely resemble each other, however different the adults may become; and so it is with very many other animals. A trace of the law of embryonic resemblance occasionally lasts till a rather late age: thus birds of the same genus, and of allied genera, often resemble each other in their immature plumage; as we see in the spotted feathers in the young of the thrush group. In the cat tribe, most of the species when adult are striped or spotted in lines; and stripes or spots can be plainly distinguished in the whelp of the lion and the puma. We occasionally though rarely see something of the same kind in plants; thus the first leaves of the ulex or furze, and the first leaves of the phyllodineous acacias, 
are pinnate or divided like the ordinary leaves of the leguminosæ.

The points of structure, in which the embryos of widely different animals within the same class resemble each other, often have no direct relation to their conditions of existence. We cannot, for instance, suppose that in the embryos of the vertebrata the peculiar loop-like courses of the arteries near the branchial slits are related to similar conditions,-in the young mammal which is nourished in the womb of its mother, in the egg of the bird which is hatched in a nest, and in the spawn of a frog under water. We have no more reason to believe in such a relation, than we have to believe that the similar bones in the hand of a man, wing of a bat, and fin of a porpoise, are related to similar conditions of life. No one supposes that the stripes on the whelp of a lion, or the spots on the young blackbird, are of any use to these animals.

The case, however, is different when an animal during any part of its embryonic career is active, and has to provide for itself. The period of activity may come on earlier or later in life; but whenever it comes on, the adaptation of the larva to its conditions of life is just as perfect and as beautiful as in the adult animal. In how important a manner this has acted, has recently been well shown by Sir J. Lubbock in his remarks on the close similarity of the larvæ of some insects belonging to very different orders, and on the dissimilarity of the larvæ of other insects within the same order, according to their habits of life. Owing to such adaptations, the similarity of the larvæ of allied animals is sometimes greatly obscured; especially when there is a division of labour during the different stages of development, as 
when the same larva has during one stage to search for food, and during another stage has to search for a place of attachment. Cases can even be given of the larvæ of allied species, or groups of species, differing more from each other than do the adults. In most cases, however, the larvæ, though active, still obey, more or less closely, the law of common embryonic resemblance. Cirripedes afford a good instance of this; even the illustrious $\mathrm{Cu}$ vier did not perceive that a barnacle was a crustacean: but a glance at the larva shows this in an unmistakable manner. So again the two main divisions of cirripedes, the pedunculated and sessile, though differing widely in external appearance, have larvæ in all their stages barely distinguishable.

The embryo in the course of development generally rises in organisation; I use this expression, though I am aware that it is hardly possible to define clearly what is meant by the organisation being higher or lower. But no one probably will dispute that the butterfly is higher than the caterpillar. In some cases, however, the mature animal must be considered as lower in the scale than the larva, as with certain parasitic crustaceans. To refer once again to cirripedes: the larvæ in the first stage have three pairs of locomotive organs, a simple single eye, and a probosciformed mouth, with which they feed largely, for they increase much in size. In the second stage, answering to the chrysalis stage of butterflies, they have six pairs of beautifully constructed natatory legs, a pair of magnificent compound eyes, and extremely complex antennæ; but they have a closed and imperfect mouth, and cannot feed: their function at this stage is, to search out by their well-developed organs of sense, and to reach by their active powers of 
swimming, a proper place on which to become attached and to undergo their final metamorphosis. When this is completed they are fixed for life: their legs are now converted into prehensile organs; they again obtain a well-constructed mouth; but they have no antennæ, and their two eyes are now reconverted into a minute, single, simple eye-spot. In this last and complete state, cirripedes may be considered as either more highly or more lowly organised than they were in the larval condition. But in some genera the larvæ become developed into hermaphrodites having the ordinary structure, and into what I have called complemental males; and in the latter the development has assuredly been retrograde, for the male is a mere sack, which lives for a short time and is destitute of mouth, stomach, and every other organ of importance, excepting those for reproduction.

We are so much accustomed to see a difference in structure between the embryo and the adult, that we are tempted to look at this difference as in some necessary manner contingent on growth. But there is no reason why, for instance, the wing of a bat, or the fin of a porpoise, should not have been sketched out with all their parts in proper proportion, as soon as any part became visible. In some whole groups of animals and in certain members of other groups this is the case, and the embryo does not at any period differ widely from the adult: thus Owen has remarked in regard to cuttle-fish, "there is no metamorphosis; the cephalopodic character is manifested long before the parts of the embryo are completed." Land-shells and fresh-water crustaceans are born having their proper forms, whilst the marine members of the same two great classes pass through considerable and often great changes during 
their development. Spiders, again, barely undergo any metamorphosis. The larvæ of most insects pass through a worm-like stage, whether they are active and adapted to diversified habits, or are inactive from being placed in the midst of proper nutriment or from being fed by their parents; but in some few cases, as in that of Aphis, if we look to the admirable drawings of the development of this insect, by Professor Huxley, we see hardly any trace of the vermiform stage.

Sometimes it is only the earlier developmental stages which fail. Thus Fritz Müller has made the remarkable discovery that certain shrimp-like crustaceans (allied to Penœus) first appear under the simple naupliusform, and after passing through two or more zoea-stages, and then through the mysis-stage, finally acquire their mature structure: now in the whole great malacostracan order, to which these crustaceans belong, no other member is as yet known to be first developed under the nauplius-form, though many appear as zoeas; nevertheless Müller assigns reasons for his belief, that if there had been no suppression of development, all these crustaceans would have appeared as nauplii.

How, then, can we explain these several facts in embryology,-namely, the very general, though not universal, difference in structure between the embryo and the adult; - the various parts in the same individual embryo, which ultimately become very unlike and serve for diverse purposes, being at an early period of growth alike;-the common, but not invariable, resemblance between the embryos or larvæ of the most distinct species in the same class;-the embryo often retaining whilst within the egg or womb, structures which are of no service to it, either at that or at a later period of 
life; on the other hand larvæ, which have to provide for their own wants, being perfectly adapted to the surrounding conditions;-and lastly the fact of certain larræ standing higher in the scale of organisation than the mature animal into which they are dereloped? I believe that all these facts can be explained, as follows.

It is commonly assumed, perhaps from monstrosities affecting the embryo at a very early period, that slight variations or individual differences necessarily appear at an equally early period. We have little evidence on this head, but what we have certainly points the other way; for it is notorious that breeders of cattle, horses, and various fancy animals, cannot positively tell, until some time after birth, what will be the merits or demerits of their young animals. We see this plainly in our own children; we cannot tell whether a child will be tall or short, or what its precise features will be. The question is not, at what period of life each variation may have been caused, but at what period the effects are displayed. The cause may have acted, and I believe often has acted, on one or both parents before the act of generation. It deserves notice that it is of no importance to a very young animal, as long as it remains in its mother's womb or in the egg, or as long as it is nourished and protected by its parent, whether most of its characters are acquired a little earlier or later in life. It would not signify, for instance, to a bird which obtained its food by having a much-curved beak whether or not whilst young it possessed a beak of this shape, as long as it was fed by its parents.

I have stated in the first chapter, that at whatever age a variation first appears in the parent, it tends to re-appear at a corresponding age in the offspring. Cer- 
tain variations can only appear at corresponding ages; for instance, peculiarities in the caterpillar, cocoon, or imago states of the silk-moth: or, again, in the fullgrown horns of cattle. But variations, which, for all that we can see might have first appeared either earlier or later in life, likewise tend to reappear at a corresponding age in the offspring and parent. I am far from meaning that this is invariably the case and I could give several exceptional cases of variations (taking the word in the largest sense) which have supervened at an earlier age in the child than in the parent.

These two principles, namely, that slight variations generally appear at a not very early period of life, and are inherited at a corresponding not early period, explain, as I believe, all the above specified leading facts in embryology. But first let us look to a few analogous cases in our domestic vàrieties. Some authors who have written on Dogs, maintain that the greyhound and bulldog, though so different, are really closely allied varieties, descended from the same wild stock; hence I was curious to see how far their puppies differed from each other: I was told by breeders that they differed just as much as their parents, and this, judging by the eye, seemed almost to be the case; but on actually measuring the old dogs and their six-days-old puppies, I found that the puppies had not acquired nearly their full amount of proportional difference. So, again, I was told that the foals of cart and race-horses-breeds which have been almost wholly formed by selection under domestication-differed as much as the full-grown animals; but having had careful measurements made of the dams and of three-days-old colts of race and 
heavy cart-horses, I find that this is by no means the case.

As we have conclusive evidence that the breeds of the Pigeon are descended from a single wild species, I compared the young within twelve hours after being hatched; I carefully measured the proportions (but will not here give the details) of the beak, width of mouth, length of nostril and of eyelid, size of feet and length of leg, in the wild parent-species, in pouters, fantails, runts, barbs, dragons, carriers, and tumblers. Now some of these birds, when mature, differ in so extraordinary a manner in the length and form of beak, and in other characters, that they would certainly have been ranked as distinct genera if found in a state of nature. But when the nestling birds of these several breeds were placed in a row, though most of them could just be distinguished, the proportional differences in the above specified points were incomparably less than in the fullgrown birds. Some characteristic points of difference -for instance, that of the width of mouth-could hardly be detected in the young. But there was one remarkable exception to this rule, for the young of the shortfaced tumbler differed from the young of the wild rockpigeon and of the other breeds, in almost exactly the same proportions as in the adult state.

These facts are explained by the above two principles. Fanciers select their dogs, horses, pigeons, \&c., for breeding, when nearly grown up: they are indifferent whether the desired qualities are acquired earlier or later in life, if the full-grown animal possesses them. And the cases just given, more especially that of the pigeons, show that the characteristic differences which have been accumulated by man's selection, and which give value to 
his breeds, do not generally appear at a very early period of life, and are inherited at a corresponding not early period. But the case of the short-faced tumbler, which when twelve hours old possessed its proper characters, proves that this is not the universal rule; for here the characteristic differences must either have appeared at an earlier period than usual, or, if not so, the differences must have been inherited, not at a corresponding, but at an earlier age.

Now let us apply these two principles to species in a state of nature. Let us take a group of birds, descended from some ancient form and modified through natural selection for different habits. Then, from the many slight successive variations having supervened in the several species at a not early age, and having been inrerited at a corresponding age, the young will have been but little modified, and they will still resemble each other much more closely than do the adults,- - just as we have seen with the breeds of the pigeon. We may extend this view to widely distinct structures and to whole classes. The fore-limbs, for instance, which once served as legs to a remote progenitor, may have become, through a long course of modification, adapted in one descendant to act as hands, in another as paddles, in another as wings; but on the above two principles the fore-limbs will not have been much modified in the embryos of these several forms; although in each form the forelimb will differ greatly in the adult state. Whatever influence long-continued use or disuse may have had in modifying the limbs or other parts of any species, this will chiefly or solely have affected it when nearly mature, when it was compelled to use its full powers to gain its own living; and the effects thus produced will 
have been transmitted to the offspring at a corresponding nearly mature age. Thus the young will not be modified, or will be modified only in a slight degree, through the effects of the increased use or disuse of parts.

With some animals the successive variations may have supervened at a very early period of life, or the steps may have been inherited at an earlier age than that at which they first occurred. In either of these cases, the young or embryo will closely resemble the mature parent-form, as we have seen with the short-faced tumbler. And this is the rule of development in certain whole groups, or in certain sub-groups alone, as with cuttle-fish, land-shells, fresh-water crustaceans, spiders, and some members of the great class of insects. With respect to the final cause of the young in such groups not passing through any metamorphosis, we can see that this would follow from the following contingencies; namely, from the young having to provide at a very early age for their own wants, and from their following the same habits of life with their parents; for in this case, it would be indispensable for their existence that they should be modified in the same manner as their parents. Again, with respect to the singular fact that many terrestrial and fresh-water animals do not undergo any metamorphosis, whilst marine members of the same groups pass through various transformations, Fritz Müller has suggested that the process of slowly modifying and adapting an animal to live on the land or in fresh water, instead of in the sea, would be greatly simplified by its not passing through any larval stage; for it is not probable that places well adapted for both the larval and mature stages, under such new and greatly 
changed habits of life, would commonly be found unoccupied or ill-occupied by other organisms. In this case the gradual acquirement at an earlier and earlier age of the adult structure would be favoured by natural selection; and all traces of former metamorphoses would finally be lost.

If, on the other hand, it profited the young of an animal to follow habits of life slightly different from those of the parent-form, and consequently to be constructed on a slightly different plan, or if it profited a larva already different from its parent to change still further, then, on the principle of inheritance at corresponding ages, the young or the larvæ might be rendered by natural selection more and more different from their parents to any conceivable extent. Differences in the larva might, also, become correlated with successive stages of its development; so that the larva, in the first stage, might come to differ greatly from the larva in the second stage, as is the case with many animals. The adult might also become fitted for sites or habits, in which organs of locomotion or of the senses, \&c., would be useless; and in this case the metamorphosis would be retrograde.

From the remarks just made we can see how by changes of structure in the young, in conformity with changed habits of life, together with inheritance at corresponding ages, animals might come to pass through stages of development, perfectly distinct from the primordial condition of their adult progenitors. Most of our best authorities are now convinced that the various larval and pupal stages of insects have thus been acquired through adaptation, and not through inheritance from some ancient form. The curious case of Sitaris-a 
beetle which passes through certain unusual stages of development-will illustrate how this might occur. The first larval form is described by M. Fabre, as an active, minute insect, furnished with six legs, two long anten$\mathrm{næ}$, and four eyes. These larræ are hatched in the nests of bees; and when the male-bees emerge from their burrows, in the spring, which they do before the females, the larvæ spring on them, and afterwards crawl on to the females whilst paired with the males. As soon as the female bee deposits her eggs on the surface of the honey stored in the cells, the larvæ of the Sitaris leap on the eggs and devour them. Afterwards they undergo a complete change; their eyes disappear; their legs and antennæ become rudimentary, and they feed on honey; so that they now more closely resemble the ordinary larvæ of insects; ultimately they undergo a further transformation, and finally emerge as the perfect beetle. Now, if an insect, undergoing transformations like those of the Sitaris, were to become the progenitor of a whole new class of insects, the course of development of the new class would be widely different from that of our existing insects; and the first larval stage certainly would not represent the former condition of any adult and ancient form.

On the other hand it is highly probable that with many animals the embryonic or larval stages show us, more or less completely, the condition of the progenitor of the whole group in its adult state. In the great class of the Crustacea, forms wonderfully distinct from each other, namely, suctorial parasites, cirripedes, entomostraca, and even the malacostraca, appear at first as larvæ under the nauplius-form; and as these larvæ live and feed in the open sea, and are not adapted for any 
peculiar habits of life, and from other reasons assigned by Fritz Müller, it is probable that at some very remote period an independent adult animal, resembling the Nauplius, existed, and subsequently produced, along several divergent lines of descent, the above-named great Crustacean groups. So again it is probable, from what we know of the embryos of mammals, birds, fishes, and reptiles, that these animals are the modified descendants of some ancient progenitor, which was furnished in its adult state with branchiæ, a swim-bladder, four fin-like limbs, and a long tail, all fitted for an aquatic life.

As all the organic beings, extinct and recent, which have ever lived, can be arranged within a few great classes; and as all within each class have, according to our theory, been connected together by fine gradations, the best, and, if our collections were nearly perfect, the only possible arrangement, would be genealogical; descent being the hidden bond of connexion which naturalists have been seeking under the term of the Natural System. On this view we can understand how it is that, in the eyes of most naturalists, the structure of the embryo is even more important for classification than that of the adult. In two or more groups of animals, however much they may differ from each other in structure and habits in their adult condition, if they pass through closely similar embryonic stages, we may feel assured that they all are descended from one parent-form, and are therefore closely related. Thus, community in embryonic structure reveals community of descent; but dissimilarity in embryonic development does not prove discommunity of descent, for in one of two groups the developmental stages may have been suppressed, or may 


\section{DEVELOPMENT AND EMBRYOLOGY. [Chap. XIV.}

have been so greatly modified through adaptation to new habits of life, as to be no longer recognisable. Even in groups, in which the adults have been modified to an extreme degree, community of origin is often revealed by the structure of the larvæ; we have seen, for instance, that cirripedes, though externally so like shellfish, are at once known by their larvæ to belong to the great class of crustaceans. As the embryo often shows us more or less plainly the structure of the less modified and ancient progenitor of the group, we can see why ancient and extinct forms so often resemble in their adult state the embryos of existing species of the same class. Agassiz believes this to be a universal law of nature; and we may hope hereafter to see the law proved true. It can, however, be proved true only in those cases in which the ancient state of the progenitor of the group has not been wholly obliterated, either by successive variations having supervened at a very early period of growth, or by such variations having been inherited at an earlier age than that at which they first appeared. It should also be borne in mind, that the law may be true, but yet, owing to the geological record not extending far enough back in time, may remain for a long period, or for ever, incapable of demonstration. The law will not strictly hold good in those cases in which an ancient form became adapted in its larval state to some special line of life, and transmitted the same larval state to a whole group of descendants; for such larvæ will not resemble any still more ancient form in its adult state.

Thus, as it seems to me, the leading facts in embryology, which are second to none in importance, are explained on the principle of variations in the many de- 
scendants from some one ancient progenitor, having appeared at a not very early period of life, and having been inherited at a corresponding period. Embryology rises greatly in interest, when look at the embryo as a picture, more or less obscured, of the progenitor, either in its adult or larval state, of all the members of the same great class.

Rudimentary, Atrophied, and Aborted Organs.

Organs or parts in this strange condition, bearing the plain stamp of inutility, are extremely common, or even general, throughout nature. It would be impossible to name one of the higher animals in which some part or other is not in a rudimentary condition. In the mammalia, for instance, the males possess rudimentary mammæ; in snakes one lobe of the lungs is rudimentary; in birds the "bastard-wing" may safely be considered as a rudimentary digit, and in some species the whole wing is so far rudimentary that it cannot be used for flight. What can be more curious than the presence of teeth in fœtal whales, which when grown up have not a tooth in their heads; or the teeth, which never cut through the gums, in the upper jaws of unborn calves?

Rudimentary organs plainly declare their origin and meaning in various ways. There are beetles belonging to closely allied species, or even to the same identical species, which have either full-sized and perfect wings, or mere rudiments of membrane, which not rarely lie under wing-covers firmly soldered together; and in these cases it is impossible to doubt, that the rudiments represent wings. Rndimentary organs sometimes retain their potentiality: this occasionally occurs with the mam. 
mæ of male mammals, which have been known to become well developed and to secrete milk. So again in the udders in the genus Bos, there are normally four developed and two rudimentary teats; but the latter in our domestic cows sometimes become well developed and yield milk. In regard to plants the petals are sometimes rudimentary, and sometimes well-developed in the individuals of the same species. In certain plants having separated sexes Kölreuter found that by crossing a species, in which the male flowers included a rudiment of a pistil, with an hermaphrodite species, having of course a well-developed pistil, the rudiment in the hybrid offspring was much increased in size; and this clearly shows that the rudimentary and perfect pistils are essentially alike in nature. An animal may possess various parts in a perfect state, and yet they may in one sense be rudimentary, for they are useless: thus the tadpole of the common Salamander or Water-newt, as Mr. G. H. Lewes remarks, "has gills, and passes its existence in "the water; but the Salamandra atra, which lives high " up among the mountains, brings forth its young full"formed. This animal never lives in the water. Yet " if we open a gravid female, we find tadpoles inside her "with exquisitely feathered gills; and when placed in "water they swim about like the tadpoles of the "water-newt. Obviously this aquatic organisation has "no reference to the future life of the animal, nor "has it any adaptation to its embryonic condition; it "has solely reference to ancestral adaptations, it "repeats a phase in the development of its progeni"tors."

An organ, serving for two purposes, may become rudimentary or utterly aborted for one, even the more 
important purpose, and remain perfectly efficient for the other. Thus in plants, the office of the pistil is to allow the pollen-tubes to reach the ovules within the ovarium. The pistil consists of a stigma supported on a style; but in some Compositæ, the male florets, which of course cannot be fecundated, have a rudimentary pistil, for it is not crowned with a stigma; but the style remains well developed and is clothed in the usual manner with hairs, which serve to brush the pollen out of the surrounding and conjoined anthers. Again, an organ may become rudimentary for its proper purpose, and be used for a distinct one: in certain fishes the swim-bladder seems to be rudimentary for its proper function of giving buoyancy, but has become converted into a nascent breathing organ or lung. Many similar instances could be given.

Useful organs, however little they may be developed, unless we have reason to suppose that they were formerly more highly developed, ought not to be considered as rudimentary. They may be in a nascent condition, and in progress towards further development. Rudimentary organs, on the other hand, are either quite useless, such as teeth which never cut through the gums, or almost useless, such as the wings of an ostrich, which serve merely as sails. As organs in this condition would formerly, when still less developed, have been of even less use than at present, they cannot formerly have been produced through variation and natural selection, which acts solely by the preservation of useful modifications. They have been partially retained by the power of inheritance, and relate to a former state of things. It is, however, often difficult to distinguish between rudimentary and nascent organs; for we can judge only by analogy 
whether a part is capable of further development, in which case alone it deserves to be called nascent. Organs in this condition will always be somewhat rare; for beings thus provided will commonly have been supplanted by their successors with the same organ in a more perfect state, and consequently will have become long ago extinct. The wing of the penguin is of high service, acting as a fin; it may, therefore, represent the nascent state of the wing: not that $I$ believe this to be the case; it is more probably a reduced organ, modified for a new function: the wing of the Apteryx, on the other hand, is quite useless, and is truly rudimentary. Owen considers the simple filamentary limbs of the Lepidosiren as the "beginnings of organs which attain full functional development in higher vertebrates;" but, according to the view lately advocated by Dr. Günther, they are probably remnants, consisting of the persistent axis of a fin, with the lateral rays or branches aborted. The mammary glands of the Ornithorhynchus may be considered, in comparison with the udders of a cow, as in a nascent condition. The ovigerous frena of certain cirripedes, which have ceased to give attachment to the ova and are feebly developed, are nascent branchiæ.

Rudimentary organs in the individuals of the same species are very liable to vary in the degree of their development and in other respects. In closely allied species, also, the extent to which the same organ has been reduced occasionally differs much. This latter fact is well exemplified in the state of the wings of female moths belonging to the same family. Rudimentary organs may be utterly aborted; and this implies, that in certain animals or plante, parts are entirely absent which 
analogy would lead us to expect to find in them, and which are occasionally found in monstrous individuals. Thus in most of the Scrophulariaceæ the fifth stamen is utterly aborted; yet we may conclude that a fifth stamen once existed, for a rudiment of it is found in many species of the family, and this rudiment occasionally becomes perfectly developed, as may sometimes be seen in the common snap-dragon. In tracing the homologies of any part in different members of the same class, nothing is more common, or, in order fully to understand the relations of the parts, more useful than the discovery of rudiments. This is well shown in the drawings given by Owen of the leg-bones of the horse, ox, and rhinoceros.

It is an important fact that rudimentary organs, such as teeth in the upper jaws of whales and ruminants, can often be detected in the embryo, but afterwards wholly disappear. It is also, I believe, a universal rule, that a rudimentary part is of greater size in the embryo relatively to the adjoining parts, than in the adult; so that the organ at this early age is less rudimentary, or even cannot be said to be in any degree rudimentary. Hence rudimentary organs in the adult are often said to have retained their embryonic condition.

I have now given the leading facts with respect to rudimentary organs. In reflecting on them, every one must be struck with astonishment; for the same reasoning power which tells us that most parts and organs are exquisitely adapted for certain purposes, tells us with equal plainness that these rudimentary or atrophied organs are imperfect and useless. In works on natural history, rudimentary organs are generally said to have been created "for the sake of symmetry," or in order 
"to complete the scheme of nature." But this is not an explanation, merely a re-statement of the fact. Nor is it consistent with itself; thus the boa-constrictor has rudiments of hind-limbs and of a pelvis, and if it be said that these bones have been retained "to complete the scheme of nature," why, as Professor Weismann asks, have they not been retained by other snakes, which do not possess even a vestige of these same bones? What would be the thought of an astronomer who maintained that the satellites revolve in elliptic courses round their planets "for the sake of symmetry," because the planets thus revolve round the sun? An eminent physiologist accounts for the presence of rudimentary organs, by supposing that they serve to excrete matter in excess, or matter injurious to the system; but can we suppose that the minute papilla, which often represents the pistil in male flowers, and which is formed of mere cellular tissue, can thus act? Can we suppose that rudimentary teeth, which are subsequently absorbed, are beneficial to the rapidly growing embryonic calf by removing matter so precious as phosphate of lime? When a man's fingers have been amputated, imperfect nails have been known to appear on the stumps, and I could as soon believe that these vestiges of nails are developed in order to excrete horny matter, as that the rudimentary nails on the fin of the manatee have been developed for this same purpose.

On the view of descent with modification, the origin of rudimentary organs is comparatively simple; and we can understand to a large extent the laws governing their imperfect development. We have plenty of cases of rudimentary organs in our domestic productions,-as the stump of a tail in tailless breeds, - the vestige of an 
ear in earless breeds of sheep,-the reappearance of minute dangling horns in hornless breeds of cattle, more especially, according to louatt, in young animals, -and the state of the whole flower in the cauliflower. We often see rudiments of various parts in monsters; but I doubt whether any of these casts throw light on the origin of rudimentary organs in a state of nature, further than by showing that rudinients can be produced; for the balance of evidence clearly indicates that species under nature do not undergo great and abrupt changes. But we learn from the study of our domestic productions that the disuse of parts leads to their reduced size; and that the result is inherited.

It appears probable that disuse has been the main agent in rendering organs rudimentary. It would at first lead by slow steps to the more and more complete reduction of a part, until at last it became rudimentary, -as in the case of the eyes of animals inhabiting dark caverns, and of the wings of birds inhabiting oceanic islands, which have seldom been forced by beasts of prey to take flight, and have ultimately lost the power of flying. Again, an organ, useful under certain conditions, might become injurious under others, as with the wings of beetles living on small and exposed islands; and in this case natural selection will have aided in reducing the organ, until it was rendered harmless and rudimentary.

Any change in structure and function, which can be effected by small stages, is within the power of natural selection; so that an organ rendered, through changed habits of life, useless or injurious for one purpose, might be modified and used for another purpose. An organ might, also, be retained for one alone of its former func- 
tions. Organs, originally formed by the aid of natural selection, when rendered useless may well be variable, for their variations can no longer be checked by natural selection. All this agrees well with what we see under nature. Moreover, at whatever period of life either disuse or selection reduces an organ, and this will generally be when the being has come to maturity and has to exert its full powers of action, the principle of inherit. ance at corresponding ages will tend to reproduce the organ in its reduced state at the same mature age, but will seldom effect it in the embryo. Thus we can understand the greater size of rudimentary organs in the embryo relatively to the adjoining parts, and their lesser relative size in the adult. If, for instance, the digit of an adult animal was used less and less during many generations, owing to some change of habits, or if an organ or gland was less and less functionally exercised, we may infer that it would become reduced in size in the adult descendants of this animal, but would retain nearly its original standard of development in the embryo.

There remains, however, this difficulty. After an organ has ceased being used, and has become in consequence much reduced, how can it be still further reduced in size until the merest vestige is left; and how can it be finally quite obliterated? It is scarcely possible that disuse can go on producing any further effect after the organ has once been rendered functionless. Some additional explanation is here requisite which I cannot give. If, for instance, it could be proved that every part of the organisation tends to vary in a greater degree towards diminution than towards augmentation of size, then we should be able to understand how an organ which has become useless would be rendered, in. 
dependently of the effects of disuse, rudimentary and would at last be wholly suppressed; for the variations towards diminished size would no longer be checked by natural selection. The principle of the economy of growth, explained in a former chapter, by which the materials forming any part, if not useful to the possessor, are saved as far as possible, will perhaps come into play in rendering a useless part rudimentary. But this principle will almost necessarily be confined to the earlier stages of the process of reduction; for we cannot suppose that a minute papilla, for instance, representing in a male flower the pistil of the female flower, and formed merely of cellular tissue, could be further reduced or absorbed for the sake of economising nutriment.

Finally, as rudimentary organs, by whatever steps they may have been degraded into their present useless condition, are the record of a former state of things, and have been retained solely through the power of inheritance,-we can understand, on the genealogical view of classification, how it is that systematists, in placing organisms in their proper places in the natural system, have often found rudimentary parts as useful as, or even sometimes more useful than, parts of high physiological importance. Rudimentary organs may be compared with the letters in a word, still retained in the spelling, but become useless in the pronunciation, but which serve as a clue for its derivation. On the view of descent with modification, we may conclude that the existence of organs in a rudimentary, imperfect, and useless condition, or quite aborted, far from presenting a strange difficulty, as they assuredly do on the old doctrine of creation, might even have been anticipated in accordance with the views here explained. 


\section{Summary.}

In this chapter I have attempted to show, that the arrangement of all organic beings throughout all time in groups under groups-that the nature of the relationships by which all living and extinct organisms are united by complex, radiating, and circuitous lines of affinities into a few grand classes,- - the rules followed and the difficulties encountered by naturalists in their classifications, - the value set upon characters, if constant and prevalent, whether of high or of the most trifling importance, or, as with rudimentary organs, of no importance,- - the wide opposition in value between analogical or adaptive characters, and characters of true affinity; and other such rules;-all naturally follow if we admit the common parentage of allied forms, together with their modification through variation and natural selection, with the contingencies of extinction and divergence of character. In considering this view of classification, it should be borne in mind that the element of descent has been universally used in ranking together the sexes, ages, dimorphic forms, and acknowledged varieties of the same species, however much they may differ from each other in structure. If we extend the use of this element of descent,- - the one certainly known cause of similarity in organic beings,-we shall understand what is meant by the Natural System: it is genealogical in its attempted arrangement, with the grades of acquired difference marked by the terms, varieties, species, genera, families, orders, and classes.

On this same view of descent with modification, most 
of the great facts in Morphology become intelligible,whether we look to the same pattern displayed by the different species of the same class in their homologous organs, to whatever purpose applied; or to the serial and lateral homologies in each individual animal and plant.

On the principle of successive slight variations, not necessarily or generally supervening at a very early period of life, and being inherited at a corresponding period, we can understand the leading facts in Embryology; namely, the close resemblance in the individual embryo of the parts which are homologous, and which when matured become widely different in structure and function; and the resemblance of the homologous parts or organs in allied though distinct species, though fitted in the adult state for habits as different as is possible. Larvæ are active embryos, which have been specially modified in a greater or less degree in relation to their habits of life, with their modifications inherited at a corresponding early age. On these same principles,and bearing in mind that when organs are reduced in size, either from disuse or through natural selection, it will generally be at that period of life when the being has to provide for its own wants, and bearing in mind how strong is the force of inheritance-the occurrence of rudimentary organs might even have been anticipated. The importance of embryological characters and of rudimentary organs in classification is intelligible, on the view that a natural arrangement must be genealogical.

Finally, the several classes of facts which have been considered in this chapter, seem to me to proclaim so plainly, that the innumerable species, genera and families, with which this world is peopled, are all descended, 
each within its own class or group, from common parents, and have all been modified in the course of descent, that I should without hesitation adopt this view, even if it were unsupported by other facts or arguments. 


\section{CHAPTER XV.}

\section{RECAPITULATION AND CONCLUSION.}

Recapitulation of the objections to the theory of Natural Selection -Recapitulation of the general and special circumstances in its favour-Causes of the general belief in the immutability of species-How far the theory of Natural Selection may be extended-Effects of its adoption on the study of Natural History -Concluding Remarks.

As this whole volume is one long argument, it may be convenient to the reader to have the leading facts and inferences hriefly recapitulated.

That many and serious objections may be advanced against the thenry of descent with modification through variation and natural selection, I do not deny. I have endeavoured to give to them their full force. Nothing at first can appear more difficult to believe than that the more complex organs and instincts have been perfected, not by means superior to, though analogous with, human reason, but by the accumulation of innumerable slight variations, each good for the individual possessor. Nevertheless, this difficulty, though appearing to our imagination insuperably great, cannot be considered real if we admit the following propositions, namely, that all parts of the organisation and instincts offer, at least, individual differences-that there is a struggle for existence leading to the preservation of profitable deviations of itructure or instinct-and, lastly, that grada- 
tions in the state of perfection of each organ may have existed, each good of its kind. The truth of these propositions cannot, I think, be disputed.

It is, no doubt, extremely difficult even to conjecture by what gradations many structures have been perfected, more especially amongst broken and failing groups of organic beings, which have suffered much extinction, but we see so many strange gradations in nature, that we ought to be extremely cautious in saying that any organ or instinct, or any whole structure, could not have arrived at its present state by many graduated steps. There are, it must be admitted, cases of special difficulty opposed to the theory of natural selection; and one of the most curious of these is the existence in the same community of two or three defined castes of workers or sterile female ants; but I have attempted to show how these difficulties can be mastered.

With respect to the almost universal sterility of species when first crossed, which forms so remarkable a contrast with the almost universal fertility of varieties when crossed, I must refer the reader to the recapitulation of the facts given at the end of the ninth chapter, which seem to me conclusively to show that this sterility is no more a special endowment than is the incapacity of two distinct kinds of trees to be grafted together; but that it is incidental on differences confined to the reproductive systems of the intercrossed species. We see the truth of this conclusion in the vast difference in the results of crossing the same two species reciprocally,that is, when one species is first used as the father and then as the mother. Analogy from the consideration of dimorphic and trimorphic plants clearly leads to the same conclusion, for when the forms are illegitimately 
united, they yield few or no seed, and their offspring are more or less sterile; and these forms belong to the same undoubted species, and differ from each other in no respect except in their reproductive organs and functions.

Although the fertility of varieties when intercrossed and of their mongrel offspring has been asserted by so many authors to be universal, this cannot be considered as quite correct after the facts given on the high authority of Gärtner and Kölreuter. Most of the varieties which have been experimented on have been produced under domestication; and as domestication (I do not mean mere confinement) almost certainly tends to eliminate that sterility which, judging from analogy, would have affected the parent-species if intercrossed, we ought not to expect that domestication would likewise induce sterility in their modified descendants when crossed. This elimination of sterility apparently follows from the same cause which allows our domestic animals to breed freely under diversified circumstances; and this again apparently follows from their having been gradually accustomed to frequent changes in their conditions of life.

A double and parallel series of facts seems to throw much light on the sterility of species, when first crossed, and of their hybrid offspring. On the one side, there is good reason to believe that slight changes in the conditions of life give vigour and fertility to all organic beings. We know also that a cross between the distinct individuals of the same variety, and between distinct varieties, increases the number of their offspring, and certainly gives to them increased size and vigour. This is chiefly owing to the forms which are crossed having been exposed to somewhat different conditions of life; 
for I have ascertained by a laborious series of experiments that if all the individuals of the same variety be subjected during several generations to the same conditions, the good derived from crossing is often much diminished or wholly disappears. This is one side of the case. On the other side, we know that species which have long been exposed to nearly uniform conditions, when they are subjected under confinement to new and greatly changed conditions, either perish, or if they survive, are rendered sterile, though retaining perfect health. This does not occur, or only in a very slight degree, with our domesticated productions, which have long been exposed to fluctuating conditions. Hence when we find that hybrids produced by a cross between two distinct species are few in number, owing to their perishing soon after conception or at a very early age, or if surviving that they are rendered more or less sterile, it seems highly probable that this result is due to their having been in fact subjected to a great change in their conditions of life, from being compounded of two distinct organisations. He who will explain in a definite manner why, for instance, an elephant or a fox will not breed under confinement in its native country, whilst the domestic pig or dog will breed freely under the most diversified conditions, will at the same time be able to give a definite answer to the question why two distinct species, when crossed, as well as their hybrid offspring, are generally rendered more or less sterile, whilst two domesticated varieties when crossed and their mongrel offspring are perfectly fertile.

Turning to geographical distribution, the difficulties encountered on the theory of descent with modification are serious enough. All the individuals of the same 
species, and all the species of the same genus, or even higher group, are descended from common parents; and therefore, in however distant and isolated parts of the world they may now be found, they must in the course of successive generations have travelled from some one point to all the others. We are often wholly unable even to conjecture how this could have been effected. Yet, as we have reason to believe that some species have retained the same specific form for very long periods of time, immensely long as measured by years, too much stress ought not to be laid on the occasional wide diffusion of the same species; for during very long periods there will always have been a good chance for wide migration by many means. A broken or interrupted range may often be accounted for by the extinction of the species in the intermediate regions. It cannot be denied that we are as yet very ignorant as to the full extent of the various climatal and geographical changes which have affected the earth during modern periods; and such changes will often have facilitated migration. As an example, I have attempted to show how potent has been the influence of the Glacial period on the distribution of the same and of allied species throughout the world. We are as yet profoundly ignorant of the many occasional means of transport. With respect to distinct species of the same genus inhabiting distant and isolated regions, as the process of modification has necessarily been slow, all the means of migration will have been possible during a very long period; and consequently the difficulty of the wide diffusion of the species of the same genus is in some degree lessened.

As according to the theory of natural selection an interminable number of intermediate forms must have 
existed, linking together all the species in each group by gradations as fine as are our existing varieties, it may be asked, Why do we not see these linking forms all around us? Why are not all organic beings blended together in an inextricable chaos? With respect to existing forms, we should remember that we have no right to expect (excepting in rare cases) to discover directly connecting links between them, but only between each and some extinct and supplanted form. Even on a wide area, which has during a long period remained continuous, and of which the climatic and other conditions of life change insensibly in proceeding from a district occupied by one species into another district occupied by a closely allie'. species, we have no just right to expect often to find intermediate varieties in the intermediate zones. For we have reason to believe that only a few species of a genus ever undergo change; the other species becoming utterly extinct and leaving no modified progeny. Of the species which do change, only a few within the same country change at the same time; and all modifications are slowly effected. I have also shown that the intermediate varieties which probably at first existed in the intermediate zones, would be liable to be supplanted by the allied forms on either hand; for the latter, from existing in greater numbers, would generally be modified and improved at a quicker rate than the intermediate varieties, which existed in lesser numbers; so that the intermediate varieties would, in the long run, be supplanted and exterminated.

On this doctrine of the extermination of an infinitude of connecting links, between the living and extinct inhabitants of the world, and at each successive period between the extinct and still older species, why is not 
every geological formation charged with such links? Why does not every collection of fossil remains afford plain evidence of the gradation and mutation of the forms of life? Although geological research has undoubtedly revealed the former existence of many links, bringing numerous forms of life much closer together, it does not yield the infinitely many fine gradations between past and present species required on the theory; and this is the most obvious of the many objections which may be urged against it. Why, again, do whole groups of allied species appear, though this appearance is often false, to have come in suddenly on the successive geological stages? Although we now know that organic beings appeared on this globe, at a period incalculably remote, long before the lowest bed of the Cambrian system was deposited, why do we not find beneath this system great piles of strata stored with the remains of the progenitors of the Cambrian fossils? For on the theory, such strata must somewhere have been deposited at these ancient and utterly unknown epochs of the world's history.

I can answer these questions and objections only on the supposition that the geological record is far more imperfect than most geologists believe. The number of specimens in all our museums is absolutely as nothing compared with the countless generations of countless species which have certainly existed. The parent-form of any two or more species would not be in all its characters directly intermediate between its modified offspring, any more than the rock-pigeon is directly intermediate in crop and tail between its descendants, the pouter and fantail pigeons. We should not be able to recognise a species as the parent of another and modi- 
fied species, if we were to examine the two ever so closely, unless we possessed most of the intermediate links; and owing to the imperfection of the geological record, we have no just right to expect to find so many links. If two or three, or even more linking forms were discovered, they would simply be ranked by many naturalists as so many new species, more especially if found in different geological sub-stages, let their differences be ever so slight. Numerous existing doubtful forms could be named which are probably varieties; but who will pretend that in future ages so many fossil links will be discovered, that naturalists will be able to decide whether or not these doubtful forms ought to be called varieties? Only a small portion of the world has been geologically explored. Only organic beings of certain classes can be preserved in a fossil condition, at least in any great number. Many species when once formed never undergo any further change but become extinct without leaving modified descendants; and the periods, during which species have undergone modification, though long as measured by years, have probably been short in comparison with the periods during which they retain the same form. It is the dominant and widely ranging species which vary most frequently and vary most, and varieties are often at first local-both causes rendering the discovery of intermediate links in any one formation less likely. Local varieties will not spread into other and distant regions until they are considerably modified and improved; and when they have spread, and are discovered in a geological formation, they appear as if suddenly created there, and will be simply classed as new species. Most formations have been intermittent in their accumulation; and their dura- 
tion has probably been shorter than the average duration of specific forms. Successive formations are in most cases separated from each other by blank intervals of time of great length; for fossiliferous formations thick enough to resist future degradation can as a general rule be accumulated only where much sediment is deposited on the subsiding bed of the sea. During the alternate periods of elevation and of stationary level the record will generally be blank. During these latter periods there will probably be more variability in the forms of life; during periods of subsidence, more extinction.

With respect to the absence of strata rich in fossils beneath the Cambrian formation, I can recur only to the hypothesis given in the tenth chapter; namely, that though our continents and oceans have endured for an encrmous period in nearly their present relative positions, we have no reason to assume that this has always been the case; consequently formations much older than any now known may lie buried beneath the great oceans. With respect to the lapse of time not having been sufficient since our planet was consolidated for the assumed amount of organic change, and this objection, as urged by Sir William Thompson, is probably one of the gravest as yet advanced, I can only say, firstly, that we do not know at what rate species change as measured by years, and secondly, that many philosophers are not as yet willing to admit that we know enough of the constitution of the universe and of the interior of our globe to speculate with safety on its past duration.

That the geological record is imperfect all will admit; but that it is imperfect to the degree required by our theory, few will be inclined to admit. If we look to long enough intervals of time, geology plainly declares 
that species have all changed; and they have changed in the manner required by the theory, for they have changed slowly and in a graduated manner. We clearly see this in the fossil remains from consecutive formations invariably being much more closely related to each other, than are the fossils from widely separated formations.

Such is the sum of the several chief objections and difficulties which may be justly urged against the theory; and I have now briefly recapitulated the answers and explanations which, as far as I can see, may be given. I have felt these difficulties far too heavily during many years to doubt their weight. But it deserves especial notice that the more important objections relate to questions on which we are confessedly ignorant; nor do we know how ignorant we are. We do not know all the possible transitional gradations between the simplest and the most perfect organs; it cannot be pretended that we know all the varied means of Distribution during the long lapse of years, or that we know how imperfect is the Geological Record. Serious as these several objections are, in my judgment they are by no means sufficient to overthrow the theory of descent with subsequent modification.

Now let us turn to the other side of the argument, Under domestication we see much variability, caused, or at least excited, by changed conditions of life; but often in so obscure a manner, that we are tempted to consider the variations as spontaneous. Variability is governed by many complex laws,- - by correlated growth, compensation, the increased use and disuse of parts, and the definite action of the surrounding conditions. There is much difficulty in ascertaining how largely our domestic 
productions have been modified; but we may safely infer that the amount has been large, and that modifications can be inherited for long periods. As long as the conditions of life remain the same, we have reason to believe that a modification, which has already been inherited for many generations, may continue to be inherited for an almost infinite number of generations. On the other hand, we have evidence that variability when it has once come into play, does not cease under domestication for a very long period; nor do we know that it ever ceases, for new varieties are still occasionally produced by our oldest domesticated productions.

Variability is not actually caused by man; he only unintentionally exposes organic beings to new conditions of life, and then nature acts on the organisation and causes it to vary. But man can and does select the variations given to him by nature, and thus accumulates them in any desired manner. He thus adapts animals and plants for his own benefit or pleasure. He may do this methodically, or he may do it unconsciously by preserving the individuals most useful or pleasing to him without any intention of altering the breed. It is certain that he can largely influence the character of a breed by selecting, in each successive generation, individual differences so slight as to be inappreciable except by an educated eye. This unconscious process of selection has been the great agency in the formation of the most distinct and useful domestic breeds. That many breeds produced by man have to a large extent the character of natural species, is shown by the inextricable doubts whether many of them are varieties or aboriginally distinct species.

There is no reason why the principles which have 
acted so efficiently under domestication should not havo aoted under nature. In the survival of favoured individuals and races, during the constantly-recurrent Struggle for Existence, we see a powerful and everacting form of Selection. The struggle for existence inevitably follows from the high geometrical ratio of increase which is common to all organic beings. This high rate of increase is proved by calculation,-by the rapid increase of many animals and plants during a succession of peculiar seasons, and when naturalised in new countries. More individuals are born than can possibly survive. A grain in the balance may determine which individuals shall live and which shall die,-which variety or species shall increase in number, and which shall decrease, or finally become extinct. As the individuals of the same species come in all respects into the closest competition with each other, the struggle will generally be most severe between them; it will be almost equally severe between the varieties of the same species, and next in severity between the species of the same genus. On the other hand the struggle will often be severe between beings remote in the scale of nature. The slightest advantage in certain individuals, at any age or during any season, over those with which they come into competition, or better adaptation in however slight a degree to the surrounding physical conditions, will, in the long run, turn the balance.

With animals having separated sexes, there will be in most cases a struggle between the males for the possession of the females. The most vigorous males, or those which have most successfully struggled with their conditions of life, will generally leave most progeny. But success will often depend on the males having spe- 
cial weapons, or means of defence, or charms; and a light advantage will lead to victory.

As geology plainly proclaims that each land has undergone great physical changes, we might have expected to find that organic beings have varied under nature, in the same way as they have varied under domestication. And if there has been any variability under nature, it would be an unaccountable fact if natural selection had not come into play. It has often been asserted, but the assertion is incapable of proof, that the amount of variation under nature is a strictly limited quantity. Man, though acting on external characters alone and often capriciously, can produce within a short period a great result by adding up mere individual differences in his domestic productions; and every one admits that species present individual differences. But, besides such differences, all naturalists admit that natural varieties exist, which are considered sufficiently distinct to be worthy of record in systematic works. No one has drawn any clear distinction between individual differences and slight varieties; or between more plainly marked varieties and sub-species, and species. On separate continents, and on different parts of the same continent when divided by barriers of any kind, and on outlying islands, what a multitude of forms exist, which some experienced naturalists rank as varieties, others as geographical races or sub-species, and others as distinct, though closely allied species!

If then, animals and plants do vary, let it be ever so slightly or slowly, why should not variations or individual differences, which are in any way beneficial, be preserved and accumulated through natural selection, or the survival of the fittest? If man can by patience 
select variations useful to him, why, under changing and complex conditions of life, should not variations useful to nature's living products often arise, and be preserved or selected? What limit can be put to this power, acting during long ages and rigidly scrutinising the whole constitution, structure, and habits of each creature,--favouring the good and rejecting the bad? I can see no limit to this power, in slowly and beautifully adapting each form to the most complex relations of life. The theory of natural selection, even if we look no farther than this, seems to be in the highest degree probable. I have already recapitulated, as fairly as I could, the opposed difficulties and objections: now let us turn to the special facts and argumentsin favour of the theory.

On the view that species are only strongly marked and permanent varieties, and that each species first existed as a variety, we can see why it is that no line of demarcation can be drawn between species, commonly supposed to have been produced by special acts of creation, and varieties which are acknowledged to have been produced by secondary laws. On this same view we can understand how it is that in a region where many species of a genus have been produced, and where they now flourish, these same species should present many varieties; for where the manufactory of species has been active, we might expect, as a general rule, to find it still in action; and this is the case if varieties be incipient species. Moreover, the species of the larger genera, which afford the greater number of varieties or incipient species, retain to a certain degree the character of varieties; for they differ from each other by a less amount of difference than do the species of smaller genera. The closely 
allied species also of the larger genera apparently have restricted ranges, and in their affinities they are clustered in little groups round other species-in both respects resembling varieties. These are strange relations on the view that each species was independently created, but are intelligible if each existed first as a variety.

As each species tends by its geometrical rate of reproduction to increase inordinately in number; and as the modified descendants of each species will be enabled to increase by as much as they become more diversified in habits and structure, so as to be able to seize on many and widely different places in the economy of nature, there will be a constant tendency in natural selection to preserve the most divergent offspring of any one species. Hence, during a long-continued course of modification, the slight differences characteristic of varieties of the same species, tend to be augmented into the greater differences characteristic of the species of the same genus. New and improved varieties will inevitably supplant and exterminate the older, less improved, and intermediate varieties; and thus species are rendered to a large extent defined and distinct objects. Dominant species belonging to the larger groups within each class tend to give birth to new and dominant forms; so that each large group tends to become still larger, and at the same time more divergent in character. But as all groups cannot thus go on increasing in size, for the world would not hold them, the more dominant groups beat the less dominant. This tendency in the large groups to go on increasing in size and diverging in character, together with the inevitable contingency of much extinction, explains the arrangement of all the forms of life in groups subordinate to groups, all within a few 
great classes, which has prevailed throughout all time. This grand fact of the grouping of all organic beings under what is called the Natural System, is utterly inexplicable on the theory of creation.

As natural selection acts solely by accumulating slight, successive, favourable variations, it can produce no great or sudden modifications; it can act only by short and slow steps. Hence, the canon of "Natura non facit saltum," which every fresh addition to our knowledge tends to confirm, is on this theory intelligible. We can see why throughout nature the same general end is gained by an almost infinite diversity of means, for every peculiarity when once acquired is long inherited, and structures already modified in many different ways have to be adapted for the same general purpose. We can, in short, see why nature is prodigal in variety, though niggard in innovation. But why this should be a law of nature if each species has been independently created no man can explain.

Many other facts are, as it seems to me, explicable on this theory. How strange it is that a bird, under the form of a woodpecker, should prey on insects on the ground; that upland geese which rarely or never swim, should possess webbed feet; that a thrush-like bird should dive and feed on sub-aquatic insects; and that a petrel should have the habits and structure fitting it for the life of an auk! and so in endless other cases. But on the view of each species constantly trying to increase in number, with natural selection always ready to adapt the slowly varying descendants of each to any unoccupied or ill-occupied place in nature, these facts cease to be strange, or might even have been anticipated.

We can to a certain extent understand how it is that 
there is so much beauty throughout nature; for this may be largely attributed to the agency of selection. That beauty, according to our sense of it, is not universal, must be admitted by every one who will look at some venomous snakes, at some fishes, and at certain hideous bats with a distorted resemblance to the human face. Sexual selection has given the most brilliant colours, elegant patterns, and other ornaments to the males, and sometimes to both sexes of many birds, butterflies, and other animals. With birds it has often rendered the voice of the male musical to the female, as well as to our ears. Flowers and fruit have been rendered conspicuous by brilliant colours in contrast with the green foliage, in order that the flowers may be readily seen, visited and fertilised by insects, and the seeds disseminated by birds. How it comes that certain colours, sounds, and forms should give pleasure to man and the lower animals, - that is, how the sense of beauty in its simplest form was first acquired,-we do not know any more than how certain odours and flavours were first rendered agreeable.

As natural selection acts by competition, it adapts and improves the inhabitants of each country only in relation to their co-inhabitants; so that we need feel no surprise at the species of any one country, although on the ordinary view supposed to have been created and specially adapted for that country, being beaten and supplanted by the naturalised productions from another land. Nor ought we to marvel if all the contrivances in nature be not, as far as we can judge, absolutely perfect, as in the case even of the human eye; or if some of them be abhorrent to our ideas of fitness. We need not marvel at the sting of the bee, when used against 
an enemy, causing the bee's own death; at drones being produced in such great numbers for one single act, and being then slaughtered by their sterile sisters; at the astonishing waste of pollen by our fir-trees; at the instinctive hatred of the queen-bee for her own fertile daughters; at the ichneumonidæ feeding within the living bodies of caterpillars; or at other such cases. The wonder indeed is, on the theory of natural selection, that more cases of the want of absolute perfection have not been detected.

The complex and little known laws governing the production of varieties are the same, as far as we can judge, with the laws which have governed the production of distinct species. In both cases physical conditions seem to have produced some direct and definite effect, but how much we cannot say. Thus, when varieties enter any new station, they occasionally assume some of the characters proper to the species of that station. With both varieties and species, use and disuse seem to have produced a considerable effect; for it is impossible to resist this conclusion when we look, for instance, at the logger-headed duck, which has wings incapable of flight, in nearly the same condition as in the domestic duck; or when we look at the burrowing tucu-tucu, which is occasionally blind, and then at certain moles, which are habitually blind and have their eyes covered with skin; or when we look at the blind animals inhabiting the dark caves of America and Europe. With varieties and species, correlated variation seems to have played an important part, so that when one part has been modified other parts have been necessarily modified. With both varieties and species, reversions to longlost characters occasionally occur. How inexplicablt on 
the theory of creation is the occasional appearance of stripes on the shoulders and legs of the several species of the horse-genus and of their hybrids! How simply is this fact explained if we believe that these species are all descended from a striped progenitor, in the same manner as the several domestic breeds of the pigeon are descended from the blue and barred rock-pigeon!

On the ordinary view of each species having been independently created, why should specific characters, or those by which the species of the same genus differ from each other, be more variable than generic characters in which they all agree? Why, for instance, should the colour of a flower be more likely to vary in any one species of a genus, if the other species possess differently coloured flowers, than if all possessed the same coloured flowers? If species are only well-marked varieties, of which the characters have become in a high degree permanent, we can understand this fact; for they have already varied since they branched off from a common progenitor in certain characters, by which they have come to be specifically distinct from each other; therefore these same characters would be more likely again to vary than the generic characters which have been inherited without change for an immense period. It is inexplicable on the theory of creation why a part developed in a very unusual manner in one species alone of a genus, and therefore, as we may naturally infer, of great importance to that species, should be eminently liable to variation; but, on our view, this part has undergone, since the several species branched off from a common progenitor, an unusual amount of variability and modification, and therefore we might expect the part generally to be still variable. But a part may be 
developed in the most unusual manner, like the wing of a bat, and yet not be more variable than any other structure, if the part be common to many subordinate forms, that is, if it has been inherited for a very long period; for in this case it will have been rendered constant by long-continued natural selection.

Glancing at instincts, marvellous as some are, they offer no greater difficulty than do corporeal structures on the theory of the natural selection of successive, slight, but profitable modifications. We can thus understand why nature moves by graduated steps in endowing different animals of the same class with their several instincts. I have attempted to show how much light the principle of gradation throws on the admirable architectural powers of the hive-bee. Habit no doubt often comes into play in modifying instincts; but it certainly is not indispensable, as we see in the case of neuter insects, which leave no progeny to inherit the effects of long-continued habit. On the view of all the species of the same genus having descended from a common parent, and having inherited much in common, we can understand how it is that allied species, when placed under widely different conditions of life, yet follow nearly the same instincts; why the thrushes of tropical and temperate South America, for instance, line their nests with mud like our British species. On the view of instincts having been slowly acquired through natural selection, we need not marvel at some instincts being not perfect and liable to mistakes, and at many instincts causing other animals to suffer.

If species be only well-marked and permanent varieties, we can at once see why their crossed offspring should follow the same complex laws in their degrees and kinds 
of resemblance to their parents,-in being absorbed into each other by successive crosses, and in other such points,-as do the crossed offspring of acknowledged varieties. This similarity would be a strange fact, if species had been independently created and varieties had been produced through secondary laws.

If we admit that the geological record is imperfect to an extreme degree, then the facts, which the record does give, strongly support the theory of descent with modification. New species have come on the stage slowly and at successive intervals; and the amount of change, after equal intervals of time, is widely different in different groups. The extinction of species and of whole groups of species which has played so conspicuous a part in the history of the organic world,almost inevitably follows from the principle of natural selection; for old forms are supplanted by new and improved forms. Neither single species nor groups of species reappear when the chain of ordinary generation is once broken. The gradual diffusion of dominant forms, with the slow modification of their descendants, causes the forms of life, after long intervals of time, to appear as if they had changed simultaneously throughout the world. The fact of the fossil remains of each formation being in some degree intermediate in character between the fossils in the formations above and below, is simply explained by their intermediate position in the chain of descent. The grand fact that all extinct beings can be classed with all recent beings, naturally follows from the living and the extinct being the offspring of common parents. As species have generally diverged in character during their long course of descent and modification, we can understand why it is that the more ancient forms, or early 
progenitors of each group, so often occupy a position in some degree intermediate between existing groups. Recent forms are generally looked upon as being, on the whole, higher in the scale of organisation than ancient forms; and they must be higher, in so far as the later and more improved forms have conquered the older and less improved forms in the struggle for life; they have also generally had their organs more specialised for different functions. This fact is perfectly compatible with numerous beings still retaining simple and but little improved structures, fitted for simple conditions of life; it is likewise compatible with some forms having retrograded in organisation, by having become at each stage of descent better fitted for new and degraded habits of life. Lastly, the wonderful law of the long endurance of allied forms on the same continent, - of marsupials in Australia, of edentata in America, and other such cases,-is intelligible, for within the same country the existing and the extinct will be closely allied by descent.

Looking to geographical distribution, if we admit that there has been during the long course of ages much migration from one part of the world to another, owing to former climatal and geographical changes and to the many occasional and unknown means of dispersal, then we can understand, on the theory of descent with modification, most of the great leading facts in Distribution. We can see why there should be so striking a parallelism in the distribution of organic beings throughout space, and in their geological succession throughout time; for in both cases the beings have been connected by the bond of ordinary generation, and the means of modification have been the same. We see the full meaning of the wonderful fact, which has struck every traveller 
namely, that on the same continent, under the most diverse conditions, under heat and cold, on mountain and lowland, on deserts and marshes, most of the inhabitants within each great class are plainly related; for they are the descendants of the same progenitors and early colonists. On this same principle of former migration, combined in most cases with modification, we can understand, by the aid of the Glacial period, the identity of some few plants, and the close alliance of many others, on the most distant mountains, and in the northern and southern temperate zones; and likewise the close alliance of some of the inhabitants of the sea in the northern and southern temperate latitudes, though separated by the whole intertropical ocean. Although two countries may present physical conditions as closely similar as the same species ever require, we need feel no surprise at their inhabitants being widely different, if they have been for a long period completely sundered from each other; for as the relation of organism to organism is the most important of all relations, and as the two countries will have received colonists at various periods and in different proportions, from some other country or from each other, the course of modification in the two areas will inevitably have been different.

On this view of migration, with subsequent modification, we see why oceanic islands are inhabited by only few species, but of these, why many are peculiar or endemic forms. We clearly see why species belonging to those groups of animals which cannot cross wide spaces of the ocean, as frogs and terrestrial mammals, do not inhabit oceanic islands; and why, on the other hand, new and peculiar species of bats, animals which can traverse the ocean, are often found on islands far dis- 
tant from any continent. Such cases as the presence of peculiar species of bats on oceanic islands and the absence of all other terrestrial mammals, are facts utterly inexplicable on the theory of independent acts of creation.

The existence of closely allied or representative species in any two areas, implies, on the theory of descent with modification, that the same parent-forms formerly inhabited both areas; and we almost invariably find that wherever many closely allied species inhabit two areas, some identical species are still common to both. Whereever many closely allied yet distinct species occur, doubtful forms and varieties belonging to the same groups likewise occur. It is a rule of high generality that the inhabitants of each area are related to the inhabitants of the nearest source whence immigrants might have been derived. We see this in the striking relation of nearly all the plants and animals of the Galapagos archipelago, of Juan Fernandez, and of the other American islands, to the plants and animals of the neighbouring American mainland; and of those of the Cape de Verde archipelago, and of the other African islands to the African mainland. It must be admitted that these facts receive no explanation on the theory of creation.

The fact, as we have seen, that all past and present organic beings can be arranged within a few great classes, in groups subordinate to groups, and with the extinct groups often falling in between the recent groups, is intelligible on the theory of natural selection with its contingencies of extinction and divergence of character. On these same principles we see how it is, that the mutual affinities of the forms within each class are so complex and circuitous. We see why certain characters 
are far more serviceable than others for classification;why adaptive characters, though of paramount importance to the beings, are of hardly any importance in classification; why characters derived from rudimentary parts, though of no service to the beings, are often of high classificatory value; and why embryological characters are often the most valuable of all. The real affinities of all organic beings, in contradistinction to their adaptive resemblances, are due to inheritance or community of descent. The Natural System is a genealogical arrangement, with the acquired grades of difference, marked by the terms, varieties, species, genera, families, \&c.; and we have to discover the lines of descent by the most permanent characters whatever they may be and of however slight vital importance.

The similar framework of bones in the hand of a man, wing of a bat, fin of the porpoise, and leg of the horse,-the same number of vertebræ forming the neck of the giraffe and of the elephant,-and innumerable other such facts, at once explain themselves on the theory of descent with slow and slight successive modifications. The similarity of pattern in the wing and in the leg of a bat, though used for such different purpose,-in the jaws and legs of a crab,-in the petals, stamens, and pistils of a flower, is likewise, to a large extent, intelligible on the view of the gradual modification of parts or organs, which were aboriginally alike in an early progenitor in each of these classes. On the principle of successive variations not always supervening at an early age, and being inherited at a corresponding not early period of life, we clearly see why the embryos of mammals, birds, reptiles, and fishes should be so closely similar, and so unlike the adult forms. We may cease marvelling at 44 
the embryo of an air-breathing mammal or bird having branchial slits and arteries running in loops, like those of a fish which has to breathe the air dissolved in water by the aid of well-developed branchiæ.

Disuse, aided sometimes by natural selection, will often have reduced organs when rendered useless under changed habits or conditions of life; and we can understand on this view the meaning of rudimentary organs. But disuse and selection will generally act on each creature, when it has come to maturity and has to play its full part in the struggle for existence, and will thus have little power on an organ during early life; hence the organ will not be reduced or rendered rudimentary at this early age. The calf, for instance, has inherited teeth, which never cut through the gums of the upper jaw, from an early progenitor having well-developed teeth; and we may believe, that the teeth in the mature animal were formerly reduced by disuse, owing to the tongue and palate, or lips, having become excellently fitted through natural selection to browse without their aid; whereas in the calf, the teeth have been left unaffected, and on the principle of inheritance at corresponding ages have been inherited from a remote period to the present day. On the view of each organism with all its separate parts having been specially created, how utterly inexplicable is it that organs bearing the plain stamp of inutility, such as the teeth in the embryonic calf or the shrivelled wings under the soldered wingcovers of many beetles, should so frequently occur. Nature may be said to have taken pains to reveal her scheme of modification, by means of rudimentary organs, of embryological and homologous structures, but we are too blind to understand her meaning. 
I have now recapitulated the facts and considerations which have thoroughly convinced me that species have been modified, during a long course of descent. This has been effected chiefly through the natural selection of numerous successive, slight, favourable variations; aided in an important manner by the inherited effects of the use and disuse of parts; and in an unimportant manner, that is in relation to adaptive structures, whether past or present, by the direct action of external conditions, and by variations which seem to us in our ignorance to arise spontaneously. It appears that I formerly underrated the frequency and value of these latter forms of variation, as leading to permanent modifications of structure independently of natural selection. But as my conclusions have lately been much misrepresented, and it has been stated that I attribute the modification of species exclusively to natural selection, I may be permitted to remark that in the first edition of this work, and subsequently, I placed in a most conspicuous position-namely, at the close of the Introduction-the following words: "I am convinced that natural selection has been the main but not the exclusive means of modification." This has been of no avail. Great is the power of steady misrepresentation; but the history of science shows that fortunately this power does not long endure.

It can hardly be supposed that a false theory would explain, in so satisfactory a manner as does the theory of natural selection, the several large classes of facts above specified. It has recently been objected that this is an unsafe method of arguing; but it is a method used in judging of the common events of life, and has often been used by the greatest natural philosophers. The undulatory theory of light has thus been arrived at; and 
the belief in the revolution of the earth on its own axis was until lately supported by hardly any direct evidence. It is no valid objection that science as yet throws no light on the far higher problem of the essence or origin of life. Who can explain what is the essence of the attraction of gravity? No one now objects to following out the results consequent on this unknown element of attraction; nowithstanding that Leibnitz formerly accused Newton of introducing "occult qualities and miracles into philosophy."

I see no good reason why the views given in this volume should shock the religious feelings of any one. It is satisfactory, as showing how transient such impressions are, to remember that the greatest discovery ever made by man, namely, the law of the attraction of gravity, was also attacked by Leibnitz, " as subversive of natural, and inferentially of revealed, religion." A celebrated author and divine has written to me that " he has "gradually learnt to see that it is just as noble a concep" tion of the Deity to believe that He created a few ori" ginal forms capable of self-development into other and " needful forms, as to believe that He required a fresh act " of creation to supply the voids caused by the action of "His laws."

Why, it may be asked, until recently did nearly all the most eminent living naturalists and geologists disbelieve in the mutability of species. It cannot be asserted that organic beings in a state of nature are subject to no variation; it cannot be proved that the amount of variation in the course of long ages is a limited quartity; no clear distinction has been, or can be, drawn between species and well-marked varieties. It cannot be maintained that species when intercrossed are 
invariably sterile, and varieties invariably fertile; or that sterility is a special endowment and sign of creation. The belief that species were immutable productions was almost unavoidable as long as the history of the world was thought to be of short duration; and now that we have acquired some idea of the lapse of time, we are too apt to assume, without proof, that the geological record is so perfect that it would have afforded us plain evidence of the mutation of species, if they had undergone mutation.

But the chief cause of our natural unwillingness to admit that one species has given birth to clear and distinct species, is that we are always slow in admitting great changes of which we do not see the steps. The difficulty is the same as that felt by so many geologists, when Lyell first insisted that long lines of inland cliffs had been formed, and great valleys excavated, by the agencies which we see still at work. The mind cannot possibly grasp the full meaning of the term of even a million years; it cannot add up and perceive the full effects of many slight variations, accumulated during an almost infinite number of generations.

Although I am fully convinced of the truth of the views given in this volume under the form of an abstract, I by no means expect to convince experienced naturalists whose minds are stocked with a multitude of facts all viewed, during a long course of years, from a point of view directly opposite to mine. It is so easy to hide our ignorance under such expressions as the "plan of creation," "unity of design," \&c., and to think that we give an explanation when we only re-state a fact. Any one whose disposition leads him to attach more weight to unexplained difficulties than to the explanation of a 
certain number of facts will certainly reject the theory. A few naturalists, endowed with much flexibility of mind, and who have already begun to doubt the immutability of species, may be influenced by this volume; but I look with confidence to the future,-to young and rising naturalists, who will be able to view both sides of the question with impartiality. Whoever is led to believe that species are mutable will do good service by conscientiously expressing his conviction; for thus only can the load of prejudice by which this subject is overwhelmed be removed.

Several eminent naturalists have of late published their belief that a multitude of reputed species in each genus are not real species; but that other species are real, that is, have been independently created. This seems to me a strange conclusion to arrive at. They admit that a multitude of forms, which till lately they themselves thought were special creations, and which are still thus looked at by the majority of naturalists, and which consequently have all the external characteristic features of true species,-they admit that these have been produced by variation, but they refuse to extend the same view to other and slightly different forms. Nevertheless they do not pretend that they can define, or even conjecture, which are the created forms of life, and which are those produced by secondary laws. They admit variation as a vera causa in one case, they arbitrarily reject it in another, without assigning any distinction in the two cases. The day will come when this will be given as a curious illustration of the blindness of preconceived opinion. These authors seem no more startled at a miraculous act of creation than at an ordinary birth. But do they really believe that at innu- 
merable periods in the earth's history certain elemental atoms have been commanded suddenly to flash into living tissues? Do they believe that at each supposed act of creation one individual or many were produced? Were all the infinitely numerous kinds of animals and plants created as eggs or seed, or as full grown? and in the case of mammals, were they created bearing the false marks of nourishment from the mother's womb? Undoubtedly some of these same questions cannot be answered by those who believe in the appearance or creation of only a few forms of life, or of some one form alone. It has been maintained by several authors that it is as easy to believe in the creation of a million beings as of one; but Maupertuis' philosophical axiom " of least action" leads the mind more willingly to admit the smaller number; and certainly we ought not to believe that innumerable beings within each great class have been created with plain, but deceptive, marks of descent from a single parent.

As a record of a former state of things, I have retained in the foregoing paragraphs, and elsewhere, several sentences which imply that naturalists believe in the separate creation of each species; and I have been much censured for having thus expressed myself. But undoubtedly this was the general belief when the first edition of the present work appeared. I formerly spoke to very many naturalists on the subject of evolution, and never once met with any sympathetic agreement. It is probable that some did then believe in evolution, but they were either silent, or expressed themselves so ambiguonsly that it was not easy to understand their meaning. Now things are wholly changed, and almost every naturalist admits the great principle of evolution. 
There are, however, some who still think that species have suddenly given birth, through quite unexplained means, to new and totally different forms: but, as I have attempted to show, weighty evidence can be opposed to the admission of great and abrupt modifications. Under a scientific point of view, and as leading to further investigation, but little advantage is gained by believing that new forms are suddenly developed in an inexplicable manner from old and widely different forms, over the old belief in the creation of species from the dust of the earth.

It may be asked how far I extend the doctrine of the modification of species. The question is difficult to answer, because the more distinct the forms are which we consider, by so much the arguments in favour of community of descent become fewer in number and less in force. But some arguments of the greatest weight extend very far. All the members of whole classes are connected together by a chain of affinities, and all can be classed on the same principle, in groups subordinate to groups. Fossil remains sometimes tend to fill up very wide intervals between existing orders.

Organs in a rudimentary condition plainly show that an early progenitor had the organ in a fully developed condition; and this in some cases implies an enormous amount of modification in the descendants. Throughout whole classes various structures are formed on the same pattern, and at a very early age the embryos closely resemble each other. Therefore I cannot doubt that the theory of descent with modification embraces all the members of the same great class or kingdom. I believe that animals are descended from at most only four or 
five progenitors, and plants from an equal or lesser number.

Analogy would lead me one step farther, namely, to the belief that all animals and plants are descended from some one prototype. But analogy may be a deceitful guide. Nevertheless all living things have much in common, in their chemical composition, their cellular structure, their laws of growth, and their liability to injurious influences. We see this even in so trifling a fact as that the same poison often similarly affects plants and animals; or that the poison secreted by the gallfly produces monstrous growths on the wild rose or oaktree. With all organic beings, excepting perhaps some of the very lowest, sexual production seems to be essentially similar. With all, as far as is at present known, the germinal vesicle is the same; so that all organisms start from a common origin. If we look even to the two main divisions-namely, to the animal and vegetable kingdoms-certain low forms are so far intermediate in character that naturalists have disputed to which kingdom they should be referred. As Professor Asa Gray has remarked, "the spores and other repro"ductive bodies of many of the lower algæ may claim " to have first a characteristically animal, and then an " unequivocally vegetable existence." Therefore, on the principle of natural selection with divergence of character, it does not seem incredible that, from some such low and intermediate form, both animals and plants may have been developed; and, if we admit this, we must likewise admit that all the organic beings which have ever lived on this earth may be descended from some one primordial form. But this inference is chiefly grounded on analogy, and it is immaterial whether or 
not it be accepted. No doubt it is possible, as Mr. G. $H$. Lewes has urged, that at the first commencement of life many different forms were evolved; but if so, we may conclude that only a very few have left modified descendants. For, as I have recently remarked in regard to the members of each great kingdom, such as the Vertebrata, Articulata, \&c., we have distinct evidence in their embryological, homologous, and rudimentary structures, that within each kingdom all the members are descended from a single progenitor.

When the views advanced by me in this volume, and by Mr. Wallace, or when analogous views on the origin of species are generally admitted, we can dimly foresee that there will be a considerable revolution in natural history. Systematists will be able to pursue their labours as at present; but they will not be incessantly haunted by the shadowy doubt whether this or that form be a true species. This, I feel sure and I speak after experience, will be no slight relief. The endless disputes whether or not some fifty species of British brambles are good species will cease. Systematists will have only to decide (not that this will be easy) whether any form be sufficiently constant and distinct from other forms, to be capable of definition; and if definable, whether the differences be sufficiently important to deserve a specific name. This latter point will become a far more essential consideration than it is at present; for differences, however slight, between any two forms, if not blended by intermediate gradations, are looked at by most naturalists as sufficient to raise both forms to the rank of species.

Hereafter we shall be compelled to acknowledge that the only distinction between species and well-marked 
varieties is, that the latter are known, or believed, to be connected at the present day by intermediate gradations, whereas species were formerly thus connected. Hence, without rejecting the consideration of the present existence of intermediate gradations between any two forms, we shall be led to weigh more carefully and to value higher the actual amount of difference between them. It is quite possible that forms now generally acknowledged to be merely varieties may hereafter be thought worthy of specific names; and in this case scientific and common language will come into accordance. In short, we shall have to treat species in the same manner as those naturalists treat genera, who admit that genera are merely artificial combinations made for convenience. This may not be a cheering prospect; but we shall at least be free from the vain search for the undiscovered and undiscoverable essence of the term species.

The other and more general departments of natural history will rise greatly in interest. The terms used by naturalists, of affinity, relationship, community of type, paternity, morphology, adaptive characters, rudimentary and aborted organs, \&c., will cease to be metaphorical, and will have a plain signification. When we no longer look at an organic being as a savage looks at a ship, as something wholly beyond his comprehension; when we regard every production of nature as one which has had a long history; when we contemplate every complex structure and instinct as the summing up of many contrivances, each useful to the possessor, in the same way as any great mechanical invention is the summing up of the labour, the experience, the reason, and even the blunders of numerous workmen; when we thus view each organic being, how far more interesting-I 
speak from experience-does the study of natural history become!

A grand and almost untrodden field of inquiry will be opened, on the causes and laws of variation, on correlation, on the effects of use and disuse, on the direct action of external conditions, and so forth. The study of domestic productions will rise immensely in value. A new variety raised by man will be a more important and interesting subject for study than one more species added to the infinitude of already recorded species. Our classifications will come to be, as far as they can be so made, genealogies; and will then truly give what may be called the plan of creation. The rules for classifying will no doubt become simpler when we have a definite object in view. We possess no pedigrees or armorial bearings; and we have to discover and trace the many diverging lines of descent in our natural genealogies, by characters of any kind which have long been inherited. Rudimentary organs will speak infallibly with respect to the nature of long-lost structures. Species and groups of species which are called aberrant, and which may fancifully be called living fossils, will aid us in forming a picture of the ancient forms of life. Embryology will often reveal to us the structure, in some degree obscured, of the prototypes of each great class.

When we can feel assured that all the individuals of the same species, and all the closely allied species of most genera, have within a not very remote period descended from one parent, and have migrated from some one birth-place; and when we better know the many means of migration, then, by the light which geology now throws, and will continue to throw, on former changes of climate and of the level of the land, 
we shall surely be enabled to trace in an admirable manner the former migrations of the inhabitants of the whole world. Even at present, by comparing the differences between the inhabitants of the sea on the opposite sides of a continent, and the nature of the various inhabitants on that continent in relation to their apparent means of immigration, some light can be thrown on ancient geography.

The noble science of Geology loses glory from the extreme imperfection of the record. The crust of the earth with its imbedded remains must not be looked at as a well-filled museum, but as a poor collection made at hazard and at rare intervals. The accumulation of each great fossiliferous formation will be recognised as having depended on an unusual concurrence of favourable circumstances, and the blank intervals between the successive stages as having been of rast duration. But we shall be able to gauge with some security the duration of these intervals by a comparison of the preceding and succeeding organic forms. We must be cautious in attempting to correlate as strictly contemporaneous two formations, which do not include many identical species, by the general succession of the forms of life. As species are produced and exterminated by slowly acting and still existing causes, and not by miraculous acts of creation; and as the most important of all causes of organic change is one which is almost independent of altered and perhaps suddenly altered physical conditions, namely, the mutual relation of organism to organism,the improvement of one organism entailing the improvement or the extermination of others; it follows, that the amount of organic change in the fossils of consecutive formations probably serves as a fair measure of the 
relative though not actual lapse of time. A number of species, however, keeping in a body might remain for a long period unchanged, whilst within the same period several of these species by migrating into new countries and coming into competition with foreign associates, might become modified; so that we must not overrate the accuracy of organic change as a measure of time.

In the future I see open fields for far more important researches. Psychology will be securely based on the foundation already well laid by Mr. Herbert Spencer, that of the necessary acquirement of each mental power and capacity by gradation. Much light will be thrown on the origin of man and his history.

Authors of the highest eminence seem to be fully satisfied with the view that each species has been independently created. To my mind it accords better with what we know of the laws impressed on matter by the Creator, that the production and extinction of the past and present inhabitants of the world should have been due to secondary causes, like those determining the birth and death of the individual. When I view all beings not as special creations, but as the lineal descendants of some few beings which lived long before the first bed of the Cambrian system was deposited, they seem to me to become ennobled. Judging from the past, we may safely infer that not one living species will transmit its unaltered likeness to a distant futurity. And of the species now living very few will transmit progeny of any kind to a far distant futurity; for the manner in which all organic beings are grouped, shows that the greater number of species in each genus, and all the species in many genera, have left no descendants, but have become utterly extinct. We can so far take a 
prophetic glance into futurity as to foretell that it will be the common and widely-spread species, belonging to the larger and dominant groups within each class, which will ultimately prevail and procreate new and dominant species. As all the living forms of life are the lineal descendants of those which lived long before the Cambrian epoch, we may feel certain that the ordinary succession by generation has never once been broken, and that no cataclysm has desolated the whole world. Hence we may look with some confidence to a secure future of great length. And as natural selection works solely by and for the good of each being, all corporeal and mental endowments will tend to progress towards perfection.

It is interesting to contemplate a tangled bank, clothed with many plants of many kinds, with birds singing on the bushes, with various insects flitting about, and with worms crawling through the damp earth, and to reflect that these elaborately constructed forms, so different from each other, and dependent upon each other in so complex a manner, have all been produced by laws acting around us. These laws, taken in the largest sense, being Growth with Reproduction; Inheritance which is almost implied by reproduction; Variability from the indirect and direct action of the conditions of life, and from use and disuse: a Ratio of Increase so high as to lead to a Struggle for Life, and as a consequence to Natural Selection, entailing Divergence of Character and the Extinction of less-improved forms. Thus, from the war of nature, from famine and death, the most exalted object which we are capable of conceiving, namely, the production of the higher animals, directly follows. There is grandeur in this view of life, 
with its several powers, having been originally breathed by the Creator into a few forms or into one; and that, whilst this planet has gone cycling on according to the fixed law of gravity, from so eimple a beginning endless forms most beautiful and most wonderful have been, and are being evolved. 


\section{GL OS SA R Y}

OF THE

\section{PRINCIPAL SCIENTIFIC TERMS USED IN THE PRESENT VOLUME.*}

ABRRRANT.-Forms or groups of animals or plants which deviate in important characters from their nearest allies, so as not to be easily included in the same group with them, are said to be aberrant.

AbERRATION (in Optics). - In the refraction of light by a convex lens the rays passing through different parts of the lens are brought to a focus at slightly different distances,-this is called spherical aberration; at the same time the coloured rays are separated by the prismatic action of the lens and likewise. bronght to a focus at different distances,- this is chromatic aberration.

AbnormaL. - Contrary to the general rule.

ABORTED.-An organ is said to be aborted, when its development has been arrested at a very early stage.

ALBINISM.-Albinos are animals in which the usual colouring matters characteristic of the species have not been produced in the skin and its appendages. Albinism is the state of being an albino.

Alawe.-A class of plants including the ordinary sea-weeds and the filamentous fresh-water weods.

- I am indebted to the kindness of Mr. W. S. Dallas for this Glossary, which has been given because several readers have complained to me that some of the cerms used were unintelligible to them. Mr. Dallas has endeavoured to give the explanations of the terms in as popular a form as possible. 
Alternation of Grnerations.-This term is applied to a peculiar mode of reproduction which prevails among many of the lower animals, in which the egg produces a living form quite different from its parent, but from which the parent-form is reproduced by a process of budding, or by the division of the substance of the first product of the egg.

Ammonites.-A group of fossil, spiral, chambered shells, allied to the existing pearly Nautilus, but having the partitions between the chambers waved in complicated patterns at their junction with the outer wall of the shell.

ANaLOGX.-That resemblance of structures which depends npon similarity of function, as in the wings of insects and birds. Such structures are said to be analogous, and to be analogues of each other.

ANIMALCULE.-A minute animal : generally applied to those visible only by the microscope.

ANNELIDS.-A class of worms in which the surface of the body exhibits a more or less distinct division into rings or segments, generally provided with appendages for locomotion and with gills. It includes the ordinary marine worms, the earthworms, and the leeches.

Antennde.-Jointed organs appended to the head in Insects, Crustacea and Centipedes, and not belonging to the mouth.

ANTHERs.- The summits of the stamens of flowers, in which the pollen or fertilising dust is produced.

Aplacentalia, Aplacentata or Aplacental Mammals. See Mammalia.

ARCHETYPAL_-Of or belonging to the Archetype, or ideal primitive form upon which all the beings of a group seem to bo organised.

Articulata. - A great division of the Animal Kingdom characterised generally by having the surface of the body divided into rings called segments, a greater or less number of which are furnished with jointed legs (such as Insects, Crustaceans and Centipedes).

AsYMmetricaL.-Having the two sides unlike.

ATROPHIED.-Arrested in development at a very early stage.

BaLANUS.-The genus including the common Acorn-shells which live in abundance on the rocks of the sea-cosst.

Batrachians.-A class of animals allied to the Reptiles, but 
andergoing a peculiar metamorphosis, in which the young 2nimal is generally aquatic and breathes by gills. (Examples, Frogs, Toads, and Newts.)

BouLDERS.-Large transported blocks of stone generally imbedded in clays or gravels.

BRACHIOPODA.-A class of marine Mollusca, or soft-bodied animals, furnished with a bivalve shell, attached to submarine objects by a stalk which passes through an aperture in one of the valves, and furnished with fringed arms, by the action of which food is carried to the mouth.

BRANCHLE.-Gills or organs for respiration in water.

BranchIaL.-Pertaining to gills or branchiæ.

Cambrian System.-A Series of very ancient Palæozoic rocks, between the Laurentian and the Silurian. Until recently these were regarded as the oldest fossiliferous rocks.

CANID E, -The Dog-family, including the Dog, Wolf, Fox, Jackal, \&c.

CARAPACE.-The shell enveloping the anterior part of the body in Crustaceans generally; applied also to the hard shelly pieces of the Cirripedes.

CARBonfrerous.-This term is applied to the great formation which includes, among other rocks, the coal-measures. It belongs to the oldest, or Palæozoic, system of formations.

CAUDAL.-Of or belonging to the tail.

CEPHALOPODS.-The highest elass of the Mollusea, or soft-bodied animals, characterised by having the mouth surrounded by a greater or less number of fleshy arms or tentacles, which, in most living species, are furnished with sucking-cups. (Examples, Cuttle-fish, Nautilus.)

Cetacea. - An order of Mammalia, including the Whales, Dolphins, \&c., having the form of the body fish-like, the skin naked, and only the fore-limbs developed.

Chrionia.-An order of Reptiles including the Turtles, Tortoises, \&c.

CrRrIPEDes.-An order of Crustaceans including the Barnacles and Acorn-shells. Their young resemble those of many other Crustaceans in form; but when mature they are always attached to other objects, either directly or by means of a stalk, and their bodies are enclosed by a calcareous shell composed of several pieces, two of which can open to give issue to a bunch of curled, jointed tentacles, which represent the limbs. 
Coccus.-The genus of Insects including the Cochineal. In these the male is a minute, winged fly, and the female generally a motionless, berry-like mass.

Cocoon.-A case usually of silky material, in which insects are frequently enveloped during the second or resting-stage (pupa) of their existence. The term "cocoon-stage" is here used as equivalent to "pupa-stage."

Coelospermous, - A term applied to those fruits of the Umbelliferæ which have the seed hollowed on the inner face.

CoLEoptera.-Beetles, an order of Insects, having a biting mouth and the first pair of wings more or less horny, forming sheaths for the second pair, and usually meeting in a straight line down the middle of the back.

Colums.-A peculiar organ in the flowers of Orchids, in which the stamens, style and stigma (or the reproductive parts) are united.

Composita or Compositous Plants,-Plants in which the inflorescence consists of numerous small flowers (florets) brought together into a dense head, the base of which is enclosed by a common envelope. (Examples, the Daisy, Dandelion, \&c.)

CONFERvE, -The filamentous weeds of fresh water.

Conglomerate.-A rock made up of fragments of rock or pebbles, cemented together by some other material.

Corolut.-The second envelope of a flower usually composed of coloured, leaf-like organs (petals), which may be united by their edges either in the basal part or throughout.

Correlation.-The normal coincidence of one phenomenon, character, \&c., with another.

CORYMB.-A bunch of flowers in which those springing from the lower part of the flower stalk are supported on long stalks so as to be nearly on a level with the upper ones.

CoTYLEDONS.-The first or seed-leaves of plants.

Crustaceans.-A class of articulated animals, having the skin of the body generally more or less hardened by the deposition of calcareous matter, breathing by means of gills. (Examples, Crab, Lobster, Shrimp, \&c.)

Curculio.-The old generic term for the Beetles known as Weevils, characterised by their four-jointed feet, and by the head being produced into a sort of beak, upon the sides of which the sntenno are inserted.

CUtaneods,-Of or belonging to the skin. 
DEGRADATION.-The wearing down of land by the action of the sea or of meteoric agencies.

Denudation.-The wearing away of the surface of the land by water.

Defontan System or formation.-A series of Palæozoic rocks, including the Old Red Sandstone.

Dicotyledons or Dicotyledonous Plants.-A class of plants characterised by having two seed-leaves, by the formation of new wood between the bark and the old wood (exogenous growth) and by the reticulation of the reins of the leaves. The parts of the flowers are generally in multiples of five.

DifFERENTIATION.-The separation or discrimination of parts or organs which in simpler forms of life are more or less united.

DrmorPHIC.-Having two distinct forms.-Dimorphism is the condition of the appearance of the same species under two dissimilar forms.

Dracious.-Having the organs of the sexes upon distinct individuals.

Diorrre.-A peculiar form of Greenstone.

DoRSAL,-Of or belonging to the back.

Edentata.-A peculiar order of Quadrupeds, charscterised by the absence of at least the middle incisor (front) teeth in both jaws. (Examples, the Sloths and Armadillos.)

ELYTRA. - The hardened fore-wings of Beetles, serving as sheaths for the membranous hind-wings, which constitute the true organs of flight.

EmBRYo.-The young animal undergoing development within the egg or womb.

EMBRYoLOGY.-The study of the development of the embryo.

ENDEMIC.-Peculiar to a given locality.

Entomostraca.-A division of the class Crustacea, having all the segments of the body usually distinct, gills attached to the feet or organs of the mouth, and the feet fringed with fine hairs. They are generally of small size.

EOCENE. -The earliest of the three divisions of the Tertiary epoch of geologists. Rocks of this age contain a small proportion of shells identical with species now living.

EpHemerous Insects.-Insects allied to the May-fily. 
FAUNA.-The totality of the animals naturally inhabiting a certain country or region, or which have lived during a given geological period.

FeLIDX.-The Cat-family.

FeraL.-Having become wild from a state of cultivation or domestication.

FLORA.-The totality of the plants growing naturally in a country, or during a given geological period.

FLORETS.-Flowers imperfectly developed in some respects, and collected into a dense spike or head, as in the Grasses, the Dandelion, \&c.

FøtaL.-Of or belonging to the fotus, or embryo in course of development.

Foraminifers.-A class of animals of very low organisation, and generally of small size, having a jelly-like body, from the surface of which delicate filaments can be given off and retracted for the prehension of external objects, and having a calcareous or sandy shell, usually divided into chambers, and perforated with small apertures.

Fassillferous.-Containing fossils.

Fossorial.-Having a faculty of digging. The Fossorial Hymenoptera are a group of Wasp-like Insects, which burrow in sandy soil to make nests for their young.

Frenum (pl. Frena).-A small band or fold of skin.

Funar (sing. Funaus).-A class of cellular plants, of which Mushrooms, Toadstools, and Moulds, are familiar examples.

Furcula,-The forked bone formed by the union of the collarbones in many birds, such as the common Fowl.

Gallinaceous Birds.-An order of Birds of which the common Fowl, Turkey, and Pheasant, are well-known examples.

Gallus.-The genus of birds which includes the common Fowl.

GANoLion.-A swelling or knot from which nerves are given off as from a centre.

GaNoID Fishes.-Fishes covered with peculiar enamelled bony scales. Most of them are extinct.

Germinal Vesicle.-A minute vesicle in the eggs of animals, from which development of the embryo proceeds.

Glacial Period.-A period of great cold and of enormous extension of ice upon the surface of the earth. It is believed that glacial periods have occurred repeatedly during the geological 
history of the earth, but the term is generally applied to the close of the Tertiary epoch, when nearly the whole of Europe was subjected to an arctic climate.

GLAND.-An organ which secretes or separates some peculiar product from the blood or sap of animals or plants.

GLotTIS.-The opening of the windpipe into the œsophagus or gullet.

GNEISS.-A rock approaching granite in composition, but more or less laminated, and really produced by the alteration of a sedimentary deposit after its consolidation.

Grallatores.-The so-called Wading-birds (Storks, Cranes, Snipes, \&c.), which are generally furnished with long legs, bare of feathers above the heel, and have no membranes between the toes.

GraNTTE,-A rock consisting essentially of crystals of felspar and mica in a mass of quartz.

HАBITAT.-The locality in which a plant or animal naturally lives. HEMIPTERA. -An order or sub-order of Insects, characterised by the possession of a jointed beak or rostrum, and by having the fore-wings horny in the basal portion and membranous at the extremity, where they cross each other. This group includes the various species of Bugs.

HERMAPHRODITE.-Possessing the organs of both sexes.

HomoLoGY.-That relation between parts which results from their development from corresponding embryonic parts, either in different animals, as in the case of the arm of man, the foreleg of a quadruped, and the wing of a bird; or in the same individual, as in the case of the fore and hind legs in quadrupeds, and the segments or rings and their appendages of which the body of a worm, a centipede, \&c., is composed. The latter is called serial homology. The parts which stand in such a relation to each other are said to be homologous, and one such part or organ is called the homologue of the other. In different plants the parts of the flower are homologous, and in general these parts are regarded as homologous with leaves.

Homopter A. - An order or sub-order of Insects having (like the Hemiptera) a jointed beak, but in which the fore-wings are either wholly membranous or wholly leathery. The Cicadce, Frog-hoppers, and Aphides, are well-known examples.

HYBRw. - The offspring of the union of two distinct species. 
HrMENoptera, - An order of insects possessing biting jaws and usua - fnur membranous wings in which there are a few veins. Bees and Wusps are familiar examples of this group. HYPERTROPHIED.-Excessively developed.

ICHNEUMONIDA.-A family of Hymenopterous insects, the members of which lay their eggs in the bodies or eggs of other insects.

ImaGo.-The perfect (generally winged) reproductive state of ab insect.

INDIGENS.-The aboriginal animal or vegetable inhabitants of a country or region.

INFLORESCENCE. - The mode of arrangement of the flowers of plants. IrFUSORIA.-A class of microscopic Animalcules, so called from their having originally been observed in infusions of vegetable matters. They consist of a gelatinous material enclosed in a delicate membrane, the whole or part of which is furnisheil with short vibrating hairs (called cilia), by means of which th. animalcules swim through the water or convey the minute particles of their food to the orifice of the mouth.

INSECTIVOROUS.-Feeding on Insects.

INVERTEBRATA, or INVERTEBRATE ANIMALS.-Those animals which do not possess a backbone or spinal column.

LACUNA.-Spaces left among the tissues in some of the lower animals, and serving in place of ressels for the circulation of the fluids of the body.

LAMELLATED.-Furnished with lamellæ or little plates.

LARTA (pl. LARTX). -The first condition of an insect at its issuing from the egg, when it is usually in the form of a grub, caterpillar, or maggot.

LARYNX. - The upper part of the windpipe opening into the gullet. LAURENTIAN_-A group of greatly altered and very ancient rocks, which is greatly developed along the course of the St. Laurence, whence the name. It is in these that the earliest known traces of organic bodies have been found.

LeGuminose,-An order of plants represented by the common Peas and Beans, having an irregular flower in which one petal stands up like a wing, and the stamens and pistil are enclosed in a sheath formed by two other petals. The fruit is a pod (or legume). 
LEMURIDE.-A group of four-handed animals, distinct from the Monkeys and approaching the Insectivorous Quadrupeds in some of their characters and habits. Its members have the nostrils curved or twisted, and a claw instead of a nail upon the first finger of the hind hands.

LEPIDOPTERA.-An order of Insects, characterised by the possession of a spiral proboscis, and of four large more or less scaly wings. It includes the well-known Butterflies and Moths.

LITTORAL,-Inhabiting the seashore.

LOEss.-A marly deposit of recent (Post-Tertiary) date, which occupies a great part of the valley of the Rhine.

Malacostraca.-The higher division of the Crustacea, including the ordinary Crabs, Lobsters, Shrimps, \&c., together with the Woodlice and Sand-hoppers.

Mammalis. - The highest class of animals, including the ordinary hairy quadrupeds, the Whales, and Man, and characterised by the production of living young which are nourished after birth by milk from the teats (Mamma, Mammary glands) of the mother. A striking difference in embryonic development has led to the division of this class into two grest groups; in one of these, when the embryo has attained a certain stage, a vascular connection, called the placenta, is formed between the embryo and the mother; in the other this is wanting, and the young are produced in a very incomplete state. The former, including the greater part of the class, are called Placental mammals; the latter, or Aplacental mammals, include the Marsupials and Monotremes (Ornithorhynchus).

MAMMIFEROUS. Having mammæ or teats (see MaMmaLIA).

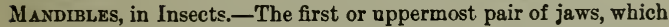
are generally solid, horny, biting organs. In Birds the term is applied to both jaws with their horny coverings. In Quadrupeds the mandible is properly the lower jaw.

MarSUPIALS.-An order of Mammalia in which the young are born in a very incomplete state of development, and carried by the mother, while sucking, in a ventral pouch (marsupium), such as the Kangaroos, Opossums, \&c. (see Mamimalia).

MAxILLE, in Insects.-The second or lower pair of jaws, which are composed of several joints and furnished with peculiar jointed appendages called palpi, or feelers. 
MrLaNisM.-The opposite of albinism; an undue development of colouring material in the skin and its appendages.

METAMORPHIC ROCKs.-Sedimentary rocks which have undergone alteration, generally by the action of heat, subsequently to their deposition and consolidation.

Mollusca.-One of the great divisions of the Animal Kingdom, including those animals which have a soft body, usually furnished with a shell, and in which the nerrous ganglia, or centres, present no definite general arrangement. They are generally known under the denomination of "shell-fish;" the cuttle-fish, and the common snails, whelks, oysters, mussels, and cockles, may serve as examples of them.

Monocotrledons, or Monocotrledonous Plants. - Plants in which the seed sends up only a single seed-leaf (or cotyledon); characterised by the absence of consecutive layers of wood in the stem (endogenous growth), by the veins of the leaves being generally straight, and by the parts of the flowers being generally in multiples of three. (Examples, Grasses, Lilies, Orchids, Palms, \&c.)

MoraINEs.-The accumulations of fragments of rock brought down by glaciers.

MORPHOLOGY.-The law of form or structure independent of function.

Mrsis-stagE.-A stage in the development of certain Crustaceans (Prawns), in which they closely resemble the adults of a genus (Mysis) belonging to a slightly lower group.

NASCENT.-Commencing development.

NATATORY.-Adapted for the purpose of swimming.

NAUPLIUS-FOR.M.-The earliest stage in the development of many Crustacea, especislly belonging to the lower groups. In this stage the animal has a short body, with indistinct indications of a division into segments, and three pairs of tringed limbs. This form of the common fresh-water Cyclops was described as a distinct genus under the name of Nauplius.

Neuration.-The arrangement of the veins or nervures in the wings of Insects.

NeUTERS.-Imperfectly developed females of certain social insects (such as Ants and Bees), which perform all the labours of the community. Hence they are also called workers.

Nictitating Membrane,-A semi-transparent membrane, which 
can be drawn across the eye in Birds and Reptiles, either to moderate the effects of a strong light or to sweep particles of dust, \&c., from the surface of the eye.

OCELLI.-The simple eyes or stemmata of Insects, usually situated on the crown of the head between the great compound eyes.

OEsOPHAGUS. -The gullet.

OoLITIC.-A great series of secondary rocks, so called from the texture of some of its members, which appear to be made up of a mass of small egg-like calcareous bodies.

OPERCULUM.-A calcareous plate employed by many Mollusca to close the aperture of their shell. The opercular valves of Cirripedes are those which close the aperture of the shell.

ORBIT.-The bony cavity for the reception of the eye.

ORGANISM.-An organised being, whether plant or animal.

ORTноSPERmous.-A term applied to those fruits of the Umbelliferæ which have the seed straight.

OscuLANT.-Forms or grotps apparently intermediate between and connecting other groups are said to be osculant.

Ora.-Eggs.

OVARIUM or OVARY (in plants).-The lower part of the pistil or female organ of the flower, containing the ovules or incipient seeds; by growth after the other organs of the flower have fallen, it usually becomes converted into the fruit.

OVIGEROUS.-Egg-bearing.

Ovules (of plants).-The seeds in the earliest condition.

PACHYDERMS.-A group of Mammalia, so called from their thick skins, and including the Elephant, Rhinoceros, Hippopotamus, \&c.

PALxozorc.-The oldest system of fossiliferous rocks.

PALPI.-Jointed appendages to some of the organs of the mouth in Insects and Crustacea.

Papilionaces.-An order of Plants (see Leguminosa).-The flowers of these plants are called papilionaceous, or butterflylike, from the fancied resemblance of the expanded superior petals to the wings of a butterfly.

PARASTTE.-An animal or plant living upon or in, and at the expense of, another organism.

Parthenogenesis.-The production of living organisms from unimpregnated eggs or seeds. 
Pedunculated.-Supported upon a stem or stalk. The pedunculated ouk has its acorns borne upon a footstalk.

PELORIA or PELORISM. - The appearance of regularity of structure in the flowers of plants which normally bear irregular flowers.

Pelvis.-The bony arch to which the hind limbs of vertebrate animals are articulated.

Petals. - The leaves of the corolla, or second eircle of organs in a flower. They are usually of delicate texture and brightly coloured.

Pryllodineous.-Having flattened, leaf-like twigs or leafstalks instead of true leaves.

Pigment.-The colouring material produced generally in the superficial parts of animals. The cells secreting it are called pigment-cells.

Pinnatz.-Bearing leaflets on each side of a central stalk.

PistiLs.-The female organs of a flower, which occupy a position in the centre of the other floral organs. The pistil is generally divisible into the ovary or germen, the style and the stigma.

Placentalia, Placentata, or Placental Mammals.-Seo MamMALIA.

PlantioRades.-Quadrupeds which walk upon the whole sole of the foot, like the Bears.

Plastic.-Readily capable of change.

Pleistocene Period.-The latest portion of the Tertiary epoch.

Plumule (in plants). - The minute bud between the seed-leaves of newly-germinated plants.

Plutonic Rocks.-Rocks supposed to have been produced by igneous action in the depths of the earth.

Pollen.-The male element in flowering plants; usually a fine dust produced by the anthers, which, by contact with the stigma effects the fecundation of the seeds. This impregnation is brought about by means of tubes (pollen-tubes) which issue from the pollen-grains adhering to the stigma, and penetrate through the tissues until they reach the ovary.

Polyandrous (flowers).-Flowers having many stamens.

Polygamous Plavts.-Plants in which some flowers are unisexual and others hermaphrodite. The unisexual (male and female) flowers, may be on the same or on different plants.

PoLYMoRPHIC.-Presenting many forms.

Polyzoary. - The common structure formed by the cells of the Polyzor, such as tho well-known Sea-mats. 
PrEHENSILE.-Capable of grasping.

PREPOTENT.-Having a superiority of power.

'PRIMARIES.-The feathers forming the tip of the wing of a bird, and inserted upon that part which represents the hand of man.

Processes.-Projecting portions of bones, usually for the attachment of muscles, ligaments, \&c.

Propolis.-A resinous material collected by the Hive-Bees from the opening buds of various trees.

Protean.-Exceedingly variable.

Protozos.-The lowest great division of the Animal Kingdom. These animals are composed of a gelatinous material, and show scarcely any trace of distinct organs. The Infusoria, Foraminifera, and Sponges, with some other forms, belong to this division.

PuPa (pl. PUP x).-The second stage in the development of an Insect, from which it emerges in the perfect (winged) reproductive form. In most insects the pupal stage is passed in perfect repose. The chrysalis is the pupal state of butterfies.

RADICLE. - The minute root of an embryo plant.

RAMus.-One half of the lower jaw in the Mammalia. The portion which rises to articulate with the skull is called the ascending ramus.

RANGE.-The extent of country over which a plant or animal is naturally spread. Range in time expresses the distribution of a species or group through the fossiliferous beds of the earth's crust.

Retina.-The delicate inner coat of the eye, formed by nervous filaments spreading from the optic nerve, and serving for the perception of the impressions produced by light.

RETrogression.-Backward development. When an animal, as it approaches maturity, becomes less perfectly organised than might be expected from its early stages and known relationships, it is said to undergo a retrograde development or metamorphosis.

RHzzOPODS.-A class of lowly organised animals (Protozoa), having a gelatinous body, the surface of which can be protruded in the form of root-like processes or filaments, which serve for locomotion and the prehension of food. The most important order is that of the Foraminifera. 
Rodents.-The gnawing Mammalia, such as the Rats, Rabbits, and Squirrels. They are especially characterised by the possession of a single pair of chisel-like cutting teeth in each jaw, between which and the grinding teeth there is a great gap.

RUBUs.-The Bramble Genus.

RUdMENTARY.-Very imperfectly developed.

Ruminants. - The group of Quadrupeds which ruminate or chew the cud, such as oxen, sheep, and deer. They have divided hoofs, and are destitute of front teeth in the upper jaw.

SACRAL_-Belonging to the sacrum, or the bone composed usually of two or more united vertebræ to which the sides of the pelvis in vertebrate animals are attached.

SARCODE.-The gelatinous material of which the bodies of the lowest animals (Protozoa) are composed.

ScUTELLX.-The horny plates with which the feet of birds are generally more or less covered, especially in front.

Sedimentary Formations.-Rocks deposited as sediments from water.

SEGmeNTS.-The transverse rings of which the body of an articulate animal or Annelid is composed.

SEPALS.-The leaves or segments of the calyz, or outermost envelope of an ordinary flower. They are usually green, but sometimes brightly coloured.

SERratures.-Teeth like those of a saw.

SEssile.-Not supported on a stem or footstalk.

Silurian Systex.-A very ancient system of fossiliferous rocks belonging to the earlier part of the Palæozoic series.

Specialisation.-The setting apart of a particular organ for the performance of a particular function.

Spinal ChoRd.-The central portion of the nerrous system in the Vertebrata, which descends from the brain through the arches of the vertebræ, and gives off nearly all the nerves to the various organs of the body.

Stamens.-The male organs of flowering plants, standing in a circle within the petals. They usually consist of a filament and an anther, the anther being the essential part in which the pollen, or fecundating dust, is formed.

Sternum.-The breast-bone.

Stiama.-The apical portion of the pistil in flowering plants. 
Stipules.-Small leafy organs placed at the base of the footstalks of the leaves in many plants.

STYLE,-The middle portion of the perfect pistil, which rises like a column from the ovary and supports the stigma at its summit.

SUBCUTANEOUS.-Situated beneath the skin.

Suctorial,-Adapted for sucking.

Sutures (in the skull).-The lines of junction of the bones of which the skull is composed.

TARSUS (pl. TARSI).-The jointed feet of articulate animals, such as Insects.

Teleostean Fishes.-Fishes of the kind familiar to us in the present day, having the skeleton usually completely ossified and the scales horny.

Tentacula or Tentacles.-Delicate fleshy organs of prehension or touch possessed by many of the lower animals.

Tertiarr.-The latest geological epoch, immediately preceding the establishment of the present order of things.

Trachea. - The windpipe or passage for the admission of air to the lungs.

TRIDACTYLE.-Three-fingered, or composed of three movable parts attached to a common base.

TriLOBITES.-A peculiar group of extinct Crustaceans, somewhat resembling the Woodlice in external form, and, like some of them, capable of rolling themselves up into a ball. Their remains are found only in the Palæozoic rocks, and most abundantly in those of Silurian age.

TrimorPHIC.-Presenting three distinct forms.

UMBELLIFER E. -An order of plants in which the flowers, which contain five stamens and a pistil with two styles, are supported upon footstalks which spring from the top of the flower stem and spread out like the wires of an umbrella, so as to bring all the flowers in the same head (umbel) nearly to the same level. (Examples, Parsley and Carrot).

UnGULATA.-Hoofed quadrupeds.

UNICELLULAR.-Consisting of a single cell.

VASCULAR.-Containing blood-vessels.

VERMIFORM,-Like a worm. 
Vertebrata: or Vertebrate Animals.-The highest division of the animal kingdom, so called from the presence in most cases of a backbone composed of numerous joints or vertebra, which constitutes the centre of the skeleton and at the same time supports and protects the central parts of the nervous system.

WhorLs. - The circles or spiral lines in which the parts of plants are arranged upon the axis of growth.

WORKERS.-See neuters.

ZоËA-STAGE.-The earliest stage in the development of many of the higher Crustacea, so called from the name of Zoëa applied to these young animals when they were supposed to constitute a peculiar genus.

Zoolds.-In many of the lower animals (such as the Corals, Medusæ, \&c.) reproduction takes place in two ways, namely, by means of eggs aud by a process of budding with or without separation from the parent of the product of the latter, which is often very different from that of the egg. The individuality of the species is represented by the whole of the form produced between two sexual reproductions; and these forms, which ar apparently individual animals, have been called zooids. 


\section{N D E X.}

ABERRANT.

\section{A.}

A berrant groups, ii. 227.

Abyssinia, plants of, ii. 167 .

Acclimatisation, i. 173.

Adoxa, i. 270.

Affinities of extinct species, ii. 106.

A organic beings, ii. 225.

Agassiz, on Amblyopsis, i. 173. $\underline{-}$, on groups of epecies suddenly appearing, ii. 88.

$\longrightarrow$, on prophetic forms, ii. 107.

_ on embryological succession, ii. 120.

, on the Glacial period, ii. 151.

$\longrightarrow$ on embryological characters, ii. 210 .

i. on the latest tertiary forms, ii. 71.

71. on parallelism of embryological development and geological succession, ii. 254.

, Alex., on pedicellariæ, i. 298.

Algæ of New Zealand, ii. 164.

Alligators, males, fighting, i. 108.

Alternate generations, ii. 239.

Amblyopsis, blind fish, i. 173.

America, North, productions allied to those of Europe, ii. 156.

$-\frac{}{1 i}$, boulders and glaciers of, ii. 159 .

-, South, no modern formations on west coast, ii. 61 .

Ammonites, sudden extinction of, ii. 99.

Anagallis, sterility of, ii. 4.

Analogy of variations, i. 197.

Ancylus, ii. 174.

Andaman Islands inhabited by a toad, ii. 182.

Animals, not domesticated from being variable, i. 19.

domestic, descended from aeveral stocks, i. 21.

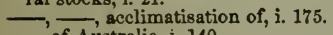

- of Australia, i. 140.

- with thicker fur in cold climates, i. 166.

$\longrightarrow$ blind, in eaves, i. 172.

, extinct, of Australia, ii. 121. Anomma, i. 361 .
BALANCEMENT.

Antarctic islands, ancient flora of, ii. 190.

Antechinus, ii. 219.

Ants attending aphides, i. 323.

-, slave-making instinct, i. 336.

- neuters, structure of, i. 359.

Apes, not haring acquired intellectual powers, i. 282.

Aphides, attended by ants, i. 323.

A phis, development of, ii. 245.

A ptery x, i. 218.

Arab horses, i. 40.

Aralo-Caspian Sea, ii. 121.

Archeopteryx, ii. 80.

Archisc, M. de, on the succession of species, ii. 103.

Artichoke, Jerusalem, i. 176.

Ascension, plants of, ii. 178.

Asclepias, pollen of, i. 236.

Asparagus, ii. 143.

Aspicarpa, ii. 209.

Asses, striped, i. 198.

-, improved by selection, i. 48.

Ateuchus, i. 168.

Aucapitaine, on land-shells, ii. 187.

Audubon, on habits of frigate-bird, i. 222 .

, on variation in birds' nests, $i$. 324.

- on heron eating seeds, ii. 176 .

A ustralia, animals of, i. 140 .

- dogs of, i. 328.

$\longrightarrow$, extinct animals of, ii. 121.

- European plants in, ii. 163.

_ glaciers of, ii. 159.

Azara, on flies destroying cattle, i. 89.

Azores, flors of, ii. 149.

B.

Babington, Mr., on British plants, i. 58 .

Baer, Von, standard of Highness, i. 151.

118 . embryonic similarity of the

Vertebrata, ii. 241.

Baker, Sir S., on the giraffe. i. 278.

Balancement of growth, i. 182.

323 
Baleen, i. 285.

Barberry, flowers of, i. 121.

Barrande, M., on Silurian colonies, ii. 90.

- , on the succession of species, ii. 103.

, on parallelism of palæozoic formations, ii. 106.

- on affinities of ancient species, ii. 108.

Barriers, importance of, ii. 130.

Bates, Mr., on mimetic butterflies, ii. $222,223,224$.

Batrachians on islands, ii. 182.

Bats, how structure acquired, i. 218.

$\longrightarrow$ distribution of, ii. 184.

Bear, catching water-insects, i. 220.

Beauty, how acquired, i. 249 ; ii. 283.

Bee, sting of, i. 255.

- , queen, killing rivals, i. 256.

- Australian, extermination of, i. 93 .

Bees fertilising flowers, i. 90.

- , hive, not sucking the red clover, i. 117.

- , Ligurian, i. 117.

, hive, cell-making instinct, i. 342.

- variation in habits, i. 324.

- parasitic, i. 336.

humble, cells of, i. 343.

Beetles, wingless, in Madeira, i. 169.

with deficient tarsi, i. 168.

Bentham, Mr., on British plants, $i$. 58.

$\longrightarrow$, on classification, ii. 211.

Berkeley, Mr., on seeds in salt water, ii. 142.

Bermuda, birds of, ii. 180 .

Birds acquiring fear, i. 325.

- beauty of, i. 252 .

- annually cross the Atlantic, ii. 150.

- colour of, on continents, i. 165 .

- footsteps and remains of, in secondary rocks, ii. 79 .

- , fossil, in caves of Brazil, ii. 121.

- of Madeira, Bermuda, and Galapagos, ii. 179, 180.

- song of males, i. 109.

_transporting seeds, ii. 148.

-, waders, ii. 175.

-, wingless, i. 167, 218.
Bizcacha, ii. 133.

attinities of, ii. 227.

Bladder for swimming, in fish, i. 230.

Blindness of cave animals, i. 170.

Blyth, Mr., on distinctness of Indian cattle, i. 21.

$\longrightarrow$, on striped hemionus, i. 199.

$\longrightarrow$, on crossed geese, ii. 10 .

Borrow, Mr., on the Spanish pointer, i. 40.

Bory St. Vincent, on Batrachians, ii. 182 .

Bosquet, M., on fossil Chthamalus, ii. 80.

Boulders, erratic, on the Azores, ii. 149.

Branchiæ, i. 231, 232.

- of crustaceans, i. 238.

Braun, Prof,, on the seeds of Fume riaceæ, i. 271.

Brent, Mr., on house-tumblers, i 326.

Britain, mammals of, ii. 185.

Broca, Prof., on Natural Selection, i. 265 .

Bronn, Prof., on duration of specitic forms, ii. 66 .

$\longrightarrow$, various objections by, i. 265.

Brown, Robert, on classification, ii. 207.

Séquard, on inherited mutilations, i. 168.

Busk, Mr., on the Polyzoa, i. 301.

Buttertlies, mimetic, ii. 222, 223, 224.

Buzarcingues, on sterility of varieties, ii. 38.

C.

Cabbage, varieties of, crossed, i, 122

Calceolaria, ii. 7, 8.

Canary-birds, sterility of hybrids: ii. 9.

Cape de Verde islands, productions of, ii. 189.

$\longrightarrow$, plants of, on mountains, ii. 162.

Cape of Good Hope, plants of, $i$. 158 ; ii. 178.

Carpenter, Dr., on foraminifers, ii. 117.

Carthamus, i. 271.

Catasetum, i. 243 ; ii. 216.

Cats, with blue eyes, deaf, i. 13.

$\longrightarrow$, variation in habits of, i. 325 .

- curling tail when going to spring, i. 254. 
Cattle destroying fir-trees, i. 88. - destroyed by flies in Paraguay, i. 89.

- , breeds of, locally extinct, $i .134$.

_ fertility of Indian and Europesn breeds, ii. 10.

, Indian, i. 21 ; ii. 10.

Cave, inhabitants of, blind, i. 170.

Cecidomyia, ii. 239.

Celts, proving antiquity of $\mathrm{man}$, i. 21.

Centres of Creation, ii. 135.

Cephalopodx, structures of eyes, i. 236.

- , development of, ii. 244.

Cercopithecus, tail of, i. 294.

Ceroxylus laceratus, i. 284.

Cervulus, ii. 9.

Cetacea, teeth and hair, 1. 179.

, development of the whalebone, i. 285 .

Cetaceans, i. 285.

Ceylon, plants of, ii. 164 .

Chalk formation, ii. 100.

Characters, divergence of, i. 134.

$\longrightarrow$, sexual, variable, i. 185, 191.

, adaptive or analogical, ii. 218.

Charlock, i. 94.

Checks, to increase, i. 83.

- mutual, i. 86.

Chelæ of Crustaceans, i. 300 .

Chickens, instinctive tameness of, i. 329 .

Chironomus, its asexual reproduction, ii. 240.

Chthamalinæ, ii. 59.

Chthamalus, cretacean species of, ii. 81.

Circumstances favourable to selection of domestic products, i. 46.

- - to natural selection, i. 124.

Cirripedes capable of crossing, i. 124.

-, carapace aborted, i. 184.

- their ovigerous frena, i. 232.

_, fossil, ii. 80 .

_ larvæ of, ii. 243.

Claparède, Prof., on the hair-claspers of the Acaridæ, i. 239.

Clarke, Rev. W. B., on old glaciers in Australia, ii. 159.

Classification, ii. 202.

Clift, Mr., on the succession of types, ii. 121.

Climste, effects of, in checking increase of beings, i. 84 .

- adsptation of, to organisms, $i$. 174.
Climbing plants, i. 230.

- development of, i. 305 .

Clover visited by bees, i. 117 .

Cobites, intestine of, i. 229.

Cockroach, i. 93.

Collections, palæontological, poor, ii. 58.

Colour, influenced by climate, i. 165. , in relation to attack by flies, i. 248 .

Columba livia, parent of domestic pigeons, i. 26.

Colymbetes, ii. 174.

Compensation of growth, i. 182.

Compositæ, flowers and seeds of, $i$. 179.

- , outer and inner florets of, $i$. 270.

, male flowers of, ii. 257.

Conclusion, general, ii. 293.

Conditions, slight changes in, favourable to fertility, ii. 27 .

Convergence of genera, i. 156.

Coot, i. 222.

Cope, Prof., on the acceleration or retardation of the period of reproduction, i. 232.

Coral-islands, seeds drifted to, ii. 145.

- reefs, indicating movements of earth, ii. 145.

Corn-crake, i. 223.

Correlated variation in domestic productions, i. 13.

Cory anthes, i. 241.

Creation, single centres of, ii. 135 .

Crinum, ii. 6.

Croll, Mr., on subaerial denudation, ii. 53,56 .

$\longrightarrow$, on the age of our oldest formations, ii. 83.

, on alternate Glacial periods in the North and South, ii. 160.

Crosses, reciprocal, ii. 14.

Crossing of domestic snimals, importance in sittering breeds, i. 23 .

, advantages of, i. $119,120$.

125 .

Cruger, Dr., on Coryanthes, i. 241.

Crustaces of New Zealand, ii. 164.

Crustacean, blind, i. 171.

- air-breathers, i. 238.

Crustaceans, their chelæ, i. 300.

Cryptocerus, i. 359.

Ctenomys, blind, i. 170 .

Cuckoo, instinct of, i. $319,330$. 
Cunningham, Mr., on the flight of the logger-headed duck, i. 167.

Currants, grafts of, ii. 19.

Currents of sea, rate of, ii. 144.

Cuvier, on conditions of existence, i. 320 .

Cuvier, on fossil monkeys, ii. 79.

$\longrightarrow$, Fred., on instinct, i. 320.

Cyclostoma, resisting salt water, ii. 187.

\section{D.}

Dana, Prof., on blind cave-animals, i. 172 .

, on relations of crustacesns of Japan, ii. 158.

- , on crustaceans of New Zealand, ii. 164.

Dawson, Dr., on eozoon, ii. 85.

De Candolle, Aug. Pyr., on struggle for existence, i. 77 .

- , on umbelliferæ, i. 181.

- on general atfinities, ii. 228.

Alph., on the variability of oaks, i. 62.

- on low plants, widely dispersed, ii. 196.

, on widely-ranging plants being variable, i. 67 .

-, on naturalisation, i. 139.

- , on winged seeds, i. 181.

$\longrightarrow$, on Alpine species suddenly becoming rare, i. 210 .

- on distribution of plants with large seeds, ii. 145.

, on vegetation of Australia, ii. 167.

- on fresh-water plants, ii. 174.

- on insular plants. ii. 178.

Degradation of rocks, ii. 52 .

Denudation, rate of, ii. 54 .

— of oldest rocks, ii. 85 .

- of granitic areas, ii. 64 .

Development of ancient forms, ii. 116.

Devonian system, ii. 113.

Dianthus, fertility of erosses, ii. 13.

Dimorphism in plants, i. 55 ; ii. 29.

Dirt on feet of birds, ii. 148 .

Dispersal, means of, ii. 140.

- during Glacial period, ii. 151.

Distribution, geographical, ii. 129.

- means of, ii. 140 .

Disuse, effect of, under nature, $i$. 167.

Divergence of character, i. 134.
Diversitication of means for same general purpose, i. 240.

Division, physiological, of labour, i. 139.

Dog, resemblance of jaw to that of the Thylacinus, ii. 220.

Dogs, hairless, with imperfect teeth, i. 14.

- descended from several wild stocks, i. 22.

- domestic instinets of, i. 327. , inherited civilisation of, i. 327 .

, fertility of breeds together, ii. 10.

- - of crosses, ii. 35.

, proportions of body in different breeds, when young, ii. 247.

Domestication, variation under, i. 7 . Double flowers, i. 358 .

Downing, Mr., on fruit-trees in America, i. 104.

Dragon flies, intestines of, i. 229.

Drift-timber, ii. 145.

Driver-ant, i. 361.

Drones killed by other bees, i. 256.

Duck, domestic, wings of, reduced, i. 12.

- beak of, i. 285.

logger-headed, i. 218.

Duck weed, ii. 173.

Dugong, affinities of, ii. 206.

Dung-beetles with deficient tarsi, $i$. 168.

Dytiscus, ii. 174.

E.

Earl, Mr. W., on the Malay Archipelago, ii. 185.

Ears, drooping, in domestic animals, i. 13.

- rudimentary, ii. 261.

Earth, seeds in roots of trees, ii. 145 .

charged with seeds, ii. 148.

Echinodermata, their pedicel aria, i. 297.

Eciton, i. 359.

Economy of organisation, i. 182.

Edentata, teeth and hair, i. 179.

, fossil species of, ii. 288.

Edwards, Milne, on physiologica! division of labour, i. 139.

$\longrightarrow$, on gradations of structure, $i$. 244. ii. 210 . 
Eggs, young birds escaping from, i. 106.

Egypt, productions of, not modified 1. 263.

Electric organs, i. 234.

Elephant, rate of increase, i. 80.

$\longrightarrow$, of Glacial period, i. 176 .

Embryology, ii. 239.

Eozoon Canadense, ii. 84.

Epilepsy inherited, i. 167.

Existence, struggle for, i. 75 .

- , condition of, i. 261 .

Extinction, as bearing on natural selection, i. 150.

of domestic varieties, i. 145.

,ii. 94 .

Eye, structure of, i. 225.

, correction for aberration, i. 255.

Eyes, reduction in moles, i. 170.

\section{F.}

Fabre, M., on hymenoptera fighting, i. 108.

- on parasitic sphex, i. 336.

, on Sitaris, ii. 252.

Falconer, Dr., on naturalisation of plants in India, i. 80.

, on elephants and mastodons, ii. 113 .

ind Cautley, on mammals of sub-Himalayan beds, ii. 122.

Falkland Islands, wolf of, ii. 183.

Faults, ii. 54.

Faunas, marine, ii. 131.

Fear, instinctive, in birds, i. 329.

Feet of birds, young molluses adhering to, ii. 174 .

Fertilisation variously effected, i. $241,252$.

Fertility of hybrids, ii. 6 .

- , from slight changes in conditions, ii. 28.

of crossed varieties, ii. 34.

Fir-trees destroyed by cattle, i. 88.

, pollen of, i. 257.

Fish, flying, i. 218.

- teleostean, sudden appearance of, ii. 81 .

$\longrightarrow$, eating seeds, ii. 146, 175 .

_. fresh-water, distribution of, ii. 172 .

Fishes, ganoid, now confined to fresh water, i. 130.

, electric organs of, i. 234.

, ganoid, living in fresh water, ii. 99 .
Fishes, of southern hemisphere, it 164.

Flat-fish, their structure, i. 290.

Flight, powers of, how acquired, $i$. 218.

Flint-tools, proving antiquity of man, i. 21.

Flower, Prof., on the Larynx, i. 297.

$\longrightarrow$, on Halitherium, ii. 108.

- on the resemblance between the jaws of the dog and Thylacinus, ii. 220.

-, on the homology of the feet of certain marsupials, ii. 232.

Flowers, structure of, in relation to crossing, i. 114.

- of compositæ and umbelliferæ, i. 179,270 .

$\longrightarrow$, beauty of, i. 252.

$\longrightarrow$ double, i. 358.

Flysch formation, destitute of organic remains, ii. 59.

Forbes, Mr. D., on glacial action in the Andes, ii. 160 .

$\longrightarrow$, E., on colours of shells, i. 165.

- on abrupt range of shells in depth, i. 210.

_ on poorness of palæontological collections, ii. 58 .

- on continuous succession of genera, ii. 93.

- on continental extensions, ii. $140,141$.

- on distribution during Glacial period, ii. 152.

, on parallelism in time and space, ii. 200.

Forests, changes in, in America, $i$. 91.

Formation, Devonian, ii. 113.

, Cambrian, ii. 84 .

Formations, thickness of, in Britain, ii. 55 .

- intermittent, ii. 69.

Formica, rufescens, i. 336.

-, sanguinea, i. 338.

- tlava, neuter of, i. 360.

Forms, lowly organised, long enduring, i. 154.

Frena, ovigerous, of cirripedes, $i$. 232.

Fresh-water productions, disperssl of, ii. 171.

Fries, on species in large geners being closely allied to other species, 1. 71 .

Frigate-bird, i. 222. 
Frogs on islands, ii. 182.

Fruit-trees, gradual improvement of, i. 42.

- in United States, i. 104.

, varieties of, acclimstised in United States, i. 176.

Fuci, crossed, ii. 15, 23.

Fur, thicker in cold climates, i. 166.

Furze, ii. 241.

G.

Galapagos Archipelago, birds of, ii. 179 .

, productions of, ii. 188, 190.

Galaxias, its wide range, ii. 172 .

Galeopithecus, i. 217.

Game, increase of, checked by vermin, i. 86.

Gärtner, on sterility of hybrids, ii. $3,4,11$.

-, on reciprocal crosses, ii. 15.

$\longrightarrow$, on crossed maize and verbascum, ii. 37.

- on comparison of hybrids and mongrels, ii. 40, 41, 42.

Gaudry, Prof., on intermediate genera of fossil mammals in Attica, ii. 107.

Geese, fertility when crossed, ii. 9 , 10.

$\longrightarrow$, upland, i. 222.

Geikie, Mr., on subaerial denudation, li. 53.

Genealogy, important in classification, ii. 212.

Generations, alternate, ii. 239.

Geoffroy St. Hilaire, on balancement, i. 182.

-, on homologous organs, ii. 233.

- Isidore, on variability of repeated parts, i. 184.

- or correlation, in monstrosities, i. 13.

$\longrightarrow$, on correlation, i. 179.

- , on variable parts being often monstrous, i. 190.

Geographical distribution, ii. 129.

Geography, ancient, ii. 303.

Geology, future progress of, ii. 302.

, imperfection of the record, $\mathrm{ii}$. 303.

Gervais, Prof., on Typotherium, ii. 108.

Giraffe, tail of, i. 245.

, structure of, i. 276 .

Glacial period, ii. 151.
Glacial period, affecting the North and South, i. 158.

Glands, mammary, i. 295.

Gmelin, on distribution, ii. 151.

Godwin-Austen, Mr., on the Malay Archipelago, ii. 71.

Goethe, on compensation of growth, i. 182.

Gomphis, i. 272.

Gooseberry, grafts of, ii. 19.

Gould, Dr. Aug. A., on land-sbells, ii. 186.

$\longrightarrow$, Mr., on colours of birds, i. 165.

- on instincts of cuckoo, i. 333.

$\longrightarrow$, on distribution of genera of birds, ii. 195.

Gourds, crossed, ii. 38.

Graba, on the Uria lacrymas, i. 113.

Grafting, capacity of, ii. 18, 19, 20 .

Granite, areas of denuded, ii. 64 .

Grasses, varieties of, i. 137 .

Gray, Dr. Asa, on the variability of oaks, i. 62.

- on man not causing variability, i. 98.

, on sexes of the holly, i. 116.

- on trees of the United States, i. 123.

, on naturalised plants in the United States, i. 139.

-, on rstivation, i. 272

, on Alpine plants, ii. 151.

- on rarity of intermediate varieties, i. 212.

, Dr. J. E., on striped mule, i 199.

Grebe, i. 221.

Grimm, on asexual reproduction, ii 240.

Groups, aberrant, ii. 227.

Grouse, colours of, i. 104.

$\longrightarrow$, red, a doubtful species, i. 59.

Growth, compensation of, i. 182.

Günther, Dr., on flat-fish, i. 292.

$\longrightarrow$, on prehensile tails, i. 295.

- on the fishes of Panama, ii. 131.

- on the range of fresh-water fishes, ii. 172 .

- on the limbs of Lepidosiren, ii. 258 .

H.

Hasst, Dr., on gleciers of New Zesland, ii. 159.

Habit, effect of, under domestics tion, i. 12. 
Habit, effect of, under nature, i. 168. i. 219 .

Häckel, Prof., on classification and the lines of descent, ii. 231.

Hair and teeth, correlated, i. 179.

Halitherium, ii. 108.

Harcourt, Mr. E. V., on the birds of Madeira, ii. 180.

Hartung, M., on boulders in the Azores, ii. 149.

Hazel-nuts, ii. 143.

Hearne, on habits of bears, i. 220.

Heath, changes in vegetation, $i$. 87.

Hector, Dr., on glaciers of New Zealand, ii. 159.

Heer, Oswald, on ancient cultivated plants, i. 20.

$\frac{1}{\mathrm{H}}$, on plants of Madeira, i. 130.

Helianthemum, i. 272.

Helix pomatia, ii. 187.

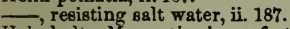

Helmholtz, M., on the imperfection of the human eye, i. 255 .

Helosciadium, ii. 143.

Hemionus, striped, i. 202.

Hensen, Dr., on the eyes of Cephalopods, i. 237.

Herbert, $W_{.}$, on atruggle for existence, i. 77 .

- , on sterility of hybrids, ii. 6 .

Hermaphrodites crossing, i. 119.

Heron eating seed, ii. 176 .

Heron, Sir R., on peacocks, i. 109.

Heusinger, on white animals poisoned by certain plants, i. 13 .

Hewitt, Mr., on sterility of first crosses, ii. 23.

Hildebrand, Prof., on the self-sterility of Corydalis, ii. 7 .

Hilgendorf, on intermediate varieties, ii. 66.

Himalaya, glaciers of, ii. 159.

- plants of, ii. 162 .

Hippeastrum, ii. 7 .

Hippocampus, i. 295.

Hofmeister, Prof., on the movements of plants, i. 308.

Holly-trees, sexes of, i. 115.

Hooker, Dr., on trees of New Zealand, i. 123.

- , on acclimatisation of Himalayan trees, i. 174.

- on flowers of umbelliferæ, $i$. 180.

1 , on the position of ovules, i. 268.
Hooker, Dr., on glaciens of Himalaya, ii. 159.

, on algæ of Now Zealand, ii. 164.

, on vegetation at the base of the Himalaya, ii. 164 .

- , on plants of Tierra del Fuego, ii. 161 .

190.

, on relations of flora of America, ii. 167 .

-, on flors of the Antarctic lands, ii. $169,189$.

- on the plants of the Galspagos, ii. $181,188$.

, on glaciers of the Lebanon, ii. 159.

- on man not causing variability, i. 97.

- on plants of mountains of Fernando Po, ii. 162.

Hooks on palms, i. 247.

- on seeds, on islands, ii. 181.

Hopkins, Mr., on denudation, ii. 63.

Hornbill, remarkable instinct of, $i$. 364.

Horns, rudimentary, ii. 261.

Horse, fossil, in L\& Plata, ii. 96.

-, proportions of, when young, ii. 247 .

Horses destroyed by flies in Paraguay, i. 89.

, striped, i. 199.

Horticulturists, selection applied by, i. 37.

Huber, on cells of bees, i. 349.

$\longrightarrow, \mathrm{P}$., on reason blended with instiuct, i. 320 .

- on habitual nature of instincts, i. 320 .

- on slave-making ants, i. 386.

, on Melipons domestica, i. 343.

Hudson, Mr., on the Ground-Woodpecker of La Plata, i. 221.

, on the Molothrus, i. 334.

Humble-bees, cells of, i. 343.

Hunter, J., on secondary serual characters, i. 185.

Hutton, Captain, on crossed geese, ii. 10.

Huxley, Prof., on structure of hermaphrodites, i. 124.

, on the affinities of the Sirenia, ii. 108.

, on forms connecting birds and reptiles, ii. 108 . 
Huxley, Prof., on homologous organe, ii. 238.

, on the development of aphis, ii. 245.

Hybrids and mongrels compared, ii. 39.

Hybridism, ii. 1.

Hydra, structure of, i. 229.

Hymenoptera, fighting, i. 108.

Hymenopterous insect, diving, i. 222.

Hyoseris, i. 271 .

I.

Ibla, i. 183.

Icebergs transporting seeds, ii. 148.

Increase, rate of, i. 79 .

Individuals, numbers favourable to selection, i. 124.

-, many, whether simultaneously created, ii. 139.

Inheritance, laws of, i. 15.

105 .

Insects, colour of, fitted for their stations, i. 103.

$\longrightarrow$, sea-side, colours of, i. 165.

- blind, in caves, i. 171 .

- luminous, i. 236.

- their resemblance to certain objects, i. 283. , neuter, i. 359.

Instinct, i. 319.

- not varying simultaneously with structure, i. 357.

Instincts, domestic, i. 325 .

Intercrossing, advantages of, i. 149, ii. 27.

Islands, oceanic, ii. 177.

Isolation favourable to selection, i. 127.

J.

Japan, productions of, ii. 158.

Java, plants of, ii. 162.

Jones, Mr. J. M., on the birds of Bermuda, ii. 180.

Jourdain, M., on the eye-spots of star-fishes, i. 225.

Jukes, Prof., on subaerial denudation, ii. 53 .

Jussieu, on classification, ii. 209.

K.

Kentucky, caves of, i. i72.

Kerguelen-land, tlora of, ii. 169, 189.
Kidney-bean, acclimatisation of, $i$. 177.

Kidneys of birds, i. 178.

Kirby, on tarsi deficient in beetles, i. 168 .

Knight, Andrew, on cause of variation, i. 8.

Kölreuter, on Intercrossing, i. 119.

- , on the barberry, i. 121 .

$\longrightarrow$, on sterility of hybrids, ii. 3,4 .

$\longrightarrow$, on reciprocal crosses, ii. 15 .

$\longrightarrow$, on crossed varieties of nicotiana, ii. 38.

, on crossing male and hermaphrodite flowers, ii. 256.

\section{1.}

Lamarck, on adaptive characters, ii. 218.

Lancelet, i. 154.

$\longrightarrow$, eyes of, i. 227.

Landois, on the development of the wings of insects, i. 231.

Land-shells, distribution of, ii. 186.

- of Madeira, naturalised, ii. 193.

, resisting salt water, ii. 187.

Languages, classification of, ii. 214.

Lankester, Mr. E. Ray, on Longevity, i. 263.

$\longrightarrow$, on homologies, ii. 237.

Lapse, great, of time, ii. 51.

Larvæ, i. $241,242,243$.

Laurel, nectar secreted by the leaves, i. 114 .

Laurentian formation, ii. 84.

Laws of variation, i. 164 .

Leech, varieties of, i. 93 .

Leguminosæ, nectar secreted by glands, i. 114.

Leibnitz' attack on Newton, ii. 294. Lepidosiren, i. 130 ; ii. 109.

- limbs in a nascent condition ii. 258.

Lewes, Mr. G. H., on species not having changed in Egypt, i. 263.

$\longrightarrow$, on the Salamandra atrs, ii. 256.

, on many forms of life having

been at first evolved, ii. 300 .

Life, struggle for, i. 77 .

Lingula, Sílurian, ii. 83.

Linnæus, aphorism of, ii. 205.

Lion, mane of, i. 109.

, young of, striped, ii. 241.

Lobelis fulgens, i. 90, 121 .

, sterility of crosses, ii. 7 . 
Lockwood, Mr, on the ova of the Hippocampus, i. 295.

Loousts transporting seeds, ii. 147.

Logan, Sir W., on Laurentian formation, ii. 84.

Lowe, Rev. R. T., on locusts visiting Madeira, ii. 147.

Lowness of structure connected with variability, i. 184.

, related to wide distribution, ii. 196.

Lubbock, Sir J., on the nerves of coccus, i. 54.

- on secondary sexual characters, i. 193.

, on a diving hymenopterous insect, i. 222.

- on affinities, ii. 73.

- , on metamorphoses, ii. 239, 242.

Lucas, Dr. P., on inheritance, i. 14.

- , on resemblance of child to parent, ii. 43.

Lund and Clausen, on fossils of Brazil, ii. 121.

Lyell, Sir C., on the struggle for existence, i. 77 .

$\longrightarrow$ on modern changes of the earth, i. 118.

, on terrestrial animals not having been developed on islands, $i$. 281.

- on a carboniferous land-shell. ii. 59 .

, on strata beneath Silurian system, ii. 84.

, on the imperfection of the geological record, ii. 88.

- on the appearance of species, ii. 88 .

$\longrightarrow$, on Barrande's colonies, ii. 90.

- on tertiary formations of Europe and North America, ii. 101.

, on parallelism of tertiary formations, ii. 106.

- , on transport of seeds by icebergs, ii. 148 .

$\ldots$, on great alterations of climate, ii. 170 .

$\longrightarrow$, on the distribution of freshwater shells, ii. 174.

, on land-shells of Madeira, ii. 193.

Lyell and Dawson, on fossilized trees in Nova Scotia, ii. 70.

Lythrum salicaria, trimorphic, ii. 32 .
M.

Macleay, on analogical characters, ii. 218 .

Macrauchenia, ii. 107.

M'Donnell, Dr, on electric organg, i. 234.

Madeira, plants of, i. 130.

$\longrightarrow$, beetles of, wingless, i. 169.

$\longrightarrow$, fossil land-shells of, ii. 121.

- birds of, ii. 180.

Magpie tame in Norway, i. 325.

Males tighting, i. 108.

Maize, crossed, ii. 37.

Malay Archipelago compared with Europe, ii. 74.

-, mammals of, ii. 185.

Malm, on flat-fish, i. 291.

Malpighiacex, small imperfect flowers of, i. 269.

$\longrightarrow$, ii. 209.

Mammæ, their development, i. 295.

$\longrightarrow$, rudimentary, ii. 255.

Mammals, fossil, in secondary formation, ii. 79.

- insular, ii. 183.

Man, origin of, ii. 304.

Manatee, rudimentary nails of, ii. 260.

Marsupials of Australia, i. 140.

- structure of their feet, ii. 232.

_ fossil species of, ii. 121.

Martens, M., experiment on seeds, ii. 144 .

Martin, Mr. W. C., on striped mules, i. 201 .

Masters, Dr., on Saponaria, i. 272.

Matteucci, on the electric organs of rays, i. 234.

Matthiola, reciprocal crosses of, ii. 15.

Maurandia, i. 307.

Means of dispersal, ii. 140.

Melipona domestica, i. 343.

Merrell, Dr., on the American cuckoo, i. 330.

Metamorphism of oldest rocks, ii. 85 .

Mice destroying bees, i. 90 .

—, acclimatisation of, i. 175 .

, tails of, i. 294.

Miller, Prof., on the cells of bees, $i$. $344,350$.

Mirsbilis, crosses of, ii. 15.

Missel-thrush, i. 93 .

Mistletoe, complex relations of, i. 3.

Mivart, Mr., on the relation of hair and teeth, i. 179. 
Mivart, Mr., on the eyes of cephalopods, i. 237.

, various objections to Natural Selection, i. 275.

$\longrightarrow$, on abrupt modifications, i. 313.

- on the resemblance of the monse and antechinus, ii. 218.

Mocking-thrush of the Galspagos, ii. 193 .

Modification of species not abrupt, ii. 298.

Moles, blind, i. 170.

Molothrus, habits of, i. 334.

Mongrels, fertility and sterility of, ii. 34 .

- and hybrids compared, ii. 39.

Monkeys, fossil, ii. 79.

Monachanthus, ii. 216.

Mons, Van, on the origin of fruittrees, i. 33.

Monstrosities, i. 51.

Moquin-Tandon, on sea-side plants, i. 166.

Morphology, ii. 231.

Morren, on the leaves of Oxalis, i. 308.

Moths, hy brid, ii. 9.

Mozart, musical powers of, i. 321.

Mud, seeds in, ii. 175.

Mules, striped, i. 201.

Muller, Adolf, on the instincts of the cuckoo, i. 331.

Müller, Dr. Ferdinand, on Alpine A ustralian plants, ii. 163.

Müller, Fritz, on dimorphic crustaceans, i. $55,362$.

$\longrightarrow$, on the lancelet, i. 154.

_ on air-breathing crustaceans, i. 238.

-, on climbing plants, i. 307.

, on the self-sterility of orchids, ii. 7 .

, on embryology in relation to classification, ii. 210.

- , on the metamorphoses of crustroeans, ii. $245,253$.

-, on terrestrial and fresh-water organisms not undergoing any metamorphosis, ii. 250.

Multiplication of species not indefinite, i. 157.

Murchison, Sir R., on the formations of Russia, ii. 60.

- on azoic formations, ii. 84.

, on extinction, ii. 94.

Murie. Dr., on the modification of the skull in ols age, i. 233.
Murray, Mr. A., on cave-insecta i. 173 .

Mustela vision, i. 216.

Myanthns, ii. 216.

Myrmecocystus, i. 359.

Myrmics, eyes of, i. 361 .

N.

Nägeli, on morphological charaoters, i. 266 .

Nails, rudimentary, ii. 260.

Nathusius, Von, on pigs, i. 249.

Natural history, future progress of, ii. 301 .

- selection, i. 97.

- system, ii. 204

Naturaliastion of forms distinct from the indigenous apecies, i. 138.

Naturalisation in New Zealand, i. 255.

Naudin, on analogous variations in gourds, i. 195.

$\longrightarrow$, on hybrid gourds, ii. 38.

, on reversion, ii. 4 .

Nautilus, Silurian, ii. 83.

Nectar of plants, i. 114.

Nectaries, how formed, i. 114.

Nelumbium luteum, ii. 176.

Nests, variations in, i. $324,355,364$.

Neuter insects, i. $359,360$.

Newman, Col., on humble-bees, i. 90.

New Zealand, productions of, not perfect, i. 255.

-, naturalised products of, ii. 119.

_, fossil birds of, ii. 121.

- glaciers of, ii. 159 .

- crustaceans of, ii. 164.

- algæ of, ii. 164

- number of plants of, ii. 178.

, flors of, ii. 189.

Newton, Sir I., attacked for irreligion, ii. 294.

- Prof., on earth attached to a partridge's foot, ii. 148.

Nicotiana, crossed varieties of, ii. 39 .

-, certsin species very sterile, ii. 14.

Nitsche, Dr., on the Polyzoa, i. 301.

Noble, Mr., on fertility of Rhododendron, ii. 8.

Nodules, phosphatic, in azoic rocks ii. 84 .

0.

Oaks, variability of, i. 62 .

Onites, appelles, i. 168. 
Ononis, small imperfect flowers of, i. 269 .

Orchids, fertilisation of, i. 241.

- , the development of their Howers, i. 303.

- , forms of, ii. 216.

Orchis, pollen of, i. 236.

Organisation, tendency to advance, i. 151.

Organs of extreme perfection, i. 223. , electric, of fishes, i. 234.

- of little importance, i. 245.

- homologous, ii. 233.

_ rudiments of, and nascent. ii. 255.

Ornithorhynchus, i. 130 ; ii. 208.

mammæ of, i. 296.

Ostrich not cspable of flight, i. 281.

, habit of laying eggs together, i. 335 . 132 .

Otter, habits of, how acquired, i. 216 .

Ouzel, water, i. 222.

Owen, Prof., on birds not flying, i. 167.

- , on vegetative repetition, $i$. 184. developed parts, $i$. 185 .

- on the eyes of fishes, i. 227.

- on the swim-bladder of fishes, i. 231 .

$\frac{i .}{96}$, on fossil horse of La Plata, ii. 96.

$\longrightarrow$, on generalized form, ii. 107.

- on relation of ruminants and pachyderms, ii. 107.

$\longrightarrow$, on fossil birds of New Zealand, ii. 121.

$\longrightarrow$, on succession of types, ii. 121.

, on affinities of the dugong, ii. 206.

206. , on homologous organs, ii. 233.

, on the metamorphosis of cephalopods, ii. 244.

P.

Pacific Ocean, faunas of, ii. 131.

Pacini, on electric organs, i. 235.

Paley, on no organ formed to give pain, i. 254.

Pallas, on the fertility of the domesticated descendants of wild stocks, ii. 10.
Palm with hooks, i. 247.

Papaper bracteatum, i. 272.

Parayuay, cattle destroyed by fliea, i. 89.

Parasites, i. 334.

Partridge, with ball of earth attached to foot, ii. 148.

Parts greatly developed, variable, i. 185 .

Parus major, i. 220.

Passiflora, ii. 7 .

Peaches in United States, i. 104.

Pear, grafts of, ii. 18.

Pedicellariæ, i. 298.

Pelagornium, flowers of, i. 180.

, sterility of, ii. 7 .

Pelvis of women, i. 178.

Peloria, i. 180.

Period, glacial, ii. 151.

Petrels, habits of, i. 221.

Phasianus, fertility of hybrids, ii. 9.

Pheasant, young, wild, i. 329.

Pictet, Prof., on groups of species suddenly appearing, ii. 77 .

- , on rate of organic change, ii. 90.

$\longrightarrow$, on continuous succession of gencra, ii. 93.

- , on ehange in latest tertiary forms, ii. 71 .

- , on close alliance of fossils in consecutive formations, ii. 114 .

- , on early transitional linke, ii. 78.

Pierce, Mr., on varieties of wolves, i. 111 .

Pigeons with feathered feet and skin between toes, i. 14 .

- breeds described, and origin of, i. 23.

, breeds of, how produced, i. 14, 47.

$\longrightarrow$, tumbler, not being able to get out of egg, i. 106.

- reverting to blue colour, i. 197.

$\longrightarrow$, instinct of tumbling, i. 327 .

_ young of, ii. 248.

Pigs, black, not affected by the paint-root, i. 13.

, modified by want of exerciee, i. 249.

Pistil, rudimentary, ii. 256.

Plants, poisonous, not affecting certain coloured animals, i. 13.

$\longrightarrow$, selection, applied to, i. 41.

- gradual improvement of, i. 42. - not improved in barbarou countries, i. 43. 
Plants, dimorphic, i. 55 ; ii. 29.

$\longrightarrow$, destroyed by insects, i. 83.

_ in midst of range, have to struggle with other plants, i. 95.

- nectar of, i. 114.

—, Heshy, on sea-shores, i. 166.

—, climbing, i. 230, 305.

__, fresh-water, distribution of, ii. 174.

17, low in scale, widely distributed, ii. 196.

Pleuronectidæ, their structure, i. 290.

Plumage, laws of change in sexes of birds, i. 109.

Plums in the United States, i. 104.

Pointer dog, origin of, i. 40.

, habits of, i. 327 .

Poison not affecting certain coloured animals, i. 13.

- similar effect of, on animals and plants, ii. 299.

Pollen of fir-trees, i. 257.

- transported by various means, i. $241,252$.

Pollinia, their development, i. 304.

Polyzoa, their avicularia, i. 301.

Poole, Col., on striped hemionus, i. 202.

Potemogeton, ii. 175.

Pouchet, on the colours of flat-fish, i. 293.

Prestwich, Mr., on English and French eocene formations, ii. 105.

Proctotrupes, i. 222.

Proteolepas, i. 183.

Proteus, i. 173.

Psychology, future progress of, ii. 304.

Pyrgoma, found in the chalk, ii. 81.

\section{Q.}

Quagga, striped, i. 201.

Quatrefages, M., on hybrid moths, ii. 9.

Quercus, variability of, i. 62.

Quince, grafts of, il. 18.

\section{R.}

Rabbits, disposition of young, i. 328 . Races, domestic, characters of, i. 18. Race-horses, Arab, i. 40.

$\longrightarrow$, English, ii. 140.

Radeliffe, Dr., the electrical organs of the torpedo, i. 234.
Ramond, on plants of Pyrenees, ii. 153.

Ramsay, Prof., on subaerial denudation, ii. 58 .

, on thickness of the British formations, ii. 55,56 .

, on faults, ii. 55 .

Ramsay, $\mathbf{M r}$., on instincts of cuckoo, i. 333 .

Ratio of increase, i. 79.

Rats supplanting each other, i. 93.

-, acclimatisation of, i. 175.

blind, in cave, i. 171 .

Rattle-snake, i. 254.

Reason and instinct, i. 319.

Recapitulation, general, ii. 267.

Reciprocity of crosses, ii. 14.

Record, geological, imperfect, ii. 48.

Rengger, on flies destroying cattle, i. 89 .

Reproduction, rate of, i. 79.

Resemblance, protective, of insects, i. 283.

to parents in mongrels and hybrids, ii. 41.

Reversion, law of inheritance, $i$. 16.

$\frac{16}{1}$, in pigeons, to blue colour, $i$. 198.

Rhododendron, sterility of, ii. 7,8 .

Richard, Prof., on Aspicarps, ii.' 209.

Richardson, Sir J., on structure of squirrels, i. 216.

, on fishes of the southern hemisphere, ii. 164.

Robinia, grafts of, ii. 19.

Rodents, blind, i. 170.

Rogers, Prof., Map of N. America, ii 65 .

Rudimentary organs, ii. 255.

Rudiments important for classification, ii. 207.

Rütimeyer, on Indian cattle, i. 21 : ii. 10 .

S.

Salamandra atra, ii. 256.

Saliva used in nests, i. 355 .

Salvin, Mr., on the beaks of ducks, i. 287 .

Sageret, on grafts, ii. 18.

Salmons, males fighting, and hooked jaws of, i. 108.

Salt water, how far injurious to seeds, ii. 142.

not destructive to land-shells, ii. 187. 
Salter, Mr., on early death of hybrid embryos, ii. 23.

Saurophagus sulphuratus, i. 220.

Schacht, Prof., on Phyllotaxy, i. 270.

Schiödte, on blind insects, i. 172.

, on flat-fish, i. 290.

Schlegel, on snakes, i. 178.

Schobl, Dr., on the ears of mice, $i$. 268.

Scott, J., Mr., on the self-sterility of orchids, ii. 7 .

- , on the crossing of varieties of verbascum, ii. 38 .

Sea-water, how far injurious to seeds, ii. 142.

- not destructive to land-shells, ii. 187 .

Sebright, Sir J., on crossed animals, i. 23.

Sedgwick, Prof., on groups of species suddenly appearing, ii. 77 .

Seedlings destroyed by insects, $i$. 83.

Seeds, nutriment in, i. 94.

-, winged, i. 181 .

- means of dissemination, $i$. 240,252 ; ii. 146.

- power of resisting salt water, ii. 143.

- , in crops and intestines of birds, ii. 146.

$\longrightarrow$, eaten by tish, ii. 146, 176.

- , in mud, ii. 175 .

- hooked, on islands, ii. 181.

Selection of domestic products, i. 34 .

- principle not of recent origin, i. 39 .

1. unconscious, i. 39.

natural, i. 97.

, sexual, i. 107.

—, objections to term, i. 99.

- natural, has not induced sterility, ii. 20.

Sexes, relations of, i. 108.

Sexual characters variable, i. 191.

- selection, i. 107.

Sheep, Merino, their selection, i. 36.

- two sub-breeds, unintentionally produced, i. 41 .

_- mountain varieties of, i. 93.

Shells, colours of, i. 165.

, hinges of, i. 240 .

—, littoral, seldom embedded, ii. 58.

same forms, ii. 117 .
sash - rater, long retain the
Shells, fresh-water, dispersal of, ii. 173.

$\longrightarrow$, of Madeira, ii. 180.

- land, distribution of, ii. 180.

_ land, resisting salt water, ii. 187.

Shrew-mouse, ii. 218.

Silene, infertility of crosses, ii. 14.

Silliman, Prof., on blind rat, i. 171.

Sirenia, th ir atfinities, ii. 108.

Sitaris, metamorphosis of, ii. 252.

Skulls of young mammals, i. 248; ii. 235.

Slave-making instinct, i. 336.

Smith, Col. Hamilton, on striped horses, i. 200.

—, Mr. Fred., on slave-making ants, i. 337.

- on neuter ants, i. 360 .

Smitt, Dr., on the Polyzoa, i. 301.

Snake with tooth for cutting through egg-shell, i. 334.

Somerville, Lord, on selection of sheep, i. 35.

Sorbus, grafts of, ii. 19.

Sorex, ii. 218.

Spaniel, King Charles's breed, i. 40.

Specialisation of organs, i. 152.

Species, polymorphic, i. 54 .

, dominant, i. 67.

$\longrightarrow$ common, variable, i. 66 .

— in large genera variable, i. 69.

_- groups of, suddenly appearing, ii. $77,82$.

- beneath Silurian formations, ii. 84 .

— successively appearing, ii. 89.

- changing simultaneously throughout the world, ii. 100.

Spencer, Lord, on increase in size of cattle, i. 40.

$\longrightarrow$, Herbert, Mr., on the first steps in differentiation, i. 155.

, on the tendency to an equilibrium in all forces, ii. 29.

Sphex, parasitic, i. 336.

Spiders, development of, ii. 245.

Sports in plants, i. 11 .

Sprengel, C. C., on crossing, i. 119.

-, on ray-florets, i. 180.

Squalodon, ii. 108.

Squirrels, gradations in structure, $i$. 216.

Staffordahire, heath, changea in, i. 8\%.

Stag-beetles, fighting, i. 108.

Star-fishes, eyes of, i. 225. 
Star-Fishes, their pedicellariæ, i. 299. Sterility from changed conditions of life, i. 10.

- of hybride, ii. 3.

- laws of, ii. 11.

$\longrightarrow$, causes of, ii. 20. from unfavourable conditions, ii. 26 .

not induced through natural selection, ii. 21.

St. Helena, productions of, ii. 178.

St. Hilaire, Aug., on variability of certain plants, i. 272.

- on classitication, ii. 209.

St. John, Mr., on habits of cats, i. 325.

Sting of bee, i. 256.

Stocks, aboriginal, of domestic animals, i. 22.

Strata, thickness of, in Britain, ii. 55.

Stripes on horses, i. 199.

Structure, degrees of utility of, i. 249.

Straggle for existence, i. 75.

Succession, geological, ii. 89 .

- of types in same areas, ii 121.

Swallow, one species supplanting another, i. 93 .

Swaysland, Mr., on earth adhering to the feet of migratory birds, if. 148.

Swifts, nests of, i. 355.

Swim-bladder, i. 230.

Switzerland, lake habitations of, $i$. 20.

System, natural, ii. 204.

T.

Tail of giraffe, i. 245.

— of aquatic animals, i. 246.

- prehensile, i. 294.

-, rudimentary, ii. 260.

Tanais, dimorphic, i. 55 .

Tarsi, deficiont, i. 168 .

Tausch, Dr., on umbelliferæ, i. 271.

Teeth and hair correlated, i. 179.

- rudimentary, in embryonic, calf, ii. $255,292$.

Tegetmeier, Mr., on cells of bees, i. $346,352$.

Temminck, on distribution aiding classitication, ii. 211.

Tendrils, their development, i. 305.

Thompson, Sir $W_{\text {, }}$ on the age of the habitable world, ii. 83.

, on the consolidation of the crust of the earth, ii. 275 .
Thouin, on grafts, ii. 19.

'Thrush, aquatic species of, i. 222.

- mocking, of the Galapagos, ii. 192.

- joung of, spotted, ii. 241.

, nest of, i. 364 .

Thuret, M., on crossed fuci, ii. 15.

Thwaites, Mr. on acclimatisation, i. 174.

Thylacinus, ii. 220.

Tierra del Fuego, dogs of, i. 328.

, plants of ii. 169 .

Timber-drift, ii. 145.

Time, lapse of, ii. 51.

by itself not causing modification, i. 126.

Titmouse, i. 220.

Toads on islands, ii. 182.

T'obacco, crossed varieties of, ii. 38 .

Tomes, Mr., on the distribution of bats, ii. 184.

Transitions in varieties rare, i. 208.

Traquair, Dr., on flat-fish, i. 293.

Trautschold, on intermediate varieties, ii. 66 .

Trees on islands belong to peculiar orders, ii. 182.

with separated sexes, i. 123.

Trifolium pratense, i. 90, 117. incarnatum, i. 117.

Trigonia, ii. 99.

Trilobites, ii. 83.

- , sudden extinction of, ii. 99.

Trimen, Mr., on imitating-insects, ii. 224 .

Trimorphism in plants, i. 55 ; ii. 29.

Troglodytes, i. 364.

Tuco-tuco, blind, i. 170.

Tumbler pigeons, habits of, hereditary, i. 327 .

, young of, ii. 248.

Turkey-cock, tuft of hair on breast, i. 110 .

- naked skin on head, i. 248.

young of, instinctively wild, i. 329.

Turnip and cabbage, analogous variatione of, i. 195.

Type, unity of, i. $260,261$.

Types, euccession of, in same sreas ii. 121.

Typotherium, ii. 108.

U.

Udders enlarged by use, i. 12.

$\longrightarrow$, rudimentary, ii. 256. 
Ulex, young leaves of, ii. 241.

Umbelliferæ, flowers and seeds of, i. 180.

, outer and inner florets of, i. 270.

Unity of type, i. $260,261$.

Uria lacrymans, i. 113.

Use, effects of, under domestication, i. 12.

- effects of, in a state of nature, i. 167 .

Utiiity, how far important in the construction of each part, i. 249.

\section{V.}

Valenciennes, on fresh-water fish, ii. 173.

Variability of mongrels and hybrids, ii. 39.

Variation under domestication, i. 8.

- caused by reproductive system being affected by conditions of life, i. 10.

under nature, i. 51.

- laws of, i. 164 .

, correlated, i. 13, 177, 248.

Variations appear at corresponding ages, i. 16, 105.

analogous in distinct species, i. 193.

$\nabla$ arieties, natural, i. 50.

-, struggle between, i. 93.

$\longrightarrow$, domestic, extinction of, i. 134.

- transitional, rarity of, i. 208.

, when crossed, fertile, ii. 34.

V arieties, when crossed, sterile, ii. 37 .

, classification of, ii. 215.

Verbascum, sterility of, ii. 7 .

, varieties of crossed, ii. 38.

Verlot, M., on double stocks, i. 358.

Verneuil, M. de, on the succession of species, ii. 103.

Vibracula of the Polyzoa, i. 301.

Viola, small imperfect flowers of, 1. 269 .

, tricolor, i. 90.

Virchow, on the structure of the crystalline lens, i. 227.

Virginia, pigs of, i. 104.

Volcanic islands, denudation of, $i$. 54.

Vulture, naked skin on head, i. 247.

W.

Wading-birds, ii. 175.

Wagner, Dr., on Cecidomyia, ii. 239.
Wagner, Moritz, on the importance of isolation, i. 127.

Wallace, Mr., on origin of species, i. 2.

- on the limit of variation under domestication, i. 48.

$\longrightarrow$, on dimorphic lepidoptera, $i$. 55,362 .

- on races in the Malay Archipelago, i. 58.

, on the improvement of the eye, i. 227.

, on the walking-stick inseot, $i$. 284.

, on laws of geographical distribution, ii. 139.

- on the Malay Archipelago, ii. 185.

, on mimetic animals, ii. 224.

Walsh, Mr. B. D., on phytophagic forms, i. 60 .

, on equal variability, i. 195.

Water, fresh, productions of, ii: 171.

Water-hen, i. 222.

Waterhouse, Mr., on Australian marsupials, i. 140.

, on greatly developed parts being variable, i. 185 .

- on the cells of bees, i. 343.

$\longrightarrow$, on general affinities, ii. 227.

Water-ouzel, i. 222.

Watson, Mr. H. C., on range of varieties of British plants, i. 57, 73.

$\longrightarrow$, on acclimatisation, i. 134.

-, on flors of Azores, ii. 149.

—, on Alpine plants, ii. 153.

, on rarity of intermediate varieties, i. 212.

- on convergence, $i .156$.

, on the indefinite multiplication of species, i. 157 .

Weale, Mr., on locusts transporting seeds, ii. 147.

Web of feet in water-birds, i. 223.

Weismann, Prof., on the causes of variability, i. 8 .

- on rudimentary organs, ii. 260.

West Indian Islands, mammals of, ii. 185 .

Westwood, on species in large genera being closely allied to others, i. 71 .

-, on the tarsi of Engidæ, i. 192. -, on the antennæ of hymenopterous insects, ii. 207.

Whales, i. 285. 
Wheat, varieties of, i. 137.

White Mountains, flora of, ii. 151.

Whittaker, Mr., on lines of escarpment, ii. 53.

Wichura, Max, on hybrids, ii. 24, 27,41 .

Wings, reduction of size, i. 169.

- of insects homologous with branchiæ, i. 231.

- rudimentary, in insects, ii. 255.

Wolf crossed with dog, i. 327.

of Falkland Isles, ii. 183.

Wollaston, Mr., on varieties of insects, i. 59.

- , on fossil varieties of shells in Madeira, i. 65.

-, on colours of insects on seashore, i. 165.

- , on wingless beetles, i. 169.

- , on rarity of intermediate varieties, i. 212.

- , on insular insects, ii. 178.

- , on land-shells of Madeira naturalised, ii. 193.

Wolves, varieties of, i. 111 .

Woodeock with earth attached to leg, ii. 148.

Wood pecker, habits of, i. 220.

$\longrightarrow$, green colour of, i. 247.
Woodward, Mr., on the duration of specitic forms, ii. 66 .

-, on Pyrgoma, ii. 81. , on the continuous succession of genera, ii. 93 .

- on the succession of types, ii. 121.

World, species changing aimultaneously throughout, ii. 100.

Wrens, nest of, i. 364 .

Wright, Mr. Chauncey, on the giratfe, i. 278.

, on abrupt modifications, $i$. 316.

Wyman, Prof., on correlation of colour and effects of poison, i. 13. - on the cells of the bee, i. 345 .

\section{Y.}

Youatt, Mr., on selection, i. 35.

-, on sub-breeds of sheep, i. 41.

- on rudimentary horns in young cattle, ii. 261.

Z.

Zanthoxylon, i. 272.

Zebra, stripes on, i. 199.

Zeuglodon, ii. 108. 


$$
+
$$






$r$ 

